INSTITUTO DE PESQUISA ENERGÉTICAS E NUCLEARES

Autarquia associada à Universidade de São Paulo

\title{
A RELAÇÃO CAUSAL ENTRE COMPROMETIMENTO E DESEMPENHO: UM ESTUDO EM CENTROS DE PESQUISA
}

MIGUEL ENRIQUE TEJOS-SALDIVIA

Tese apresentada como parte dos requisitos para obtenção do Grau de Doutor em Ciências na Área de Tecnologia Nuclear - Materiais

Orientador:

Dr. Jesualdo Luiz Rossi

Co-orientador:

Dr. Guilherme Ary Plonski

SÃO PAULO 
INSTITUTO DE PESQUISA ENERGÉTICAS E NUCLEARES

Autarquia associada à Universidade de São Paulo

\section{A RELAÇÃO CAUSAL ENTRE COMPROMETIMENTO E DESEMPENHO: UM ESTUDO EM CENTROS DE PESQUISA}

MIGUEL ENRIQUE TEJOS-SALDIVIA

Tese apresentada como parte dos requisitos para obtenção do Grau de Doutor em Ciências na Área de Tecnologia Nuclear - Materiais com ênfase em Gestão Tecnológica

Orientador:

Dr. Jesualdo Luiz Rossi

Co-orientador:

Dr. Guilherme Ary Plonski

SÃO PAULO

2006

EXEMPLAR REVISADO PELO AUTOR 
Dedico com carinho este trabalho à minha esposa Ximena e aos meus filhos: Ernesto, Carla e André. 


\section{AGRADECIMENTOS}

Sou extremamente grato ao Dr. Jesualdo Luiz Rossi por ter sido meu orientador, pelo seu profissionalismo, competência e dedicação, sem os quais este trabalho não seria o mesmo. Agradeço pela amizade e pelo exemplo.

Minha gratidão ao $\mathrm{Dr}$. Guilherme Ary Plonski pelas inúmeras oportunidades concedidas nestes anos e que tornaram possível este trabalho.

Ao Prof. Dr. Dirceu da Silva da FECAP, quem me levou a conhecer a técnica da Modelagem de Equações Estruturais, fortalecendo assim este estudo e por ter sido o grande participante no fechamento deste trabalho.

À Profa. Dra. Maria Filomena Ricco Fontes do ITA pelas suas constantes sugestões as quais melhoraram e muito este trabalho.

Ao Prof. Dr. Sérgio Salles Filho da Unicamp pelas suas correções.

Ao Instituto de Pesquisas Energéticas e Nucleares, IPEN-CNEN/SP, pela oportunidade de desenvolver este estudo.

Ao Centro Técnico Aeroespacial, CTA, pelo apoio e incentivo.

Aos servidores dos laboratórios do "Centro de Ciência e Tecnologia de Materiais - CCTM" do IPEN e aos servidores dos laboratórios do "Instituto de Aeronáutica e Espaço - IAE" do CTA, pela colaboração em responder a pesquisa.

À Divisão de Materiais - AMR do CTA-IAE, em nome do seu Chefe Dr. Pedro Paulo de Campos.

Sou extremamente grato pelo apoio e estímulos constantes de todos os amigos do CTA e a todos os amigos do IPEN. Destaco, entre outros, aos membros da CPG - em particular à Ana, Ilze, Vera e Fernando, à MSc. Ana Cláudia Martinelli Feher do IPEN, ao doutorando do IPEN José Osman Santos, ao Prof. Dr. Adonis Marcelo Saliba-Silva do IPEN, ao Anl. de Sistemas Luiz Aldo das Neves do IAE e ao Dr. Sérgio Luís Graciano Petroni do IAE/CTA.

Às muitas bibliotecárias que me ajudaram, destacando entre outras, especialmente às da AMR, da FEA e do IPEN.

A todos os amigos que me acompanharam nesta jornada e contribuíram direta ou indiretamente para a realização deste trabalho, meu muito obrigado! 


\title{
A RELAÇÃO CAUSAL ENTRE COMPROMETIMENTO E DESEMPENHO: UM ESTUDO EM CENTROS DE PESQUISA
}

\author{
Miguel Enrique Tejos-Saldivia
}

\begin{abstract}
RESUMO
Neste estudo, foram analisadas relações existentes entre liderança, motivação, clima organizacional, trabalho em equipe e o comprometimento organizacional e ocupacional. O estudo exploratório foi realizado em três partes, na primeira procurou-se identificar os fatores de desempenho mais importantes numa relação maior resultantes da pesquisa bibliográfica e na segunda buscou-se quantificar os quatro fatores de desempenho junto aos comprometimentos organizacional e ocupacional. Na primeira parte foi realizada uma pesquisa exploratória e na segunda parte foram entrevistados 52 servidores do CCTM no Instituto de Pesquisas Energéticas e Nucleares - IPEN e 252 servidores do IAE no Centro Técnico Aeroespacial - CTA. A pesquisa utilizou 18 indicadores de comprometimento organizacional e 18 indicadores de comprometimento ocupacional, todos extraídos do instrumento de Meyer, Allen e Smith. Além destes, foram utilizadas 7 variáveis demográficas e 71 variáveis de desempenho construídas a partir da revisão teórica realizada. Os resultados obtidos com a pesquisa exploratória da primeira parte identificaram os quatro fatores de desempenho já citados e na segunda parte os resultados obtidos nos dois principais locais comprovaram a hipótese que os locais ou grupos de servidores que apresentam maior grau de comprometimento tendem a um maior grau de desempenho. Na terceira parte do estudo utilizou-se a técnica de modelagem de equações estruturais partindo de um modelo teórico definido com as 12 variáveis de desempenho mais importantes em ambos locais da pesquisa e com o apoio dos softwares estatísticos SPSS e LISREL obteve-se um modelo de relacionamento causal mais fortalecido para explicar as variáveis envolvidas.
\end{abstract}




\title{
THE CAUSAL RELATION BETWEEN COMMITMENT AND PERFORMANCE: A STUDY IN RESEARCH CENTERS
}

\author{
Miguel Enrique Tejos-Saldivia
}

\begin{abstract}
In this work relation among leadership, motivation, organizational climate, teamwork, and the organizational and occupational commitment, were studied. The exploratory study was accomplished in three parts. In the first it was identified the more important performance factors in a larger relation resultant of the bibliographical research and in the second, it was undertaken a quantification the 4 performance factors together to the organizational and occupational commitments. In the first part, it was accomplished an exploratory research close to some experienced servants, with emphasis in the management area. In the second part it was interviewed 52 employees of the CCTM's at the Energy and Nuclear Research Institute - IPEN and 252 employees of the IAE at the Aerospace Technical Center - CTA. This research used 18 indicators of the organizational commitment and 18 indicators of the occupational commitment, all extracted from the instrument of Meyer, Allen and Smith. Beyond of these, it was used 7 demographic variables and 71 performance variables built from the theoretical revision. The results obtained with the exploratory research of the first part identified the 4 factors aforementioned performance factors. In the second part the obtained results in the two firsts places proved the hypothesis that the servants' locations or groups that show a higher degree of commitment tend to a higher degree of performance. In the third part of this study it was used the Structural Equations Modelling - SEM, from one theoretic model defined with the 12 more important variables from performance in both researched locals and with assistance of two statistical softwares SPSS and LISREL it was obtained a model of causal relations more strengthened to explain the relationship among the used variables.
\end{abstract}




\title{
LA RELACIÓN CAUSAL ENTRE COMPROMETIMIENTO Y DESEMPEÑO: UN ESTUDIO EN CENTROS DE PESQUISA
}

\author{
Miguel Enrique Tejos-Saldivia
}

\begin{abstract}
RESUMEN
En este trabajo se estudiaron las relaciones que existen entre liderazgo, motivación, clima organizacional, trabajo en equipo y el comprometimiento organizacional y ocupacional. El estudio empírico fue realizado en tres partes, en la primera se buscó identificar los factores de desempeño más importantes de una relación mayor que resultó de una revisión bibliográfica y en la segunda parte se buscó medir los 4 factores de desempeño y el comprometimiento organizacional y ocupacional. En la primera parte se realizó una investigación exploratoria junto a algunos servidores mas experimentados y destacados en el área de gestión y, en la segunda parte fueron entrevistados 52 servidores del CCTM y 252 servidores del IAE del Centro Técnico Aeroespacial - CTA. La investigación utilizó 18 indicadores del comprometimiento organizacional y 18 indicadores del comprometimiento ocupacional, todos extraídos del instrumento de Meyer, Allen y Smith. Además de estos, fueron utilizadas 7 variables demográficas y 71 variables de desempeño construidas a partir de una revisión teórica. Los resultados obtenidos con la investigación exploratoria de la primera parte, identificaron los cuatro factores de desempeño ya citados y en la segunda parte los resultados obtenidos en los dos principales locales demostraron que los locales o grupos de servidores que presentan mayor grado de comprometimiento tienden a un mayor nivel de desempeño. En la tercera parte de esta investigación se utilizó la técnica de Modelamiento de Ecuaciones Estructurales - SEM, partiendo de un modelo teórico definido con las 12 variables de desempeño más importantes en ambos locales investigados y con el apoyo de los software SPSS y LISREL se obtuvo un modelo de relacionamiento causal más fuerte para explicar las variables involucradas.
\end{abstract}




\section{SUMÁRIO}

Página

1 O PROBLEMA DA PESQUISA .1

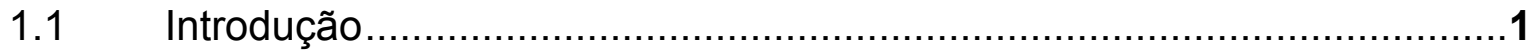

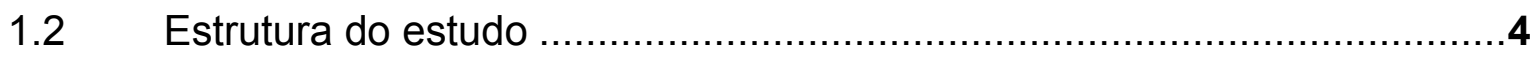

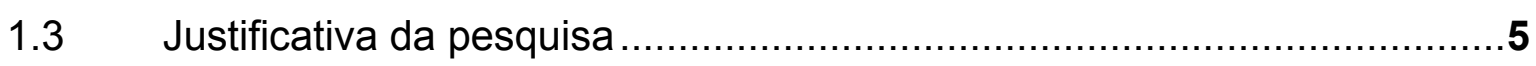

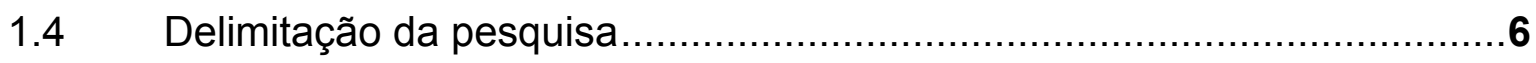

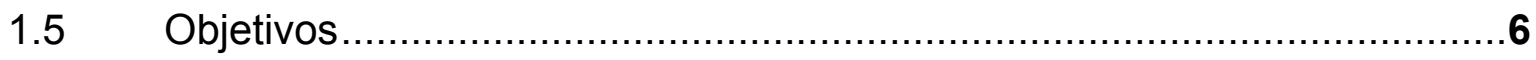

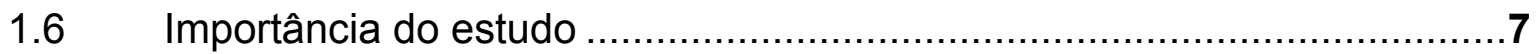

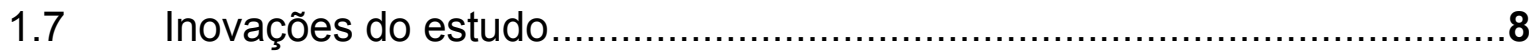

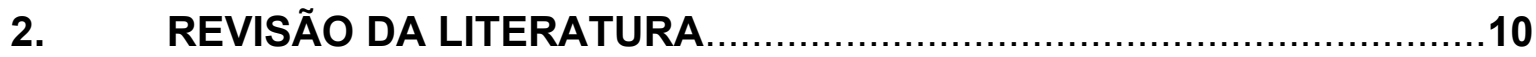

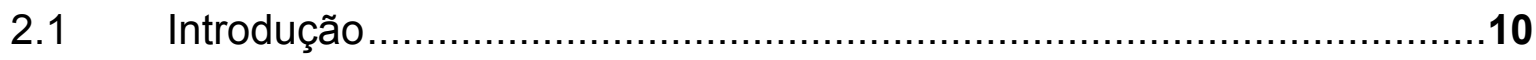

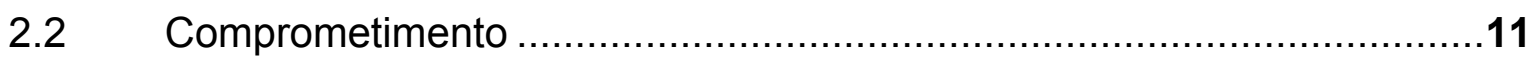

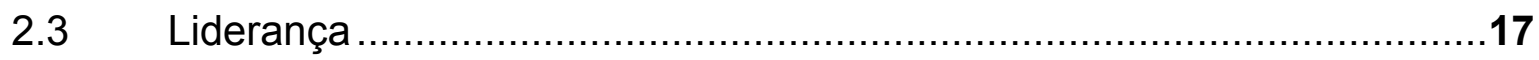

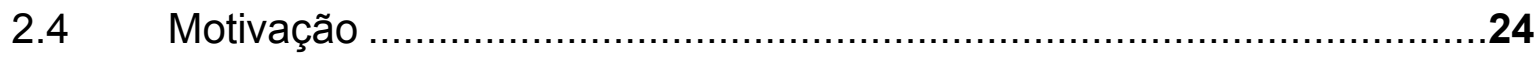

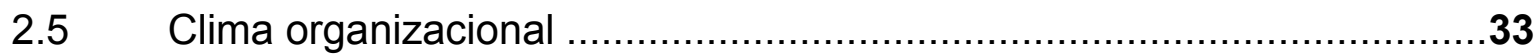

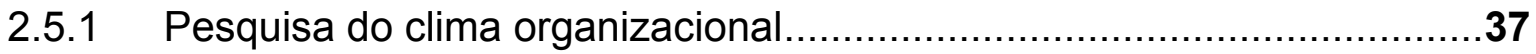

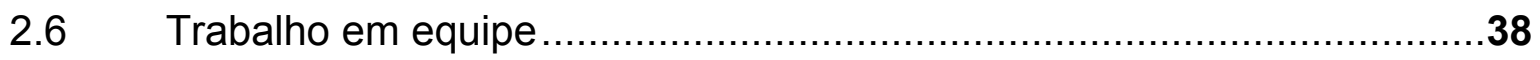

2.7 Justificativa da escolha pelos quatro fatores de desempenho ................42

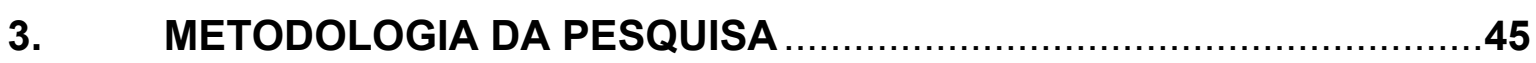

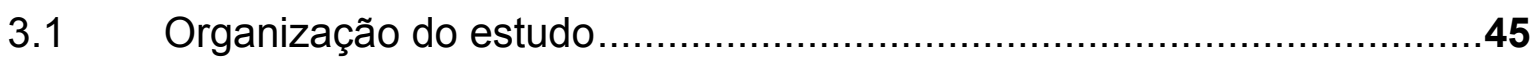

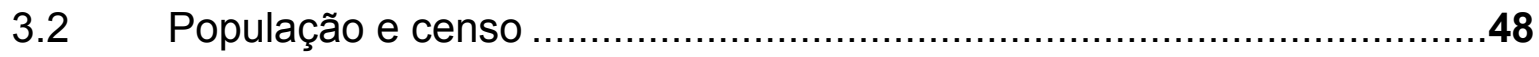

3.3 Definição operacional das variáveis .................................................49

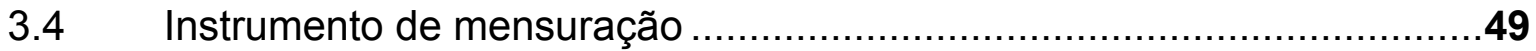

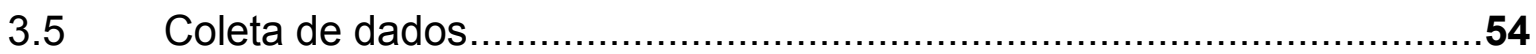

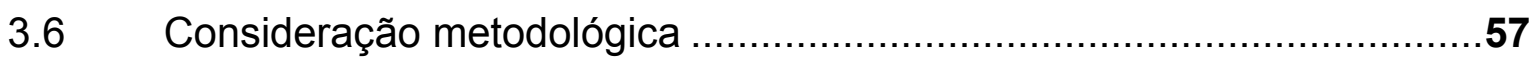

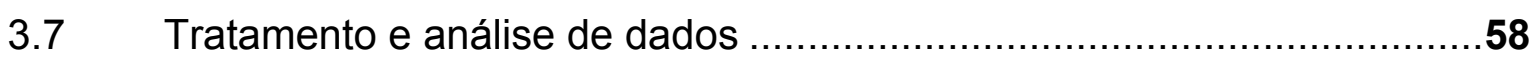

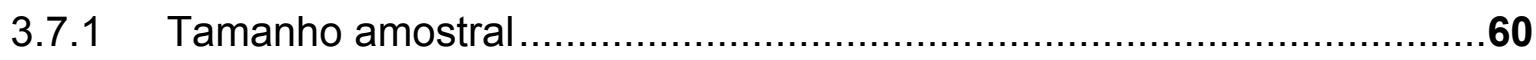

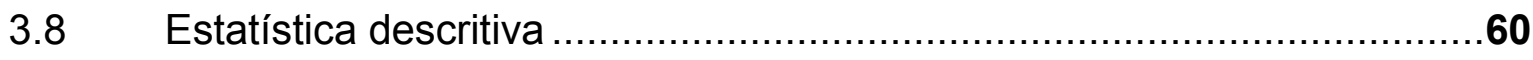

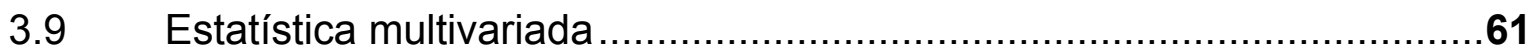

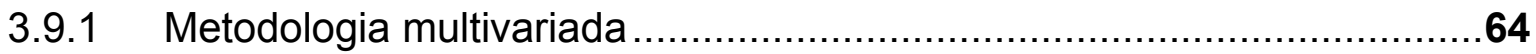




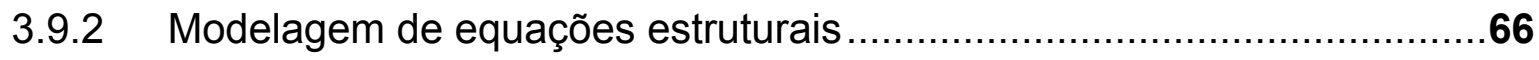

3.9.2.1 Análise de caminho ...................................................................72

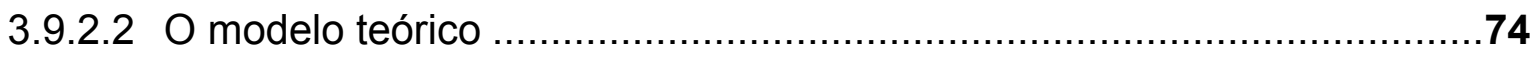

3.9.2.3 Seleção da matriz de entrada dos dados ..........................................74

3.9.2.4 Seleção do método de estimação.......................................................74

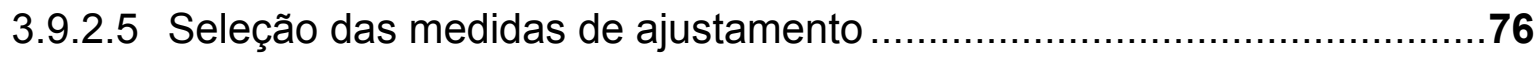

3.9.2.6 Procedimentos de avaliação individual dos constructos ..........................79

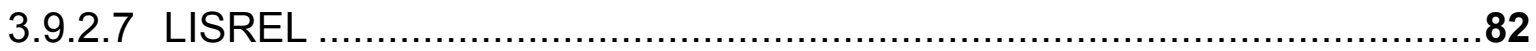

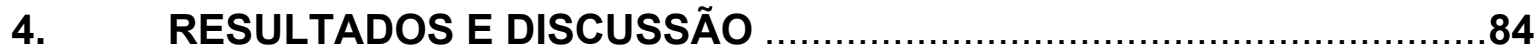

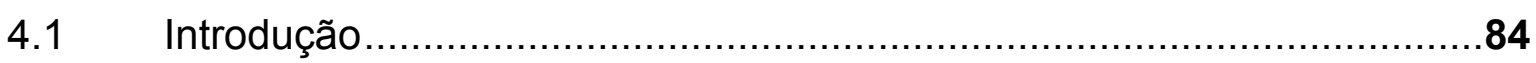

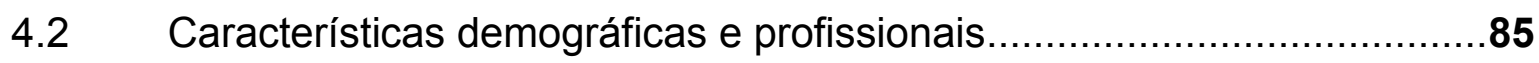

4.3 Comparando as respostas entre o CTA e o IPEN ….............................88

4.4 Comprometimento organizacional e ocupacional (Ricco) .......................90

4.5 Comprometimento organizacional e ocupacional .................................95

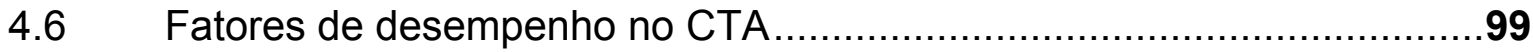

4.7 Fatores de desempenho no IPEN....................................................103

4.8 Comparando o desempenho entre o CTA e o IPEN .............................106

4.9 Coeficiente alfa de Cronbach...............................................................107

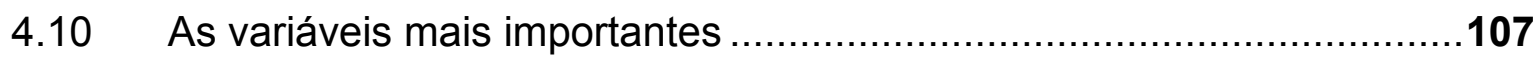

4.11 Elaboração dos modelos estrutural e de mensuração ..........................109

4.11.1 Modelo completo inicial (estrutural e de medidas) ..............................114

4.12 Procedimento de avaliação e escolha do modelo integrado...................116

4.13 Resultados do modelo escolhido .......................................................120

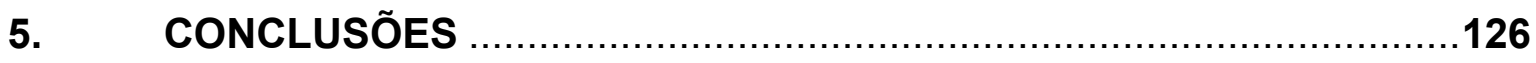

6 RECOMENDAÇÕES PARA TRABALHOS FUTUROS .....................129

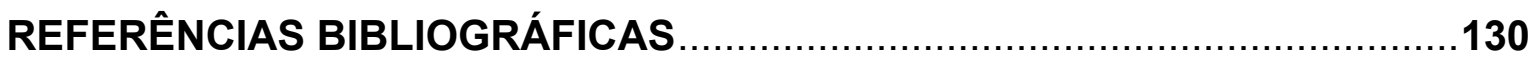

ANEXOS 


\section{LISTA DE TABELAS}

Tabela

Páginas

Tabela 2.1 - Fatores comuns aos conceitos de clima organizacional considerando o enfoque em atributos organizacionais segundo vários autores......35

Tabela 4.1 - Comprometimento nas Divisões do CTA .................................... 92

Tabela 4.2 - Comprometimento nos Laboratórios do IPEN ...............................94

Tabela 4.3 - Comprometimento nos laboratórios do CTA ................................ 96

Tabela 4.4 - Comprometimento nos laboratórios do IPEN $\ldots \ldots \ldots \ldots \ldots \ldots \ldots \ldots \ldots \ldots . . \ldots 6$

Tabela 4.5 - Comprometimento nos grupos do CTA .................................... 98

Tabela 4.6 - Comprometimento nos grupos do IPEN .................................. 98

Tabela 4.7 - Desempenho nos Laboratórios do CTA .................................... 101

Tabela 4.8 - Desempenho nos grupos do CTA ..................................... 102

Tabela 4.9 - Desempenho nos laboratórios do IPEN ................................... 104

Tabela 4.10 - Desempenho nos grupos do IPEN .................................. 105

Tabela 4.11 - Medidas de ajustamento para os modelos REQUIP e ACEITA .... 119

Tabela 4.12 - Resíduos normalizados do modelo REQUIP ............................ 121

Tabela 4.13 - Resíduos normalizados do modelo ACEITA .............................. 122 


\section{LISTA DE FIGURAS}

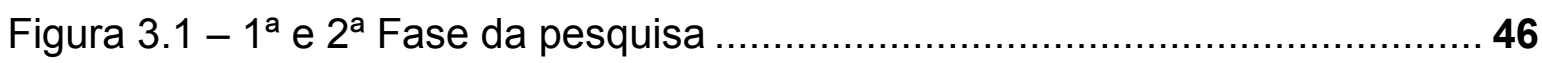

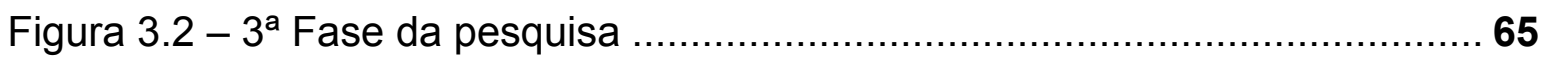

Figura 4.1 - Variáveis demográficas no CTA e no IPEN .............................. 86

Figura 4.2 - Comprometimento organizacional normativo CRN5 …................ 89

Figura 4.3 - Comprometimento ocupacional afetivo CCA3 …....................... 89

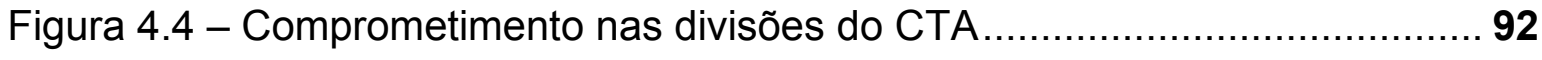

Figura 4.5 - Comprometimento nos laboratórios do IPEN ...........................94

Figura 4.6 - Relação estrutural do modelo ACEITA .................................. 113

Figura 4.7 - Relação estrutural do modelo REQUIP.................................. 113

Figura 4.8 - Relação estrutural do modelo REORG ................................ 114

Figura 4.9 - Relação estrutural do modelo IDENT ....................................... 114

Figura 4.10 - Diagrama do modelo ACEITA ........................................ 115

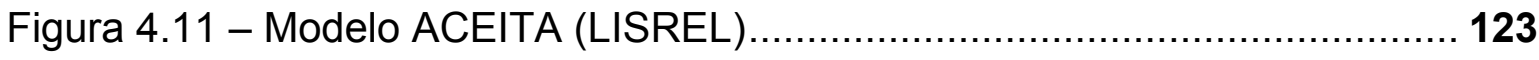




\section{LISTA DE ABREVIATURAS}

ACA Divisão de Ciências Atmosféricas do IAE;

ACEITA Modelo aceitação e participação;

AD-I Coordenadoria de Informática do IAE;

AEL Divisão de Eletrônica do IAE;

AEV Divisão de Ensaios em Vôo do IAE;

AFC Análise fatorial confirmatória;

AFE Análise fatorial exploratória;

AGFI Adjusted goodness-of-fit;

AIE Divisão de Instrumentação e Ensaios do IAE;

AME Divisão de Mecânica do IAE;

AMR Divisão de Materiais do IAE;

ANPAD Associação Nacional de Pós-Graduação e Pesquisa em Administração;

AQI Divisão de Química do IAE;

ASA Divisão de Sistemas Aeronáuticos do IAE;

ASD Divisão de Sistemas de Defesa do IAE;

ASE Divisão de Sistemas Espaciais do IAE;

AVE-Q Coordenadoria Setorial da Qualidade Espacial do IAE;

C Concordo da questão;

CC Comprometimento ocupacional;

CCA Comprometimento ocupacional afetivo;

$\mathrm{CCl} \quad$ Comprometimento ocupacional instrumental;

CCN Comprometimento ocupacional normativo;

CCTM Centro de Ciência e Tecnologia de Materiais do IPEN;

CEB Laboratório de Cerâmicas Estruturais e Biomateriais do CCTM;

CFI Comparative fit index;

CM Laboratório de Comportamento Mecânico do CCTM;

CNEN Comissão Nacional de Energia Nuclear;

$\mathrm{CO} \quad$ Fator clima organizacional; 
COA Ambiente do fator clima organizacional;

COC Criatividade do fator clima organizacional;

COD Desempenho do fator clima organizacional;

Comp Comprometimento em geral;

$\mathrm{COO}$ Organização do fator clima organizacional;

CP Concordo parcialmente da questão;

CR Comprometimento organizacional;

CRA Comprometimento organizacional afetivo;

CRI Comprometimento organizacional instrumental;

CRN Comprometimento organizacional normativo;

C\&T Ciência e tecnologia;

CT Concordo totalmente da questão;

CTA Comando-Geral de Tecnologia Aeroespacial;

CTS Laboratório de Corrosão e Tratamento de Superfícies do CCTM;

D Discordo da questão;

DE Desempenho;

DOT.NET Linguagem de programação em computação;

DP Discordo parcialmente da questão;

DRX Laboratório de Difração de Raios X do CCTM;

DT Discordo totalmente da questão;

EC Laboratório de Eletro-cerâmicas do CCTM;

EnANPAD Encontro nacional da Associação Nacional de Pós-Graduação e Pesquisa em Administração;

Eng. Engenheiros;

FACE Faculdades de Ciências Econômicas da UFMG;

FEA Faculdade de Economia, Administração e Contabilidade da USP;

FGV Fundação Getúlio Vargas;

GFI Goodness-of-fit index;

GLS Generalized least squares (método dos mínimos quadrados generalizados);

I Indiferente à questão;

IAE Instituto de Aeronáutica e Espaço do CTA;

IDENT Modelo identidade;

INT Instituto Nacional de Tecnologia; 
INTERNET Rede mundial de computadores:

INTRANET Rede interna de computadores dentro de uma organização;

IPEN Instituto de Pesquisa Energéticas e Nucleares;

ITA Instituto Tecnológico da Aeronáutica;

Labs. Laboratórios;

LI $\quad$ Fator liderança;

LIA Atitudes do fator liderança;

LIC Características do fator liderança;

LII Importância do fator liderança;

LISREL Linear structural relations;

MaM Laboratório de Materiais Magnéticos do CCTM;

MG Estado de Minas Gerais;

MiM Laboratório de Microscopia e Microanálise do CCTM;

ML Maximum likelihood (Máxima verossimilhança);

MLE Maximum likelihood estimation (Estimativa da máxima verossimilhança);

MO Fator motivação;

MOA Ambiente do fator motivação;

MOC Chefia do fator motivação;

MOM Motivação do fator motivação;

MOO Organização do fator motivação;

MORC Reconhecimento do fator motivação;

MORL Relacionamento do fator motivação;

MPI

Laboratório Metalurgia do Pó e Intermetálicos do CCTM;

MPS Motivating potential score (Pontuação do potencial de motivação);

NFI Normed fit index;

NNFI Nonnormed fit index;

$\mathrm{OCQ} \quad$ Organizational commitment questionnaire;

PCR Laboratório de Processamento Cerâmico de Resíduos do CCTM;

P\&D Pesquisa e Desenvolvimento;

PGT Núcleo de Política e Gestão Tecnológica da USP;

PHP Linguagem de programação em computação;

PM Laboratório de Processamento de Materiais do CCTM;

PNB Produto nacional bruto; 
PNQ Prêmio nacional da qualidade;

PUC Pontífice da Universidade Católica;

REORG Modelo relacionamento com a organização;

REQUIP Modelo relacionamento com a equipe;

RMSEA Root mean square error of approximation;

SEM Strutural equations modeling (Modelagem de equações estruturais);

SGI Sistema de gestão integrada;

SOFC Laboratório de Insumos e Componentes do CCTM;

TE Fator trabalho em equipe;

TEA Ambiente do fator trabalho em equipe;

TECD Conduta do fator trabalho em equipe;

TECP Comprometimento do fator trabalho em equipe;

TEM Missão do fator trabalho em equipe;

TER Relacionamento do fator trabalho em equipe;

TETRAD Programa para modelos estatísticos ou causais;

UFLA Universidade Federal de Lavras;

UFMG Universidade Federal de Minas Gerais;

ULS Unweighted least squares (Método dos mínimos quadrados nãoponderados);

USP Universidade de São Paulo;

VCC Laboratório de Vidros e Compósitos Cerâmicos do CCTM;

VD Variável dependente;

VI Variável independente;

VLS Veículo lançador de satélites;

WLS Weighted Least Squares (Método dos mínimos quadrados ponderados). 


\section{CAPÍTULO 1}

\section{O PROBLEMA DA PESQUISA}

\subsection{Introdução}

Os locais de P\&D requerem muito investimento, principalmente àqueles que envolvem alta tecnologia e que é o caso em estudo. Se junto ao anterior consideram-se as dificuldades do nosso País onde o órgão financiador da pesquisa é o Governo e como este vem apresentando cada vez menos recursos para tal finalidade nos últimos anos, observou-se que uma das necessidades destes locais é que apresente um melhor desempenho nas suas atividades. Uma forma de melhorar o desempenho destes locais é através de melhorias de gestão ou práticas na área, o qual é o assunto deste estudo.

A área de gestão atualmente é, dentro dos institutos de pesquisas, uma das principais preocupações num ambiente de constantes mudanças decorridas, sejam eles produtos de inovações tecnológicas, de novas estruturas administrativas ou de estratégias devido aos novos conceitos gerenciais. Considerando-se que as entidades de P\&D do governo, são também rotuladas de que a eficiência não é o fator principal das suas atividades, e levando-se em conta simultaneamente que a imagem do serviço público é confundida muitas vezes como de baixa eficiência, entende-se que, o trabalho proposto apresenta um alto grau de interesse e se torna uma necessidade. Salles (2000) questiona se excelência científica (ou tecnológica) deve ser complementada com eficiência gerencial, e é exatamente neste ponto que se quer explorar este trabalho.

O tema da eficiência é na atualidade uma necessidade do dia-a-dia das organizações vivendo estas um ambiente de competitividade e de constantes melhorias. Vive-se numa época de competitividade e globalização e neste período as organizações públicas não escapam a constantes mudanças e transformações.

A necessidade das organizações de P\&D serem mais competitivas exige mudanças e estas podem acontecer mediante a implementação de novos 
modelos de gestão, de novas tecnologias, de uma maior flexibilidade, uma maior agilidade e de novas estratégias. Outro ponto que não se pode esquecer é a alta idade média dos equipamentos utilizados nos centros de pesquisa, por volta de 15 ou mais anos, assim, para melhorar esta obsolescência e igual sobrevivência, a solução procurada vem de encontro ao problema citado.

$\mathrm{O}$ interesse na área de centros de pesquisas restringe-se às organizações em ciência e tecnologia, no campo do serviço público. Entretanto, estas entidades são poucas e, conseqüentemente, o material de referência é muito escasso. Agora, se for associada à eficiência ao universo dos centros de pesquisa, o grau de dificuldade aumenta.

No campo da prestação de serviços, estes institutos governamentais devem atender a padrões de excelência tecnológica como necessidade de sobrevivência (Salles, 2000), e deve-se considerar que estes estão enfrentando a cada dia, mais a concorrência dos institutos privados, dada a crescente demanda de serviços, fato comprovado pelo INMETRO. Desse fato, conclui-se também a necessidade urgente de melhorar o desempenho destes locais.

Entende-se que num centro de pesquisa, geralmente, podem-se dividir suas atividades em três: a de P\&D propriamente dita, a de ensino e a de serviços tecnológicos, onde nesta última concentram-se os laboratórios os quais são locais que executam serviços de ensaios, desenvolvimentos, experimentos, apoios ou calibrações. Infelizmente, nestes locais não existem condições de se automatizar o trabalho, o qual permitiria uma menor participação da mão-de-obra e conseqüente diminuição na variabilidade do processo resultando assim na melhoria do desempenho.

As estatísticas comparativas entre os países que investem em C\&T frações apreciáveis de seus PNB e aqueles que não o fazem refletem abundantemente diferenças de riqueza, de poder e de perspectivas de desenvolvimento de suas respectivas sociedades. O poderio militar desses países também é evidência mais do que convincente da importância estratégica da C\&T.

Neste cenário envolvido é comum encontrar a aplicação das normas de gestão da qualidade, principalmente as da série ISO NBR 9000 em geral, a ISO NBR 17025 específica para laboratórios e mais recentemente em implantação a NBR 15100 na área aeroespacial. Tais normas reforçam a estrutura técnica destas organizações, porém isto se não for bem empregado não garante 
resultados de eficiência, já que isto pode negativamente aumentar a burocracia e deixar o sistema mais oneroso nas suas atividades operacionais. Este fato leva a procurar uma saída visando obter melhorias na eficiência.

Há inúmeras formas de olhar uma organização, mais nenhuma é completa se não se consideram as pessoas. "Uma organização é composta de pessoas, que trazem para seu interior suas necessidades, interesses, sonhos, potencialidades e limitações" (Casado, 2002, p. 235).

McGregor (1980, p. 48) diz que "as pessoas quando privadas de oportunidades para satisfazerem as suas necessidades comportam-se com atitudes e comportamentos negativos". A pesquisa comportamental nas organizações tem percebido que não se pode compreender o indivíduo sem compreender a organização na qual ele está inserido.

Ao se estabelecer uma análise em torno dos fatores que afetam 0 desempenho no trabalho e de vínculos de comprometimento em relação à organização e à ocupação, além de considerar a ausência de pesquisas anteriores que possam servir de balizadoras, seja para a estruturação de uma análise mais adequada, seja para subsidiar maiores aprofundamentos na análise dos resultados, verifica-se que, a complexidade da pesquisa aumenta.

Este trabalho envolve a área de serviços tecnológicos, em centros de pesquisa, no campo da ciência e tecnologia, em organizações públicas. Acreditase que em centros de pesquisa privados e para outras áreas este estudo teria que ser verificado.

O presente trabalho visa inicialmente verificar qual é a relação e o grau de intensidade entre fatores que influenciam o desempenho dos serviços tecnológicos e o comprometimento ocupacional e organizacional nos centros de pesquisa. A importância do estudo foi conhecer os fatores principais de desempenho que aplicados, leva a obter uma organização com uma maior eficiência, com serviços realizados a um custo menor e, conseqüentemente, um maior potencial de desenvolvimento. Tenta-se verificar como um maior comprometimento resulta num maior desempenho individual dos seus funcionários e conseqüentemente das organizações envolvidas. Finalmente, a pesquisa em uma primeira etapa de exploração dos dados, foi à fonte para definir um modelo teórico a partir de uma análise fatorial exploratória que indicou as variáveis mais importantes em ambos locais estudados. Este modelo junto aos 
seus "rivais" foi rodado no software LISREL e após diversas análises dos indicadores de ajuste, conseguiu-se obter o modelo mais explicativo e ajustado que indica o relacionamento causal entre as variáveis envolvidas.

\subsection{Estrutura do estudo}

Este trabalho está estruturado em seis capítulos apresentados a seguir. O capítulo introdutório é dividido em sete partes: na primeira parte, uma abordagem inicial do problema; em seguida, é formulada a estrutura do estudo; na terceira parte, a justificativa da pesquisa; na quarta parte, a delimitação da pesquisa; na quinta parte, os objetivos gerais e parciais do estudo; na sexta parte, a importância do estudo; na última parte, citam-se as inovações do estudo.

O capítulo 2 trata da revisão da literatura, dos temas do comprometimento organizacional e ocupacional destacando o modelo utilizado dos três componentes de Meyer et al. (1993), este último validado no Brasil entre outros por Medeiros (1997) e Ricco (1998). Também se detalha a bibliografia dos quatro fatores de desempenho (liderança, clima organizacional, motivação e trabalho em equipe), resultantes da primeira pesquisa e finaliza o capítulo com algumas justificativas que reforçam a escolha dos 4 fatores de desempenho citados anteriormente.

O capítulo 3 expõe a metodologia da pesquisa apresentando-se a organização do estudo na primeira parte, a população e censo da pesquisa na segunda parte, a definição das variáveis na terceira parte, o instrumento de mensuração na quarta parte, a coleta dos dados na quinta parte, uma consideração metodológica na sexta parte, o tratamento e análise dos dados além do tamanho amostral na sétima parte, a estatística descritiva na oitava parte e finalmente a estatística multivariada, na qual se destacam principalmente sua metodologia, a modelagem de equações estruturais, a análise de caminhos, o modelo teórico, a seleção da matriz de entrada de dados, a seleção do método de estimação, a seleção das medidas de ajustamento, a avaliação individual dos constructos e finaliza com uma apresentação do programa estatístico LISREL.

O capítulo 4 apresenta os resultados e as discussões, iniciando-se com uma introdução das técnicas estatísticas na primeira parte; na segunda parte realiza-se a apresentação e discussão das variáveis demográficas; na terceira parte há uma comparação das respostas de ambos locais pesquisados; na quarta 
parte analisam-se os resultados do comprometimento organizacional e ocupacional segundo o critério de Ricco (1998); na quinta parte discutem-se os resultados do comprometimento organizacional e ocupacional com dados normalizados; na sexta parte são analisados e discutidos os resultados do desempenho no CTA; na sétima parte de forma semelhante à anterior, porém agora para os dados de desempenho do IPEN; na oitava parte comparam-se os resultados do desempenho entre o CTA e o IPEN; na nona parte apresenta-se o coeficiente de confiabilidade alfa de Cronbach para os quatro constructos de ambas as populações; na décima parte uma análise fatorial exploratória define as variáveis mais importantes em ambos locais estudados; na décima primeira parte discute-se a elaboração dos modelos estrutural, de mensuração e inicial na modelagem de equações estruturais; na décima segunda parte a avaliação e escolha do modelo integrado; e finalmente, na décima terceira parte, discutem-se os resultados do modelo escolhido.

O capítulo 5 apresenta as conclusões do estudo. Destaca-se no decorrer do estudo a comprovação de que em locais ou grupos de maior grau de comprometimento os fatores de desempenho apresentam índices maiores, e finalmente discute-se o modelo final ajustado como resultado da utilização da modelagem de equações estruturais com o software LISREL, modelo este que explica o relacionamento causal entre as principais variáveis de desempenho envolvidas. O capítulo 6 detalha as recomendações e trabalhos futuros.

Finalmente o estudo encerra-se com as referências bibliográficas e os diversos anexos e apêndices utilizados.

\subsection{Justificativa da pesquisa}

As empresas cada vez mais têm despendido uma grande quantidade de esforços na busca e retenção de pessoas com melhor qualificação e que estejam propensas a serem comprometidas com as organizações. As atividades de recrutamento e seleção de pessoal tentam, mais do que nunca, prover as empresas com indivíduos comprometidos e com desempenho superior. Aliado ao dispêndio da seleção de pessoal, os programas de retenção de talentos aumentam seus custos cada vez mais, decorrentes dos benefícios e salários oferecidos pelas organizações (O’Reilly e Pfeffer, 2001). Do anterior se deduz que se precisa de uma ferramenta que auxilie na busca e retenção de pessoas 
melhor qualificadas, mais comprometidas e de desempenho superior.

Para a pesquisa, o importante não é só identificar os indivíduos comprometidos com a organização ou com o seu trabalho ou medir o grau de comprometimento de cada um, mas é, principalmente, identificar os fatores de desempenho que influem no comprometimento, e em qual dos dois tipos numa maior proporção. O anterior indica a necessidade de Identificar no conjunto o grau de comprometimento e desempenho dos seus participantes.

O que as organizações devem fazer com a grande massa de empregados que não possuem um forte compromisso com a organização? Segundo O'Reilly e Pfeffer (2001) a solução para as empresas é a criação de sistemas de gestão de pessoas que alinhem os interesses dos empregados com os dos dirigentes em favor do benefício mútuo.

Como última justificativa do estudo cita-se a necessidade de conhecer as variáveis mais importantes de desempenho e seu relacionamento causal entre elas.

\subsection{Delimitação da pesquisa}

Esta pesquisa foi aplicada no setor dos institutos de pesquisa, na área de Ciência e Tecnologia, em dois locais de excelência, um no campo aeroespacial, o outro no campo nuclear.

Em termos geográficos, a pesquisa foi realizada nas cidades de São Paulo e de São José dos Campos, onde se encontram ambos os institutos os quais são ligados a uma universidade de nome, sendo o ITA ao CTA e a USP ao IPEN. No CTA a pesquisa foi realizada nos laboratórios do maior instituto, Instituto de Aeronáutica e Espaço - IAE local de destaque com o desenvolvimento e fabricação do Veículo lançador de satélites - VLS do programa espacial brasileiro, e no IPEN, onde o estudo aconteceu no Centro de Ciência e Tecnologia de Materiais - CCTM com destaque na área de pesquisas de materiais.

\subsection{Objetivos}

O primeiro objetivo geral foi verificar a relação entre principais fatores de desempenho e o comprometimento ocupacional - CC e o comprometimento organizacional - $\mathrm{CR}$, destacando o papel dos comprometimentos organizacional e ocupacional, como preceptores de diferentes níveis de desempenho das equipes 
de trabalho.

Precisaram-se verificar inicialmente os fatores, fossem estes comportamentais das pessoas ou próprios da organização, que influenciam positivamente no desempenho dos laboratórios de um centro de pesquisa. Como resultado da revisão da literatura obteve-se uma relação de fatores, os quais foram avaliados na pesquisa exploratória visando uma redução no número, isto para poder avaliá-los. Assim, precisaram-se descobrir quais eram os fatores mais importantes no desempenho da prestação de serviços tecnológicos num centro de pesquisa.

O segundo objetivo geral foi propor e escolher um modelo de relacionamento causal, das principais variáveis de desempenho, utilizando a modelagem de equações estruturais - SEM. Foi definido um modelo teórico de relacionamento causal e através do software LISREL foi verificado este modelo e outros similares tentando definir o modelo mais apropriado de relacionamento causal que explique o problema tratado.

Para atingir os objetivos gerais citados anteriormente, foi necessária a formulação de objetivos específicos detalhados a seguir:

- Verificar se os quatro fatores de desempenho resultantes da pesquisa da primeira fase contribuem de modo significativo para a explicação do comprometimento;

- Verificar se as variáveis mais representativas são as mesmas nos dois casos estudados;

- Caso existam diferenças entre as principais variáveis, verificar se tais diferenças podem ser explicadas em função das organizações;

- Identificar as variáveis mais confiáveis dos dois centros de pesquisa estudados;

- Compor os constructos que contemplaram a natureza dos fatores de influência;

- Pesquisar possíveis relações de causalidade ou de dependência desses constructos.

\subsection{Importância do estudo}

A importância do estudo é conhecer inicialmente fatores que influenciam positivamente no desempenho dos centros de pesquisa, e segundo, 
conhecer quais são os principais fatores numa relação maior, e finalmente se existe e qual é o grau de relação entre os fatores de desempenho e o comprometimento organizacional e ocupacional.

Outro fato muito relevante deste trabalho é a apresentação e discussão do modelo de relacionamento causal que explica o vínculo entre as principais variáveis do desempenho das organizações pesquisadas.

A pesquisa é atual, importante e viável, características que segundo Castro (1977) descrevem algumas das variáveis que qualifica uma boa tese acadêmica.

Não se pretende obter neste estudo resultados definitivos, mas sim abrir novos caminhos para futuras pesquisas na mesma linha e assim confirmar os resultados obtidos.

\subsection{Inovações do estudo}

Foi provado que os locais com maior grau de comprometimento tendem a apresentar um maior desempenho.

A escolha de um conjunto dos quatro mais importantes fatores de desempenho entre vinte e seis resultantes de uma revisão bibliográfica.

O questionário elaborado resultou ser uma ferramenta de avaliação de laboratórios de centros de pesquisa.

Foram identificadas as 12 variáveis de desempenho mais importantes e reconhecidas, juntamente pelos públicos do CTA e do IPEN.

Foi proposto um modelo de relacionamento causal, a partir de um modelo baseado na teoria e nas 12 variáveis mais importantes de desempenho e com a utilização do software LISREL foi melhorado resultando num modelo fortalecido que explica o relacionamento causal entre as variáveis envolvidas.

O estudo mostra de forma objetiva, diferente do encontrado até 0 momento, uma ferramenta de avaliação de desempenho e um modelo de relacionamento causal em centros de pesquisa.

Entende-se que por ser o ambiente laboratorial pouco conhecido e explorado, não existindo trabalhos de metodologia objetiva no cenário dos centros de pesquisas, este trabalho fornece na prática uma metodologia objetiva para avaliação de comprometimento, fatores de desempenho e de entidades similares. 
Acredita-se que após a mensuração do grau de comprometimento e dos quatro fatores de desempenho deste projeto se terá mais um caminho para conhecer, avaliar e melhorar a reestruturação das instituições de pesquisa seja na sua gestão, no controle, nas atividades de programação e em atividades de recursos humanos para seleção e valorização de servidores comprometidos e de melhor desempenho.

O modelo obtido através da modelagem de equações estruturais com as 12 variáveis mais importantes de desempenho é um caminho aberto a novas descobertas, verificações e utilidades no campo do desempenho individual dos servidores. 


\section{CAPÍTULO 2}

\section{REVISÃO DA LITERATURA}

\subsection{Introdução}

Trabalhos que envolvem assuntos de gestão em institutos de pesquisas, resultam numa dificuldade na busca do seu material bibliográfico. Neste cenário muitas vezes as melhorias da área de gestão resultam do enriquecimento de experiências práticas entre institutos de pesquisa e do intercâmbio de conhecimentos entre os participantes deste meio. $O$ contato permanente com pessoas de outros institutos de pesquisas semelhantes deve ser uma prática constante visando sempre obter subsídios de baixo custo.

Este capítulo procura apresentar o referencial teórico dos temas utilizados. Para tal após a introdução, o primeiro item apresentado traz questões relacionadas ao comprometimento organizacional e ocupacional, assim como resultados de estudos e o modelo de Meyer et al. (1993) utilizado para quantificar o comprometimento organizacional e ocupacional.

O segundo item apresenta questões relacionadas à liderança e suas principais teorias.

O terceiro item apresenta questões e modelos teóricos no decorrer do tempo sobre a motivação, incluindo de forma sucinta um resumo das diversas teorias.

O quarto item apresenta objetivamente o conceito de clima organizacional, bem como, sua relação com a cultura organizacional e a medida do mesmo.

O quinto item apresenta questões sobre o tema do trabalho em equipe, suas características, importância e questões a considerar na sua aplicação.

Este capítulo encerra-se com uma discussão que justifica a escolha dos quatro fatores de desempenho junto ao tema do comprometimento organizacional e ocupacional. 


\subsection{Comprometimento}

Comprometimento é aquilo que transforma uma promessa numa realidade. Todas as organizações e em todas suas áreas gostariam de contar com empregados comprometidos com as suas respectivas instituições. Um alto comprometimento entre os empregados conduz a um baixo turnover e consequentemente a um alto desempenho organizacional (Hunt et al., 1985).

Allen e Meyer (1990) afirmam que não há um consenso com relação à definição de comprometimento, o que é ratificado por Bastos (1994) ao ressaltar a redundância, ambigüidade e imprecisão dos conceitos existentes nessas definições. Entretanto, na esfera científica, Bastos (1996) assinala que o termo assume o sentido de adesão, indicando um forte envolvimento do funcionário com os diversos aspectos do ambiente de trabalho.

Até 1988 não existiam no país trabalhos sobre o tema em discussão. Os primeiros trabalhos sobre comprometimento apareceram no país em 1989 na XIX Reunião Anual de Psicologia (Borges-Andrade, 1989, Moraes e Dias, 1989, e Siqueira, 1989). Hoje a situação está muito diferente. Entre 1993 e 2005 foram apresentados 46 artigos no EnANPAD, com uma média de quatro artigos nos últimos cinco anos (2001-2005). Existem visões distintas do comprometimento as quais têm evoluído e se tornado referências ao longo dos anos, parecendo improvável que qualquer uma das abordagens dominará e será aceita como a definição correta de comprometimento (Meyer et al., 1990).

Porter et al. (1974, p. 604) define o conceito de comprometimento como "a força da identificação de um indivíduo e seu envolvimento com uma organização específica".

Bastos (1994) estabeleceu vários significados para a palavra comprometimento. Dentre elas identificou o comprometimento com um significado de engajamento, agregamento e envolvimento. Mais adiante ressaltou o comprometimento como uma disposição, comprometimento é usado para descrever não só ações, mas o próprio indivíduo é assim tomado como um estado, caracterizado por sentimentos ou reações afetivas positivas tais como lealdade em relação a algo. Segundo Bastos (1994), comprometimento é ainda uma propensão à ação, de se comportar de determinada forma, de ser um indivíduo disposto a agir.

Mowday, Steers e Porter (1979, p. 225), em seu clássico trabalho 
Measurement of organizational commitmentt usaram a definição elaborada por Porter e Smith para definir comprometimento: "comprometimento é uma relação forte entre um indivíduo identificado e envolvido com uma organização, e pode ser caracterizado por três fatores: estar disposto a exercer um esforço considerável em benefício da organização; a crença e a aceitação dos valores e objetivos da organização e um forte desejo de se manter como membro da organização".

Comprometer-se é, basicamente, assumir uma responsabilidade ou um compromisso com alguém, com um grupo ou com uma organização. Dito desta forma, o conceito de comprometimento seria do ponto de vista da teoria das organizações, tão amplo quanto provavelmente pouco útil, na medida em que abarcaria tantas possibilidades formais e subjetivas que sua avaliação tenderia a ser inconsistente. Isto não significa que comprometimento não tenha relação com a assunção de compromisso e de responsabilidade, mas que é preciso investigar o que move um sujeito a adotar comportamentos ou atitudes comprometidas ou não (Barbosa e Faria, 2000).

Segundo Senge (1998), o comprometimento pressupõe um sentimento total de responsabilidade na transformação das metas e objetivos em realidade; para tanto, os indivíduos valem-se da criatividade e inovação, desenvolvem alternativas e procuram os meios mais eficientes para garantir o sucesso do que se propuseram a fazer.

Medeiros (1997, p. 3) cita que [...] Uma das grandes preocupações das organizações tanto no meio acadêmico como no empresarial, é a de conseguir selecionar e manter, indivíduos competentes, dedicados, engajados e, principalmente, envolvidos com os problemas da organização [....] há hoje uma busca por pessoas que não trabalham só pelo salário, mas trabalham pelo prazer, pelo significado que o trabalho tem para a vida delas.

McGregor (1980, p. 46) faz um questionamento: "Por que as pessoas não são produtivas? Pagamos bons salários, oferecemos boas condições de trabalho, damos excelentes benefícios e emprego estável. No entanto, as pessoas não querem fazer mais que o esforço mínimo". Os questionamentos levantados por McGregor podem ser traduzidos como: Por que as pessoas não são comprometidas com a organização? ou, Que fatores estão faltando ao empregado para que ele seja comprometido?. McGregor (1980, p. 48) diz que "as pessoas quando privadas de oportunidades para satisfazerem as suas 
necessidades comportam-se com atitudes e comportamentos negativos".

Alguns poucos estudos ampliaram o escopo de análise acerca do comprometimento introduzindo reflexões sobre o sindicato e a carreira, por exemplo. Todavia, a maioria dos trabalhos aborda a organização como foco do comprometimento (Allen e Meyer, 1990; Borges-Andrade, 1989; Mowday, Porter e Steers, 1982; Becker, 1992).

Mowday, Steers e Porter (1979), durante a década de 1970, culminaram com a validação de um instrumento para se medir o comprometimento organizacional atitudinal (ou afetivo) - o OCQ, Organizational commitment questionnaire. O OCQ constitui-se de "uma escala formada por quinze indicadores de comprometimento, possuindo uma versão reduzida com nove itens. A escala do OCQ é do tipo Likert [...]".

A abordagem mais dominante na literatura, dentro de um vasto material de enfoques sobre o comprometimento organizacional, é o afetivo, a partir dos trabalhos de Mowday, Steers e Porter (1979). Mathieu e Zajac (1990) citam que o segundo mais popular enfoque do comprometimento organizacional estudado tem sido o calculativo (ou instrumental), cuja origem está no trabalho de Howard Becker.

\section{O modelo de Meyer, Allen e Smith}

O trabalho de Allen e Meyer (1990) foi, certamente, um dos mais influentes nos estudos sobre comprometimento. Embora suas idéias estejam baseadas nos estudos de Kanter (1968), Mowday, Steers e Porter (1979), Buchanan (1974) e Becker (1960), os seus três tipos de comprometimento podem ser encontrados como fundamento em grande parte dos trabalhos, sobretudo dos autores brasileiros.

O modelo de conceitualização de três componentes de Meyer e Allen foi validado no Brasil, entre outros, por Medeiros e Enders (1997), e seguido por Ricco (1998) e Bandeira (1999). O modelo de Meyer, Allen e Smith (1993) que foi utilizado neste estudo, ele é conceitualizado em três componentes:

- comprometimento organizacional afetivo - CRA, como um apego, como um envolvimento, onde ocorre a identificação com a organização. Segundo Meyer et al. (1990, p. 710), "empregados [...] com um forte comprometimento afetivo permanecem na organização porque eles querem [...]"; 
- comprometimento organizacional instrumental - CRI, percebido como custos associados a deixar a organização. Segundo Meyer et al. (1990, p. 710), "empregados com [...] comprometimento instrumental permanecem porque eles precisam [...]";

- comprometimento organizacional normativo - CRN, como uma obrigação moral em permanecer na organização. Segundo Allen e Meyer (1990, p. 3), "empregados com [...] comprometimento normativo permanecem porque eles sentem que são obrigados".

\section{Antecedentes do Comprometimento Organizacional}

Buchanan (1974) realizou uma pesquisa e concluiu que três experiências do trabalho explicavam $78 \%$ da escala de variância do comprometimento, sendo elas: as atitudes de grupo com a organização, o desafio do trabalho no primeiro ano e os conflitos de lealdade.

Steers (1977) elaborou um modelo de dois componentes: antecedentes do comprometimento e resultados do comprometimento. Os resultados alcançados pelo autor confirmaram que todas as três variáveis do ambiente (características pessoais, características do trabalho e experiências do trabalho) apresentam relação significativa com o comprometimento.

Recorrendo a técnicas de meta-análise, Mathieu e Zajac (1990) reviram e analisaram a consistência de estudos anteriores dos antecedentes e conseqüentes do comprometimento organizacional. Nas características pessoais, os resultados confirmaram que idades mais elevadas se correlacionam com níveis maiores de comprometimento. Quanto ao estado civil, os resultados provaram que pessoas casadas estavam associadas a níveis maiores de comprometimento.

Com relação ao nível de capacidade (ability) dos profissionais, Stevens et al. (1978, apud Mathieu e Zajac, 1990) sugeriram que os funcionários altamente qualificados são de grande valor para a organização, e sendo assim, é provável que recebam maiores recompensas, aumentando por sua vez, seu comprometimento instrumental. Entretanto, não foi encontrada correlação entre nível de capacitação e comprometimento (Mathieu e Zajac, 1990). No tocante à variável "escopo do trabalho", verificou-se a mais alta correlação com o comprometimento organizacional, comparada às outras variáveis antecedentes. 
No tocante ao agrupamento relações grupo-líder, Mathieu e Zajac (1990) consideram cinco variáveis, das quais se destaca: na interdependência de tarefas, onde Morris e Steers (1980, p. 56 apud Mathieu e Zajac, 1990) sugeriram que numa alta dependência funcional, os empregados se tornam mais conscientes de sua contribuição influenciando assim positivamente seu comprometimento afetivo com a organização; a variável comunicação do líder apresentou uma alta correlação positiva.

No Brasil o comprometimento organizacional tem sido estudado longamente nos últimos anos (entre outros Medeiros, 1997 e 2003; Ricco, 1998; Bandeira; 1999; Rocha e Bastos, 1999, Chang Jr., 2001, os diversos trabalhos do Enanpad). O anterior não tem acontecido com o comprometimento ocupacional onde se encontram no país poucos trabalhos, citando entre outros, Bastos (1992, 1994, 1996, 1997 e 2000) e Oliveira (1998). No exterior encontram-se alguns, mas sempre em quantidade muito inferior aos encontrados para o compromisso organizacional. Destacam-se no exterior entre outros, os trabalhos de Blau (1985, 1988,1989), Morrow (1983, 1993), Morrow e Goetz (1988), Bishop e Solomon (1989), Carson e Bedian (1994), Koslowsky (1987) e Lazar (2006).

Ricco (1998) realizou uma pesquisa no CTA sobre comprometimento organizacional com o quadro de pesquisadores. Funcionalmente no CTA como no IPEN, o quadro de servidores de nível superior é formado pelos pesquisadores, pelos assistentes, mas principalmente pelos tecnologistas. Neste estudo no caso do CTA ao menos $95 \%$ dos respondentes de nível superior são tecnologistas. Ricco (1998) concluiu que mesmo em condições adversas os pesquisadores do CTA estavam comprometidos. O componente que mais sobressaiu como indicativo de permanência foi o afetivo.

Passados 8 anos do estudo de Ricco (1998) que pesquisou o comprometimento em condições adversas no CTA, destacam-se as mesmas dificuldades financeiras, os pesquisadores continuam vestindo a camisa e a coragem de serem motivados apenas por fatores intrínsecos.

Lazar (2006) realizou sua pesquisa utilizando o mesmo instrumento aqui utilizado, de Meyer et al. (1993), para mensurar os comprometimentos ocupacional e organizacional e concluiu que ambos os comprometimentos afetam na decisão do empregado em deixar a organização. 


\section{Comprometimento ocupacional - CC}

A maioria dos trabalhos é dedicada ao comprometimento organizacional, poucos ao comprometimento ocupacional, o qual apresenta conceituações diversas dedicadas à ocupação, ao trabalho, à profissão. A pouca clareza faz este campo pouco explorado. Por outro lado, Blau et al. (1993) na sua pesquisa detectaram que os indivíduos fazem diferenças sensíveis entre seu emprego, a organização, a ocupação e o trabalho em geral.

Cetin (2006) interpreta o comprometimento ocupacional como a devoção das pessoas em relação à sua ocupação. Morrow (1983) identificou cinco conceitos no comprometimento no trabalho: valor, emprego, organização, união e carreira.

Segundo Morrow e Wirth (1989) o comprometimento ocupacional exige três condições:

○ O objetivo da ocupação;

- A crença nos valores e a aceitação da mesma; e

- Mostrar um esforço para sobreviver na sua ocupação e sócio com sua ocupação.

Cetin (2006) discute o comprometimento ocupacional, citando que desde o início o CC foi considerado como o comprometimento afetivo para uma ocupação, o qual não só envolve com prazer o desempenho das pessoas na sua ocupação, mas também, a devoção delas para sua ocupação. $\mathrm{O} \mathrm{CCl}$ (instrumental) está relacionado com o investimento das pessoas com a sua ocupação, e está relacionado também com o custo que é muito alto quando deixa a organização. O CCN (normativo) está relacionado ao sentimento de responsabilidade e obrigação para com o trabalho

Meyer et al. (1993) generalizaram os três componentes do comprometimento: afetivo (CCA e CRA), instrumental ( $\mathrm{CCl}$ e $\mathrm{CRI}$ ) e normativo (CCN e CRN); para ambos os tipos, ocupacional (CC) e organizacional (CR), entretanto este instrumento tem sido utilizado basicamente no comprometimento organizacional. Meyer et al (1993) citam: o CCA está relacionado a experiências positivas sobre a ocupação. O CCl está relacionado às responsabilidades sobre o comprometimento. O CCN está relacionado com experiências positivas também e no geral ao sentimento da responsabilidade percebida para com os outros. 
Aryee e Tan (1992) tentaram validar um modelo utilizando o LISREL de antecedentes e resultados do comprometimento ocupacional, mas os dados não conseguiram um bom ajuste.

Numa série de estudos Blau (1985, 1988, 1989) desenvolveu e demonstrou a validade discriminante e a generalização da quantificação do comprometimento da carreira.

Morrow e Goetz (1988) examinaram o profissionalismo como uma forma de comprometimento no trabalho, encontrando ser não-redundante com outras formas de comprometimento no trabalho: envolvimento no emprego e o comprometimento organizacional. No raciocínio anterior, Aranya et al. (1981) sugeriram o comprometimento profissional que seria a crença e aceitação nas metas e valores da profissão, a esperteza para exercer esforços a seu favor e um desejo para reter os participantes na sua profissão.

Hunt et al. (1985) propuseram 6 grupos de antecedentes do comprometimento ocupacional: os atributos pessoais, os investimentos pessoais, as variáveis de socialização antecipatória, os comportamentos de pesquisa de emprego, o relacionamento no trabalho e as características do emprego.

Darden et al. (1989), no seu trabalho concluíram que a diferença entre os comprometimentos organizacional e ocupacional é muito pequena. Darden et al. (1989), concluíram que ambos os comprometimentos estão altamente correlacionados $(r=0,88)$.

$\mathrm{Na}$ continuação detalha-se a revisão bibliográfica dos quatro fatores de desempenho que serão confrontados aos comprometimentos organizacional e ocupacional.

\subsection{LIDERANÇA}

De acordo com Chopra (2002, p. 63) a liderança pode ser entendida pelo significado do acronismo de leaders (líderes em inglês): look and listen (olhar e ouvir); empowerment (dar poder); awareness (ter consciência); doing (fazer); emotional freedom and emphaty (ter liberdade emocional e empatia); responsability (ter responsabilidade) e synchronicity (ter sincronismo).

Gardner (1990, p. 17) define liderança como "é o processo de persuasão, ou de exemplo, através do qual um indivíduo (ou equipes de liderança) induz um grupo a dedicar-se a objetivos defendidos pelo líder, ou partilhados pelo 
líder e seus seguidores". Conforme Gardner além da eficácia e competência, o líder prefigura objetivos, estabelece metas, transmite uma visão, dá soluções ou tenta concentrar as energias para alcançar objetivos mais abrangentes. $O$ autor acrescenta que o líder não cria motivação do nada, ele libera ou canaliza motivos existentes (Gardner, 1990).

Maximiano (2005, p. 286) define liderança da seguinte maneira:

"A liderança é uma função, papel, tarefa ou responsabilidade que qualquer pessoa precisa desempenhar, quando é responsável pelo desempenho de um grupo. Independentemente de suas qualidades, muitas pessoas são colocadas em posições de liderança, em que precisam dirigir os esforços de outros para realizar objetivos...".

A definição de liderança citada por Kotter (1992, p. 15-16):

"é o processo de levar a um grupo (ou grupos) numa determinada direção, fundamentalmente por meios não coercitivos. Uma liderança eficiente a definimos como aquela que produz um movimento na direção daquilo que é melhor, no longo prazo, para o grupo [...]".

Das definições anteriormente citadas de liderança observa-se que para alguns, a liderança é a característica de um grupo, para outros é a característica do indivíduo. Para os primeiros, liderança é sinônimo de prestígio, da manutenção de determinado posto, da realização de atividades importantes para o grupo e observando que a liderança depende da aceitação do líder pelo grupo de modo a se conseguir uma integração do esforço. Para os que a identificam com o indivíduo, a liderança significa a posse de algumas características da personalidade, tais como domínio, controle do ego ou agressividade.

A palavra liderança refere-se à capacidade pessoal inerente ao indivíduo, que influencia ou orienta o comportamento alheio. Constitui uma necessidade de trabalho em equipe (um outro fator de desempenho resultante desta pesquisa) e para que a equipe funcione e atinja seus resultados precisa, geralmente, de um líder. O líder é o indivíduo, a liderança é a função.

Predomina nas organizações a busca de profissionais com potencial de liderança, que utilizarão seu potencial intelectual para promover mudanças. Schein (1992) cita que os lideres necessitam começar a pensar como agentes de mudança, pois o problema não é somente como adquirir novos conceitos ou habilidades, mas também como desaprender o que não é mais útil para a organização.

Para Bergamini (1994) a liderança é um tipo de atributo que influencia o comportamento das pessoas. Conforme Fiedler deduz de algumas definições 
(1981, p. 03) "[...] constitui a liderança uma relação entre pessoas em que influência e poder estão distribuídos de forma desigual, porém legítima. O poder pode ser conferido ao líder, mediante consentimentos dos membros do grupo, por meio de um contrato de trabalho ou por força de lei, mas cabe a ele exercê-lo".

Para Davis e Newstrom (1992), o sucesso da liderança depende de comportamentos apropriados, habilidades e ações e não de traços pessoais. Comportamentos podem ser aprendidos e modificados, enquanto que traços são relativamente rígidos. Entende-se por habilidades os atributos que o líder adquire ou desenvolve, por meio de experiência, treinamento e convivência social. Segundo Davis e Newstrom (1992), os líderes possuem três tipos de habilidades: técnica (conhecimentos do trabalho), conceitual (pensar em termos de modelos, estruturas e planos) e humana (trabalhar com pessoas).

Bergamini e Coda (1997a, p. 213) mencionam que "a eficácia da liderança depende da definição que o líder dá a respeito da situação que sirva como base para a ação dos demais".

\section{Relação entre liderança e poder}

Segundo Gardner (1990, p. 71), liderança e poder não são iguais citando "[...] mas são duas coisas que se entrelaçam em muitos pontos. O poder é a capacidade de garantir o resultado que se deseja e de impedir outro resultado, que não se deseja”. Para Hersey e Blanchard (1986), liderança é simplesmente qualquer tentativa de influenciar, enquanto o poder do líder é o seu potencial de influência.

Etzioni (1974) identificou três elementos que influenciam o comportamento alheio: coercitivo (punição), manipulativo (recompensa) e normativo (crenças e símbolos). Um líder não necessitaria dispor de sua autoridade formal para ter poder. Deveria sim, tentar utilizar suas características pessoais ou carismáticas, ou seja, de seu poder de referência, como fonte de influência e usar este poder para levar os outros a fazer aquilo que deseja. O poder de referência ou poder carismático desenvolve-se da admiração por alguém e de um desejo de ser como aquela pessoa (Mathias, 2001). 


\section{Teorias da liderança}

Existe muita literatura devido a ser este um tema sempre do interesse do público. Conforme o relato de alguns autores (Bergamini, 1994; Robbins, 1999) as teorias que se referem ao tema liderança podem ser classificadas em três escolas de pensamento: a) teoria dos traços; b) teorias sobre os estilos de liderança; e, c) teorias contingenciais ou situacionais da liderança.

\section{$\checkmark$ Teoria dos traços}

Constitui a primeira sistematização dos estudos sobre liderança, destacando sua ênfase especialmente nas características do líder (Bergamini, 1994).

"Por traço entendemos geralmente um atributo de personalidade ou um modo de interagir com outros que seja independente da situação, isto é, uma característica da pessoa e não da situação (Fiedler, 1981, p. 20)".

A teoria dos traços deixa lacunas ao ignorar a interação entre líder e liderados, bem como, a não-especificação da importância relativa dos traços. Robbins (1999) relata do por que a abordagem de traços não teve mais sucesso sugerindo quatro razões: "ela não considera as necessidades de seus seguidores, geralmente falha em esclarecer a importância relativa de vários traços, não separa a causa do efeito e ignora fatores situacionais".

\section{Teorias comportamentais}

Uma das principais críticas á teoria dos traços é que a maioria das características pessoais não é diretamente observável. As teorias comportamentais superam este problema, na medida em que a análise recai no que o líder faz e a maneira como faz. As teorias comportamentais podem ser divididas em três vertentes: a experiência da Universidade de Yowa, os estudos da Ohio State University e o continuum de Likert.

\section{A experiência da Universidade de Yowa}

Conforme Fiedler (1981), em 1939 aconteceu um dos primeiros e mais famosos estudos sobre estilo de liderança, pioneiras para o estudo do conhecimento da influência dos diferentes estilos de liderança no comportamento emocional e o desenvolvimento do grupo, realizado por Kurt Lewin, Ronald Lippitt e 
Ralph White. Este trabalho permitiu a notável comprovação de que o mesmo grupo de pessoas se comportará de forma muito diferente quando atua sob líderes que se comportam de forma diferente.

Fiedler (1981) relata que os grupos dotados de líderes democráticos eram os mais satisfeitos e funcionavam de maneira mais positiva e ordenada. $O$ número e o grau de atos agressivos eram maiores nos grupos liderados autocraticamente.

\section{Estudos da Ohio State University}

Segundo Luthans e Martinko (1979, apud Mathias, 2001) no final dos anos de 1940, tiveram início na Ohio State University estudos que visavam identificar dimensões independentes do comportamento do líder. Através da técnica estatística de análise fatorial foram descobertas duas dimensões: estrutura inicial e consideração.

Os pesquisadores desenvolveram o Questionário de Opinião dos Líderes objetivando obter informações sobre as autopercepções que os lideres tinham a respeito de seu próprio estilo de liderança.

O comportamento de um líder poderia ser descrito num quadrante onde cada uma das quatro combinações tinha um grau alto ou baixo de cada dimensão. A pesquisa descobriu que os líderes com alta estrutura inicial e alta consideração tendiam a atingir alto desempenho e satisfação de subordinado, mais frequentemente, do que aqueles que se classificavam nas outras três combinações.

\section{Continuum de Likert}

Bergamini (1994) relata este outro programa realizado pelo grupo da Universidade de Michigan e encabeçado por Rensis Likert. Likert segue a orientação no delineamento dos estilos denominando-os como estilo de chefia "orientado para o empregado" e estilo de chefia "orientado para a produção". Cada um desses estilos representa dois extremos de um continuum englobando graduações que vão desde a participação total do subordinado até o tipo de comportamento característico da falta de consulta, onde o subordinado deve seguir aquilo que lhe é indicado fazer sem ao menos conhecer as razões. 
Likert formaliza sua teoria e propõe um contínuo de quatro graduações de participação (Bergamini, 1994):

- Sistema 1 - "Os chefes não têm confiança nos subordinados. É um sistema autocrático, centralizador e coercitivo. O processo de controle está centrado no topo da organização".

- Sistema 2 - "Os chefes têm uma confiança condescendente nos subordinados. É um sistema menos rígido. O processo de controle está ainda concentrado no topo, mas algo já é delegado para níveis intermediários".

- Sistema 3 - "Os chefes têm confiança substancial, mas não total nos subordinados. Utilizam-se recompensas, raramente punições para motivar".

- Sistema 4 - "Os chefes têm confiança total nos seus subordinados. É um sistema francamente democrático e participativo. Os trabalhadores são motivados pela participação".

Pode-se dizer que o Sistema 1 representa um estilo administrativo autoritário altamente estruturado, orientado para tarefas; o Sistema 4 é um estilo administrativo orientado para relações, baseado em equipe e muita confiança. Os Sistemas 2 e 3 representam estágios intermediários entre os dois extremos. Likert recomenda que as empresas dos Sistemas 1 e 2 passem para os Sistemas 3 e 4, onde haverá maior participação e maior satisfação das pessoas o que consequentemente poderá elevar seus padrões de produtividade.

\section{$\checkmark$ Enfoque situacional da liderança}

Este tipo de teoria parte do princípio de que não existe um único estilo ou característica de liderança válida para qualquer situação e tem a preocupação com os diferentes tipos de comportamentos dos líderes. Várias abordagens existem comprovando sucesso, sendo tratadas aqui duas delas: a) o modelo contingencial de Fiedler; b) a teoria situacional de Hersey e Blanchard.

\section{Modelo de Fiedler}

Tais estudos começaram a partir de 1951 na Universidade de Illinois. O modelo denominado Contingency Model ou Modelo de dependência foi desenvolvido por Fiedler. Fiedler identificou três dimensões contingenciais, que definem os fatores situacionais chaves, os quais por sua vez determinam a eficácia da liderança (Maximiano, 2005): 
- relações líder - membro: o grau de segurança, confiança e respeito que os subordinados têm por seu líder;

- estrutura da tarefa: descrição detalhada de como a tarefa está sendo feita;

- poder da posição: autoridade na administração de recompensas e punições.

Fiedler (1981) constata que quanto melhores as relações líder - membro, mais estruturado o trabalho e quanto maior o poder da posição, mais favorável é a situação para o líder.

\section{A teoria situacional de Hersey e Blanchard}

A denominada Teoria de Liderança Situacional foi desenvolvida na Califórnia-USA, na década de 1970, por Paul Hersey e Kenneth H. Blanchard. A Liderança Situacional utiliza as mesmas dimensões que Fiedler identificou: comportamento de tarefas e comportamento de relacionamentos.

"De acordo com a Liderança Situacional, não existe um único modo melhor de influenciar as pessoas. O estilo de liderança que uma pessoa deve adotar com indivíduos ou grupos depende do nível de maturidade das pessoas que o líder deseja influenciar" (Hersey e Blanchard, 1986, p. 188).

Hersey e Blanchard (1986) efetuaram combinações dos quatro estilos de liderança (determinar, persuadir, compartilhar e delegar), com comportamento de tarefa e relacionamentos. O comportamento da tarefa é a medida com que o líder dirige as pessoas. O comportamento de relacionamento é a medida com que um líder se empenha em comunicar-se bilateralmente com as pessoas.

Basicamente, a chave da utilização da Liderança Situacional consiste em avaliar os quatro níveis de maturidade dos liderados (M1, M2, M3 e M4) e comportar-se de acordo com o modelo, sendo que os quatro níveis a seguir são:

- M1 - as pessoas são incapazes e estão sem vontade ou inseguras demais para assumir a responsabilidade de fazerem alguma coisa;

- M2 - as pessoas são incapazes, mas querem fazer as tarefas que são necessárias;

○ M3 - as pessoas são capazes, mas não querem fazer o que o líder quer;

- M4 - as pessoas são capazes e estão com vontade de fazer o que é pedido para elas. 


\section{$\checkmark$ Liderança transacional e transformacional}

Conclui-se a revisão das teorias de liderança com a mais recente, a qual foi iniciada por James McGregor na década de 1970. Na liderança transacional existe a troca que ocorre entre o líder e o seguidor que se assenta numa base econômica, política ou psicológica. Tal troca acaba quando não há mais benefícios para ambos os lados.

Robbins (2005, p. 285) cita que o "líder transformacional é aquele que inspira seus seguidores a transcender seus próprios interesses para o bem da organização, e que é capaz de causar um efeito profundo e extraordinário sobre seus liderados".

$\mathrm{Na}$ liderança transformacional os líderes eficazes possuem grande sensibilidade e respeito aos desejos e necessidades de seus seguidores. Os líderes transformacionais são considerados, também, carismáticos. Deluga (apud Maximiano, 2005, p. 303) menciona:

"Carisma é a influência que o líder transformador exerce sobre os seguidores. O carisma apela às emoções dos seguidores e estimula sua identificação com o líder. O carisma é a condição mais importante, mas não a única, para que surja um líder transformador".

Os líderes transformacionais estimulam colaboradores a ter novos comportamentos e a agir. Transformam a consciência dos seguidores sobre diversas questões.

\subsection{Motivação}

A palavra motivação (motivo) tem sua etimologia no latim movere, que quer dizer mover. A motivação de uma pessoa depende da força de motivos. Os motivos são às vezes definidos como necessidades, desejos ou impulsos no interior do indivíduo. Os motivos são dirigidos para objetivos, estes podem ser conscientes ou inconscientes (Hersey e Blanchard, 1986).

O trabalho não é apenas um meio pelo qual o homem garante a sua sobrevivência. As pessoas se constroem como indivíduos e como membros de uma comunidade nas relações que estabelecem no ambiente profissional e na sua ação produtiva.

Tendo como foco o contexto organizacional, Robbins (1999, p. 109) conceitua motivação "como a vontade de empregar altos níveis de esforço em 
direção às metas organizacionais, condicionada pela capacidade do esforço de satisfazer alguma necessidade do indivíduo".

Wagner III e Hollenbeck, (1999) registram: [...] a motivação dos membros é um fator importante que afeta a produtividade em equipe e que pode ser gerenciada para evitar ou minimizar a perda de processo. A motivação é um determinante crucial da realização pessoal e é igualmente fundamental na determinação da realização de uma equipe, ou seja, os membros devem estar suficientemente motivados para alcançar o mais alto nível de produtividade permitido por seus talentos [...]

Sachuk (1998, p. 11) estudando a motivação e o processo de indução dos indivíduos na organização, afirma que "[...] o processo motivacional tem sido objeto de pesquisas, orientadas por diferentes abordagens teóricas, tais como: o behaviorismo, o cognitivismo e a psicanálise". Para os behavioristas, ou comportamentalistas, o que induz à ação são as conseqüências dos efeitos produzidos pelo comportamento passado do indivíduo, seja recompensa ou punição. Para os cognitivistas, o que impulsiona o indivíduo para a ação são os valores, a cognição e as representações internalizadas que possui em relação ao mundo que o rodeia. Na abordagem psicanalítica, centrada no desejo, a motivação é tratada indiretamente, de forma dinâmica, pressupondo forças internas que direcionam o comportamento humano.

O consultor John Cymbaum (2004) registra: "Na verdade, ninguém motiva ninguém. As pessoas se sentem motivadas, basicamente, por conta do grau de satisfação com o conteúdo do próprio trabalho, da identificação com a carreira, do nível de satisfação com relação à empresa, do quanto se sentem integradas ao grupo social com que trabalham e da identificação com o estilo adotado pelos líderes".

A literatura mostra que não há consenso a respeito da motivação, porém há concordância quanto à sua complexidade. Os constructos a serem apresentados não são excludentes, mas se complementam.

\section{A dinâmica do processo de motivação}

Conforme Robbins (1999), o processo de motivação se inicia com uma necessidade. Essa necessidade insatisfeita cria um estado de tensão, que estimulará impulsos dentro desse indivíduo, sendo motivado para atingir 
determinados objetivos. Caso o comportamento seja bem-sucedido, os objetivos satisfarão a necessidade e levarão à redução do estado de tensão.

Sigmund Freud explica o processo motivacional utilizando 0 deslocamento da energia psíquica. Freud (apud Hall e Lindzey, 1984), a partir do método de associação livre, desenvolveu a primeira teoria abrangente da personalidade, e, segundo Laplanche e Pontalis (2001), distinguiu o aparelho psíquico em três instâncias: o id, o ego e o superego. Para Freud (apud Hall e Lindzey, 1984, p. 26) na maioria das vezes o comportamento do indivíduo é o resultado da interação dessas três instâncias, sendo que raramente alguma delas age isoladamente.

\section{Motivação: fatores intrínsecos e extrínsecos}

Basicamente existem dois enfoques, o da motivação intrínseca e o da motivação extrínseca. Lawler III (1997, p. 132) cita "[...] indivíduos são motivados tanto por recompensas extrínsecas, como por exemplo, o salário, como por recompensas intrínsecas, tais como sentimentos de realização e de competência". Muitos autores consideram a motivação apenas como intrínseca, acreditando que esse seja um processo interior que leva à ação e das quais as ocorrências externas não fazem parte (Bergamini, 1997). Este estudo foi realizado com o enfoque da motivação intrínseca.

Conforme Bowditch e Buono (1992), os fatores motivacionais intrínsecos são as recompensas internas que uma pessoa recebe quando desenvolve um trabalho, existindo, portanto, uma relação direta entre trabalho e recompensas.

Deci (apud Bergamini, 1997, p. 33) defende que a motivação somente pode ser considerada como um processo intrínseco, destacando "se refere ao processo de desenvolver uma atividade pelo prazer que ela proporciona, isto é, desenvolver uma atividade pela recompensa inerente a essa mesma atividade".

Com relação aos fatores motivacionais extrínsecos, de acordo a Bowditch e Buono (1992, p. 53-54), se referem às "recompensas externas que ocorrem fora do trabalho, oferecendo satisfação indireta na hora em que o trabalho está sendo feito". Lipp (1982, p. 195), por sua vez, conceitua motivação extrínseca "como aquela que é controlada por reforços administrados por um 
agente externo [...]". Exemplo do anterior são os benefícios como assistência médica, planos de aposentadoria, bônus, participação nos lucros etc.

\section{Teorias da motivação}

As "teorias" sobre motivação são muito numerosas [...] mas é possível reagrupar essas teorias em duas categorias, aquelas que se prendam à descrição do conteúdo das motivações e aquelas que procuram analisar, na sua seqüência, o processo motivacional. (Lèvy-Leboyer, 1994).

Nesse item, apresentar-se-á uma sucinta panorâmica das teorias de motivação: de conteúdo, as teorias motivacionais de processo e finalmente os modelos de condicionamento respondente e operante desenvolvidos por B. F. Skinner.

\section{Teorias de motivação de conteúdo}

Nesse item, abordar-se-ão os seguintes modelos teóricos: a teoria da hierarquia das necessidades de Abraham Maslow, a teoria de higienemotivacional de Frederick Herzberg, as teorias $\mathrm{X}$ e $\mathrm{Y}$ de Douglas McGregor e a teoria dos "três estados psicológicos" de Hackman e Oldham.

\section{Teoria de Abraham Maslow}

Trata-se da teoria mais lembrada quando se fala em motivação, a apresentada por Abraham Maslow em 1943 (Casado, 2002) e publicada em sua obra Motivation and Personality, em 1954. Esta teoria entende o indivíduo como um ser carente, que se encontra sempre em busca da satisfação de alguma necessidade. Maslow (1954, p. 73) cita "o homem é um animal que deseja e que raramente alcança um estado de completa satisfação, exceto durante um curto tempo. À medida que satisfaz um desejo, sobrevém outro que quer ocupar seu lugar. Quando este se satisfaz, surge outro, [...]".

Archer (1997) corrobora a idéia anterior, quando afirma que a mente do ser humano nunca descansa, uma vez que suas necessidades são insaciáveis. Seu intelecto servirá sempre como organizador de seu compromisso para satisfazer uma necessidade.

A Teoria da Motivação Humana de Maslow, conhecida como Hierarquia das Necessidades, baseia-se na existência de cinco grupos de metas nomeadas 
como necessidades básicas. Essas necessidades: fisiológicas, de segurança, de amor (ou sociais), de estima e de auto-realização, relacionam-se entre si e se organizam em uma hierarquia de preponderância.

O fato que tornou a teoria das necessidades humanas tão importantes foi que o reconhecimento da incapacidade que as necessidades já satisfeitas motivarem o comportamento humano (Hampton, 1992).

\section{Teoria da higiene-motivacional de F. Herzberg}

Esta teoria nasceu de um profundo estudo de entrevistas realizadas na indústria de Pittsburg nos Estados Unidos procurando investigar os fatores que impactavam as pessoas deixando-as felizes e infelizes no trabalho (Herzberg, 1968).

Sobre a satisfação e insatisfação Herzberg (1968) registrou "o oposto da satisfação profissional não seria a insatisfação, mas sim nenhuma satisfação profissional; e da mesma maneira, o oposto da insatisfação profissional seria nenhuma insatisfação profissional e não a satisfação".

Herzberg (1968) aponta como fatores motivadores intrínsecos ao trabalho: as realizações, o reconhecimento pelas realizações, o trabalho em si, a responsabilidade e o crescimento ou progresso. Quanto aos fatores (higiênicos) que evitam a insatisfação no trabalho, extrínsecos ao trabalho, o autor cita: a administração e política da empresa, a supervisão, os relacionamentos interpessoais, as condições de trabalho, o salário, o status e a segurança.

A contribuição da teoria de dois fatores de Herzberg foi importante para a efetividade das práticas de gestão de pessoas alertando aos dirigentes organizacionais das limitações dos programas de incentivos baseados em recompensas extrínsecas (bônus, participação nos lucros). Após um determinado patamar, essas formas de incentivos passam a ter efeitos cada vez menos duradouros e passam a ser vistas não como prêmios.

\section{Teorias X e Y de McGregor}

Douglas McGregor insatisfeito com as relações humanas centrou seus estudos na relação entre o sucesso organizacional e a capacidade dos líderes em prever e controlar o comportamento humano (Ferreira et al., 1997). McGregor formula duas teorias gerenciais, $\mathrm{X}$ e $\mathrm{Y}$, fundamentadas no princípio da direção e 
controle e no princípio da integração. Conforme McGregor (1980), na teoria X, os líderes assumem as seguintes premissas do comportamento humano:

- O ser humano, normalmente, tem aversão natural ao trabalho e o evita sempre que pode;

- A maioria das pessoas precisa ser coagida, controlada, dirigida, ameaçada de punição, a fim de que se esforce para a realização dos objetivos organizacionais;

- O ser humano, de modo geral, prefere ser dirigido, evita responsabilidades, é pouco ambicioso e quer garantia acima de tudo.

Conforme McGregor (1980) cita, o indivíduo é um animal carente, sempre orientando seu comportamento para a satisfação das suas necessidades, em um processo sem fim, do seu nascimento à morte. Corroborando o pensamento da teoria de Maslow, McGregor afirma que as necessidades humanas obedecem a uma hierarquia de importância.

As críticas recebidas $\mathrm{e}$ as inadequações da teoria $\mathrm{X}$ à realidade organizacional, contribuíram para que McGregor (1980) formulasse a teoria $\mathrm{Y}$, cujas premissas do comportamento humano são apresentadas a seguir:

- O trabalho pode ser tanto uma fonte de satisfação como de punição;

- O controle externo e a coação não são as únicas maneiras de direcionar os esforços humanos em vista dos objetivos organizacionais;

- O comprometimento com os objetivos está relacionado às recompensas associadas com o seu alcance;

- O ser humano apreende não somente a aceitar responsabilidades, como também as procura;

- O potencial humano está muito mais presente na população do que se imagina;

- Nas organizações industriais, as potencialidades do indivíduo estão sendo parcialmente aproveitadas.

\section{Teoria de Hackman e Oldham}

Esta teoria teve suas origens nos trabalhos iniciais de Turner e Lawrence em 1965 e de Hackman e Lawler em 1971. Hackman e Oldham (1975, p. 160) sugerem que "três estados psicológicos críticos" devem estar presentes nos funcionários, quais sejam: a significância experimentada do trabalho, a 
responsabilidade experimentada pelos resultados do trabalho e o conhecimento dos resultados das atividades do trabalho.

Para que os três estados sejam atingidos, é necessária a criação de cinco dimensões centrais do trabalho (Hackman e Oldham, 1975):

- Variedade de habilidades;

- Identidade com a tarefa;

- Significância da tarefa;

- Autonomia;

- Feedback pelo próprio trabalho.

Hackman e Oldham (1975) propuseram um instrumento de avaliação do potencial motivacional dos empregados denominado Pontuação do potencial de motivação (Motivating potential score - MPS).

\section{Teoria das expectativas}

Esta teoria teve suas origens no cognitivismo. Evans (1976) registra que uma teoria cognitiva supõe que um determinado comportamento se efetiva em decorrência do reconhecimento da recompensa final. Tal enfoque está em oposição ao enfoque mecanicista (determinista), que supõe que o indivíduo se portaria como agente passivo de forças que atuam sobre ele.

Conforme Weiner (1972), os cognitivistas se dividem em dois grupos: 1) considera a expectativa como principal elemento cognitivo de ação e 2) consideram que muitos processos cognitivos determinam à ação.

Evans (1976) cita que Kurt Lewin acreditou que o comportamento é uma função conjunta da interação do meio-ambiente e do indivíduo, ao mesmo tempo em que defendia que a motivação dependia do modo como as pessoas percebiam o estado de coisas que influenciavam seu comportamento, havendo uma diferença entre o mundo percebido e o real. A teoria da expectativa, baseada nos conceitos de expectativa e valência, é talvez a teoria da motivação e do trabalho mais amplamente aceita entre os psicólogos industriais e organizacionais de então (Wahba e House, 1974).

\section{Teoria da expectativa de Vroom}

Tal teoria foi definida por Victor Vroom e ampliada e refinada por Lawler e Porter entre outros (Davis e Newstrom, 1992). Em seu livro Work and Motivation 
de 1964, Vroom apresentou sua teoria, descrevendo os modelos de força e valência, cujos elementos cognitivos constituintes eram: valência, instrumentalidade e expectativas (Vroom, 1964).

\section{Conceito de valência}

Vroom (1964) define valência como a orientação efetiva de uma pessoa para um resultado específico. A valência (valor antecipado) pode ser positiva quando uma pessoa prefere alcançá-lo a não alcançá-lo, ou pode ter valência zero quando a pessoa é indiferente, ou valência negativa quando ela prefere não alcançá-lo a alcançá-lo.

\section{Conceito de instrumentalidade}

O conceito de instrumentalidade foi introduzido por Georgopoulos, Mahoney e Jones em 1957 quando usaram o conceito de goal-path para explicar variações na produtividade dos trabalhadores (Whaba e House, 1974). Se um trabalhador perceber que a alta produtividade é o caminho que o leva a suas metas pessoais, ele tenderá a ser produtivo, mas, se perceber que a baixa produtividade é o caminho para atingir suas metas, ele tenderá a apresentar baixa produtividade (Mitchell e Albright, 1972).

\section{Conceito de expectância}

Para Davis e Newstrom (1992, p. 73) expectância é "a força na crença de que o esforço relacionado ao trabalho resultará na conclusão da tarefa".

Conforme Vroom (1964, p. 18) a expectância é uma associação açãoresultado, sendo que seus valores variam de zero, indicando nenhuma probabilidade que uma ação será seguida por um resultado, a um, indicando a certeza de que a ação será seguida por um resultado.

\section{Teoria de Porter e Lawler}

Foi originada por Porter e Lawler (1968) partindo do princípio de que o nível de desempenho no trabalho deve ser visto não como conseqüência da satisfação, mas como causa. Segundo os autores, a satisfação no trabalho ocorre quando algumas das necessidades ou desejos são atendidos. A satisfação deve 
ser vista como uma variável conseqüente do desempenho, e não como seu antecedente.

Para Porter e Lawler (1968) se determinadas organizações recompensam seus funcionários proporcionalmente aos seus desempenhos no trabalho, e se os empregados percebem isso, então um alto nível de satisfação no trabalho deve estar relacionado com seu desempenho superior.

Outras atitudes no trabalho, tão ou mais importantes que a satisfação, deve ser considerada para a compreensão da motivação profissional (Porter e Lawler, 1968). O modelo conceitual de Porter e Lawler (1968) propõe que a alta administração tome atitudes no sentido de melhorar o desempenho por meio do aumento do esforço de seus empregados.

\section{Teoria da manutenção do comportamento}

Anteriormente foram apresentadas teorias que tratavam 0 comportamento como uma variável essencialmente independente de seu ambiente. A continuação explora-se uma teoria que explica como determinados comportamentos podem ser preservados no decorrer do tempo. Também, a seguir, a motivação será analisada como uma variável dependente.

De acordo com Lipp (1982), B. F. Skinner foi o precursor desta teoria em 1932, com seu livro The Behavior of Organisms onde baseia suas idéias em dados de experiências rigorosamente controladas. Skinner repudia o uso da palavra motivação, explicando o comportamento humano como determinado por contingências de reforçamento.

Conforme Lipp (1982) a teoria de Skinner está baseada em três pressupostos:

1. “[...] o comportamento humano é aprendido ou através de condicionamento respondente ou através de condicionamento operante";

2. "é o que versa sobre o fato do comportamento do organismo obedecer a leis específicas, o que permite sua predição e controle";

3. o meio ambiente pode agir de três modos distintos na determinação do comportamento humano: a) na modelagem e manutenção do repertório do comportamento; b) no modo em que proporciona a ocasião que dá margem à ocorrência do comportamento, e c) através de ação seletiva que ele teve 
durante a evolução das espécies, a qual determina a constituição genética humana.

Reese (1976) cita Skinner quem distingiu em 1938 duas espécies de comportamento: respondente e operante. O comportamento respondente é controlado por seus antecedentes, enquanto, o comportamento operante é controlado por suas conseqüências. Segundo Bergamini (1997, p. 46-47), Skinner trabalha com dois elementos-chave na sua teoria, o reforço positivo e o reforço negativo, "elementos estes que considera como capazes de estruturar ou extinguir determinados tipos de comportamento".

\subsection{CLIMA ORGANIZACIONAL}

Antes de falar de clima organizacional deve-se falar de cultura organizacional. Inicialmente é interessante salientar que não é possível reunir o termo genérico cultura num único conceito sem antes considerar as visões humanista, filosófica, etnológica e antropológica. Como solução escolheu-se uma das definições de cultura do dicionário de Ferreira (1986, p. 409) "o complexo dos padrões de comportamento, das crenças, das instituições e de outros valores espirituais e materiais transmitidos coletivamente e característicos de uma sociedade".

Passando agora ao conceito de cultura organizacional, Torres Jr. (2000) considera duas perspectivas: primeiro, a cultura como padrões de pressupostos básicos construídos na interação entre os colaboradores de uma organização conforme propõe Schein (1992); e segundo, a cultura como um conjunto de valores expressos em símbolos capazes de construir a identidade organizacional como propõem Fleury e Fisher (1996). Existem duas figuras no conceito anterior: os colaboradores com sua interação diária, contribuindo para manter a cultura organizacional; a organização, que se encarrega de criar os símbolos que expressam a cultura já construída ou que se deseja promover, e que contribuem também para seu gerenciamento. Do anterior conclui-se a cultura organizacional como um conjunto formado pela interação dos colaboradores com a organização como um todo, somada aos valores construídos pela prática e expressos nos símbolos que a empresa propõe. Independente do conceito de cultura organizacional adotado acredita-se que é a manutenção ou a necessidade de 
mudança da cultura em uma organização que se estabelece como um gerador e/ou regulador do clima organizacional.

Existe uma estreita relação entre o conceito de clima e o conceito de cultura organizacional. Edgard Schein (apud Fleury e Fisher, 1996, p. 20) - uma das referências mais citadas no meio acadêmico para o tema da cultura organizacional - considera a cultura como "o conjunto de pressupostos básicos (basic assumptions) que um grupo inventou, descobriu ou desenvolveu ao aprender como lidar com os problemas de adaptação externa e integração interna que funcionaram bem o suficiente para serem considerados válidos e ensinados a novos membros como a forma correta de perceber, pensar e sentir, em relação esses problemas".

O clima organizacional é um conjunto de atitudes ou valores que afetam a forma como os indivíduos se relacionam uns com os outros e com a instituição; ele é medido pela percepção que os funcionários têm sobre o grau de satisfação em relação a determinadas características do ambiente de trabalho da instituição onde eles atuam; é uma avaliação de até que ponto as aspirações dos funcionários estão sendo atendidas pela instituição. O clima organizacional está ligado à conjuntura interna e externa da instituição e é por definição, circunstancial. A cultura organizacional é mais permanente, ela é lentamente construída e de forma mais constante. A cultura é mais submersa e latente. O clima é algo mais visível.

A gestão do clima organizacional se configura como um fator estratégico para atingir os resultados e os objetivos de um negócio, e os resultados da avaliação do clima organizacional como indicadores para os gestores da empresa. Portanto, o estudo do clima organizacional é também um instrumento de avaliação do modelo de gestão adotado.

De acordo com Leitão (1996) nas diversas definições de clima organizacional é possível destacar alguns elementos fundamentais: primeiro, a percepção como instrumento de detecção do clima, o qual é subjetivo por tratarse de um constructo individual; segundo, os atributos, que são aspectos característicos da organização. Desta forma, o clima organizacional seria considerado como a percepção global que o indivíduo tem de seu ambiente de trabalho influenciado por dimensões individuais e organizacionais. 
Oliveira (1990) mostrou os fatores comuns no processo de conceituação de clima organizacional que diversos autores de destaque consideram como enfoque em atributos organizacionais, conforme apresentado na Tabela 2.1.

A propriedade básica do clima organizacional é ser mutável. Também relativamente maleável; portanto, podem ser modificado através de ações gerenciais, políticas e sistêmicas. É ainda um conceito bastante influenciável por valores e normas grupais mais duradouros, ou seja, por uma outra noção também bastante popular e muito lembrada no mundo das organizações: cultura organizacional.

Tabela 2.1 - Fatores comuns aos conceitos de clima organizacional considerando o enfoque em atributos organizacionais segundo vários autores.

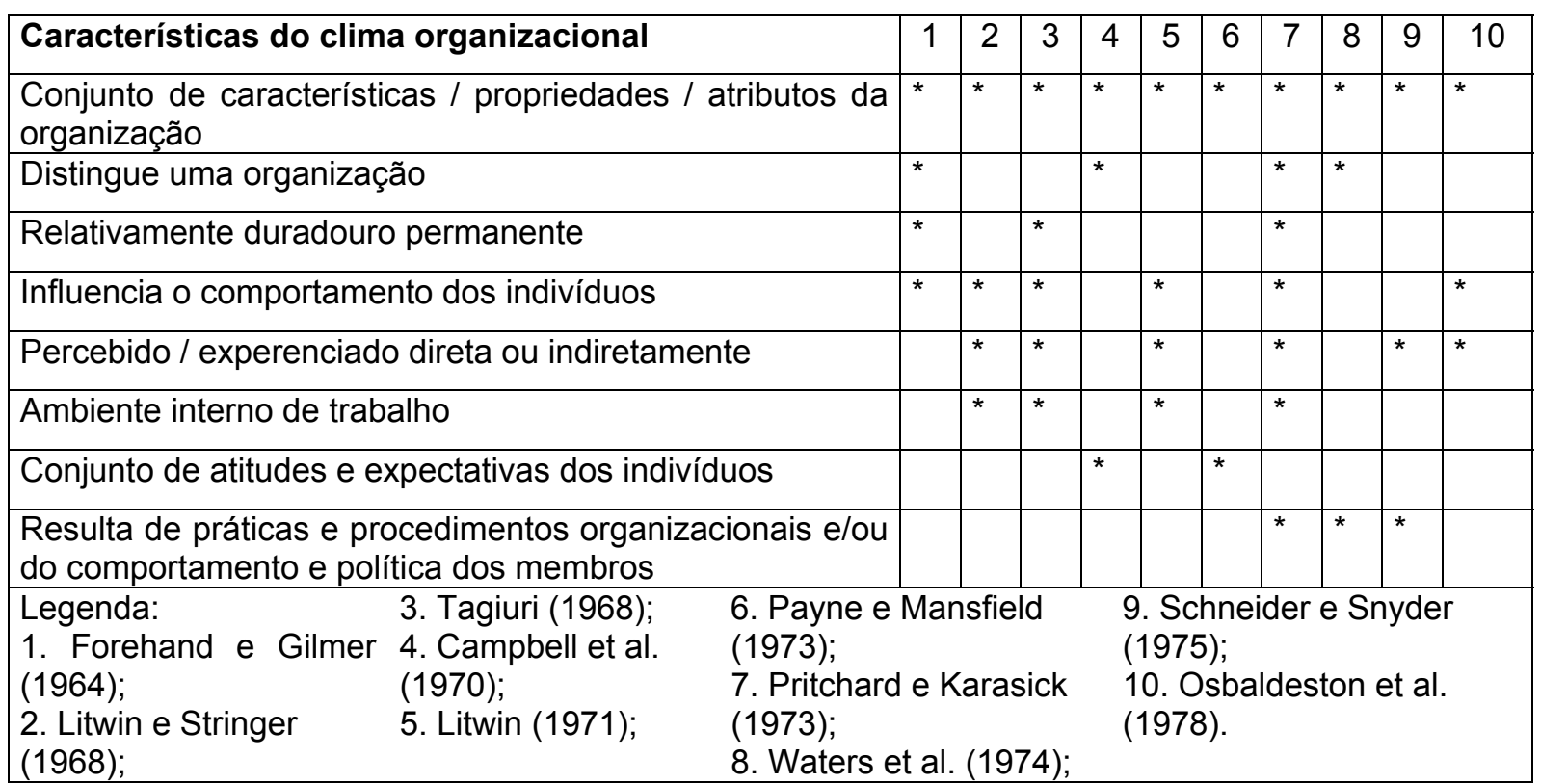

Fonte: Oliveira (1990, p. 37)

O clima organizacional é o ambiente dentro dos quais as pessoas de uma organização fazem os seus trabalhos. O clima não pode ser tocado ou visualizado, porém pode ser percebido e mensurado em seus diversos aspectos. Cada pessoa tem uma forma de pensar, agir e concretizar seus impulsos. Manter um ambiente agradável não é tão complexo quanto se imagina. Já foi comprovado que a maior insatisfação do empregado não é o salário, e sim a sensação de ser integrante não-participativo da organização. 
Luz (2004) cita: ..."Para o funcionário atender bem é preciso que saiba, que possa e que queira fazê-lo. Saber fazer é uma questão de conhecimento, habilidade ou atitude. Poder fazer é uma questão de ter e poder usar os recursos necessários. Querer fazer é uma questão volitiva que depende do estado de espírito, do ânimo, da satisfação das pessoas quando realizam o seu trabalho. Logo, o "querer fazer" está associado ao clima organizacional, que muitas vezes é onde encontramos as causas da má qualidade dos atendimentos". Brescancini (2005) tem a mesma opinião ao citar: ..."Baseia-se no fato de que, para atender bem a um cliente, o funcionário tem de saber, poder e querer fazê-lo. $A$ competência técnica cumpre a etapa do saber. $O$ acesso aos recursos necessários dá conta do poder. Querer fazer depende do ânimo, do entusiasmo, do estado de espírito, enfim, da satisfação das pessoas quando realizam o seu trabalho"...

Como se nota, existe uma idéia em comum nas definições acima de clima organizacional: em todas elas, o clima organizacional está ligado, diretamente, à maneira como o colaborador percebe a organização com a sua cultura, suas normas, seus usos e costumes, como ele interpreta tudo isso e como ele reage, positiva ou negativamente, a essa interpretação.

A conclusão é que o clima organizacional não pode ser "criado" pela organização, no sentido literal de se produzir alguma coisa num determinado momento, mas é algo que já existe, vive e é atuante. Ele é resultante, principalmente, de fatores internos, das decisões tomadas e da maneira como o pessoal é administrado pelos seus chefes, atinge diretamente ao colaborador, no que diz respeito à percepção que ele tem da organização, induzindo-o a determinado comportamento.

Também não se pode esquecer que, sendo a organização um verdadeiro universo de diferentes interesses, conseqüência de posturas pessoais e profissionais diferenciadas, não existirá uma só organização em que todas as pessoas que dela participem tenham conceitos e valores uniformes. Não é correto acreditar que todos, dentro da organização, frente às suas políticas, normas e costumes, interpretem e reajam da mesma maneira, tenham os mesmos valores e a mesma intensidade de aceitação ou rejeição sobre os mesmos aspectos ou acontecimentos da vida profissional e pessoal. 
Isto significa que uma mesma situação existente na organização, num determinado momento, será percebida de maneira diferente pelos diversos grupos de colaboradores. Alguns terão uma percepção positiva, e a considerarão como uma situação agradável ou motivadora, porque de alguma maneira ela atende suas aspirações e desejos. Outros, frente à mesma situação, terão uma percepção negativa porque, de maneira contrária, ela não atende seus interesses.

Pode-se afirmar que, além da organização não criar o seu clima organizacional, existe dentro de uma mesma organização, diferentes climas organizacionais num determinado momento, causados pelos mesmos acontecimentos, mas com efeitos diferentes nos diversos públicos internos, causando sensações agradáveis para uns e desagradáveis para outros. Então, não é possível se falar da existência de apenas um clima organizacional único e uniforme; o clima irá variar de acordo com a situação psicológica e o estágio motivacional em que se encontra cada colaborador e a maneira como ele interpreta o cenário da empresa, através das informações recebidas ou percebidas no ambiente interno.

Existem iniciativas como as do Instituto Nacional de Tecnologia - INT que iniciou no começo de 1997 (Krutman, 1999) o projeto Compartilhando habilidades, que com voluntários do Instituto e sem remuneração proferem cursos, experiências e desenvolvem habilidades, obtendo no final entre outros a melhoria do clima organizacional.

De todo o anterior pode-se concluir então que, clima organizacional é: "A maneira, positiva ou negativa, como os colaboradores, influenciados por fatores internos ou externos à organização, percebem e reagem num determinado momento, ao conjunto de variáveis e fatores como as políticas, os procedimentos, usos e costumes existentes e praticados pela organização“.

\subsubsection{Pesquisa do clima organizacional - PCO}

Uma ferramenta muito utilizada e de extrema valia é a pesquisa do clima organizacional. A pesquisa do clima organizacional visa em um primeiro momento, proporcionar a análise da organização com o seu ambiente, bem como o conjunto de condições que caracterizam o estado de satisfação e/ou insatisfação dos colaboradores na organização e das demais pessoas que com eles interagem. Esta ferramenta que identifica o clima, o ambiente e as condições 
de relacionamento colaborador/empresa, serve como base para a formulação de estratégias de mudanças e reformulações estruturais, ajudando os administradores a obterem respostas precisas sobre a opinião dos colaboradores.

A PCO é uma importante ferramenta para mensurar as ações de recursos humanos através de instrumentos voltados para análise do ambiente interno, a partir do levantamento de suas necessidades. Retrata os aspectos críticos que configuram o momento motivacional dos funcionários da empresa, através da apuração de seus pontos fortes, deficiências, expectativas e aspirações. É uma das principais ferramentas para avaliar o grau de satisfação dos clientes internos.

Pesquisas mostram que só o fato dela ser aplicada numa organização, isto já motiva os funcionários, na medida em que eles sentem-se ouvidos, respeitados em suas opiniões e como parte importante em todo o processo. No entanto, se nada for feito com os resultados, à pesquisa poderá ter efeito contrário, com os colaboradores passando a desconfiar da organização.

Por isso a maioria das empresas está buscando a pesquisa de clima organizacional, que tem como objetivo e propósito investigar e dissolver (na maioria dos casos) os focos de problemas existentes nas empresas e as formas de prevenção para que os mesmos que surjam e gerem tais focos de problemas, afetando todo o bem-estar das instituições.

Coda (1992, p. 177) justifica a PCO quando cita "o clima organizacional costuma apresentar variações mais freqüentes, cíclicas ou não, sendo inerente, portanto às PCO uma repetição periódica".

A PCO deve utilizar uma metodologia objetiva e segura, isenta de comprometimento com a situação atual, em busca de dados reais. A análise, o diagnóstico e as sugestões são usados como instrumentos valiosos para o sucesso de programas voltados para a melhoria da qualidade, do aumento da produtividade e de avaliação de políticas internas.

\subsection{TRABALHO EM EQUIPE}

Nos últimos anos, nota-se que a utilização de equipes tem crescido nas organizações. Tal crescimento, em grande parte, reflete a crença de que as equipes são a estrutura apropriada para implementar estratégias formuladas para 
lidar com as demandas de desempenho e oportunidades presentes no ambiente de constantes mudanças (Mohrman e Cohen, 1995, apud Reszecki, 2002, p. 4).

Para Katzenbach (2001, p. 16) uma equipe é "um pequeno número de pessoas com habilidades complementares, comprometidas com o mesmo objetivo, as mesmas metas de desempenho e a mesma abordagem, pelos quais elas se consideram mutuamente responsáveis".

O trabalho em equipe não ocorre naturalmente. Trabalhar em conjunto, em um ambiente de equipe é um comportamento que deve ser aprendido (Parker, 1994). Um dos desafios que as organizações que trabalham com esta característica, é lidar na adaptação de um ambiente que alinha grupos e indivíduos que são interdependentes em termos de tarefas visando fomentar o trabalho em equipe na busca de objetivos gerais compartilhados.

Lawler (1991) menciona Eric Trist em 1951 como o precursor do trabalho em equipe, ao criar sua própria equipe com trabalhadores de minas de carvão. Tal trabalho serviu como modelo no desenvolvimento de organizações nos anos 1960 e 1970.

Robbins (2005, p. 212) cita "Cada vez mais, as equipes se tornam, a forma básica de trabalho nas organizações contemporâneas". Para Robbins (2005, p. 213) "uma equipe de trabalho gera uma sinergia positiva por meio do esforço coordenado. Os esforços individuais resultam em um nível de desempenho maior do que a soma daquelas contribuições individuais".

Uma pesquisa conduzida pela Hewitt Associates (Sherman et al., 1998) aponta que dois terços de 1.811 empregadores norte-americanos consultados utilizam equipes de trabalho nas suas atividades.

O trabalho em equipe surgiu fortemente nos últimos tempos como uma nova proposta de trabalho. Atualmente é bastante comum encontrar-se grupos de pesquisa dentro dos institutos que contam com a colaboração de profissionais de várias áreas. É importante salientar que hoje se faz necessário sair do casulo e aceitar que se faz muito pouco quando se trabalha sozinho e que com cooperação mútua fica mais fácil alcançar um objetivo e mudar a realidade dentro dos institutos.

Trabalho em equipe é a capacidade de colocar os interesses do grupo acima dos interesses próprios. Trabalhar em equipe significa juntar esforços no sentido de aproveitar as aptidões ou o lado mais desenvolvido de cada um para 
se obter uma soma de resultados favoráveis para todos. O tratamento multidisciplinar - várias especialidades trabalhando com um único objetivo - prova que a soma das partes resulta num maior desempenho individual.

Shonk (1997) menciona que existem duas razões básicas para que as empresas se organizem em equipes. A primeira é permitir que os empregados contribuam de maneira mais completa, e a segunda, é aumentar a produtividade organizacional. Como grandes vantagens do trabalho em equipe, Robbins (2005) cita que as equipes são mais flexíveis e respondem melhor as mudanças do que departamentos tradicionais. Acrescenta ainda que o trabalho em equipe tenha a capacidade de se estruturar, desdobrar, reforçar e se dissolver rapidamente.

\section{Quando é desejável o trabalho em equipe?}

As equipes não são a solução para todas as necessidades da organização e quando mal aplicadas podem tornar-se dispendiosas. Ulrich (2000, p. 23) salienta a necessidade da equipe e do comprometimento quando cita "um dos erros mais graves que os gerentes cometem ao procurar aumentar o capital intelectual é dar ênfase somente à competência. Ter mais funcionários competentes que não estão empenhados em realizar um bom trabalho é como tentar ganhar de um time de atletas com uma equipe que só tem estrelas. Apesar dos bons jogadores, o sucesso de uma empresa é resultado do trabalho em grupo, do comprometimento e da adesão a uma meta e a um modelo".

O trabalho em equipe é desejável quando na realização de atividades precisa-se da interdependência entre áreas em virtude da necessidade de se reunir pessoas com habilidades múltiplas, opiniões e experiências diversas e responsabilidades necessárias, para que o objetivo seja atingido (Katzenbach e Smith, 1993). Tais características anteriormente citadas do trabalho em equipe, coincidem com os requisitos dos locais pesquisados (laboratórios), os quais na realização das suas atividades diárias justamente exigem pessoas que preencham tais requisitos e onde muitas vezes nos laboratórios predomina a organização matricial.

É importante salientar que hoje se faz muito pouco quando se trabalha sozinho e que com cooperação mútua fica mais fácil alcançar um objetivo e mudar a realidade dentro dos institutos de pesquisa. $O$ trabalho em equipe está relacionado com os seguintes fatores: a união, a responsabilidade, as habilidades, 
o comprometimento, a motivação e os desafios.

Lawler (1991) cita que equipes de trabalho foram chamadas de grupos de trabalho autônomos, grupos de trabalho autogerenciáveis ou grupos de trabalho semi-autônomos, terminologia usada para identificar que as equipes de trabalho tinham não somente a responsabilidade por uma área do ambiente de trabalho, mas que elas poderiam tomar várias decisões referentes ao trabalho realizado.

Para Katzenbach e Smith (1993) uma equipe é um pequeno número de pessoas com habilidades complementares, comprometidas com um objetivo comum, com o cumprimento de uma meta e entendimento semelhante do que os mantêm mutuamente responsáveis como uma equipe.

Para Maximiano (1993) a palavra equipe é comumente usada para designar grupos de pessoas que trabalham juntas em qualquer espécie de organização, sendo que um grupo começa a se caracterizar como equipe quando quatro fatores estão simultaneamente presentes: organização, interação, motivação e percepção.

Reszecki (2002, p. 109) conclui seu trabalho com a definição de equipe: "um pequeno número de pessoas, com habilidades complementares, que trabalham juntas e têm um alto grau de interdependência, comprometidas para alcançarem um objetivo comum, e entendimento semelhante de que trabalham juntas para produzir produtos ou entregar serviços pelos quais são mutuamente responsáveis".

Como dificuldade das equipes, Frame (1995) cita a falta de comprometimento do membro com a equipe, vinculada com a troca de participantes, esta última característica das equipes após cada membro completar seu trabalho e a equipe continuar uma atividade maior, afetará a eficácia e eficiência das equipes.

Santos (2005) enumera algumas vantagens relativas ao trabalho em equipe: a equipe tem mais fontes de informação; a equipe é mais criativa; o trabalho em equipe incrementa a aprendizagem; a satisfação das pessoas quando participam de um processo de decisão; e, os membros da equipe aprendem mais sobre si próprios.

Numa equipe, tem que prevalecer a seguinte filosofia: "juntos podemos chegar mais longe porque podemos juntar talentos e capacidades". Uma equipe 
considerada perfeita é aquela que possui maior diversidade de habilidades e experiências entre os seus participantes.

\section{Grupos e equipes}

Robbins (2005, p. 213) diferencia grupos de equipes de trabalho. Um grupo diz é "dois ou mais indivíduos, em interação e interdependência, que se juntam para atingir um objetivo". Robbins (2005, p. 186) subclassifica grupos em quatro tipos: grupos de comando e de tarefas (os dois como organização formal), e de interesse e de amizades (estes como aliança informal).

Uma equipe é duas ou mais pessoas que precisam coordenar suas atividades para alcançar um objetivo comum. A definição do objetivo comum e a coordenação necessária para atingi-lo é que diferenciam a equipe do grupo.

A diferença entre uma equipe e um grupo é o fato de um ser homogêneo e o outro ser heterogêneo. Um, agrupa pessoas com aptidões e interesses semelhantes, enquanto o outro as aptidões e interesses não são necessariamente iguais. Grupo é um conjunto de pessoas com um objetivo e em geral se reúnem por afinidades. Equipe é um conjunto de pessoas com objetivos comuns atuando no cumprimento de metas específicas. Na equipe todos trabalham voltados para os mesmos objetivos e têm seus papéis e funções definidas.

\subsection{JUSTIFICATIVA DA ESCOLHA PELOS QUATRO FATORES DE DESEMPENHO}

Foram escolhidos neste estudo três fatores comportamentais: liderança, motivação e trabalho em equipe; e um fator organizacional: o clima organizacional.

O clima organizacional foi o fator, dos quatro escolhidos, mais envolvido com os outros três. Não há forma de separar o clima dos outros porque estes sempre fazem parte, principalmente salientando sua alta ligação com a motivação e o trabalho em equipe. O clima organizacional além de ser um fator altamente utilizado hoje para verificar o ambiente interno dos servidores é um fator preponderante no desempenho e tem sido medido no IPEN nos últimos anos $(1999,2000,2002)$ onde a mesma pesquisa foi realizada as três vezes e sendo diferente da elaborada neste estudo. Após a escolha do comprometimento pelo 
autor, como parte integrante da pesquisa soube-se que o IPEN na sua última pesquisa de novembro de 2005 incluiu também algumas questões de comprometimento (Feher, 2005) reforçando assim a decisão do autor por ter escolhido o comprometimento junto ao clima organizacional como fatores ligado ao desempenho. Lembra-se ao leitor que esta pesquisa foi encerrada em 19.06.2005, ou seja, cinco meses antes da realizada pelo IPEN e que envolveu o comprometimento.

Quando se pesquisaram os fatores de desempenho, a criatividade tinha fortes chances de escolha, pensamento reforçado por Chang Jr. (2001) no seu estudo que incluiu a variável criatividade, como antecedente, e comunicação, como conseqüente ao comprometimento. Fonseca e Bastos (2002) confirmaram que nos ambientes de trabalho em que a criatividade é estimulada e nos quais se encontram níveis significativos de comprometimento organizacional, a percepção de desempenho é maior do que naqueles em que essas condições não são atendidas. Entretanto, para o autor influenciou no descarte da criatividade o fato dos laboratórios pesquisados, terem ou estarem no ambiente dos sistemas da qualidade o qual torna os procedimentos obrigatórios e assim sendo muitos vêm o ambiente de padronização em sentido contrário ao item criatividade, por isso, optou-se por descartar a criatividade.

A escolha dos fatores liderança junto à motivação é justificada por Bergamini e Coda, (1997, p. 13), quando citam:

\footnotetext{
"Ninguém poderá ser eficaz como líder se não entende que antes de mais nada, cada um vê no próprio trabalho a oportunidade de realizar as suas próprias potencialidades, buscando conseguir uma indispensável ligação com a comunidade em sentido mais amplo [...] É exatamente a partir desse tipo de conceito que se pode cotejar dentro de um mesmo contínuo os dois termos, motivação e liderança que, embora não sejam exatamente sinônimos, [...] são, necessariamente, parentes próximos".
}

Vianna (2005, p. viii) menciona que para atingirem níveis superiores de excelência, as organizações necessitam entender a dinâmica do comportamento humano, pois as competências somente emergirão se as pessoas se encontrarem motivadas e comprometidas com os objetivos organizacionais. Vianna (2005, p. 9) ao se referir ao problema do seu estudo cita o relacionamento forte entre as variáveis: comprometimento, motivação e clima organizacional como parte de seu problema central. 
Bergamini (1997a, p. 323-324) reforça o vínculo da liderança e motivação ao registrar "ao tratar com liderança se lida, de alguma forma, com aspectos motivacionais, tanto que na década de 70 o aprofundamento do estudo do aspecto motivacional vinculado à liderança veio ligar definitivamente os dois termos“.

Lessa (2003, p. 112) destaca a importância da motivação e o comprometimento quando conclui que entre outros fatores que podem impactar no desempenho das equipes, citando: "a equipe precisa que as pessoas estejam motivadas e comprometidas, que conheçam as metas e resultados a serem atingidos e as necessidades e expectativas dos clientes".

Tudo aquilo que na organização pode ser avaliado e depende de fatores internos pode ser melhorado. Esse famoso princípio da qualidade vale tanto para pessoas e processos quanto para o ambiente de trabalho. O "ambiente de trabalho" ou clima organizacional tem-se revelado um fator importante na procura da qualidade, está presente também nos Organismos que avaliam e certificam a qualidade. O critério 6.3 do Prêmio Nacional da Qualidade (PNQ), "Bem-estar e satisfação dos funcionários", aborda o ambiente e o clima motivacional de trabalho e a maneira pela qual a organização promove o bemestar, a satisfação e o desenvolvimento de todos os funcionários. A norma NBR ISO 9000, em sua nova versão 2000 contempla significativamente este aspecto, o clima organizacional atua diretamente sobre a motivação da equipe e no resultado de seu comportamento e desempenho. O primeiro dos sete critérios de excelência do modelo PNQ é a liderança. 


\section{CAPÍTULO 3}

\section{METODOLOGIA DA PESQUISA}

A metodologia utilizada tem características qualitativas e quantitativas: as entrevistas realizadas na primeira pesquisa com o intuito de reduzir o número de fatores de desempenho resultante da revisão bibliográfica são de cunho qualitativo; e a aplicação do questionário da segunda pesquisa para quantificar o comprometimento ocupacional e organizacional e os quatro fatores de desempenho, além de, principalmente o tratamento estatístico posterior, corresponde à parte quantitativa do estudo.

\subsection{Organização do estudo}

A pesquisa envolveu inicialmente a investigação de duas variáveis principais, o desempenho individual no trabalho percebido em relação aos pares e o comprometimento dos servidores com a organização e com a ocupação. Inicialmente tenta-se verificar se os ambientes organizacionais onde os índices de comprometimentos organizacional e ocupacional são mais elevados, os servidores percebem seus pares como mais produtivos do que naqueles em que os índices de comprometimento são mais baixos.

Foram escolhidos para aplicar a pesquisa os locais de maior concentração de laboratórios nas duas organizações. No CTA a escolha recaiu no Instituto de Aeronáutica e Espaço - IAE, e no IPEN no Centro de Ciência e Tecnologia de Materiais - CCTM. Entende-se por laboratório, o local onde se realizam atividades de ensaios, calibrações, experimentos, desenvolvimento ou apoio a uma atividade maior ou posterior, nas mais diversas áreas de atuação.

Numa primeira fase (vide Figura 3.1) após a definição do problema e como resultados da revisão bibliográfica foram extraídas idéias sobre fatores de desempenho e junto aos locais envolvidos definiram-se uma relação de 26 fatores que influenciam no desempenho dos seus participantes.

Posteriormente o autor intencionalmente escolheu da relação anterior quais seriam os mais importantes e decidiu-se por quatro o qual foi corroborado 


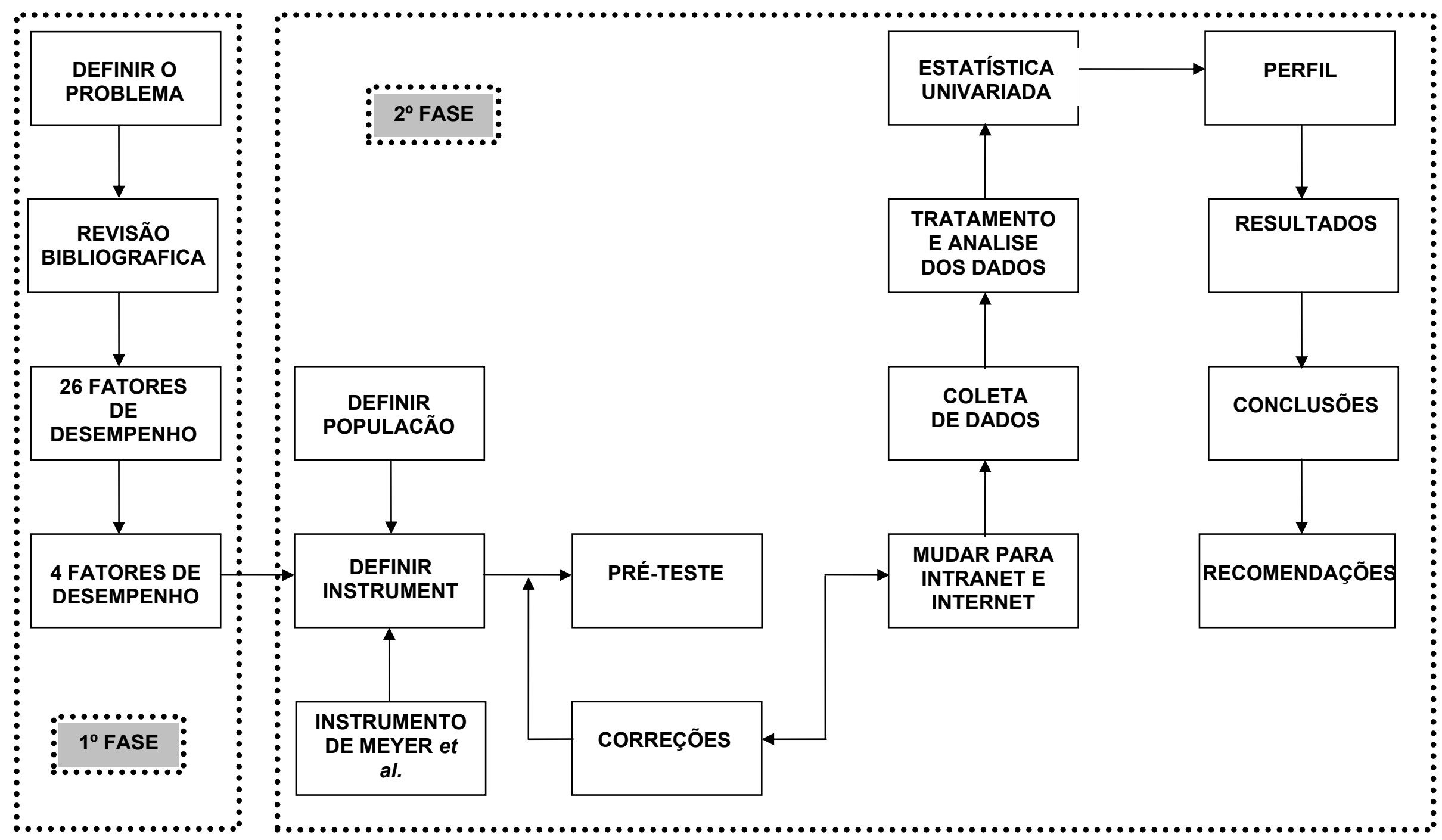

Finu ra $311^{\text {a }}$ e $7^{\mathrm{a}}$ Fase da nesculisa 
por alguns especialistas de ambos locais estudados que consideram muito coerente a escolha dos fatores que influenciam o desempenho na prestação de serviços tecnológicos num centro de pesquisa. Os quatro fatores escolhidos foram: clima organizacional, liderança, motivação e trabalho em equipe.

Numa segunda fase (vide Figura 3.1) estes 4 fatores mais importantes foram confrontados junto ao nível de comprometimento organizacional e ocupacional para verificar seu grau de relacionamento. Esta fase se inicia a partir da definição dos 4 fatores de desempenho e do instrumento o qual requereu previamente a definição da população envolvida e considerou o instrumento de Meyer et al. (1993) para quantificar os comprometimentos organizacional e ocupacional; posteriormente este instrumento sofre o pré-teste e as correções necessárias até estar pronto para ser aplicado; neste estudo houve a conveniência de aplicá-lo na rede interna Intranet no CTA e na rede mundial Internet para o público do IPEN; a continuação realiza-se a coleta de dados procurando maximizar a participação dos convidados; em seguida o tratamento e análise de dados verificando algumas premissas da teoria; a definição da estatística univariada; a análise das variáveis demográficas e profissionais para definição do perfil dos respondentes e finalmente os resultados das análises, as conclusões obtidas e as recomendações futuras.

Os dados da segunda fase foram coletados através de um questionário fechado. Tal questionário continha sete questões demográficas. Trabalhou-se com os quatro fatores de desempenho resultantes da pesquisa exploratória da primeira fase que contribuíram com setenta e uma questões as quais foram confrontadas aos níveis de comprometimento organizacional e ocupacional com dezoito questões para cada tipo de comprometimento, perfazendo um total no instrumento de cento e catorze questões.

Finalmente numa terceira fase, utilizando a modelagem de equações estruturais junto ao software LISREL foi definido um modelo teórico de relacionamento causal entre as principais variáveis de desempenho, sendo analisado esse e outros modelos concorrentes para concluir pela escolha de um modelo que melhor explicou a relação entre as variáveis envolvidas. 


\subsection{População e censo}

A pesquisa foi realizada no IPEN e no CTA, instituições de P\&D que contam com aproximadamente 4.500 funcionários. No IPEN foi escolhido o CCTM como local de aplicação e no CTA foi o IAE, ambos locais escolhidos por concentrarem muitos dos laboratórios de cada organização. Ambas as organizações, de características semelhantes no campo da C\&T e de destaque pela sua excelência tecnológica numa área de destaque.

Neste caso, ambas as populações foram as resultantes de um censo com todos os envolvidos; salvo casos especiais como férias, licenças de curto e longo período. O censo foi realizado cabendo a cada responsável de laboratório fornecer a relação completa dos seus integrantes, inclusive com aqueles que estavam ausentes das suas atividades.

Em alguns laboratórios os servidores trabalham numa estrutura matricial, o que levou a dividir racionalmente estes nos locais envolvidos. Também se teve o caso de existir um único responsável para 2 ou 3 laboratórios, sendo que neste caso foi aceito de comum acordo a divisão de ter um responsável por apenas um laboratório para que a opinião de cada servidor seja igual à dos outros.

No IPEN a população da pesquisa foi composta inicialmente por todos os componentes dos 12 laboratórios do CCTM (Anexo I), conforme relação a seguir a qual inclui: Processamento Cerâmicos de Resíduos - PCR com 4 servidores, Insumos e Componentes - SOFC com 7 servidores, Eletro-Cerâmicas - EC com 5 servidores, Cerâmicas Estruturais e Biomateriais - CEB com 7 servidores, Comportamento Mecânico - CM com 4 servidores, Processamento de Materiais - PM com 10 servidores, Corrosão e Tratamento de Superfícies - CTS com 8 servidores, Difração de Raios X - DRX com 2 servidores, Materiais Magnéticos - MaM com 7 servidores, Metalurgia do Pó e Intermetálicos - MPI com 8 servidores, Microscopia e Microanálise - MiM com 7 servidores, e finalmente, Vidros e Compósitos Cerâmicos - VCC com 2 servidores, perfazendo um total de 71 servidores do CCTM dos quais eliminando os repetidos pela sua atividade matricial e os impossibilitados acabaram como convidados 63 servidores a responder a pesquisa.

A população da pesquisa no CTA foi composta inicialmente por todos os componentes dos noventa Laboratórios do IAE (durante a coleta dos dados 
existiam mais 6 laboratórios cujas atividades estavam momentaneamente suspensas), a qual incluiu (veja Anexo II): um na Divisão de Ciências Atmosféricas - ACA com 4 servidores, 4 na Coordenadoria da Qualidade Espacial - AVE-Q com 14 servidores, 12 na Divisão de Eletrônica - AEL com 36 servidores, 16 na Divisão de Integração e Ensaios - AIE com 47 servidores, 2 na Divisão de Mecânica - AME com 6 servidores, 12 na Divisão de Química - AQI com 41 servidores, 3 na Divisão de Sistemas Espaciais - ASE com 19 servidores, 4 na Divisão de Ensaios em Vôo - AEV com 14 servidores, 18 na Divisão de Materiais AMR com 45 servidores, 8 na Divisão de Sistemas de Defesa - ASD com 27 pessoas, e, finalmente 16 na Divisão de Sistemas Aeronáuticos - ASA com 44 servidores, perfazendo um total no IAE de 297 pessoas eliminando 2 impossibilitados, obtendo no final, 295 convidados a responder a pesquisa.

A quantidade de participantes da pesquisa é um fator crucial nos métodos estatísticos uma vez que, como observam Hair Jr. et al. (1998, p. 604), "desempenham um importante papel na estimação e interpretação dos resultados da modelagem de equações estruturais, [...] fornecendo uma base para a estimação do erro amostral".

\subsection{Definição operacional das variáveis}

Kerlinger (1980) cita que as variáveis devem apresentar duas definições: a constitutiva e a operacional. A primeira, é definida por intermédio de outros conceitos e que apesar de serem usadas por cientistas, não é suficiente para propósitos científicos, pois não permitem verificar as hipóteses. Para que as hipóteses possam ser verificadas empiricamente Kerlinger (1980) sugere que as variáveis sejam definidas de forma operacional, ou seja, o pesquisador deve atribuir significado a cada variável, especificando as atividades ou operações necessárias para medi-la ou manipulá-la.

\subsection{Instrumento de mensuração}

O instrumento de pesquisa é considerado neste estudo como um dos recursos fundamentais para a investigação que se propõe conduzir. É o veículo que busca representar, na forma de questões, uma série de considerações teóricas levantadas, julgadas de relevância, para se testar hipóteses com os dados empíricos. É o elemento que permite apurar o valor das variáveis, através 
das constatações individuais sobre os motivos de escolha e outras características de interesse. Ele é importante, na medida em que as conclusões obtidas estão apoiadas nas informações resultantes de sua aplicação. A sua representatividade e a sua validade proporcionam consistência e credibilidade para as conclusões.

O questionário estruturado (Anexo III) foi elaborado para a coleta de dados da segunda fase. Segundo Selltiz et al. (1987), este tipo de questionário apresenta uma série de vantagens, podendo-se citar: menor tempo para ser respondido; mais fácil de responder; tem caráter anônimo; evita vieses do entrevistador.

$\mathrm{Na}$ concepção do questionário, foram observadas recomendações sugeridas por Selltiz et al. (1987), no que tange ao conteúdo das questões, aos procedimentos na construção do mesmo, à importância da aparência visual, à clareza e objetividade das perguntas, e, à abordagem de vários aspectos relacionados ao tema da pesquisa. Também foi observada uma série de recomendações mencionadas em Terribili Filho (2002), quanto a como deve ser um instrumento de pesquisa quantitativa:

- ter uma boa apresentação física, de forma a motivar o pesquisado e a mantê-lo estimulado a responder todas as questões formuladas;

- conter perguntas elaboradas com clareza e objetividade, a fim de se evitar vieses de entendimento por parte do respondente;

- abordar vários aspectos relacionados à área em investigação, bem dosada na quantidade e na complexidade de questões;

- utilizar linguagem compreensível aos respondentes.

Considerando o método de pesquisa escolhido, foram desenvolvidos dois tipos de instrumentos de coleta de dados: um roteiro de entrevista e observações para a primeira fase, e um questionário com questões fechadas e escalas do tipo Likert para a segunda fase. O questionário da segunda fase é composto de quatro partes, apresentadas a seguir:

I. Apresentação: Na primeira parte é feita uma apresentação do instrumento ao respondente, esclarecendo o objetivo e orientando seu preenchimento. Procura estimulá-lo ao preenchimento com perguntas claras e de curta duração para respondê-las. Exalta a importância da participação do respondente para a organização 
participante, e destaca o sigilo das informações e sua nãoidentificação;

II. Caracterização do censo: a segunda parte é formada pelos dados pessoais com 7 questões onde as variáveis demográficas foram: sexo, faixa etária e formação profissional. As variáveis da vida profissional foram: o nível funcional, tempo de formação, tempo na organização atual e o tempo se aplica, como chefe de laboratório;

III. Comprometimento - Comp: a terceira parte é constituída pelo instrumento sobre comprometimento extraído de Meyer et al. (1993):

- Comprometimento organizacional - CR: são 18 questões, sendo 6 questões de cada tipo de comprometimento (afetivo CRA, instrumental - CRI e normativo - CRN);

- Comprometimento ocupacional - CC: semelhante ao comprometimento ocupacional com 18 questões formada pelos mesmos 3 tipos de comprometimento e com 6 questões de cada (afetivo - CCA, instrumental - CCl e normativo - CCN).

IV. Desempenho - DE: a quarta parte é formada pelos 4 fatores de desempenho resultantes da primeira pesquisa:

- Clima organizacional - CO: constou com 8 questões sobre o ambiente do CO (COA), 5 sobre a criatividade do CO (COC), 2 sobre o desempenho do CO (COD) e 6 sobre a organização do $\mathrm{CO}(\mathrm{COO})$ perfazendo um total de 21 questões para este fator de desempenho;

- Liderança - LI: teve um total de 15 questões, sendo 3 questões sobre a importância da LI (LII), 4 sobre atitudes da LI (LIA) e 8 sobre características da LI (LIC);

- Motivação - MO: concentrou o maior número de questões com 21, formada por 5 questões que avaliam o ambiente da MO (MOA), 5 analisam a chefia da MO (MOC), 2 sobre a organização da $\mathrm{MO}$ (MOO), 3 quantificam a motivação própria da $\mathrm{MO}(\mathrm{MOM}), 2$ sobre o relacionamento da $\mathrm{MO}(\mathrm{MORL}) \mathrm{e}$ 
finalmente 4 medem o reconhecimento da $\mathrm{MO}$ (MORC);

๑ Trabalho em equipe - TE: formado pelo menor número de questões sendo 14, das quais 2 sobre a missão do TE (TEM), 3 sobre o relacionamento do TE (TER), 3 sobre a conduta do TE (TECD), 4 sobre o ambiente do TE (TEA), e finalmente 2 sobre o comprometimento do TE (TECP).

No final, o instrumento aplicado apresentou um campo "aberto", para livre expressão e comentários no eventual interesse de manifestação pelo respondente. As observações e considerações feitas nesse espaço foram tratadas qualitativamente, analisando-se sua pertinência ao objeto de estudo, e colaboração prestada. Não houve nada representativo neste campo.

A terceira e quarta parte do instrumento foram compostas por perguntas fechadas e dispostas com múltiplas alternativas, permitindo respostas rápidas, sendo solicitado ao respondente manifestar seu grau de concordância ou discordâncias frente às assertivas das questões lhes apresentadas sobre 0 comprometimento e os quatro fatores de desempenho. O Anexo III apresenta todas as questões do instrumento e sua estrutura dividida por fator e domínio

Foi utilizada na terceira e quarta parte do instrumento uma escala ordinal somatória Likert com 5 graduações (discordo totalmente, discordo, indiferente, concordo e concordo totalmente). Cada resposta recebeu uma classificação numérica que refletiu o grau de favorecimento de atitude do respondente. O número 0 representou a impressão menos favorável a cada item, ou seja, discordo totalmente, e o número "4", significou a atitude mais favorável a cada item, ou seja, concordo totalmente. Como existiam algumas poucas respostas negativas na terceira parte sobre o comprometimento, houve a transformação desse número para o complemento onde a soma de ambos os números fosse "4". Mais tarde durante o tratamento dos dados constatou-se que não foi a melhor opção iniciar a escala com o valor zero e deveria começar a mesma a partir do valor um.

Muitos estudos das ciências sociais utilizam a escala do tipo somatória Likert. Para Cooper e Schindler (2003), esta escala apresenta muitas vantagens ao pesquisador: mais fácil e rápida de construir; cada item passa por um teste empírico para verificar sua capacidade de discriminação; é mais confiável no sentido das respostas ao item pelo respondente; e, finalmente, fornece um 
número maior de dados do que muitas outras escalas. A escala do tipo Likert é considerada uma escala ordinal, pois a origem dos números que medem é arbitrária, além de que, como observam Selltiz et al. (1987), a escala tipo Likert permite a ordenação dos respondentes, através da favorabilidade de sua atitude com relação ao item, mas não apresenta uma base para dizer quanto um indivíduo é mais favorável que outro ao item questionado.

Esta escala tem sido amplamente utilizada em pesquisas de natureza quantitativa. Pereira (2001, p. 65) a exalta como "paradigma da mensuração qualitativa", sugerindo que seu intenso uso seja proveniente de suas características de contemplar oposição entre contrários, de reconhecer gradiente, de incluir situação intermediária e de ter uma "relação adequada entre precisão e acurácia da mensuração" (1).

Inicialmente o autor estava propenso a usar uma escala de 6 pontos seguindo Matell e Jacoby (1972), ou de 7 conforme Moura (1997). Com o apoio de 2 estatísticos do Laboratório de Estudos Epidemiológicos do Instituto de Saúde Pública da USP, e considerando a pouca experiência e habilidade do público do CTA em responder a pesquisas e principalmente numa área fora do seu dia-a-dia, optou-se pela escala de cinco pontos para manter a figura do respondente neutro. Chau (1999) mostrou que escalas de 7 pontos apresentam resultados semelhantes a escalas de 5 pontos não afetando a confiabilidade da mesma.

Foi utilizada na primeira fase a confirmação dos indicadores de desempenho mais importantes, mediante as entrevistas não-estruturadas, que resultou ser um mecanismo adequado para o sistema de medição, tendo em vista que muitas vezes as pessoas se sentem constrangidas para expressar o que sabem. A experiência do entrevistador neste cenário foi necessária, já que se usou a entrevista pessoal. Também foram válidas todas as observações detectadas por ocasião do teste do modelo. As observações e entrevistas foram instrumentos usados simultaneamente.

A observação foi utilizada na pesquisa já que o problema e os objetivos não estavam claramente definidos. Esta técnica é bastante utilizada para pesqui-

\footnotetext{
(1) É pertinente, nesse sentido, retratar a definição do autor para esses conceitos que utiliza o exemplo do tiro ao alvo: acurácia é a capacidade da medida em representar bem o objeto medido, enquanto precisão é a fineza com que se realiza a medida (baixa dispersão). Assim, uma escala de 0 a 10 teria um refinamento de precisão, mas perderia a acurácia, já que tornaria difícil estabelecer dez categorias de classificação (Pereira, 2001).
} 
sas exploratórias, tendo como objetivo familiarizar o pesquisador com o problema em estudo, de forma a lhe permitir desenvolver hipóteses de relações casuais e especificações claras dos comportamentos ou situações.

$\mathrm{Na}$ primeira fase do estudo foram analisados os fatores comportamentais resultantes da revisão bibliográfica: liderança, motivação, resistências às mudanças, trabalho em equipe, competências, perfil do funcionário, criatividade, tomada de decisões e comunicação.

Semelhante ao anterior, como fatores organizacionais foram avaliados os seguintes itens: qualidade de vida, gestão do conhecimento, sistema de gestão integrada (SGI), clima organizacional, desempenho das pessoas, avaliação de funcionários, implementação, organização que aprende, tecnologia, gestão estratégica, treinamento-gestão de pessoas, sucesso-paixão pelos clientes e pelo trabalho, o trabalho em casa, trabalho-emprego e o uso da Internet.

Como resultado da primeira fase da pesquisa, conseguiu-se diminuir o número de fatores comportamentais e organizacionais para um total de 4 , os quais fizeram parte da segunda fase junto à mensuração dos comprometimentos organizacional e ocupacional. Os 4 fatores de desempenho escolhidos foram: clima organizacional, liderança, motivação e trabalho em equipe. Como justificativas do porque destes quatro fatores, reforçam esta decisão as observações no item 2.7 da revisão bibliográfica no capitulo 2 .

\subsection{Coleta de dados}

A técnica de levantamento adotada foi a de corte transversal, amplamente utilizada e que tem como característica básica à coleta de informações de todas as variáveis simultaneamente. Contrapõe-se ao método longitudinal, onde as medidas são obtidas dos mesmos indivíduos em ocasiões repetidas (MacCallum e Austin, 2000). Segundo Malhotra (2001), o método transversal traz como vantagem à representatividade da amostragem e a menor distorção nas respostas.

A validação desse instrumento foi feita junto a um grupo de servidores atuantes em ambos os institutos com a aplicação do pré-teste frente a pessoas com experiência ou afinidade na área de gestão. O pré-teste resultou ter sido importante, não só para a escolha da tática de realização da pesquisa propriamente dita, bem como, visando fortalecer o questionário, procurou-se um 
melhor esclarecimento das dúvidas preliminares e até para melhorar $\mathrm{o}$ entendimento das questões do mesmo, inclusive de forma diferente para cada instituto. As opiniões e críticas feitas e a manifestação de dificuldades encontradas, permitiram adequar termos do questionário, apurar duração do preenchimento, e outros fatores de ajustes do recurso, refinando seus termos.

Durante o pré-teste e na medida em que respondentes experientes e prestativos com experiência na área de gestão e separadamente para cada uma das duas organizações pesquisadas, sugeriam melhorias ou esclarecimentos, estas eram aplicadas e o instrumento alterado era repassado a um novo respondente do pré-teste.

Como se tratou de uma pesquisa extensa - 114 questões - e considerando também que o assunto não era o dia-a-dia dos servidores dos laboratórios; então em média cada respondente levou cerca de 30 minutos para o seu completo preenchimento em papel. Mais tarde com algumas alterações e já aplicada na Internet o tempo de preenchimento caiu para a metade. A Internet passa uma imagem de modernidade, abrevia em muito o tempo da pesquisa com a digitação das respostas pelo próprio respondente e pela redução dos custos incluindo a eliminação do papel e a garantia neste caso em que o instrumento programado somente podia ser aceito para envio dos dados apenas quando ele estivesse com todas as respostas preenchidas.

A pesquisa foi realizada primeiramente no CTA. O questionário foi disponibilizado na rede interna, na Intranet do IAE, no link Qualidade, "http://www.intraiae/PesquisaMiguelTejos/pesquisa.htm", dispensando assim o uso de papel e a digitação dos dados. Durante o preenchimento, diariamente o autor verificava a relação dos novos respondentes e enviava um e-mail agradecendo à relação nominal dos novos respondentes.

Em ambos locais foi realizada uma cobrança corpo-a-corpo com os servidores que ainda não tinham respondido. 252 servidores responderam de uma relação de 295 convidados no caso do CTA ( $86 \%$ dos convidados) versus 52 respondentes do IPEN de uma relação de 63 convidados (com um nível de resposta de $83 \%$ ). No IPEN a cobrança maior foi por parte do orientador. No CTA foi por parte do autor.

Quando da segunda fase no CTA, a pouca experiência dos programadores na linguagem inicial "PHP" levou a aplicação ao fracasso, tendo 
sido alterada para programação em "DOT.NET" funcionando desta forma a contento. Por tratar-se de uma página única, cada respondente permanecia no sistema muito tempo conectado, o qual induzia às quedas no sistema porque ultrapassava os 5000 segundos programados como tempo máximo de conexão para cada respondente.

Quando da aplicação no IPEN e considerando a experiência na aplicação no CTA fez dividir o questionário em três páginas independentes (podia ser preenchida por cada página), minimizando assim o tempo de conexão e garantindo a obtenção de dados sem problemas. No IPEN esta pesquisa foi disponibilizada na Internet no site "www.monda.org/tesemt", permitindo com vantagens que fosse preenchida fora do local e horário de trabalho ${ }^{(2)}$, o qual não tinha acontecido no caso anterior do CTA.

A pesquisa estava programada de modo que o banco de dados não aceitava questionários incompletos, informando ao respondente a(s) questão(ões) faltante(s), o qual foi uma enorme facilidade já que obrigava a responder todas as questões garantindo assim o recebimento no banco de dados de questionários completos com todos os itens respondidos.

Cada respondente recebeu uma senha dupla. No caso do CTA ela permitia o acesso ao questionário. Uma senha era formada pelas letras "a, b ou c" minúscula e mais dois dígitos, a segunda senha era formada pela confirmação das primeiras letras de cada nome do respondente, as quais eram preenchidas nos campos usuário e login respectivamente.

No caso do IPEN a senha era formada pela letra "p" e mais três números e os respondentes deveriam preencher no campo e-mail: “jesualdo@ipen.br".

A aplicação dos questionários foi iniciada primeiramente no CTA com a tentativa na linguagem "PHP" em 31.03.05, tendo sido alterada para programação em "DOT.NET" e retomada com esta nova linguagem em 18.04.05 e finalizada em 16.05.05 com 252 respondentes. No IPEN a pesquisa foi iniciada na Internet no dia 10.05.05, sendo encerrada no dia 19.06.05 com 52 respondentes.

(2) A operacionalização computacional do questionário online, assim como sua aplicação e construção do banco de dados foram realizadas por um pesquisador do IPEN, Dr. Adonis Marcelo Saliba-Silva. 


\subsection{Consideração metodológica}

Com o intuito de utilizar técnicas estatísticas na análise de dados, assumiu-se que diversas escalas do questionário fossem de natureza intervalar, apesar de serem conceitualmente ordinais. Um dado numa escala intervalar permite-nos dizer quanto mais um objeto tem de um atributo do que outro (Dillon e Goldstein, 1984). Essas escalas deveriam ter o cálculo de tendência central efetuado com base no conceito de mediana, e não de média. Dillon e Goldstein (1984) destacam que as propriedades estatísticas de muitas das técnicas multivariada assentam-se em pressupostos explícitos referentes ao nível de mensuração e ao formato da distribuição dos dados analisados, face às propriedades matemáticas a eles associados. A maior parte dos métodos de análise pressupõe que pelo menos um dos blocos de variável (independente ou dependente) utilize escalas métricas.

Alguns autores defendem a utilização de escalas ordinais do tipo Likert, mesmo quando a técnica exige escalas intervalares, demonstrando que as mesmas podem ser assumidas como métricas. Mazzon (1981, p. 64) cita que Stevens (1946) verificou que "escalas normalizadas" poderiam ser tratadas como intervalares. Para Abelson \& Turkey, 1970 (apud Mazzon, 1981, p. 65), "a atribuição de valores numéricos a categorias de uma escala métrica ordinal permite seu tratamento como se fosse medida como escala intervalar". Mazzon destaca entre outro alguns pesquisadores que adotaram tal procedimento: Mindak (1961, p. 31), Carter et al. (1968, p. 666-674), Abelson \& Turkey (1970, p. 307417) Green \& Tull (1975, p. 288), Kerby (1979, p. 378), Perreault \& Barksdate (1979, p. 252), Kinnear \& Taylor (1981, p. 318, 324-5). Assumir que a escala ordinal adotada possa ser considerada como escala métrica encontra respaldo em muitas pesquisas da área de ciências sociais, não obstante questionamentos de vários autores (Cesar, 2004).

O uso da escala ordinal, uma das possíveis causas de violação da condição de distribuição normal multivariada dos indicadores, exigiu alguns cuidados no tratamento das informações, como o uso da matriz de correlação policórica e a aplicação de métodos alternativos de estimação, conforme descrito posteriormente na seção a seguir que abordará a análise dos dados. 


\subsection{Tratamento e análise de dados}

Após a codificação e tabulação dos dados dos respondentes, as duas matrizes de arquivo do tipo Excel foram submetidas ao processo de verificação de dados. O exame dos dados numa fase anterior á aplicação de uma técnica estatística é fundamental para que o pesquisador adquira uma compreensão crítica sobre as características desses dados, pois o conhecimento das relações existentes entre as variáveis colabora para sua interpretação, permite uma maior articulação entre os resultados e propicia o refinamento de modelos mais complexos (Hair Jr. et al., 1998). Embora este estudo não tivesse problemas de missing values e de outliers, é importante destacar a rotina geral de análise de dados proposta por Hair Jr. et al. (1998), na verificação de algumas premissas e, caso contrário, ações corretivas devem ser adotadas:

- Avaliação dos missing values: trata-se das observações ou valores ausentes (missing values) que podem ocorrer por uma série de razões como incapacidade, falta de entendimento ou negação do entrevistado em responder uma questão. Hair Jr. et al. (1998) recomendam a substituição dos missing values pelos valores da média dos dados de cada variável. Lembrase ao leitor que neste estudo a programação garantiu o fato de não aceitar respostas não preenchidas ou incompletas.

- Identificação de outliers: são considerados outliers aquelas observações que apresentam um padrão diferente do encontrado nas outras observações (Hair Jr. et al., 1998), e que podem distorcer as variâncias e co-variâncias entre as variáveis (Bagozzi e Baumgartner, 1994). Hair Jr. et al. (1998) sugerem para sua identificação, a aplicação do teste de padronização de variáveis pelo cálculo dos escores $Z$ e a exclusão dos casos com valores superiores a $|3|$, sendo esta uma forma univariada de detectar e corrigir o problema. Outra técnica muito utilizada é a Distância Mahalanobis $\left(D^{2}\right)$, um indicador da distância multivariada entre os valores de um caso individual e as médias amostrais (Hair Jr. et al.) que é gerado de um teste estatístico.

- Avaliação da normalidade dos dados: a normalidade dos dados é considerada premissa fundamental para a realização da análise multivariada. Refere-se ao formato da distribuição de uma variável métrica e sua correspondência à distribuição normal (Hair Jr. et al., 1998). Caso a 
distribuição dos dados não apresentar normalidade, o uso de testes estatísticos, principalmente os multivariados, não deveria ser aplicado. Há duas formas de verificar a normalidade: por meios estatísticos ou por meio de gráficos, sendo que os primeiros utilizam como critérios os valores de assimetria e curtose e, nos segundos, considera-se mais apropriada quando a distribuição dos dados for mais significativa do que os testes estatísticos (Tabachnick \& Fidell, 1996). No estudo, os dados foram submetidos à análise de normalidade (uni e multivariada), a partir da avaliação dos valores de assimetria e curtose (nível de significância de 0,01). Na detecção de normalidade univariada, foi adotado o teste de Kolmogorov-Smirnov, resultando a significância $p$ para todas as variáveis, em valores menores que 0,0001, o qual indica tratar-se de uma não-normalidade. O anterior levará mais tarde ao autor durante a utilização da modelagem de equações estruturais a recorrer ao método dos mínimos quadrados não-ponderados ULS (Unweighted least squares), por ser menos exigente com a normalidade dos dados.

Durante a análise dos dados a variável formação no caso do CTA teve que ser verificada individualmente para os servidores de nível superior porque alguns não preencheram este item e apareciam com a formação inicial que indicava o programa. Tal fato descobriu-se ao comparar a variável "função" com a variável "formação" o qual resultava em resultados diferentes.

No caso do IPEN o banco de dados foi entregue na seqüência que os respondentes preencheram o questionário, precisando agrupá-los pelos locais de trabalho quando da análise que requeria desta forma. No caso do CTA o banco de dados foi entregue na seqüência inicial correta.

A partir do banco de dados (pelo critério de Ricco com os valores subtraídos em "2", ou com dados normalizados), realizou-se a soma para cada respondente em cada um dos domínios ${ }^{(3)}$. Finalmente calculou-se a média das somas dos respondentes de cada um dos domínios, obtendo assim um índice para cada um dos vinte e quatro domínios. Finalmente foi calculada a média das médias de cada fator de desempenho obtendo assim a média única de cada fator

(3) Entende-se por domínio o agrupamento de variáveis de um mesmo grupo ou de aquelas que tenham afinidade. 
de desempenho.

\subsubsection{Tamanho amostral}

MacCallum e Austin (2000) observaram uma ampla diversidade em amostras de estudos com Hair Jr. et al. (1998) apontando que, na medida em que se aumenta o tamanho amostral, o método de estimação por máxima verossimilhança (MLE), o procedimento mais comum de estimação, aumenta sua sensibilidade em detectar diferenças entre os dados. Para tamanhos amostrais muito grandes (acima de 400), o modelo torna-se "muito sensível", e quase sempre detecta qualquer diferença, fazendo com que todas as medidas de ajustamento acusem ajustes "pobres". Os autores, mesmo ressalvando que não existe um tamanho amostral correto, recomendam a adoção de uma quantidade entre 100 e 200 observações. Neste estudo o método que deu melhores resultados foi o dos mínimos quadrados não-ponderados (unweighted least squares - ULS). O número de observações de 304, embora pequeno para amostras de modelagem de equações estruturais, onde normalmente encontramse um número de observações superior a 500, não apresentou problemas pela sua baixa quantidade, destacando que neste estudo não se tratou de uma amostra de uma população maior e sim de um censo formado com o total da população existente.

Observa-se que, as amostras são probabilísticas, posto que a probabilidade de um indivíduo pertencer a uma das amostras é conhecida (Churchill, 1999; Malhotra, 2001; Cooper e Schindler, 2003).

\subsection{Estatística descritiva}

Após a verificação da consistência de cada um dos arquivos Excel, eles foram transformados para utilização nos softwares estatísticos SPSS® e LISREL ®. Estes arquivos foram processados pelas suas respectivas técnicas:

- Univariadas: por tabelas de freqüência relativas de cada um dos itens do questionário, bem como de estatísticas descritivas básicas - média, mediana, desvio-padrão etc. - que mostram as características da amostra em relação aos itens do questionário. 
- O teste de confiabilidade dos dados foi realizado com o coeficiente alfa de Cronbach, o qual mede a consistência interna do teste, sendo utilizado o subprograma Scale-reliability analysis do programa SPSS 14.0. O teste de confiabilidade é imperativo e mede o desempenho de um instrumento em uma dada população evitando o agrupamento de questões aparentemente relevantes (Litwin 1995, apud Oliveira Neto 2001).

\subsection{Estatística multivariada}

Em qualquer estudo o pesquisador se defronta com uma grande quantidade de dados que precisam ser classificados para posteriormente serem analisados. Com o desenvolvimento e o fácil acesso ao computador pessoal nas últimas décadas e com o apoio dos seus programas de computação, além das diversas técnicas estatísticas hoje existentes, tudo resultou num grande avanço no tratamento desses dados, tendo como conseqüência o destaque e a aplicação da análise multivariada (Hair Jr. et al. 1998).

Hair Jr. et al. (1998) salientam que o uso de técnicas apropriadas depende dos objetivos desejados do estudo. Desta forma, considerando os interesses delineados e as particularidades deste estudo, utilizou-se o tratamento estatístico multivariado dos dados com a análise fatorial e a modelagem de equações estruturais - SEM, complementado por análises univariadas.

As técnicas univariadas utilizadas permitiram conhecer preliminarmente o perfil dos respondentes e suas características profissionais, bem como, avaliar o grau de concordância ou discordância com as assertivas elaboradas na pesquisa.

As técnicas multivariada de segunda geração utilizadas aumentaram o poder de explicação dos dados, já que segundo César (2004) tem como objetivos fundamentais, entre outros, a redução dos dados, a simplificação estrutural, o grupamento dos dados, e a investigação de dependência entre as variáveis. Como este estudo é derivado do comportamento das pessoas deve ser observado sob vários aspectos. A análise multivariada contribui para o entendimento da correlação de múltiplas variáveis que podem estar relacionadas ao fenômeno em estudo e são analisadas de forma simultânea.

As análises multivariada são técnicas de processamento matemático e estatístico de dados que permitem a revelação de informações que não são aparentes nas medidas originais (Pereira, 2001). A análise fatorial pode identificar 
a estrutura de um conjunto de variáveis, bem como, fornecer o processo para a redução de dados. Esta técnica estatística tem como objetivo descrever a estrutura de dependência de um conjunto de variáveis através da criação de fatores, que são variáveis que, supostamente, medem aspectos comuns (Barroso, 2003).

Esta técnica fatorial pode atingir seus objetivos através de uma análise exploratória na redução de dados em fatores ou posteriormente através de uma análise confirmatória na validação de fatores (Hair Jr. et al., 1998). Neste estudo o primeiro método utilizado foi a análise fatorial exploratória com o intuito de identificar os novos fatores e as variáveis mais representativas do instrumento de pesquisa, neste caso reduzindo o número de variáveis de 71 para 12, utilizandose o método dos componentes principais para a extração dos fatores e a rotação ortogonal "varimax" levando-se em conta somente os fatores com auto valores maiores do que 1, segundo o critério de Kaiser. A vantagem de usar o método de extração dos componentes principais é que não há a pressuposição da normalidade das variáveis envolvidas (Barroso, 2003). Na composição dos fatores se consideraram somente as variáveis que apresentaram cargas fatoriais obedecendo a critérios definidos por Hair Jr. et al. (1998). O objetivo desta etapa de análise foi simplificar o esquema teórico a ser testado - uma vez que o número de indicadores utilizados para mensurar era grande e esta técnica permite reduzir as variáveis originais

O segundo método utilizado neste estudo foi à análise fatorial confirmatória, pelo método de estimação unweighted least squares - ULS, como forma de testar quais variáveis deveriam ser agrupadas na estrutura proposta, e então obter a validação dos fatores.

Considera-se que a principal diferença da análise fatorial confirmatória em relação à exploratória está na possibilidade do pesquisador ter controle sobre a especificação de indicadores para cada constructo, confirmando e validando as escalas para a mensuração de constructos específicos. Já na técnica fatorial exploratória, tem-se como resultado a carga de cada variável para cada fator.

Para classificar os diversos métodos multivariados existentes, vejam-se as propostas de Hair Jr. et al. (1998) e Dillon e Goldstein (1984). Para Hair Jr. et al. (1998), inicialmente se estabelece o critério de dependência ou interdependência, onde o pesquisador na relação de dependência analisa o tipo 
de relacionamento entre as variáveis (diversos relacionamentos entre variáveis dependentes - VD, e variáveis independentes - VI, várias VDs num único relacionamento e uma única VD num único relacionamento). Após a classificação anterior realiza-se a avaliação das escadas utilizadas: métricas ou não-métricas. Na relação de interdependência o pesquisador analisa se a ênfase no tratamento dos dados está na interdependência entre as variáveis, entre atributos dos objetos ou entre respondentes ou casos.

Para Dillon e Goldstein (1984) após a definição de dependência ou interdependência, se analisa nos modelos de dependência, se esta se refere a um ou mais critérios e finalmente se as escalas são métricas ou não-métricas. No caso dos modelos de interdependência o pesquisador analisa se as variáveis são métricas ou não-métricas, classificando assim as técnicas a partir deste critério.

Desta forma, para a verificação de relacionamento entre as variáveis propostas para o presente estudo, no sentido da confirmação de aspectos teóricos hipotetizados, e na identificação de causalidade entre os fatores que influenciam o desempenho, optou-se pela adoção da modelagem de equações estruturais - SEM - que pode abordar uma ampla variedade de relações causais. Segundo Hair Jr. et al (1998), entre os dois tipos de análises mais comuns, destacam-se a análise fatorial confirmatória e a estimação de uma série de equações estruturais.

Pereira (2001) sugere um roteiro genérico de procedimentos para o pesquisador conduzir a análise de seus dados qualitativos:

- Reconhecer e delimitar adequadamente seu objeto de estudo;

- Identificar uma estratégia eficiente de medida;

- Editar e processar suas medidas originais de forma a dar-lhes versatilidade de análise;

- Distinguir a melhor estratégia de análise para suas medidas, ponderando seus objetivos e o potencial de suas medidas no sentido de quando se ajustam às premissas da técnica de análise escolhida;

- Conduzir a análise verificando o ajuste da técnica escolhida, ou seja, quanta e quão bem suas conclusões podem ser válidas;

- Interpretar as conclusões da análise realizada à luz do conhecimento tanto do objeto estudado quanto das técnicas utilizadas para sua análise. 


\subsubsection{Metodologia multivariada}

Dentre as formas utilizadas em pesquisas descritivas, a técnica de levantamento de corte transversal é apontada como a mais conhecida e amplamente empregada, pois tem como premissa a coleta de informações junto a uma amostra da população em um único momento (Churchill, 1999). A vantagem deste método é permitir a obtenção de uma "fotografia" das variáveis de interesse da pesquisa em um determinado momento do tempo e a de enfatizar a seleção de uma amostra significativa e representativa da população-alvo (Malhotra, 2001). Destaca-se que esta técnica não é recomendada para as inferências de relações causais ou estudos experimentais, dado que é impossível controlar a influência de elementos externos, devido a que todas as variáveis são medidas simultaneamente (Hair Jr. et al., 1998; Malhotra, 2001).

É comum o uso de dados provenientes de levantamentos de corte transversal em estudos de modelagem de equações estruturais, pois permitem a investigação de modelos complexos compostos por um conjunto de equações descritivas das inter-relações entre as variáveis endógenas e exógenas (Steenkamp e Baumgartner, 2000).

A modelagem de equações estruturais apresenta a vantagem de trazer grande flexibilidade para o investigador ao facilitar a ligação entre a teoria e os dados empíricos (Chin, 1998). Também, permite examinar múltiplos relacionamentos entre conjuntos de variáveis de forma simultânea, o qual constitui sua grande vantagem, ao contrário da maioria das técnicas de análise multivariada (Hair Jr. et al., 1998).

Assim, considerando os objetivos deste estudo, na análise multivariada foram definidas onze etapas no processo da modelagem de equações estruturais desta pesquisa, partindo do pressuposto que a coleta de dados e o tratamento e análise dos dados já aconteceu na $2^{\mathrm{a}}$ Fase do estudo. A Figura 3.2 apresenta a $3^{\mathrm{a}}$ Fase do estudo, suas atividades e sua seqüência no esquema.

As onze etapas da $3^{a}$ Fase se detalham a seguir: definição da estatística multivariada a ser utilizada; análise fatorial exploratória para redução de dados procurando definir as variáveis mais importantes; proposição do modelo teórico a partir das variáveis mais importantes; análise fatorial confirmatória para testar quais variáveis devem ser agrupadas e validar os fatores finalizando assim com a definição do modelo estrutural. Ocorre a partir do modelo teórico uma 


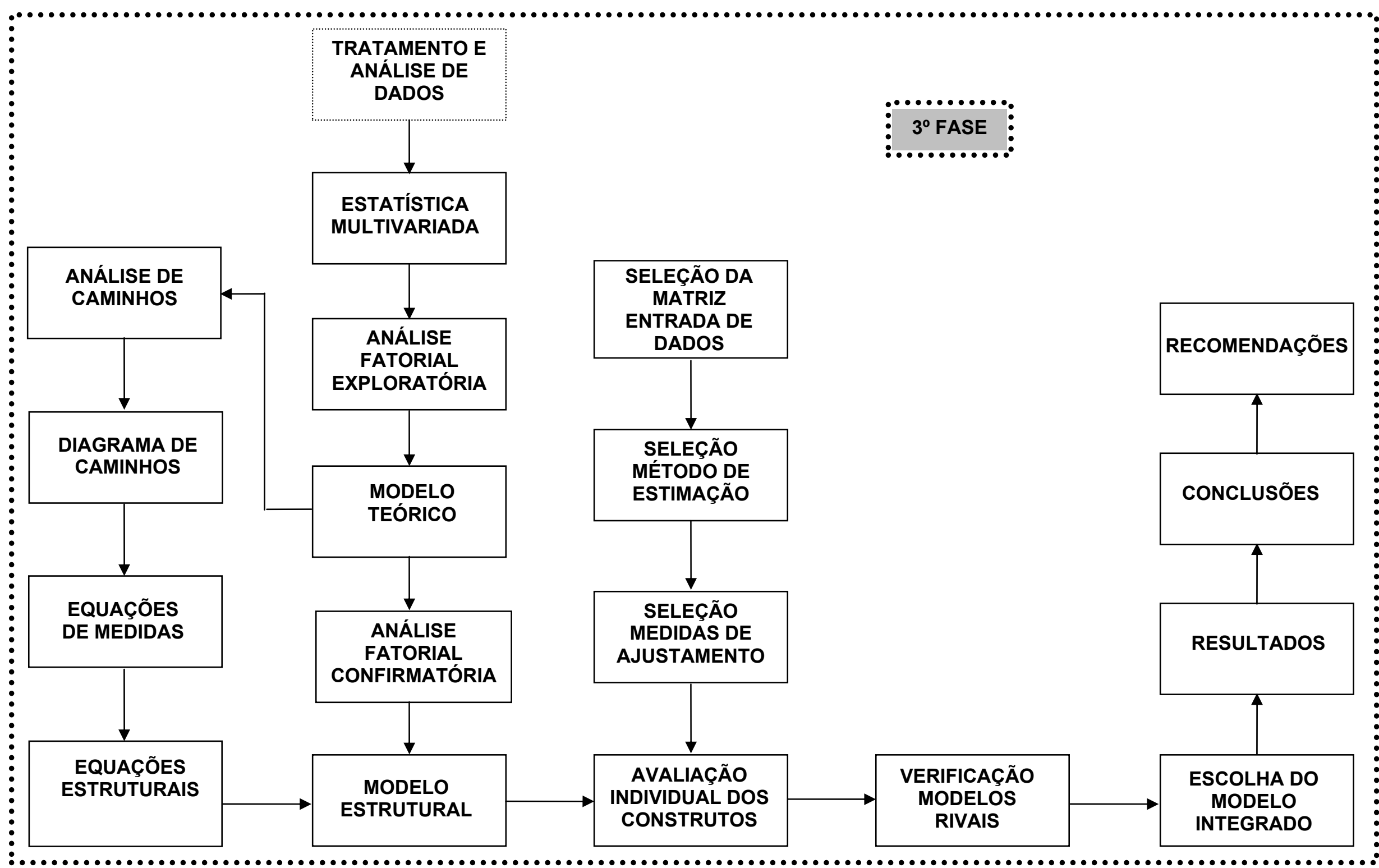

Figura 3.2. $3^{\mathrm{a}}$ Fase da pesquisa (modelagem de equações estruturais). 
seqüência em paralelo com a análise de caminhos que considera todas as relações causais importantes; o diagrama de caminhos que é baseado na teoria e estima a intensidade de cada relacionamento; as equações de medidas que ajustam interiormente os constructos; e as equações estruturais que ligam os constructos e definem finalmente também o modelo estrutural nesta seqüência em paralelo iniciada no modelo teórico. A partir do modelo estrutural continua a avaliação individual dos constructos; a verificação dos modelos rivais por orientação da teoria; a escolha do modelo integrado de melhor ajuste; análise dos resultados obtidos e finalmente, o desenvolvimento das conclusões e recomendações. Na avaliação individual dos constructos, existe a obrigatoriedade de considerar o atendimento às medidas de ajustamento previamente selecionadas, bem como do método de ajuste a ser utilizado e tudo partindo da seleção da matriz de entrada de dados.

\subsubsection{Modelagem de equações estruturais (SEM) ${ }^{(4)}$}

A técnica foi denominada inicialmente de path analysis devido aos artigos de Sewell Wright em $1921^{(5)}$ e $1934^{(6)}$ (Maruyama, 1998), um geneticista que tentou resolver equações simultâneas no esclarecimento de influências genéticas entre gerações. Mais tarde, com o advento dos computadores e de programas que propiciavam a realização de operações mais complexas, o termo modelagem causal foi introduzido. Como este termo foi rejeitado por alguns cientistas sociais, passou-se a utilizar a denominação de equações estruturais. No âmbito das ciências sociais, Maruyama (1998) cita Blalock (1964) e Duncan (1966) como os pioneiros no uso da técnica.

Entre os programas mais conhecidos que processam as equações estruturais encontram-se o LISREL (Jöreskog \& Sörbom, 2001), o EQS (Bentler, 1985) e o AMOS (Arbuckle, 1997), este último utilizado por Chang Jr., (2001) e Perin (2001). Hair Jr. et al. (1998) cita que o LISREL é sinônimo da SEM por ser o mais amplamente utilizado em diversas áreas, entretanto existem outros como:

\footnotetext{
(4) Corresponde à sigla adotada em inglês para Modelagem de Equações Estruturais (Structural Equations Modelling).

${ }^{(5)}$ Wright, S. (1921). Correlations and causation. Journal of Agricultural Research, v. 20, p 557585.

(6) Wright, S. (1934). The method of path coefficients. Annals of Mathematical Statistics, v. 5, p. 161-215.
} 
PROC CALIS da SAS, COSAN e LVPLS.

A modelagem de dados pela técnica de equações estruturais (SEM) permite ao pesquisador verificar hipóteses de relacionamentos entre variáveis latentes $^{(7)}$ e observáveis ${ }^{(8)}$, constituindo-se assim numa importante ferramenta para a avaliação de teorias e relações causais tendo nas suas vantagens mais evidentes: a potência e a versatilidade da análise (Schuler, 1995).

A técnica de estatística multivariada SEM permite a análise de todas as variáveis dependentes e independentes ao mesmo tempo, e com vários tipos de relacionamentos entre elas, inclusive com caminhos de retroalimentação. A SEM é uma extensão de diversas técnicas multivariada, mais especificamente da regressão multivariada e da análise fatorial.

A SEM estabelece relacionamentos separados para cada conjunto de variáveis dependentes, ou seja, estima ao mesmo tempo uma série de equações de regressão múltipla as quais são separadas entre sim, porém interdependentes. Assim, são previamente identificadas as variáveis que terão efeitos sobre outras e tais variáveis são consideradas exógenas porque suas causas são externas ao modelo estudado. Por outro lado, são consideradas variáveis endógenas todas aquelas cujas causas estão relacionadas às variáveis exógenas ou a outras variáveis internas do sistema.

O modelo de correlações expressa as relações entre as variáveis dependentes e as independentes, mesmo aquelas relações entre variáveis dependentes que se tornam variáveis independentes em outros relacionamentos. Todos os relacionamentos são transformados numa série de equações estruturais para cada variável dependente.

Esta técnica proporciona ao pesquisador a condição de acomodar diversos relacionamentos de dependência inter-relacionados num único modelo. Está próxima da regressão multivariada, que pode estimar um único relacionamento - uma equação. A SEM pode estimar muitas equações por vez, sendo que estas podem estar inter-relacionadas, ou seja, a variável dependente

\footnotetext{
${ }^{(7)}$ As variáveis latentes ou endógenas são aquelas que representam o efeito das outras variáveis, de modo similar às variáveis dependentes em estudos experimentais (Kline, 1998, p. 16)

(8) Hair Jr. et al. (1998, p. 581) consideram as variáveis observáveis ou manifestas (também denominadas de exógenas ou indicadores) como "valores observáveis para uma questão ou item específico, obtidos dos respondentes em resposta à questão ou observados pelos pesquisadores".
} 
de uma equação pode ser independente em outra equação. A utilização dessa técnica permite ao pesquisador modelar relacionamentos complexos, o que não seria possível com quaisquer outras técnicas estatísticas multivariadas.

A técnica da SEM propicia ao investigador a análise simultânea de um conjunto de relações múltiplas e interdependentes entre as variáveis por meio de uma série de regressões múltiplas, sendo principalmente indicada quando uma variável dependente torna-se independente em outro relacionamento. Também, possui condições de estimar estas relações de uma forma compreensível, permitindo uma transição de uma análise exploratória para confirmatória (Hair Jr. et al., 1998).

Toda técnica de SEM pode ser reconhecida por duas características: estimação de relacionamentos múltiplos e de dependência inter-relacionada; a habilidade de representar conceitos não-observados nesses relacionamentos e contabilizar os erros de medidas no processo de estimação.

A maior diferença entre a SEM e os outros métodos, ou técnicas multivariada, é o uso de relações separadas para cada conjunto de variáveis dependentes: a SEM estima uma série de equações de regressões multivariada de modo separado, mas que se interdependem (Hair Jr. et al., 1998). Esta interdependência é formalizada por definição prévia de um modelo que será utilizado pelo programa estatístico. Em primeiro lugar, o pesquisador estabelece o modelo de correlações entre as variáveis tendo em vista a teoria que os suporta e os objetivos da pesquisa, definindo as variáveis independentes que predizem cada variável dependente.

A SEM se diferencia das outras técnicas multivariada já que as outras assumem a ausência de erros. A SEM assume que os erros existem e que podem ter diversas origens: metodológica, conceitual, viés de resposta etc. A SEM incorpora em sua análise a possibilidade de existência do erro, estimando o coeficiente estrutural entre a variável dependente e independente, e a confiabilidade da variável independente entendida como o grau em que a variável independente é livre de erro (Hair Jr. et al., 1998).

Além da estimação dos relacionamentos multivariados de dependência inter-relacionada, a técnica de SEM também tem a habilidade de incorporar as variáveis latentes na análise as quais não seriam de outra maneira observáveis (Hair Jr. et al., 1998). É preciso que se tenha claro que o poder desta técnica 
estatística está na confirmação da existência de modelos e não na exploração da existência dos mesmos.

$\mathrm{Na}$ análise fatorial confirmatória, as variáveis latentes são vistas como exógenas, ou seja, neste tipo de análise, não se verifica a causa dos interrelacionamentos entre as variáveis, mas a força dos relacionamentos entre as variáveis que determinam os fatores (Maruyama, 1998).

Os fatores teorizados são chamados de constructos exógenos. Hair Jr. et al (1998, p. 580) citam: "constructo ou variável exógena têm apenas indicações causais que partem deles e não são previstos por quaisquer outros constructos do modelo".

Especificamente para constructo Hair Jr. et al. (1998, p. 579) apresentam a seguinte definição:

Constructo é uma abstração que o pesquisador pode definir em termos conceituais, mas que não pode ser medida diretamente (por exemplo, através de uma única resposta que represente o conceito por completo), ou ser medido sem erros. Os constructos são a base para formar 0 relacionamento causal, uma vez que são a "mais pura" representação possivel de um conceito.

Cooper e Schindler (2003, p. 53) definem constructo em ciências sociais como "uma imagem ou idéia inventada especificamente para uma determinada pesquisa e/ou criação da teoria". Os constructos devem ser medidos através de indicadores, já que não podem ser medidos diretamente (Hair Jr. et al., 1998). A determinação desses indicadores está apoiada nos achados da literatura.

Embora teoricamente não exista limite para o número de variáveis no SEM, existe uma regra prática, mas não fundamentada, que afirma que a significância estatística do modelo fica difícil de ser obtida quando o número de variáveis excede a 20.

Dentre outros autores (Hair et al, 1998; Maruyama, 1998) afirmam que a adoção da modelagem de equações estruturais inicia-se com a construção de um modelo teórico para que seja possível então conhecer se os dados correlacionados representam a estrutura teórica hipotética. Trata-se de um procedimento que reúnem diversas técnicas de destaque, como a regressão múltipla e a análise fatorial, que permite a análise de modelos compostos por distintas relações entre variáveis latentes indiretamente medidas por múltiplos 
indicadores (Chin, 1998). Partindo de um modelo teórico (estrutural), amparado em um modelo de mensuração, a modelagem de equações estruturais avalia um conjunto de regressões múltiplas, separadas, porém interdependentes (Perin, 2001). O modelo estrutural apresenta o conjunto de relações de dependência, associando os constructos do modelo hipotetizado; já o modelo de mensuração operacionaliza tal análise a partir de um conjunto de variáveis observáveis ligadas a cada variável latente (Hair Jr. et al., 1998).

Cabe salientar o alerta de MacCallum e Austin (2000) e de Chin (1998), para o fato de que mesmo quando o ajuste é bem aceito, é conveniente considerar modelos alternativos ("rivais") porque outros modelos podem apresentar ajuste igualmente bom ou superior.

$\mathrm{Na}$ modelagem de equações estruturais, podem ser encontrados três tipos de relações entre variáveis, sejam estas latentes ou observáveis: de associação, de efeito direto e de efeito indireto. A de associação diz respeito à relação entre duas variáveis presentes no modelo sem uma direção definida, sendo idêntica à relação tipicamente avaliada pela análise de correlação. O efeito direto, assumido como a base da modelagem de equações estruturais, consiste em uma relação direcional entre duas variáveis, tipicamente analisada pelas técnicas de análise de variância (ANOVA) e regressão múltipla. Finalmente, o efeito indireto é exercido por uma variável independente sobre uma variável dependente por intermédio de uma ou mais variáveis intervenientes ou mediadoras.

Segundo Hair Jr. et al. (1998) a aplicação das equações estruturais deve acontecer em três estratégias diferentes, de acordo com o objetivo do estudo:

- $\quad$ Na primeira estratégia, na confirmação de modelos (confirmatory modeling strategy), o objetivo é a validação do ajustamento estatístico do modelo teórico proposto, procurando ou não sua confirmação. Os relacionamentos estão colocados e o objetivo é a confirmação dos relacionamentos. A SEM é utilizada para avaliar a significância estatística do modelo. Pesquisadores demonstraram que esta técnica tem um viés, portanto, recomenda-se um teste mais rigoroso utilizando a comparação entre modelos alternativos.

- $\quad$ Na segunda estratégia, na avaliação dos modelos concorrentes (competing models strategy), realiza-se uma comparação entre diferentes modelos 
teóricos, a partir de teorias rivais ou resultados conflitantes da pesquisa, procurando identificar o modelo que apresenta o melhor ajustamento para o mesmo conjunto de dados. Existe o programa chamado TETRAD que, a partir da matriz de dados e do modelo inicial de relacionamentos, examina os padrões de relacionamentos e isola aqueles que podem ser empiricamente explicados.

- Finalmente, no desenvolvimento de modelos (model development strategy), procura-se avaliar e melhorar um modelo teórico pré-estabelecido, com intuito de incrementar seu ajustamento estatístico com modificações e reespecificações graduais nas relações entre as variáveis, desde que estas estejam embasadas por uma argumentação teórica sólida (MacCallum, 1995; Hair Jr. et al., 1998). Os relacionamentos não são conhecidos e o objetivo é descobri-los; ou, se conhecidos, o objetivo é reespecificá-los de modo a explicar melhor o fenômeno. O pesquisador deve empregar a SEM para tentar obter insights para a reespecificação do modelo, e não para testá-lo empiricamente.

Neste estudo, devido à ausência de comprovação empírica anterior do modelo teórico ora proposto, bem como, considerando os objetivos e as hipóteses do trabalho, entende-se que a estratégia de desenvolvimento de modelos é a que acontece neste caso. Para realizar esta estratégia, foi obedecida uma seqüência de etapas de acordo com as recomendações na literatura de modelagem de equações estruturais (Anderson e Gerbing, 1988; MacCallum, 1995; Kline, 1998; Garver e Mentzer, 1999), apresentada a seguir:

1. Elaboração dos modelos estrutural e de mensuração;

2. Seleção da matriz de entrada dos dados;

3. Seleção do método de estimação;

4. Seleção das medidas de ajustamento;

5. Avaliação individual dos constructos; e

6. Avaliação do modelo integrado.

É importante destacar que os procedimentos de avaliação mencionados anteriormente foram realizados em dois momentos distintos, obedecendo às sugestões de Anderson e Gerbing (1988) e Garver e Mentzer (1999). Conhecida como abordagem de duas etapas (two-step approach), inicialmente o modelo de 
mensuração é avaliado com a aplicação do método de análise fatorial confirmatória $(\mathrm{CFA})^{(9)}$, aplicada individualmente a cada uma das variáveis latentes do modelo, procurando verificar suas validades convergentes e discriminantes (Bagozzi et al., 1991; Reise et al., 1993; Hair Jr. et al., 1998; Garver e Mentzer, 1999). Após satisfazer estas condições, foram verificadas as relações estruturais hipotetizadas entre as variáveis latentes com a estimação das medidas de ajustamento do modelo integrado (Garver \& Mentzer, 1999).

\subsubsection{Análise de caminho (path analysis)}

A análise de caminho assume alguns pressupostos, citando os mais importantes (Dillon e Goldstein, 1984):

- Todos os relacionamentos entre variáveis são lineares;

- Os resíduos são assumidos como não-correlacionados entre si;

- O modelo é recursivo, ou seja, só são considerados relacionamentos numa única direção;

- Todas as variáveis devem ser mensuradas em escalas intervalares;

- As variáveis dependentes são consideradas como medidas sem erro; e

- Considera-se que todas as relações causais importantes foram incluídas no modelo.

Segundo Maruyama (1998) a análise de caminhos está relacionada a modelos de fluxo causal direcional único, nos quais as medidas de cada variável conceitual são perfeitamente confiáveis.

Para melhor determinar o relacionamento entre as variáveis do modelo proposto, elabora-se um mapa, indicando as variáveis e o modo como elas se relacionam. Este mapa é conhecido por diagrama de caminhos (path diagram).

Os relacionamentos entre variáveis são representados por flechas. Uma flecha de direção única indica o impacto de uma variável independente sobre uma dependente; uma flecha curva, com seta nas duas extremidades, indica que as duas variáveis são correlacionadas, como se fosse uma multicolinearidade no caso da regressão multivariada - efeito recursivo. O diagrama de caminhos é a base para a análise de caminhos que estima a intensidade de cada relacionamen-

\footnotetext{
${ }^{(9)}$ Corresponde à sigla adotada em inglês para análise fatorial confirmatória (confirmatory fator analysis).
} 
to. Para tanto é utilizada uma matriz de correlação ou covariância como dados de entrada.

Os diagramas de caminho devem ser montados tendo em vista a teoria que os suporta, propiciando assim, uma explicação consistente e compreensiva do fenômeno. Partindo deste ponto, podem-se modificar esses diagramas de caminho, visando obter uma melhor explicação do problema. A SEM é muito mais uma metodologia confirmatória, guiada mais pela teoria do que pelos resultados empíricos (Hair Jr. et al., 1998).

O erro mais crítico no desenvolvimento de modelos teóricos é o esquecimento ou a omissão de uma ou mais variáveis preditivas - problema conhecido como erro de especificação.

É importante verificar possíveis erros existentes nas análises de caminhos, como por exemplo, erros de medidas nas variáveis observadas, erros de especificação do modelo e multicolinearidade entre os parâmetros.

Hair et al (1998) sugerem durante a análise fatorial a obtenção da validade de conteúdo que avalia subjetivamente a correspondência entre os itens individuais e o conceito através do julgamento de especialistas, pré-testes com múltiplas subpopulações ou outros meios.

Para a análise ou validação teórica dos itens, Pasquali (2003) sugere dois tipos: a análise do conteúdo e a análise semântica do teste. Para a análise do conteúdo do teste, Pasquali (2003) cita que deve ser feita por peritos na área do constructo, pois o que se pretende é verificar se os itens realmente descrevem o constructo a ser medido. Neste estudo foi solicitada a dois profissionais da área de gestão e conhecedores dos locais de aplicação a validação de conteúdo.

No caso da análise semântica, os juízes, segundo Pasquali (2003), devem ser os sujeitos da própria população para a qual se quer construir o teste. Este autor destaca, ainda, a preocupação com o entendimento dos itens por servidores com maior habilidade na compreensão do tema de gestão, bem como, dos servidores de menor contato e menor compreensão destes itens.

$\mathrm{Na}$ análise semântica do questionário, realizou-se um pré-teste, apresentando o questionário a um grupo de estudiosos na área de gestão e que fazem parte dos quadros dos institutos envolvidos. O refinamento dos itens foi obtido através das críticas e opiniões manifestadas e das dificuldades apontadas, além de ser possível verificar o tempo de duração do preenchimento. 


\subsubsection{O modelo teórico}

Segundo Aaker (1998), modelos representam hipóteses ou suposições sobre o funcionamento de uma determinada situação real, bem como as relações de interdependências entre suas partes. Os modelos teóricos podem auxiliar no entendimento de certa realidade, na medida em que relacionam os constructos envolvidos e proporcionam uma síntese dos antecedentes e/ou conseqüências do constructo que está sendo analisado (Sampieri et al., 1991, apud Perin).

O desenvolvimento de modelos teóricos requer cuidados especiais dos pesquisadores a fim de que não o façam sem o devido embasamento científico. É imprescindível que o processo de modelagem esteja teoricamente alicerçado em pressupostos e hipóteses com comprovado lastro teórico (Sutton \& Staw, 1995).

\subsubsection{Seleção da matriz de entrada dos dados}

Diferente de outras técnicas estatísticas multivariada, a modelagem de equações estruturais não utiliza os dados diretamente observados (coletados) para suas estimações, mas uma matriz de correlação ou covariância gerada a partir dos dados coletados (Hoyle, 1995b). Cabe ao investigador optar por um dos tipos de matrizes, tendo cada uma suas propriedades e suas indicações distintas.

A matriz de correlação é mais indicada quando o propósito do estudo é somente entender o padrão da relação entre os constructos, não procurando a explicação da variância total desses. Por outro lado, quando se tem como objetivo de estudo o teste de teoria, a matriz de covariância é considerada mais apropriada, pois esta possui condições de realizar comparações válidas entre diferentes populações ou amostras, o que não é possível na estimação de um modelo a partir de uma matriz de correlação (Hair Jr. et al., 1998; Hoyle \& Panter, 1995). O software LISREL utilizado neste estudo trabalha com diversos tipos de matrizes.

\subsubsection{Seleção do método de estimação}

Tendo sido especificados os modelos estrutural e de mensuração e tendo sido escolhido o tipo de matriz de entrada de dados, o próximo passo é a definição do método de estimação. Os métodos mais comumente utilizados na estimação de parâmetros são o de maximum likelihood estimation (MLE) e o de generalized least squares (GLS). Ambos têm como pressuposto que as variáveis 
são métricas e possuem distribuição normal. Entretanto, sabe-se que nas pesquisas sociais muitas vezes os dados não satisfazem essas condições. Assim, a técnica de modelagem de equações estruturais, com uma razoável freqüência, considerando o uso de tais métodos de estimação, enfrenta a violação dos requisitos de distribuição contínua e normal (Chou e Bentler, 1995; West, Finch Curran, 1995). A situação foi contornada conforme foi explicado no item 3.5 sobre consideração metodológica além da utilização do método ULS por ser este menos exigente quanto à normalidade das variáveis.

As conseqüências mais visíveis da violação destes pressupostos são as diminuições da acurácia do teste de Qui-quadrado (valores elevados e ocasionando a rejeição indevida de muitos modelos), e o registro de erros padronizados muito baixos, o qual gera viés nos testes de todos os parâmetros estimados e com a apresentação de resultados extremamente significativos (Hu e Bentler, 1995; West, Finch e Curran, 1995; Ullman, 2001). Para os casos de violação da distribuição normal e contínua, também são sugeridos métodos como os de Satorra-Bentler, Yuan-Bentler, asymptotically distribuiton free (ADF), entre outros (Hu e Bentler, 1995; West, Finch e Curran, 1995; Ullman, 2001).

A solução dentre as escolhas disponíveis depende da intensidade da não-normalidade dos dados e do tamanho da amostra analisada. Conforme Hair Jr. et al. (1998), a técnica de estimação maximum likelihood estimation (MLE) é considerada apropriada para amostras entre 100 e 200 respondentes, mesmo podendo não ser representativas da população. Quanto maior é a dimensão da amostra (acima de 400 respondentes), maior será a sensibilidade da técnica para detectar diferenças entre os dados, prejudicando desta forma, as medidas de ajustamento do modelo. Hair Jr. et al. (1998) registram uma alternativa no caso de grandes amostras, é a utilização da técnica de estimação ADF (asymptotically distribution free), a qual não depende da normalidade dos dados e requer a presença de amostras maiores.

Havendo definido o método de estimação do modelo, neste estudo o ULS já justificado anteriormente, o próximo passo foi escolher as medidas para avaliação do ajuste do modelo proposto, conforme apresentado a seguir. 


\subsubsection{Seleção das medidas de ajustamento}

$\mathrm{Na}$ verificação de adequação do modelo proposto, utilizou-se um conjunto de medidas de ajustamento, pois não existe um único coeficiente que resuma o ajuste do modelo. Também, os parâmetros para avaliação dessas medidas (aceitação ou rejeição) não são rígidos, pois, dependendo da complexidade e da atualidade do modelo proposto, o pesquisador deverá definir os limites aceitáveis de ajustamento.

Considerando as medidas de ajuste disponíveis, foram empregadas as medidas de adequação absolutas, as quais determinam o grau em que 0 modelo (estrutural e de mensuração) prediz a matriz de covariância ou correlação observada, e as medidas de ajustes incrementais, as quais comparam o modelo proposto a um modelo básico denominado de modelo nulo (Hair Jr. et al., 1998). A continuação serão expostos os índices de ajustes gerais empregados:

(a) Qui-quadrado ponderado sobre graus de liberdade $\left(\chi^{2} /\right.$ graus de liberdade): esta relação mostra a diferença entre as matrizes observada e estimada. Quanto maior o valor do Qui-quadrado em relação aos graus de liberdade, maiores serão as diferenças entre as matrizes observada e estimada, sendo considerados aceitáveis valores iguais ou menores a 5 . É um índice de ajuste muito sensível ao tamanho amostral. O teste do Qui-quadrado, conforme alertam Hair et al. (1998), é um bom indicador de ajuste de modelo apenas para amostras com tamanho entre 100 e 200 observações, e problemático na medida em que o número de elementos amostral aumenta consideravelmente (Maruyama, 1998). Por essa razão, outros índices devem ser considerados na análise (Maruyama, 1998).

É importante destacar que, em razão do uso da matriz de correlação assintótica como dado de entrada no sistema, o Qui-quadrado utilizado foi o da teoria normal de mínimos quadrados ponderados, no programa LISREL ${ }^{\circledR}$.

Além deste indicador, foi avaliado o coeficiente de significância $(p)$ que estabelece as diferenças estatísticas entre as matrizes do modelo, sendo aceitáveis níveis superiores a "0,05", o qual indicaria 
que as matrizes observada e estimada não são estatisticamente distintas. Entretanto, como o teste de Qui-quadrado sofre os efeitos da não-normalidade dos dados, o número de parâmetros e o tamanho da amostra (Anderson e Gerbing, 1988; Hu e Bentler, 1995; West, Finch e Curran, 1995; Hair Jr. et al., 1998), conseqüentemente, é recomendável que a análise desta medida seja complementada pela análise dos outros indicadores de ajustamento.

(b) Goodness-of-fit (GFI): medida não-padronizada que apresenta variações no intervalo de zero (ajuste fraco) a um (ajuste perfeito), indicando a comparação entre os resíduos das matrizes observada e estimada. Assumem-se como aceitáveis valores iguais ou superiores a "0,8/0,9". Medida não-estatística que representa o grau geral de ajuste do modelo, ou a soma de variância e covariância que, juntas, são explicadas pelo modelo (Dillon e Goldstein, 1984). Esta é uma medida que independe do tamanho da amostra e é robusta em relação a pressupostos de normalidade;

(c) Adjusted Goodness-of-Fit Index (AGFI): Trata-se de uma extensão do índice GFI, ajustado pela razão dos graus de liberdade para o modelo proposto pelos graus de liberdade para um modelo nulo. O nível de aceite recomendado é maior ou igual a "0,9";

(d) Root Mean Square Error of Approximation (RMSEA): esta medida serve para corrigir a tendência que $O$ Qui-quadrado apresenta em rejeitar modelos especificados a partir de grandes amostras. Ela representa a discrepância por grau de liberdade da raiz quadrada da média dos resíduos dos modelos observados e esperados ao quadrado (Hair Jr. et al., 1998; Ullman, 2001). É representativa do grau de ajuste que poderia ser esperado se 0 modelo fosse mensurado na população e não na amostra. É considerada aceita se está no intervalo entre "0,05" e "0,08";

Com relação às medidas comparativas de ajustamento, as quais procuram comparar o modelo proposto ao modelo nulo (null model), estas foram as seguintes: 
(e) Normed Fit Index (NFI): é um dos indicadores mais populares e compara o modelo proposto e o modelo nulo (Hair Jr. et al., 1998). Possui os mesmos intervalos de variação - zero (ajuste fraco) a um (ajuste perfeito) - bem como, os valores de aceitação são iguais ou superiores a "0,9";

(f) Tucker-Lewis index (TLI) conhecido como nonnormed fit index (NNFI): é considerado o indicador mais robusto. Combina uma medida de parcimônia em um índice comparativo entre os modelos proposto e nulo contemplando a ponderação pelos graus de liberdade. Seus valores oscilam na faixa de zero a um, sendo aceitáveis valores iguais ou superiores a "0,9" (Hair Jr. et al., 1998);

(g) Comparative fit index (CFI): medida incremental que também compara o modelo nulo e o estimado. Segundo Hair Jr. et al. (1998), é a medida mais apropriada em estratégias de desenvolvimento de modelos ou em situações de amostra pequena. Sua variação é de zero (ajuste pobre) a um (ajuste perfeito), sendo recomendável igual ou acima de "0,8/0,9".

A avaliação dos índices de ajustamento propicia aos investigadores meios para julgar a necessidade de efetuar sensíveis mudanças no modelo proposto, procurando assim uma maior adequação dos constructos e do modelo geral. Conforme Bagozzi e Baumgartner (1994), a reespecificação de um modelo deve ser realizada sempre com aporte teórico para manter a lógica conceitual. Hair Jr. et al. (1998) preconizam que o modelo seja inicialmente ajustado a partir do exame dos resíduos, excluindo as variáveis que estejam prejudicando o modelo com covariâncias com $T$-value (ou resíduo ajustado) superior a "2,58". Um outro procedimento sugerido é o estabelecimento de novas relações entre as variáveis latentes ou entre os constructos, existindo sempre, suporte teórico para tanto.

As medidas anteriormente descritas foram utilizadas nos procedimentos de avaliação individual dos constructos, bem como, na avaliação do modelo integral. 


\subsubsection{Procedimentos de avaliação individual dos constructos}

A análise fatorial confirmatória é plenamente reconhecida por diversos autores (Anderson e Gerbing, 1988; Bagozzi, Yi e Phillips, 1991; Reise, Widaman e Pugh, 1993; Dunn, Seaker e Waller, 1994; Hair Jr. et al., 1998; Garver e Mentzer, 1999) como sendo o tipo de análise mais adequado e rigoroso para a verificação da validade individual dos constructos, pois ela possibilita analisar suas propriedades como a unidimensionalidade, a confiabilidade, a validade convergente a validade discriminante (Garver e Mentzer, 1999).

Hair Jr et al. (1998) citam que a análise fatorial confirmatória tem como propósito verificar a correspondência entre variáveis latentes e observáveis, de modo semelhante à análise fatorial exploratória. Entretanto, sua peculiaridade está no controle que o pesquisador possui para indicar as variáveis observáveis que corresponderão a cada variável latente, propiciando assim o estabelecimento de cargas positivas dos indicadores em seus supostos fatores e cargas restritas a zero em outros fatores (Hair Jr. et al., 1998). Pensando na análise fatorial exploratória, percebe-se que a totalidade das variáveis observáveis atua como indicadores de todas as dimensões, uma vez que todas possuem cargas em todos os fatores (Hair Jr. et al., 1998). Esta técnica é utilizada em estudos de modelagem de equações estruturais para indicar as medidas de ajuste de constructos ou do modelo integral, colaborando para a avaliação da validade destes (Anderson e Gerbing, 1988) e se torna particularmente útil na avaliação de escalas de medida (Hair Jr. et al., 1998).

O primeiro passo na avaliação das propriedades de um constructo é a verificação da identificação do modelo. Hair Jr. et al. (1998) registram que os problemas de identificação são caracterizados pela inabilidade do modelo proposto em gerar estimativas significativas e lógicas. A sugestão dos autores para evitar o problema é dotar o modelo de mais equações do que variáveis nãoconhecidas, gerando assim, o modelo sobre-identificado (overindentified model). Para sua obtenção, sugere-se que durante a análise fatorial confirmatória o valor da variância dos constructos seja fixado em "1" de forma que os valores das cargas fatoriais possam ser calculados livremente, evitando assim, problemas de estimação de parâmetros (Byrne, 1995).

O segundo passo é analisar a unidimensionalidade dos constructos. Esta análise consiste em verificar o grau em que os indicadores representam uma 
única variável latente ou constructo (Garver e Mentzer, 1999). Na avaliação da unidimensionalidade de um constructo, é condição básica que os indicadores formadores de um constructo apresentem um ajuste aceitável para um modelo com um único fator ou dimensão (Hair Jr. et al., 1998). A unidimensionalidade é uma premissa para a confiabilidade do constructo (HAIR et al., 1998).

Neste trabalho, a unidimensionalidade foi analisada a partir da comparação dos resíduos padronizados, estimados em análises fatoriais confirmatórias, efetuadas separadamente por constructo. Conforme Garver e Mentzer (1999), a unidimensionalidade do constructo é determinada pela presença de resíduos padronizados relativamente baixos, com valores iguais ou inferiores a "2,58" (três desvios-padrão), em módulo, e um nível de significância de "0,05". A validade individual dos constructos e suas propriedades são realizadas no LISREL atendendo aos valores referenciais das medidas de ajuste indicadas na Tabela 4.11.

O terceiro passo é a análise da confiabilidade dos constructos na avaliação individual das variáveis latentes. A confiabilidade indica o grau de consistência interna entre os múltiplos escores de uma variável, referindo-se à extensão na qual um mesmo instrumento de medidas produz resultados coerentes em diversas mensurações (Dillon et al., 1994; Malhotra, 2001). Neste estudo os constructos foram submetidos ao teste de confiabilidade composta e à medida de variância extraída que indica o quanto da variância dos indicadores observáveis pode ser explicado pelos respectivos constructos latentes (Hair Jr. et al., 1998). Para tanto, foram empregadas as fórmulas de Fornell e Larcker (1981), como segue:

$$
\begin{aligned}
& \text { Confiabilidade do constructo }=\frac{\left(\sum \lambda\right)^{2}}{\left(\sum \lambda\right)^{2}+\sum \varepsilon_{j}} \\
& \text { Variância extraída }=\frac{\sum \lambda^{2}}{\sum \lambda^{2}+\sum \varepsilon_{j}}
\end{aligned}
$$

onde $\boldsymbol{\lambda}$ significa o parâmetro estimado (carga fatorial) padronizado da relação entre $o$ indicador e a variável latente, e $\varepsilon_{\mathrm{j}}$ representa o erro de mensuração do 
indicador. A confiabilidade aceitável acontece para valores iguais ou maiores que 0,70 para a confiabilidade do constructo e iguais ou maiores que " 0,50 " para a variância extraída (Hair Jr. et al., 1998; Garver e Mentzer, 1999).

O quarto passo na avaliação individual dos constructos é a verificação da validade. Após garantir sua definição conceitual, sua unidimensionalidade e os níveis de confiabilidade, o pesquisador deve validar a escala. A validade indica se o instrumento de medida registra de forma precisa aquilo que pretende mensurar (Nunnally, 1994). Validade é o grau em que uma escala ou um conjunto de medidas representa com precisão o conceito de interesse. Dentre das principais formas de validade verificadas pelos pesquisadores (Evrard et al., 1997; Hair Jr. et al., 1998; Churchill, 1999; Malhotra, 2001) encontram-se: a validade preditiva, ligada à predição de acuracidade de uma forma de comportamento externa à medida do instrumento per se; a validade de conteúdo, ligada à correspondência entre as variáveis observáveis empregadas no instrumento e as definições teóricas do constructo avaliado; a validade do constructo, que procura identificar se de fato esse constructo está sendo mensurado e quais os indicadores empíricos que se relacionam com seus constructos teóricos, sendo considerada tanta a validade convergente (medidas relacionadas ao mesmo constructo possuem correlação entre si) quanto à validade discriminante (divergência de medidas relacionadas a diferentes constructos); e, finalmente, a validade nomológica, ligada à correspondência dos resultados obtidos com a base teórica constituída.

Malhotra (2001, p. 266) cita que "a relação entre confiabilidade e validade pode ser entendida como se uma medida é perfeitamente válida é também perfeitamente confiável. A validade perfeita implica confiabilidade perfeita. Embora a falta de confiabilidade constitua evidência negativa para a validade, a confiabilidade por si só não implica a validade. A confiabilidade é uma condição necessária, mas não suficiente, para a validade".

No presente estudo, a validade convergente foi verificada através do exame da significância estatística dos parâmetros estimados, a partir dos seus respectivos $t$-values (Garver e Mentzer, 1999). Considera-se válido (aceitável) quando uma das cargas fatoriais relativas aos indicadores associados à variável latente apresenta significância estatística ( $p<0,05$ ), isto é, possui t-value maior ou 
igual a "1,96", equivalente a dois desvios-padrão (Dunn, Seaker e Waller, 1994; Garver e Mentzer, 1999).

Para a avaliação da validade discriminante, utilizou-se um teste sugerido por Fornell e Larcker (1981), procedimento este, que compara a variância extraída do constructo com as suas variâncias compartilhadas, representadas por seus quadrados dos coeficientes de correlação, com os demais constructos. A validade discriminante é positiva quando os constructos apresentam variâncias extraídas maiores do que as respectivas variâncias compartilhadas.

Tendo sido avaliadas as premissas de unidimensionalidade, da confiabilidade e das validades convergente e discriminante dos constructos do modelo, o próximo passo é a avaliação do modelo integrado, o qual acontecerá no capítulo 4.

\subsubsection{LISREL}

O LISREL nasceu no final da década de 1960 e início da década de 1970, quando Karl Joreskog, Dag Sorbom e outras pessoas dos Serviços de Testes Educacionais criaram programas de computação para uso em pesquisa educacional e análise fatorial (Hayduk, 1987). Na atualidade suas aplicações estão nos mais diversos campos da pesquisa e tem-se firmado num predomínio sobre os softwares concorrentes devido aos seus múltiplos resultados.

A seguir destacam-se algumas vantagens do LISREL sobre os outros softwares:

- ele é específico para o SEM;

- ele faz análise de resíduos em geral;

o somente executa comandos que são coerentes e corretos;

- o processo no todo é uma análise matemática;

- é o mais robusto de todos os softwares.

Segundo Hair Jr. et al. (1998) a visualização completa do processo LISREL (linear structural relations) parte do diagrama de caminhos que descreve - conjunto de relacionamentos causais através das variáveis endógenas e exógenas e resulta em três equações básicas e em oito matrizes (identificadas com letras gregas), sendo quatro matrizes de coeficientes e mais quatro matrizes adicionais de covariância: 
- O primeiro passo é traduzir o diagrama de caminhos numa série de equações estruturais para cada variável endógena;

- Com as equações estruturais definidas a medição de cada constructo deve ser definida;

- Devem-se especificar o conjunto de equações para ambos os modelos: estrutural e de medidas. Inicialmente definem-se as equações estruturais e de medidas. As variáveis originais devem ser identificadas como indicadores endógenos ou exógenos;

- $\quad$ Existem duas matrizes de correlação das equações estruturais, a primeira é a matriz Phi que indica as correlações dos constructos exógenos, e a segunda, é a matriz Psi, que registra as correlações entre as equações estruturais e os constructos endógenos;

- As correlações do modelo de medidas são registradas em duas matrizes que indicam os erros de medidas dos indicadores dos constructos endógenos e exógenos. 


\section{CAPÍTULO 4}

\section{RESULTADOS E DISCUSSÃO}

\subsection{Introdução}

$\mathrm{Na}$ análise dos dados coletados, foram empregadas técnicas estatísticas de natureza univariada e multivariada, com a utilização dos softwares estatísticos SPSS 14.0 e LISREL 8.71. Dentre elas, destacam-se as estatísticas descritivas, a análise de confiabilidade, a análise fatorial exploratória e confirmatória e a modelagem de equações estruturais. A seguir apresenta-se uma breve descrição destas técnicas já detalhadas no capítulo 3.

A análise descritiva foi utilizada para a caracterização da amostra com a apresentação de médias e distribuição de freqüências das variáveis. Desta forma, obteve-se um conhecimento sobre o perfil dos respondentes.

A análise de confiabilidade é um meio de avaliação das respostas obtidas, procurando verificar se os itens especificados dizem respeito ao constructo que está sendo mensurado (Churchill, 1999). A técnica empregada para verificar a consistência interna dos dados foi o coeficiente alfa de Cronbach. Churchill (1999) indica que este coeficiente ideal estaria por volta de "0,90", entretanto, pesquisas realizadas na área de comportamento das pessoas (Yu, 2001 e UCLA), apresentam índices inferiores aceitáveis, até um valor mínimo de "0,7". Segundo Malhotra (2001) o coeficiente alfa de Cronbach, mede a confiabilidade da consistência interna que é a média de todos os coeficientes possíveis resultantes das diferentes divisões da escala em duas metades. Uma propriedade importante do coeficiente alfa é que seu valor tende a aumentar com o acréscimo do número de itens na escala. Por isto o coeficiente alfa pode ser artificialmente - e inadequadamente - inflacionado pela inclusão de vários itens redundantes da escala.

A análise fatorial exploratória é uma técnica que permite a redução dos dados, a partir da análise de inter-relação entre um grande número de variáveis e sua explicação em termos de suas dimensões comuns (Hair Jr. et al., 1998). 
Desta forma, esta técnica pode ser utilizada com o intuito de resumir um conjunto de variáveis num número menor de fatores, propiciando assim a operacionalização do banco de dados e o processo de análise.

A análise fatorial confirmatória permite testar quais variáveis deveriam ser agrupadas na estrutura proposta, e então obter a validação dos fatores, bem como, tendo controle sobre a especificação de indicadores para cada constructo, confirmar e validar as escalas para a mensuração de constructos específicos.

A modelagem de equações estruturais - SEM, foi à técnica estatística que constituiu a base analítica deste estudo e que permite: verificar hipóteses de relacionamentos entre variáveis latentes e observáveis; analisar vários tipos de relacionamentos entre variáveis dependentes e independentes ao mesmo tempo, inclusive com caminhos de retroalimentação; acomodar diversos relacionamentos de dependência inter-relacionados num único modelo.

A seguir será feita uma análise das variáveis demográficas e profissionais visando conhecer o perfil dos respondentes.

\subsection{Características demográficas e profissionais}

A Figura 4.1 apresenta o gráfico das sete variáveis demográficas e profissionais levantadas na pesquisa, encontrando do lado esquerdo aquelas que representam o caso do CTA e do lado direito da figura as que representam o caso do IPEN.

Analisando em conjunto as variáveis demográficas e profissionais do CTA e do IPEN, notam-se certas diferenças. No histograma da variável "sexo", no caso do CTA $14 \%$ é do sexo feminino e $86 \%$ masculino, sendo que no IPEN a diferença entre as duas respostas é menor, sendo 35\% mulheres e 65\% homens.

Sobre a variável "faixa etária", no caso do CTA existe uma concentração de $46 \%$ dos servidores entre 39 e 49 anos e com participação destes em todas as faixas etárias. No caso do IPEN existe apenas uma pequena diferença na maioria, na faixa etária dos 39 aos 49 anos num percentual de $44 \%$ da população seguido com 38\% na faixa acima dos 50 anos e destacando que não há nesta organização representante na faixa abaixo dos 29 anos. Salienta-se o fato de o CTA ter realizado diversos concursos nos últimos 13 anos ingressando muita gente jovem, o qual não aconteceu no IPEN, conseqüentemente assim a 
idade média da população do IPEN é maior, com $82 \%$ acima dos 39 anos contra $57 \%$ da população do CTA.
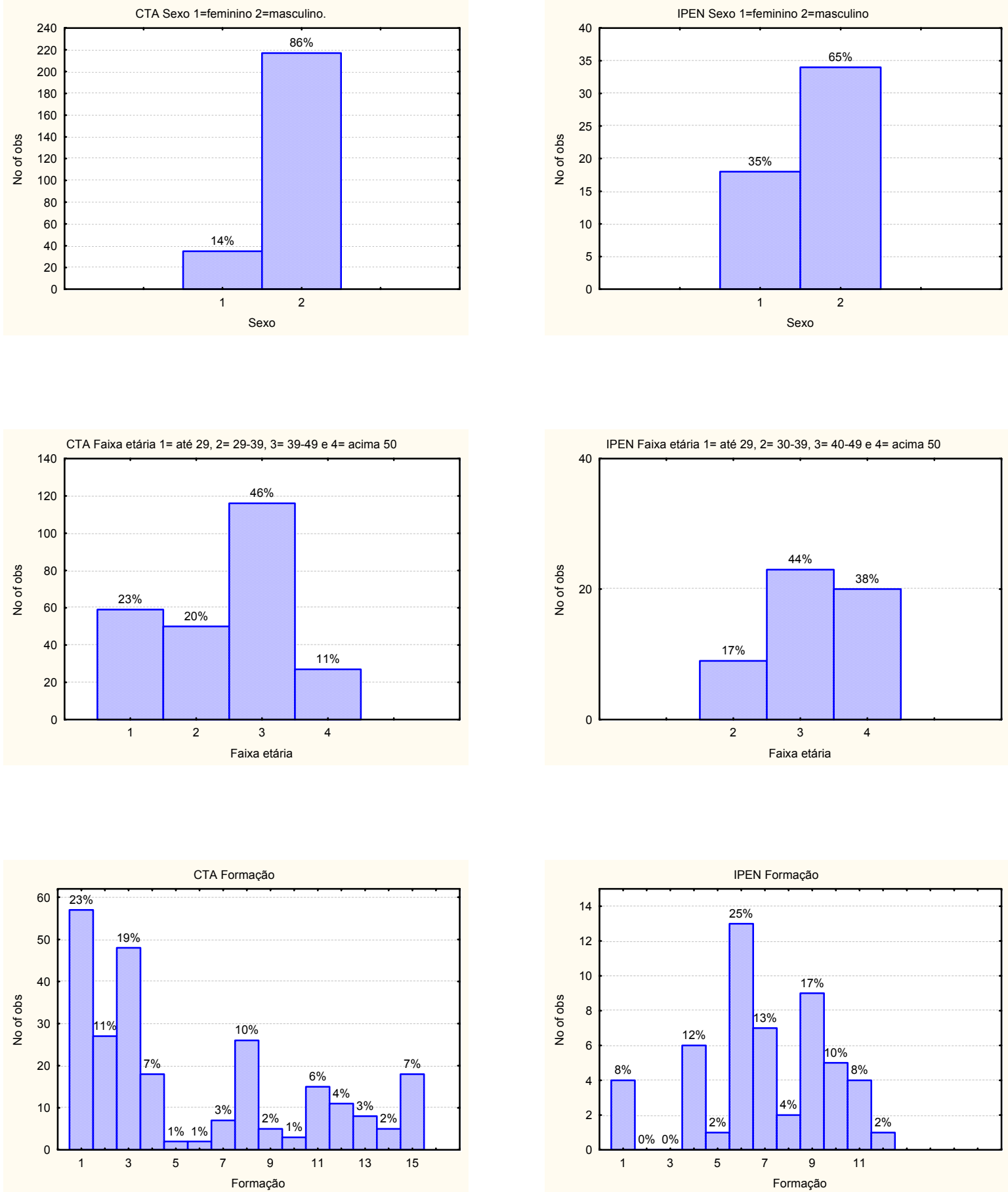

Figura 4.1. Gráficos que apresentam as variáveis demográficas do CTA (lado esquerdo) e do IPEN (lado direito). 

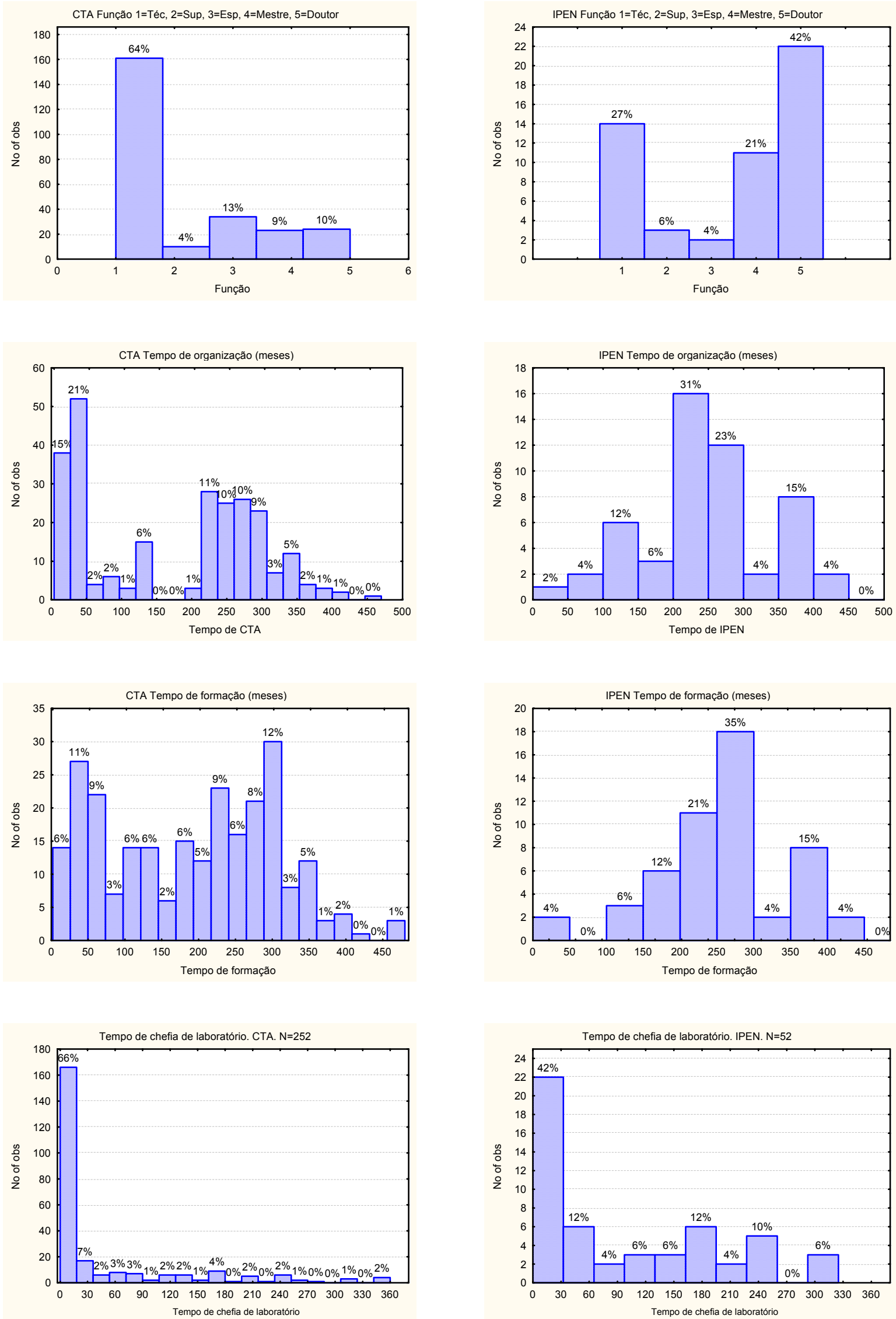

Figura 4.1. Continuação dos Gráficos que apresentam as variáveis demográficas do CTA (lado esquerdo) e do IPEN (lado direito). 
Na variável "formação" predomina no CTA os técnicos mecânicos com $23 \%$ seguidos pelos técnicos elétricos com 19\% perfazendo um total de técnicos de $60 \%$ da população lembrando que no IPEN todos os técnicos representam apenas $27 \%$ da população. No IPEN a maioria dos formados é de físicos e tem $25 \%$ do censo seguidos pelos engenheiros metalúrgicos com $17 \%$.

A variável "função" do CTA é concentrada nos técnicos com $64 \%$ e os pós-graduados representam somente $32 \%$ do total dos respondentes, dentro do qual a maioria é de servidores com grau superior e com apenas curso de especialização com $13 \%$ do total (os outros $10 \%$ são doutores e $9 \%$ mestres). Até que o percentual de pós-graduados no CTA tem melhorado com os concursos onde têm ingressado no caso de nível superior, pessoas que quase na maioria já possui doutorado. No caso do IPEN, a situação levantada e que é reflexo geral do restante do Instituto apresenta uma alta titulação, representando $67 \%$ do total os servidores com pós-graduação (42\% doutores, $21 \%$ mestres e $4 \%$ com especialização).

$\mathrm{Na}$ variável "tempo na organização" existem duas situações muito diferentes. No CTA as duas maiores concentrações de populações somam $36 \%$ para respondentes com até 50 meses na organização e com um mínimo de 4 meses. No IPEN as duas faixas maiores são, de 31\% para servidores de 200 a 250 meses e de $23 \%$ para os de 250 a 300 meses na organização.

Na variável "tempo de formação" encontra-se no CTA uma miscelânea de valores muito próximos sendo que as duas principais populações atingem 19\% com tempo entre 260 a 300 meses de formado. No IPEN destacam-se as duas maiores populações com $56 \%$ do total e tempo entre 200 a 300 meses dos quais $35 \%$ correspondem apenas ao tempo entre 250 a 300 meses.

Sobre a variável "tempo na chefia do laboratório", ambas as instituições apresentam gráficos semelhantes com pouco tempo na sua maioria, existindo um predomínio de $42 \%$ com servidores até 14 meses no CTA e de $42 \%$ também com até 32 meses no IPEN.

\subsection{Comparando as respostas entre o CTA e o IPEN}

De modo geral as respostas do IPEN foram muito mais coesas, tal vez por tratar-se de um público mais homogêneo. Analisando os histogramas das respostas entre as duas pesquisas realizadas, no CTA e no IPEN, chama a 
atenção à extraordinária semelhança entre todas as respostas, nas suas partes dois e três do questionário, com exceção de apenas duas variáveis: a questão 5 do comprometimento organizacional normativo - CRN5 - e a questão 3 do comprometimento ocupacional afetivo - CCA3. A questão CRN5 é "eu não deixaria minha organização agora porque eu tenho uma obrigação moral com as pessoas daqui" e a questão do comprometimento ocupacional afetivo - CCA3 é "eu sinto orgulho de ter ingressado na minha profissão". Os histogramas das questões são apresentados nas Figuras 4.2 e 4.3.
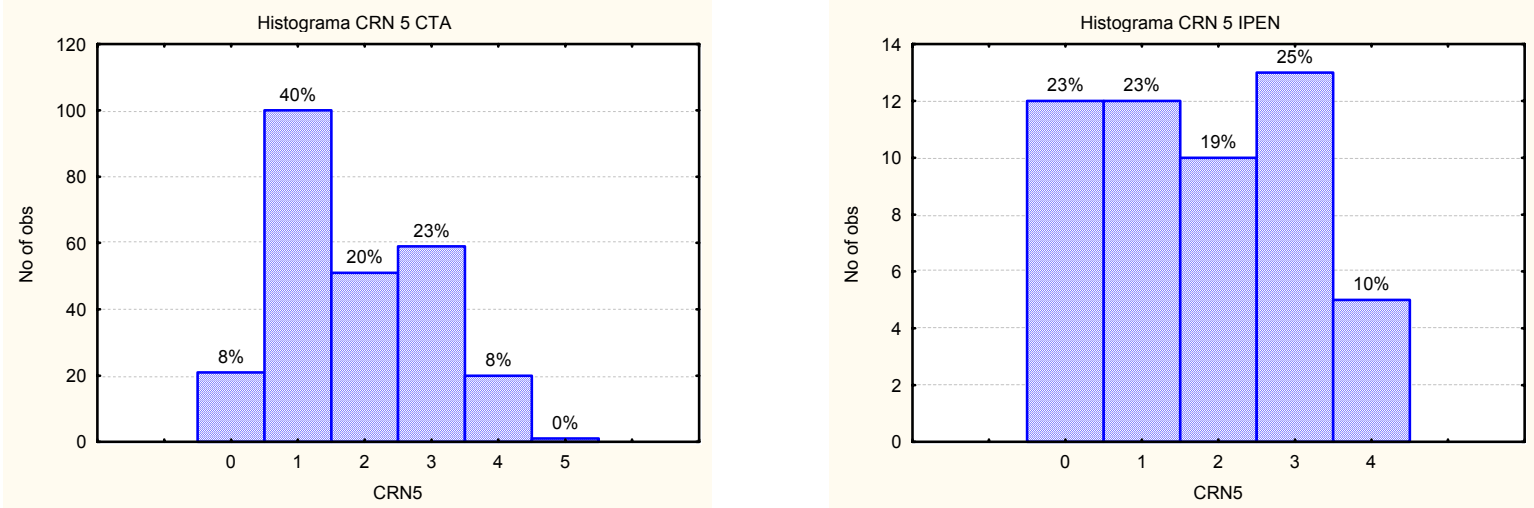

Figura 4.2. Gráficos mostrando o comprometimento organizacional normativo CRN5, no CTA (lado esquerdo) e no IPEN (lado direito).
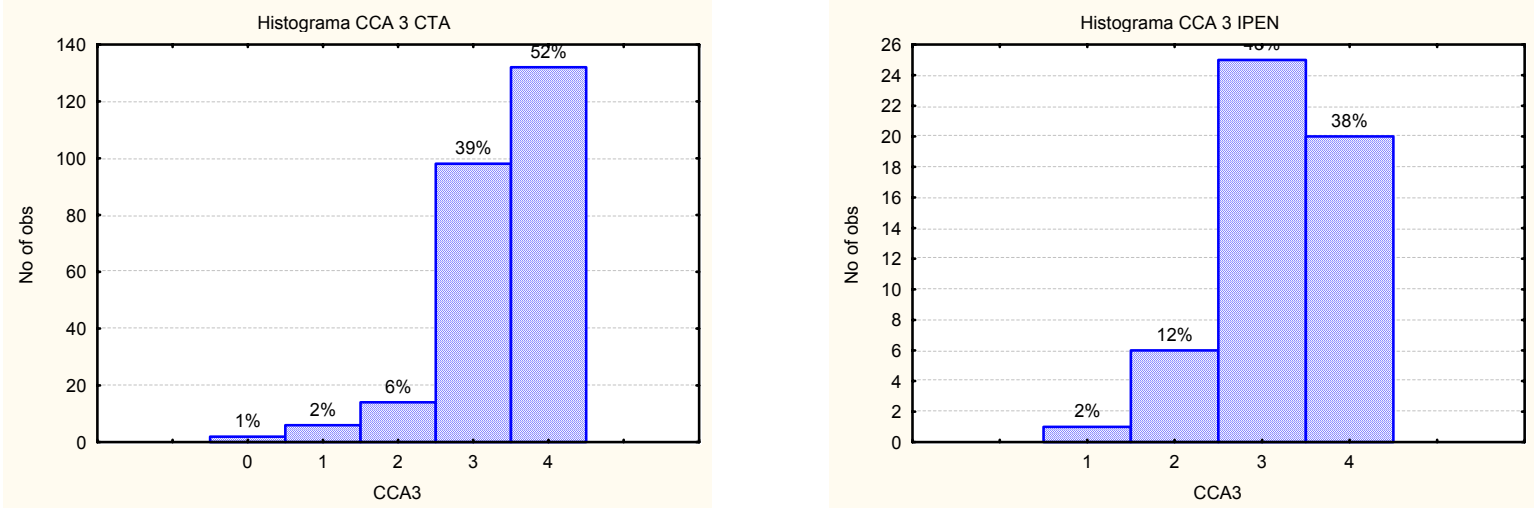

Figura 4.3. Gráficos mostrando o comprometimento ocupacional afetivo - CCA3, no CTA (lado esquerdo) e no IPEN (lado direito).

A diferença entre as respostas da questão CRN5, por tratar-se de uma questão negativa, significa que quem responde discordo interpreta-se como o 
inverso, ou seja, está respondendo a "eu deixaria a organização porque não tenho obrigação moral com as pessoas daqui". A diferença entre as respostas de ambos os institutos está nas duas avaliações inferiores porque as três maiores apresentaram pequena diferença ( $1 \%$ a $2 \%$ ). Considerando as respostas discordo totalmente e discordo, as somas de ambas são parecidas (48\% e 46\%), sendo que a diferença está numa maior concentração do discordo no caso do CTA, o qual significaria que a maioria $(40 \%)$ das pessoas do CTA tem uma posição mais suave no sentimento de deixar a organização por não sentir nenhuma obrigação de ficar.

A diferença entre as questões CCA3 entre ambos os centros de pesquisas está na ordem da maioria, o que é a maioria para um é o segundo lugar para o outro. A maioria acontece entre o concordo - $\mathrm{C}$ para o IPEN e o concordo totalmente - CT para o CTA, sendo que também chama atenção que a proporção da primeira para a segunda maioria em ambos os histogramas mantém quase a mesma proporção. $O$ que é diferente é que no IPEN ninguém teve uma posição radical de discordar totalmente em não sentir orgulho na escolha da profissão. Talvez o fato que $64 \%$ dos respondentes no CTA ocuparem a função de técnico de nível médio tenha influenciado numa média final maior nesta questão ao vislumbrar estes servidores a chance de poder estudar e atingir posições maiores no futuro.

\subsection{Comprometimento organizacional e ocupacional (segundo Ricco)}

Seguindo o critério usado por Ricco (1998), foi realizada uma nova tabela para cada centro de pesquisa a partir do banco de dados original, onde se extraíram 2 pontos a cada uma das respostas. Com esta nova tabela se obteve individualmente, para cada questão uma variação total entre “+2" a "-2", sendo o "0" o divisor dos locais que apresentam comprometimento, resultando valores positivos para os indivíduos comprometidos e negativos para aqueles não comprometidos.

Posteriormente foi realizada a soma para cada divisão respondente e pela média das somas de cada uma, obteve-se assim o índice registrado na Tabela 4.1 para cada um dos seis tipos de comprometimentos em cada uma das Divisões do IAE. Os valores da Tabela 4.1 resultaram no final, entre "-12" a "+12" para a soma das seis questões de cada tipo de comprometimento. 
No estudo todo se trabalhou apenas com duas casas decimais e usouse o critério do valor acima de cinco para o arredondamento superior e abaixo de quatro para o arredondamento inferior. Em todas as tabelas a seguir visando facilitar sua visualização foram pintados na cor vermelha os números negativos quando aplicável. O valor máximo superior de cada coluna foi pintado numa faixa da cor amarela e o valor mínimo inferior de cada coluna foi pintado numa faixa da cor azul. Os valores mínimos quando são negativos apresentam os números na cor vermelha e uma faixa azul por cima destes.

$\mathrm{Na}$ Tabela 4.1 do CTA, destacam-se os maiores índices de comprometimento nas colunas do comprometimento afetivo, tanto no tipo do comprometimento organizacional - CRA - como no do tipo ocupacional - CCA. O comprometimento organizacional afetivo - CRA, apresenta uma média final de " 5,13 ", e o comprometimento ocupacional afetivo - CCA, com um índice final de "7,80", sendo este último valor o maior de todos os seis comprometimentos e acompanhado sempre em cada Divisão do IAE em segundo lugar, pelo tipo organizacional afetivo - CRA. Apenas a exceção é da Divisão de Defesa - ASD, onde o segundo lugar é ocupado pelo comprometimento ocupacional instrumental - CCl. Lembra-se que ao destacar altos índices do comprometimento ocupacional afetivo - CCA - significa maiores índices de desempenho. Nota-se claramente que em cada divisão os índices são sempre maiores para o comprometimento ocupacional que para o organizacional, indicando completamente um maior comprometimento com a ocupação, com a carreira do que com a organização.

Vendo os valores negativos dos vários tipos de comprometimento, nota-se a tendência do maior não-comprometimento no comprometimento ocupacional do tipo normativo - CCN. O anterior indica que em mais de $54 \%$ das Divisões do IAE o tipo CCN acusa nos servidores na sua ocupação a tendência do não-comprometimento talvez pelas obrigações que a organização impõe, recordando tratar-se de uma organização de cunho militar. Ao considerar somente as médias, o comprometimento organizacional instrumental - CRI, que apresenta três valores negativos, indica o tipo de maior não-comprometimento dos três. 0 comprometimento organizacional instrumental - CRI apresenta todos seus valores muito próximos do limiar, com uma média de apenas “+0,09” e um desvio-padrão de "0,28". 
Tabela 4.1. Comprometimento nas Divisões do CTA segundo Ricco.

\begin{tabular}{cccccccccc}
\hline Labs & CRA & CRI & CRN & CR & CCA & CCI & CCN & CC & Comp \\
\hline ACA & $\mathbf{8 , 2 5}$ & $\mathbf{0 , 6 7}$ & $\mathbf{5 , 5}$ & $\mathbf{4 , 8 1}$ & $\mathbf{1 0 , 5}$ & $\mathbf{5}$ & $\mathbf{4 , 2 5}$ & $\mathbf{6 , 5 8}$ & $\mathbf{5 , 6 9}$ \\
\hline ASE & 6,63 & $-0,03$ & 3,5 & 3,37 & 9,25 & 4,06 & 2,63 & 5,31 & 4,34 \\
\hline AMR & 5 & 0,34 & 2,24 & 2,53 & 7,8 & 3,93 & 0,41 & 4,05 & 3,29 \\
\hline AVE-Q & 6,07 & 0,17 & 1 & 2,41 & 8,29 & $\mathbf{1 , 5 7}$ & 0,07 & 3,31 & 2,86 \\
\hline AIE & 4,86 & 0,01 & 1,45 & 2,11 & 7,4 & 2,69 & 0,62 & 3,57 & 2,84 \\
\hline AQI & 4,18 & 0,21 & 0,59 & 1,66 & 6,62 & 3,79 & $-0,29$ & 3,37 & 2,51 \\
\hline ASA & 4,35 & $-0,07$ & 0,68 & 1,65 & 7,46 & 1,68 & $-0,11$ & 3,01 & 2,33 \\
\hline AEL & 4,59 & 0,1 & 0,59 & 1,76 & 7,34 & 2,34 & $-\mathbf{2}$ & 2,56 & 2,16 \\
\hline AME & 5 & 0,03 & $-\mathbf{1 , 2}$ & 1,28 & $\mathbf{6 , 6}$ & 4,2 & $-\mathbf{2}$ & 2,93 & 2,11 \\
\hline ASD & $\mathbf{2 , 8}$ & 0,03 & $-1,1$ & $\mathbf{0 , 5 8}$ & 6,75 & 3,95 & $-0,05$ & 3,55 & 2,06 \\
\hline AEV & 4,7 & $-0,47$ & $-1,2$ & 1,01 & 7,8 & 1,6 & $-1,8$ & $\mathbf{2 , 5 3}$ & $\mathbf{1 , 7 7}$ \\
\hline Média & 5,13 & 0,09 & 1,1 & 2,11 & 7,8 & 3,17 & 0,16 & 3,71 & 2,91 \\
\hline Desvio & 1,43 & 0,28 & 2,07 & 1,26 & 1,19 & 1,22 & 1,91 & 1,44 & 1,35 \\
\hline
\end{tabular}

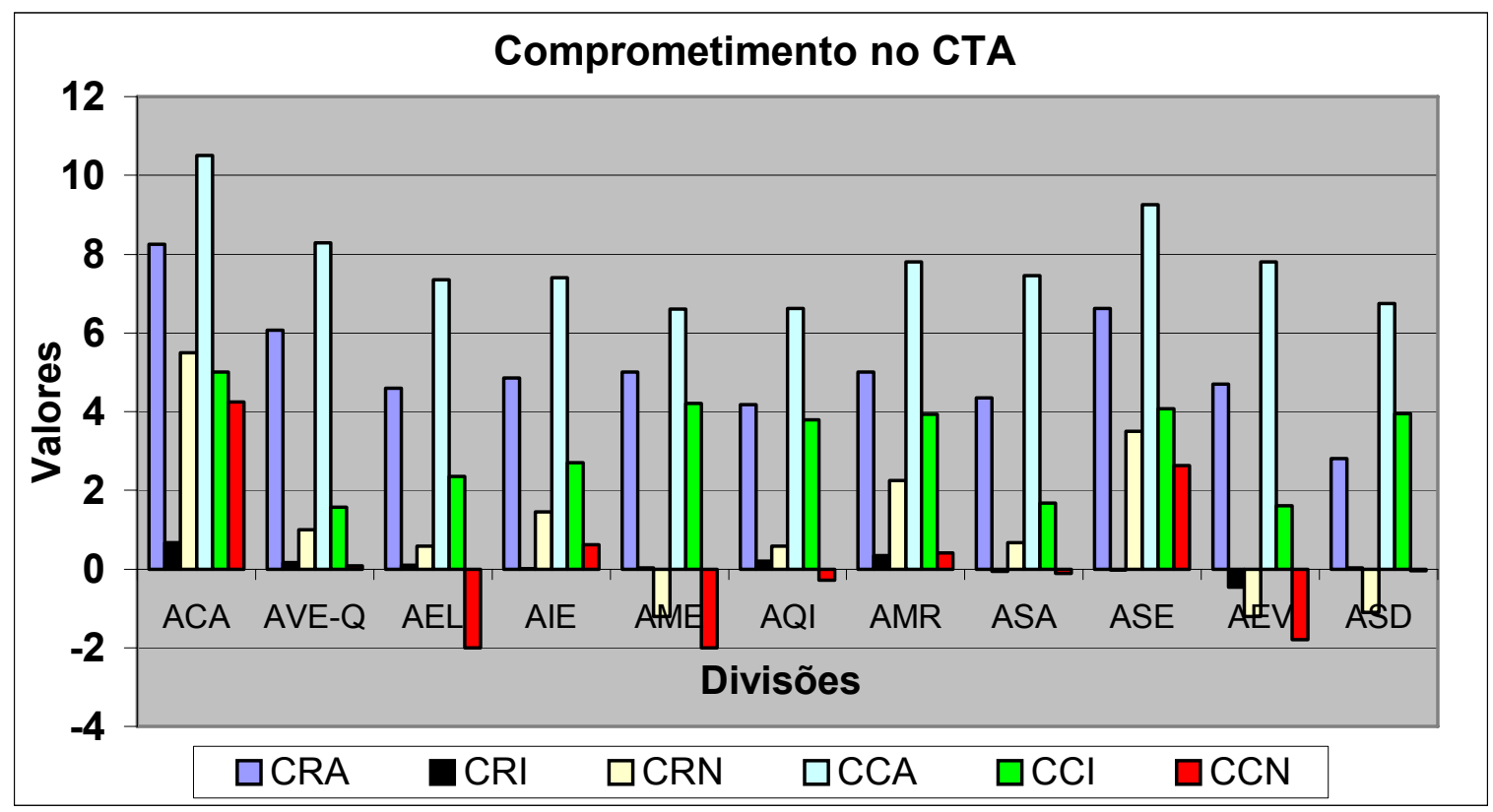

Figura 4.4. Gráfico mostrando o comprometimento nas Divisões do CTA segundo Ricco.

A Divisão de Ciências Atmosféricas - ACA destaca-se pelos seus altos índices de comprometimento, apresentando os valores mais altos em todos os 
seis tipos de comprometimento, sendo que em alguns deles apresenta um destaque especial, como é o caso já citado anteriormente do comprometimento ocupacional normativo - CCN com valor de " $+4,25$ " e sendo a média de apenas "+0,16". Também se destacam nesta divisão o comprometimento organizacional normativo - CRN com valor “+5,50" onde a média é de “+1,1", e também o comprometimento organizacional instrumental - CRI, com valor "+0,67" e com média "+0,09".

Cabe alertar ao leitor sobre as diferenças das populações entre o CTA e o IPEN e da quantidade de pessoas em cada local ou grupo envolvido neste estudo para fins de saber o número real de respondentes. No item 3.1 foram detalhados os números do censo dos servidores convidados a responder. No caso do CTA a quantidade de observações é mais robusta, embora existam 2 locais com números inferiores a 10 pessoas. A seguir temos cada divisão do IAE com o número de convidados e entre parêntesis o número real de respondentes: Ciências Atmosféricas - ACA: 4 (4); Coordenadoria da Qualidade Espacial - AVEQ: 4 (14); Eletrônica - AEL: 36 (29); Integração e Ensaios - AIE: 47 (42); Mecânica - AME: 6 (5); Química - AQI: 41 (34); Sistemas Espaciais - ASE: 19 (16); Ensaios em Vôo - AEV: 14 (10); Materiais - AMR: 45 (41); Sistemas de Defesa - ASD: 27 (20) e Sistemas Aeronáuticos - ASA: 44 (37). No caso do IPEN, a seguir os laboratórios e o número de convidados tendo entre parêntesis o número de respondentes: Processamento Cerâmico de Resíduos - PCR: 4 (2); Insumos e Componentes - SOFC: 7 (3); Eletro-Cerâmicas - EC: 5 (4); Cerâmicas Estruturais e Biomateriais - CEB: 7 (5); Comportamento Mecânico - CM: 4 (4); Processamento de Materiais - PM: 10 (9); Corrosão e Tratamento de Superfícies CTS: 8 (7); Difração de Raios X - DRX: 2 (1); Materiais Magnéticos - MaM: 7 (6); Metalurgia do Pó e Intermetálicos - MPI: 8 (6); Microscopia e Microanálise - MiM: 7 (4) e Vidros e Compôsitos Cerâmicos - VCC: 2 (1).

Nota-se que todos os laboratórios do IPEN tiveram menos de 10 respondentes cada um, o qual torna a quantidade de observações muito frágil para conclusões estatísticas, assim este instituto apenas indicará indícios dos seus resultados não podendo levar a conclusões. Seus resultados não serão muito detalhados. Sempre é importante verificar se a quantidade de respondentes é representativa em termos estatísticos. 
Tabela 4.2. Comprometimento nos Laboratórios do IPEN segundo Ricco.

\begin{tabular}{cccccccccc}
\hline Labs & CRA & CRI & CRN & CR & CCA & CCI & CCN & CC & Comp \\
\hline MiM & 3,25 & 1,75 & $\mathbf{5 , 7 5}$ & 3,58 & $\mathbf{1 0 , 2 5}$ & 3,25 & $\mathbf{6 , 2 5}$ & $\mathbf{6 , 5 8}$ & $\mathbf{5 , 0 8}$ \\
\hline SOFC & 6 & 1,67 & 4 & 3,89 & 7,67 & $\mathbf{7}$ & 0,67 & 5,11 & 4,5 \\
\hline PCR & $\mathbf{7}$ & 0,5 & 5 & $\mathbf{4 , 1 7}$ & 7 & $\mathbf{0}$ & 3 & 3,33 & 3,75 \\
\hline MPI & 4 & 1,17 & 0,67 & 1,95 & 5,33 & 4,83 & 0,33 & 3,5 & 2,72 \\
\hline CEB & 5,6 & $-0,2$ & 1,4 & 2,27 & 6 & 2,6 & 0 & 2,87 & 2,57 \\
\hline CM & 5,5 & 2 & 0,75 & 2,75 & 5,5 & 0,5 & $-1,25$ & 1,58 & 2,17 \\
\hline PM & 2,11 & 3,11 & $-2,67$ & 0,85 & 6,44 & 3,44 & 0,33 & 3,4 & 2,13 \\
\hline CTS & 4,86 & $-2,71$ & $-0,29$ & 0,62 & 7,29 & 2,43 & -2 & 2,57 & 1,6 \\
\hline MaM & $\mathbf{0}$ & $\mathbf{3 , 3 3}$ & $-2,5$ & $\mathbf{0 , 2 8}$ & $\mathbf{4}$ & 4 & $-2,5$ & 1,83 & 1,06 \\
\hline EC & 6,25 & -4 & -1 & 0,42 & 6,25 & 0,75 & $-5,5$ & $\mathbf{0 , 5}$ & $\mathbf{0 , 4 6}$ \\
\hline DRX & 4 & 10 & 7 & 7 & 7 & 7 & 7 & 7 & 7 \\
\hline VCC & -7 & 9 & -12 & $-3,33$ & 2 & 8 & -8 & 0,67 & $-1,33$ \\
\hline Médias & 3,46 & 2,14 & 0,51 & 2,04 & 6,23 & 3,355 & $-0,14$ & 3,25 & 2,65 \\
\hline Desvio & 3,83 & 4,07 & 5,06 & 2,59 & 2,02 & 2,65 & 4,3 & 2,01 & 2,3 \\
\hline
\end{tabular}

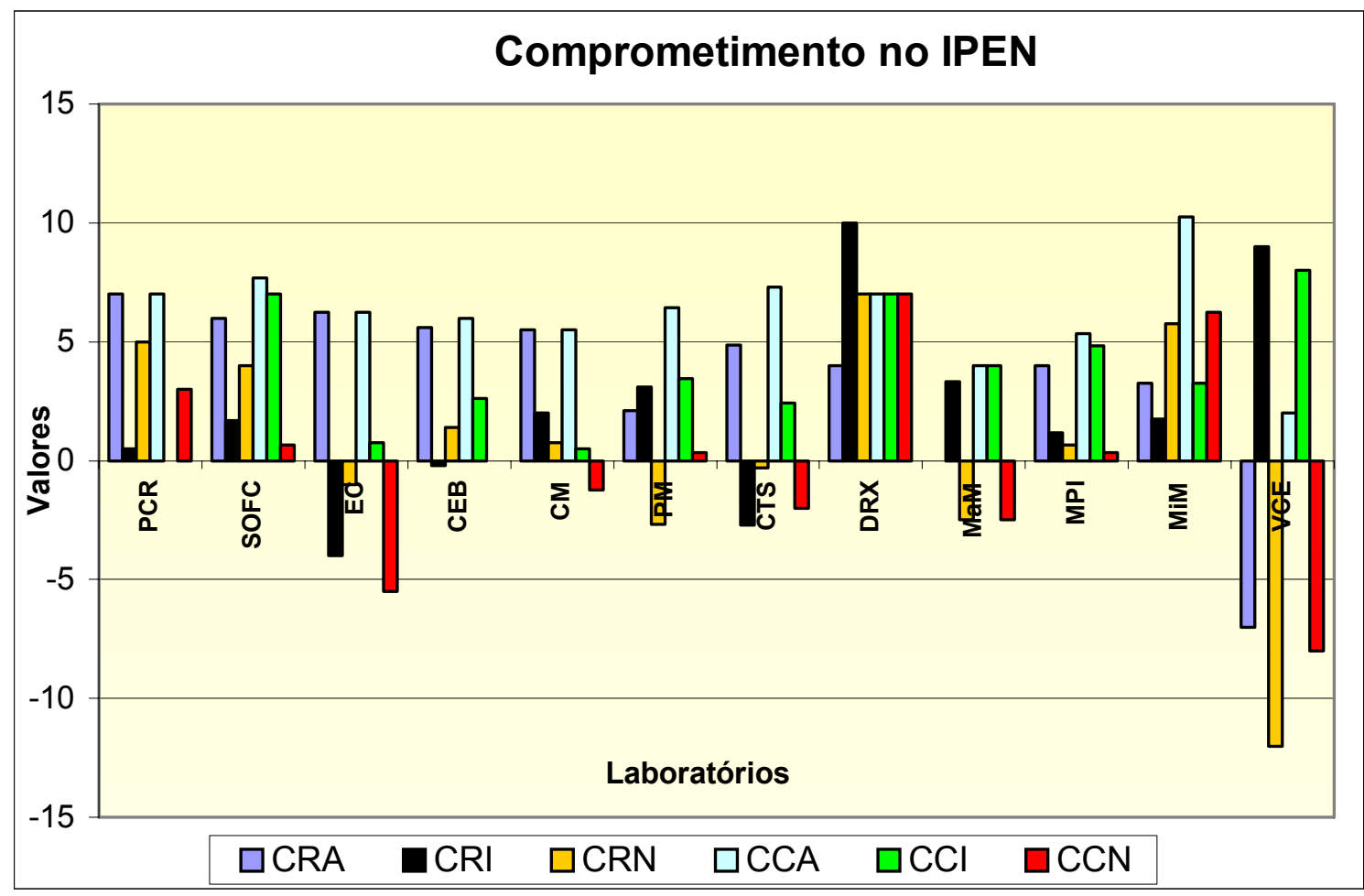

Figura 4.5. Comprometimento nos Laboratórios do IPEN segundo Ricco. 
Neste censo têm-se dois Laboratórios do IPEN que possuem apenas dois servidores e sendo que apenas um deles respondeu à pesquisa, resultando em valores muito dispersos dos restantes e o qual tornou muito frágeis suas respostas. Assim, de partida optou-se por desconsiderar neste estudo estes dois laboratórios: o de Difração de Raios X - DRX e o de Vidros e Compósitos Cerâmicos - VCC do IPEN. O leitor observa na Tabela 4.2 a média final destes laboratórios, "7" para o DRX e "-1,33" para o VCC com média de "2,65" e desviopadrão de "2,3".

Olhando os resultados de comprometimento e não-comprometimento nota-se aqui, como também aconteceu anteriormente no caso do CTA (veja Tabela 4.1), que todos os locais estão comprometidos, uns mais outros menos, porém os resultados finais foram sempre positivos.

Comparando as Tabelas 4.1 e 4.2 encontram-se no caso do CTA valores superiores de comprometimento em relação ao IPEN, onde os valores máximos foram " 5,69 " para o CTA e " 5,08 " para o IPEN. Os valores mínimos que indicam o não-comprometimento foram favoráveis ao IPEN com valor de "0,46" versus os " 1,77 " do CTA, e finalmente as médias indicando um maior comprometimento foram de "2,91" para o CTA e "2,65" para o IPEN.

\subsection{Comprometimento organizacional e ocupacional}

A continuação, deste ponto em diante serão utilizadas tabelas com dados normalizados, ou seja, onde a média é igual a zero e o desvio-padrão é igual a um. Destaca-se que nas próximas análises não será mais utilizado o critério de Ricco (1998) como aconteceu no item anterior.

A Tabela 4.3 do CTA apresenta os resultados do comprometimento no CTA usando dados normalizados, encontrando nesta o predomínio absoluto da Divisão ACA nos seis tipos de comprometimento e conseqüentemente nos resumos dos comprometimentos organizacional - CR, ocupacional - CC e geral Comp. (organizacional e ocupacional juntos). Assim pede-se ao leitor memorizar esta informação para mais tarde ser confrontada se também estes locais obterão estas colocações nos resultados dos fatores de desempenho. Aqui a Divisão de Ciências Atmosféricas - ACA ocupou o primeiro lugar e o segundo (porém distante) foi da Divisão de Sistemas Espaciais - ASE. 
Tabela 4.3. Comprometimento nos Laboratórios do CTA.

\begin{tabular}{cccccccccc}
\hline Labs & CRA & CRI & CRN & CR & CCA & CCI & CCN & CC & Comp \\
\hline ACA & $\mathbf{3 , 5 9 6}$ & $\mathbf{3 , 1 4 6}$ & $\mathbf{4 , 1 1 1}$ & $\mathbf{3 , 6 1 8}$ & $\mathbf{3 , 6}$ & $\mathbf{1 , 9 5 6}$ & $\mathbf{3 , 9 7 5}$ & $\mathbf{3 , 1 7 7}$ & $\mathbf{3 , 3 9 7}$ \\
\hline ASE & 1,936 & $-0,677$ & 2,207 & 1,155 & 2,138 & 1,059 & 2,525 & 1,907 & 1,531 \\
\hline AMR & 0,288 & 1,362 & 1,114 & 0,921 & 0,347 & 0,888 & 0,384 & 0,54 & 0,731 \\
\hline AVE-Q & 1,318 & 0,409 & $-0,021$ & 0,569 & 0,949 & $-1,418$ & 0,085 & $-0,128$ & 0,220 \\
\hline AIE & 0,155 & $-0,43$ & 0,330 & 0,018 & $-0,143$ & $-0,304$ & 0,583 & 0,045 & 0,032 \\
\hline AQI & $-0,622$ & 0,612 & $-0,412$ & $-0,140$ & $-1,188$ & 0,728 & $-0,328$ & $-0,263$ & $-0,202$ \\
\hline ASA & $-0,370$ & $-0,834$ & $-0,351$ & $-0,518$ & $-0,097$ & $-1,253$ & $-0,08$ & $-0,476$ & $-0,497$ \\
\hline AEL & $-0,198$ & 0,086 & $-0,484$ & $-0,199$ & $-0,178$ & $-0,597$ & $-1,876$ & $-0,884$ & $-0,541$ \\
\hline AME & 0,054 & $-0,272$ & $-2,128$ & $-0,782$ & $-0,971$ & 1,163 & $-1,916$ & $-0,575$ & $-0,678$ \\
\hline ASD & $-2,053$ & $-0,332$ & $-1,936$ & $-1,440$ & 0,963 & 0,933 & $-0,117$ & $-0,049$ & $-0,745$ \\
\hline AEV & $-0,076$ & $-2,969$ & $-2,064$ & $-1,703$ & 0,31 & $-1,409$ & $-1,733$ & $-0,944$ & $-1,324$ \\
\hline Média & 0,366 & 0,009 & 0,033 & 0,136 & 0,521 & 0,159 & 0,137 & 0,214 & 0,175 \\
\hline Desvio & 1,478 & 1,505 & 1,902 & 1,46 & 1,379 & 1,193 & 1,811 & 1,259 & 1,322 \\
\hline
\end{tabular}

Tabela 4.4. Comprometimento nos Laboratórios do IPEN.

\begin{tabular}{cccccccccc}
\hline Labs & CRA & CRI & CRN & CR & CCA & CCI & CCN & CC & Comp \\
\hline MiM & $-0,16$ & 0,593 & $\mathbf{4 , 8 7 1}$ & 1,767 & $\mathbf{4 , 1 1}$ & 0,186 & $\mathbf{5 , 6 3 3}$ & $\mathbf{3 , 3 1}$ & $\mathbf{2 , 5 3 9}$ \\
\hline SOFC & $\mathbf{1 , 7 7 4}$ & 0,515 & 3,319 & 1,869 & 1,41 & $\mathbf{3 , 1 9 8}$ & 0,983 & 1,863 & 1,866 \\
\hline PCR & $\mathbf{2 , 9 1 8}$ & $-0,32$ & 4,293 & $\mathbf{2 , 2 9 6}$ & 0,72 & $-2,7$ & 2,961 & 0,325 & 1,31 \\
\hline MPI & 0,241 & 0,073 & 0,492 & 0,269 & $-0,8$ & 1,334 & 0,584 & 0,369 & 0,319 \\
\hline CEB & 1,497 & $-1,14$ & 1,07 & 0,475 & $-0,4$ & $-0,54$ & 0,26 & $-0,241$ & 0,117 \\
\hline CM & 1,376 & 0,838 & 0,615 & 0,943 & -1 & $-2,48$ & $-0,7$ & $-1,386$ & $-0,22$ \\
\hline PM & $-1,34$ & 1,477 & $-2,548$ & $-0,8$ & 0 & 0,195 & 0,616 & 0,261 & $-0,27$ \\
\hline CTS & 0,926 & $-3,11$ & $-0,495$ & $-0,89$ & 1,1 & $-0,68$ & $-1,41$ & $-0,332$ & $-0,61$ \\
\hline MaM & $-3,14$ & $\mathbf{1 , 6 4 9}$ & $-2,409$ & $-1,3$ & $-2,3$ & 0,654 & $-1,91$ & $-1,195$ & $-1,25$ \\
\hline EC & 1,995 & $-4,11$ & $-0,74$ & $-0,95$ & $-0,2$ & -2 & $-4,35$ & $-2,198$ & $-1,57$ \\
\hline DRX & 0,297 & 7,326 & 6,11 & 4,578 & 1,29 & 3,177 & 6,248 & 3,571 & 4,074 \\
\hline VCC & $-8,79$ & 6,352 & $-11,09$ & $-4,51$ & $-4,9$ & 3,639 & $-6,43$ & $-2,575$ & $-3,54$ \\
\hline Médias & $-0,201$ & 0,845 & 0,291 & 0,312 & $-0,081$ & 0,332 & 0,207 & 0,148 & 0,230 \\
\hline Desvio & 3,151 & 3,298 & 4,546 & 2,281 & 2,202 & 2,189 & 3,658 & 1,959 & 2,017 \\
\hline
\end{tabular}

Sobre os valores mínimos da Tabela 4.3 que indicam os locais nãocomprometidos, não existe uma heterogeneidade, encontrando o destaque da Divisão de Ensaios em Vôo - AEV num domínio e nos resumos dos comprometimentos CR, CC e Comp. a Divisão de Mecânica - AME destaca-se 
negativamente nos dois domínios do comprometimento normativo, e a Divisão de Defesa - ASD no domínio CRA. A Divisão de Ensaios em Vôo - AEV ficou com o último lugar e a Divisão de Defesa - ASD com o penúltimo lugar. Lembra-se ao leitor que os primeiros e os últimos lugares da Tabela 4.3 coincidem com os resultados da Tabela 4.1 que utilizou o critério de Ricco.

A Tabela 4.4 do IPEN, não apresentou uma predominância como aconteceu na Tabela 4.3 do CTA. Nesta Tabela 4.4, diferente da sua similar anterior para o caso do CTA, houve dois Laboratórios que se destacaram simultaneamente com valores máximos e mínimos (Processamento Cerâmico de Resíduos - PCR e Materiais Magnéticos - MaM) denotando respostas muito diversas no seu grau de comprometimento e não-comprometimento, seus participantes são comprometidos em relação a um tipo de comprometimento e não-comprometidos em relação a outro tipo.

Comparando as Tabelas 4.3 e 4.4 não houve um predomínio nos laboratórios de um dos dois centros de pesquisa como único local mais comprometido, sendo o valor máximo do CTA de "3,4" versus os "2,54" do IPEN. Os valores mínimos de não-comprometimento atingiram valores maiores no IPEN com "-1,57" versus os "-1,32" do CTA. A média geral foi maior para o IPEN com "0,23" indicando um maior comprometimento contra " 0,18 " no caso do CTA.

A continuação, as Tabelas 4.5 do CTA e 4.6 do IPEN apresentam um estudo por grupos de servidores diferente dos locais de trabalho como foi mencionado anteriormente. Escolheram-se 7 grupos representativos do censo, relacionados a seguir: como o tempo de 20 anos é um divisor no tempo na organização dos servidores, decidiu-se dividir num grupo com mais e outro com menos de 240 meses de tempo de organização; dividir dois grupos por sexo, feminino e masculino, e mais três grupos que representam as formações mais representativas do censo: engenheiros, físicos e técnicos.

De forma semelhante como foi citado para os locais (divisões no CTA e laboratórios no IPEN) veja-se a quantidade de respondentes para cada grupo em cada estudo. A seguir no caso do IPEN, com uma população de 52 respondentes, cada grupo teve os seguintes números de respondentes registrados entre parêntesis: acima ou igual há 240 meses: (29); abaixo de 240 meses: (23); técnicos: (12); físicos: (13); engenheiros: (21); mulheres: (18); e homens: (34). 
Para o caso do CTA com um total de 252 respondentes os números de cada grupo são indicados entre parêntesis: acima ou igual a 240 meses: (99); abaixo de 240 meses: (152); técnicos: (150); físicos: (2); engenheiros: (67); mulheres: (35); e homens: (217).

$\mathrm{Na}$ quantidade de respondentes de cada grupo chama à atenção a pequena quantidade de físicos no caso do CTA, totalmente inexpressiva como tamanho amostral.

Tabela 4.5. Comprometimento nos grupos do CTA.

\begin{tabular}{lccccccccc}
\hline Grupos & CRA & CRI & CRN & CR & CCA & CCI & CCN & CC & Comp \\
\hline $\mathbf{2 4 0}$ mêses & $\mathbf{0 , 8 4 0}$ & $\mathbf{1 , 1 3 1}$ & 0,522 & $\mathbf{0 , 8 3 1}$ & 0,088 & $\mathbf{0 , 6 5 7}$ & $\mathbf{0 , 5 7 7}$ & $\mathbf{0 , 4 4 1}$ & $\mathbf{0 , 6 3 6}$ \\
\hline Homens & 0,176 & 0,041 & 0,236 & 0,151 & 0,087 & $-0,002$ & 0,249 & 0,111 & 0,131 \\
\hline Técnicos & $-0,068$ & 0,698 & 0,186 & 0,272 & $-0,546$ & $-0,062$ & 0,207 & $-0,134$ & 0,069 \\
\hline Eng. & $-0,140$ & $-1,026$ & $-0,769$ & $-0,645$ & 0,416 & 0,274 & $-0,547$ & 0,048 & $-0,298$ \\
\hline <240 mêses & $-0,544$ & $-0,732$ & $-0,338$ & $-0,538$ & $-0,057$ & $-0,425$ & $-0,373$ & $-0,285$ & $-0,411$ \\
\hline Mulheres & $-1,091$ & $-0,255$ & $-1,461$ & $-0,936$ & $-0,540$ & 0,014 & $-1,545$ & $-0,690$ & $-0,813$ \\
\hline Físicos & 0,318 & $-3,61$ & $\mathbf{2 , 2 1 1}$ & $-0,359$ & $\mathbf{2 , 0 7 8}$ & $-7,180$ & $-3,338$ & $-2,814$ & $-1,586$ \\
\hline Média & $-0,073$ & $-0,536$ & 0,084 & $-0,175$ & 0,218 & $-0,961$ & $-0,682$ & $-0,475$ & $-0,325$ \\
\hline Desvio & 0,621 & 1,550 & 1,158 & 0,617 & 0,891 & 2,763 & 1,364 & 1,090 & 0,722 \\
\hline
\end{tabular}

Tabela 4.6. Comprometimento nos grupos do IPEN.

\begin{tabular}{cccccccccc}
\hline Grupos & CRA & CRI & CRN & CR & CCA & CCI & CCN & CC & Comp \\
\hline Técnicos & 0,40 & $\mathbf{2 , 8 3 3}$ & $\mathbf{2 , 2 4 2}$ & $\mathbf{1 , 8 2 5}$ & $-0,202$ & $-1,052$ & $\mathbf{2 , 5 9 1}$ & 0,446 & $\mathbf{1 , 1 3 5}$ \\
\hline $\mathbf{2 4 0}$ mêses & $\mathbf{1 , 8 8 6}$ & 0,157 & 1,528 & 1,190 & 1,024 & 0,586 & 1,072 & $\mathbf{0 , 8 9 4}$ & 1,042 \\
\hline Físicos & 0,953 & $-0,677$ & $-0,261$ & 0,005 & $\mathbf{1 , 6 0 9}$ & $\mathbf{1 , 0 0 8}$ & $-0,177$ & 0,814 & 0,409 \\
\hline Mulheres & $-0,392$ & $-0,663$ & 0,539 & $-0,172$ & 0,896 & 0,837 & 0,059 & 0,597 & 0,213 \\
\hline Homens & 0,208 & 0,351 & $-0,285$ & 0,091 & $-0,474$ & $-0,443$ & $-0,031$ & $-0,316$ & $-0,113$ \\
\hline Eng. & $-0,653$ & $-0,299$ & $-0,287$ & $-0,413$ & $-0,031$ & 0,928 & $-0,372$ & 0,175 & $-0,119$ \\
\hline$<\mathbf{2 4 0}$ mêses & $-2,378$ & $-0,198$ & $-1,927$ & $-1,501$ & $-1,291$ & $-0,739$ & $-1,351$ & $-1,127$ & $-1,314$ \\
\hline Média & 0,003 & 0,215 & 0,221 & 0,146 & 0,219 & 0,161 & 0,256 & 0,212 & 0,179 \\
\hline Desvio & 1,348 & 1,217 & 1,370 & 1,085 & 1,004 & 0,875 & 1,252 & 0,719 & 0,828 \\
\hline
\end{tabular}

Na Tabela 4.6 do IPEN destaca-se o grupo dos técnicos com o maior índice de comprometimento organizacional (grifado na cor amarela), seguido em segundo lugar pelo grupo dos servidores com tempo igual ou superior a 240 meses na organização. $O$ grupo dos técnicos teve o destaque em três domínios (CRI, CRN e CCN) e dois resumos (CR e Comp) e o grupo dos maiores ou iguais 
há 240 meses na organização, destacou-se positivamente num domínio (CRA) e num resumo (CC). Destaca-se assim, nitidamente o pensamento dos técnicos com valores elevados de comprometimento organizacional - CR, manifestando o fato de querer permanecer na organização.

Nos índices mais baixos (grifados na cor azul) da Tabela 4.6, houve uma caracterização muito predominante do grupo dos servidores com menos de 240 meses de organização com o destaque em cinco domínios e nos três resumos, seguido pelos engenheiros no penúltimo lugar sem destaque nenhum, nem com valores máximos de comprometimento, nem mínimos de nãocomprometimento.

Ao comparar o comprometimento dos grupos nas Tabelas 4.5 e 4.6 a situação é totalmente favorável aos grupos do IPEN confirmando um grau maior de comprometimento, sendo que os valores máximos de comprometimento do IPEN foram "1,14" contra "0,64" do CTA. Os valores mínimos indicam um maior não-comprometimento do CTA com "-1,59" versus os "-1,31" do IPEN, e a média foi maior para os grupos do IPEN com "0,18" versus os "-0,33" do CTA.

Os resultados são coerentes em ambos os casos com a literatura a qual diz que as pessoas com maior tempo de organização são mais comprometidas e o qual foi confirmado com o grupo de mais de 240 meses de organização que apresentou um grau maior de comprometimento que do grupo com menos de 20 anos. Diferentemente aconteceu com as mulheres que a literatura as considera mais comprometida que os homens e os resultados confirmaram a afirmação anterior apenas no IPEN.

\subsection{Fatores de desempenho no CTA}

Analisando a Tabela 4.7 dos fatores de desempenho nas Divisões do CTA, vemos que de forma semelhante como aconteceu no comprometimento, vide Tabela 4.3, a Divisão de Ciências Atmosféricas - ACA se destaca como o local que detém a maioria dos maiores índices. Tais índices encontram-se em nove domínios de um total de dezoito que compõem os quatro fatores de desempenho e em dois destes fatores também, sendo que nos outros dois fatores a diferença com o valor máximo foi pequena, obtendo no final o primeiro lugar nos fatores de desempenho. 
A segunda divisão de destaque foi a de Sistemas Espaciais - ASE na liderança de cinco domínios e um fator de desempenho. É interessante destacar que as três divisões de maior grau de comprometimento, como foram apresentadas anteriormente na Tabela 4.3, também são as mesmas que atingiram o maior grau nos fatores de desempenho, mostrado agora na Tabela 4.7, o qual vai de encontro à comprovação deste estudo, ou seja, locais de maior comprometimento são também locais onde se percebem índices elevados de desempenho. Olhando os valores mínimos, os destaques são para a Divisão de Sistemas Aeronáuticos - ASA com sete domínios e um fator de desempenho obtendo o último lugar na tabela. No penúltimo lugar ficou a Divisão de Mecânica AME com a maior quantidade de valores mínimos, oito domínios e três dos quatro fatores de desempenho. Tais resultados tendo as Divisões ASA e AME nos últimos lugares no desempenho, são diferentes das duas Divisões, Ensaios em Vôo - AEV e de Defesa - ASD, que obtiveram os dois últimos lugares no comprometimento (veja Tabela 4.3), o qual leva a concluir que locais de nãocomprometimento não significam necessariamente locais de baixo desempenho.

No ambiente do clima organizacional - COA encontra-se o maior valor da Tabela 4.7 e de todos os domínios na Divisão de Ciências Atmosféricas - ACA, indicando a grande satisfação dos respondentes na avaliação do ambiente nesta divisão. O domínio ambiente do trabalho em equipe (TEA) apresentou a maior média ("0,48") da Tabela 4.7 e o ambiente do clima organizacional a segunda maior média ("0,42"), indicando ser o ambiente uma característica principal na procura do maior desempenho destes locais.

Destaca-se o fato que como a maioria dos respondentes no caso do CTA é de nível técnico e os servidores que possuem nível superior, porém contratados como técnicos são impedidos de cursar na organização a pósgraduação, bem como, esta última não é reconhecida como gratificação de titulação (o que representaria um acréscimo a mais do seu salário base). Tal fato é reconhecido no IPEN, onde os técnicos recebem esta gratificação.

A Tabela 4.8 a seguir é semelhante à Tabela 4.7 no tocante a medir os mesmos fatores de desempenho, porém para um outro público que foram os 7 grupos afins já mencionados anteriormente. Nesta Tabela 4.8 o grupo que se destaca com os maiores valores de desempenho é dos técnicos, apresentando a primazia em 8 domínios e 2 fatores. O segundo lugar foi ocupado pelo grupo dos 
Tabela 4.7. Desempenho nos Laboratórios do CTA.

\begin{tabular}{|c|c|c|c|c|c|c|c|c|c|c|c|c|c|c|c|c|c|c|c|c|c|c|c|}
\hline Labs & COA & $\operatorname{coc}$ & OD & 00 & CO & LII & LIA & LIC & LI & MOA & MOC & MOO & MOM & MORL & MORC & MO & TEM & TER & TECD & TEA & TECP & TE & DE \\
\hline $\mathbf{A C A}$ & 5,05 & 1,12 & 0,13 & 2,81 & 2,28 & 0,42 & 1,04 & 55 & 1,0 & 1,5 & ,28 & 1,31 & 1,13 & 0,81 & 0,73 & 1,13 & 0,90 & 1,56 & 1,95 & 2,36 & 1,87 & 1,73 & $\begin{array}{c}1,5 \\
3\end{array}$ \\
\hline ASE & 3,11 & $-0,29$ & 0,45 & 1,81 & 1,27 & 0,61 & 0,52 & 1,86 & 1,0 & 1,81 & 1,41 & 0,19 & 1,45 & 1,05 & 1,31 & 1,20 & 0,59 & 1,06 & 1,14 & 2,06 & 1,09 & 1,19 & $\begin{array}{c}1,1 \\
8\end{array}$ \\
\hline AMR & 1,13 & 0,28 & 0,79 & 0,95 & 0,79 & $-0,03$ & 0,2 & 0,86 & 0,34 & 0,85 & 0,56 & 0,35 & 0,51 & 0,17 & 0,80 & 0,54 & 0,25 & 0,19 & $-0,07$ & $-0,14$ & 0,20 & 0,09 & $\begin{array}{c}0,4 \\
4\end{array}$ \\
\hline A E V & $-0,46$ & $-0,34$ & $-0,05$ & , ,80 & ,41 & 1,22 & 1,88 & 35 & 1,15 & $-0,66$ &, 07 & $-0,32$ & $-0,04$ & 66 &, 60 & , 17 & $-0,43$ & 1,04 & 1,10 & 0,25 & 0,48 &, 49 & $\begin{array}{c}0,1 \\
8\end{array}$ \\
\hline AVE-Q & 0,7 & $-0,006$ & 0,25 & 0,24 & 0,3 & $-0,68$ & 0,35 & 0,77 & 0,15 & $-0,75$ & 1,46 & $-0,57$ & $-0,2$ & $-0,26$ & $-0,003$ & $-0,05$ & 0,16 & 0,60 & 0,7 & 0,23 & $-0,19$ & 0,3 & $\begin{array}{c}0,1 \\
6 \\
\end{array}$ \\
\hline$A \mid E$ & 0,52 & $-0,54$ & $-0,02$ & $-0,94$ & $-0,25$ & $-0,13$ & $-0,21$ & $-0,29$ & $-0,21$ & 0,39 & 0,59 & $-0,3$ & 0,35 & 0,66 & $-0,24$ & 0,24 & $-0,12$ & 0,74 & 0,59 & $-0,23$ & 0,19 & 0,23 & $\begin{array}{c}0,0 \\
6\end{array}$ \\
\hline AEL & 0,71 & $-0,03$ & $-0,24$ & $-0,22$ & 0,06 & $-0,17$ & $-1,18$ & $-0,52$ & $-0,62$ & 0,34 & 0,66 & $-0,26$ & $-0,33$ & $-0,14$ & $-0,04$ & 0,04 & $-0,03$ & 0,12 & 0,67 & 1,02 & 0,15 & 0,38 & $\begin{array}{c}0,0 \\
3\end{array}$ \\
\hline $\mathbf{A} \mathbf{Q} \mathbf{I}$ & $\mid-0,86$ & 0,62 & $-0,12$ & ,70 & 09 & 0,04 & $-0,32$ & 0,25 & $-0,01$ & $-0,06$ & ,67 & 0,34 & $-0,15$ & $-0,45$ & 0,56 & $-0,07$ & 0,1 & $-0,38$ & $-0,55$ & $-0,69$ & 0,07 & $-0,29$ & 0,09 \\
\hline ASD & $-2,12$ & $-0,50$ & $-0,34$ & $-0,14$ & $-0,78$ & 0,42 & 0,8 & $-0,03$ & 0,4 & $-0,67$ & $-0,12$ & $-0,09$ & $-0,93$ & $-0,4$ & $-0,62$ & $-0,47$ & $-0,03$ & $-1,15$ & $-0,86$ & $-0,81$ & $-0,21$ & $-0,61$ & 0,43 \\
\hline AME & $-0,81$ & $-0,59$ & $-0,82$ & $-1,64 \mid$ & $\mid-0,97$ & $-0,05$ & $-0,14$ & $-2,73$ & $-0,97$ & $-1,37$ & $-2,79$ & $-0,76$ & $-0,67$ & $-1,18$ & $-2,26$ & $-1,51$ & 0,25 & 0,55 & 0,89 & 2,18 & 0,12 & 0,8 & 0,66 \\
\hline A S A & $-2,38$ & 0,21 & $-0,56$ & $\mid-1,12$ & $-0,96$ & $-0,33$ & $-0,15$ & $-1,42$ & $-0,63$ & $-1,53$ & $-2,03$ & 0,08 & $-0,63$ & $-0,67$ & $-0,94$ & $-0,95$ & $-0,53$ & $-1,37$ & $-1,54$ & $-0,89$ & $-1,25$ & $-1,12$ & 0.95 \\
\hline Média & 0,42 & $-0,007$ & $-0,05$ & 0,15 & 0,13 & 0,12 & 0,25 & 0,06 & 0,14 & $-0,01$ & 0,03 & $-0,003$ & 0,04 & 0,02 & $-0,12$ & $-0,007$ & 0,10 & 0,27 & 0,37 & 0,48 & 0,23 & 0,29 & $\begin{array}{c}0,13 \\
1 \\
\end{array}$ \\
\hline Desvio & 2,18 & 0,54 & 0,45 & 1,34 & 1,00 & 0,52 & 0,81 & 1,31 & 0,72 & 1,10 & 1,39 & 0,56 & 0,75 & 0,70 & 0,99 & 0,81 & 0,41 & 0,92 & 1,02 & 1,23 & 0,78 & 0,8 & $\begin{array}{c}0,72 \\
9\end{array}$ \\
\hline
\end{tabular}


Tabela 4.8. Desempenho nos Grupos do CTA.

\begin{tabular}{|c|c|c|c|c|c|c|c|c|c|c|c|c|c|c|c|c|c|c|c|c|c|c|c|}
\hline Grupo & COA & COC & COD & coo & CO & LII & LIA & LIC & LI & MOA & MOC & MOO & MOM & MORL & MORC & MO & TEM & TER & TECD & TEA & TECP & TE & DE \\
\hline Técnicos & 0,12 & 0,05 & 0,16 & 0,62 & 0,24 & 0,11 & 0,23 & 0,72 & 0,36 & 0,43 & 0,16 & 0,24 & 0,05 & 0,1 & 0,02 & 0,17 & 0,18 & 0,13 & $-0,06$ & 0,03 & 0,12 & 0,08 & 0,19 \\
\hline Homens & 0,12 & $-0,05$ & 0,05 & 0,16 & 0,07 & 0,07 & 0,06 & 0,18 & 0,10 & 0,13 & 0,15 & 0,06 & 0,09 & 0,04 & $-0,19$ & 0,05 & 0,03 & 0,12 & 0,09 & 0,18 & 0,002 & 0,08 & 0,07 \\
\hline$<240$ Mêses & 0,01 & $-0,21$ & $-0,009$ & $-0,07$ & $-0,07$ & 0,08 & 0,22 & 0,15 & 0,15 & $-0,02$ & 0,35 & $-0,10$ & $-0,13$ & $-0,11$ & $-0,32$ & $\mid-0,06$ & $-0,06$ & 0,18 & 0,14 & 0,02 & $-0,03$ & 0,05 & 0,004 \\
\hline$>240$ Mêses & $-0,02$ & 0,33 & 0,01 & 0,11 & 0,11 & $-0,13$ & $-0,34$ & $-0,23$ & $-0,23$ & 0,03 & $-0,53$ & 0,16 & 0,19 & 0,16 & 0,5 & 0,09 & 0,1 & $-0,28$ & $-0,22$ & $-0,03$ & 0,05 & $-0,08$ & $-0,007$ \\
\hline Eng. & $-0,17$ & $-0,16$ & $-0,21$ & $-0,66$ & $-0,3$ & $-0,25$ & $-0,65$ & 0,45 & $-0,15$ & $-0,68$ & $-0,61 \mid$ & $-0,38$ & $-0,35$ & $-0,20$ & $-0,08$ & $|-0,38|$ & $-0,24$ & $-0,42$ & $-0,04$ & $-0,01$ & $-0,27 \mid$ & $-0,2$ & $-0,27$ \\
\hline Mulheres & $-0,75$ & 0,33 & $-0,29$ & $\mid-0,99$ & $-0,42$ & $-0,43$ & $-0,37$ & $-1,11$ & $-0,64$ & $-0,81$ & $-0,91$ & $-0,39$ & $-0,58$ & $-0,27$ & $-0,2$ & $-0,53$ & $-0,20$ & $-0,75$ & $-0,56$ & $-1,09$ & $-0,02$ & $-0,52$ & $-0,52$ \\
\hline Físicos & $-6,90$ & $-3,60$ & $-2,01$ & $-5,88$ & $-4,6$ & 1,27 & 3,94 & $-1,75$ & 1,15 & $-3,73$ & $-7,67 \mid$ & $-0,45$ & 1,74 & $-3,15$ & $-3,03$ & $-2,71$ & $-0,74$ & $-4,06$ & $-3,44$ & $-5,81$ & $-1,66$ & $-3,14$ & $-2,61$ \\
\hline M é d i a & $-1,08$ & $-0,47$ & $-0,33$ & $-0,96$ & $-0,71$ & 0,10 & 0,44 & $-0,23$ & 0,11 & $-0,66$ & $-1,3$ & $-0,12$ & 0,15 & $-0,49$ & $-0,47$ & $-0,48$ & $-0,13$ & $-0,73$ & $-0,58$ & $-0,96$ & $-0,26$ & $-0,53$ & $-0,45$ \\
\hline Desvio & 2,58 & 1,4 & 0,76 & 2,23 & 1,73 & 0,55 & 1,58 & 0,89 & 0,56 & 1,42 & 2,85 & 0,28 & 0,75 & 1,18 & 1,16 & 1,02 & 0,31 & 1,51 & 1,28 & 2,18 & 0,63 & 1,17 & 0,98 \\
\hline
\end{tabular}


homens, o qual teve apenas o predomínio de um domínio e de um fator. Os outros valores máximos encontram-se muito divididos, o qual é uma característica desta tabela.

Olhando os valores mais baixos dos 2 últimos grupos, o pior é o dos físicos que não deve ser considerado. O penúltimo lugar é ocupado pelo grupo das mulheres com 3 valores mínimos sendo 2 domínios e um fator.

Comparando o comprometimento dos grupos do CTA (vide Tabela 4.6), com o desempenho dos mesmos da Tabela 4.8, coincide a primeira posição do grupo dos homens tanto no comprometimento quanto no desempenho. Nas outras posições não se apresenta uma clara tendência.

Ao comparar o desempenho dos laboratórios (Tab. 4.7), com os grupos definidos (Tab. 4.8), observa-se que os índices de desempenho obtido pelos laboratórios são muito maiores, dada à afinidade de grupos formados que trabalham no dia-a-dia procurando um objetivo comum.

\subsection{Fatores de desempenho no IPEN}

Realizando o mesmo procedimento do item 4.6 para o caso do CTA obteve-se aqui a Tabela 4.9 para o caso do IPEN. Nota-se aqui um forte predomínio do Laboratório de Insumos e Componentes - SOFC em 11 do total de 18 domínios e em 2 dos 4 fatores de desempenho obtendo a primeira posição no índices de desempenho.

Na segunda posição está o Laboratório de Microscopia e Microanálise MiM, tendo a primazia em 5 domínios e 2 fatores, sendo que os dois primeiros lugares concentraram 19 dos 22 valores máximos da tabela. Olhando os valores mínimos da Tabela 4.9, a última posição foi do Laboratório de Processamento Cerâmico de Resíduos - PCR, com 7 domínios e 2 fatores apresentando o comportamento mais negativo no fator trabalho em equipe. Na penúltima posição ficou o Laboratório de Processamento de Materiais - PM, com 4 domínios e um fator.

Conforme foi discutido no item 4.6 do caso do CTA, os 2 primeiros locais no comprometimento resultaram também ser os mesmos dois primeiros no desempenho, ficando assim comprovado um dos objetivos do estudo. Acontece aqui para o caso do IPEN uma situação pouco diferente onde os 2 laboratórios mais comprometidos apresentados na Tabela 4.4 (MiM e SOFC) aparecem com 
Tabela 4.9. Desempenho nos Laboratórios do IPEN.

\begin{tabular}{|c|c|c|c|c|c|c|c|c|c|c|c|c|c|c|c|c|c|c|c|c|c|c|c|}
\hline$L a b$ & COA & COC & COD & COO & C 0 & LII & LIA & L I C & L I & MOA & MOC & MOO & MOM & MORL & MORC & MO & TEM & TER & TECD & TEA & TECP & $\mathbf{T} \quad \mathbf{E}$ & D \\
\hline SOFC &, 95 & $-2,32$ & 2,24 & 3,31 & 1,54 & 0,37 & $-0,2$ & 1,08 & 0,42 & 1,08 & 1,81 & 1,04 & 1,13 & 0,95 & 0,63 & 1,11 & 1,92 & 2,13 & 0,64 & 3,08 & 1,09 & 1,77 & 1,27 \\
\hline M i M &, 14 & 1,50 & 0,72 & 2,47 & 1,21 & 2,21 & 0,45 & 2,92 & 1,86 & 1,87 & 0,12 & $-0,2$ & 1,21 & $-0,62$ & 1,89 & 0,71 & 1,02 & 0,56 & $-0,007$ & $-0,45$ & 0,27 & 0,28 & 0,89 \\
\hline C E B & $-2,5$ & $-0,97$ & 0,9 & 0,25 & $-0,58$ & 0,03 & $-0,88$ & 0,81 & $-0,01$ & 2,89 & 1,31 & 0,72 & 0,21 & 0,70 & 1,47 & 1,22 & 0,23 & 0,48 & $-0,19$ & $-0,73$ & 0,57 & 0,07 & 0,29 \\
\hline M P I & 1,06 & $-0,08$ & 0,12 & 0,05 & 0,29 & 0,17 & 1,46 & 1,31 & 0,98 & $-0,11$ & 0,22 & $-0,72$ & 0,08 & $-0,0003$ & $-0,21$ & $-0,12$ & $-0,74$ & 0,06 & 0,46 & 0,25 & 0,09 & 0,03 & 0,19 \\
\hline C M & 1,66 & 0,40 & 0,04 & 0,76 & 0,72 & $-0,34$ & $-1,67$ & $-2,46$ & $-1,49$ & 0,29 & 0,47 & 0,35 & $-0,17$ & 0,56 & 0,53 & 0,34 & 0,33 & $-0,2$ & 0,47 & 0,05 & 0,78 & 0,29 & 0,10 \\
\hline C T S & 0,4 & $-0,5$ & 0,18 & 0,74 & 0,21 & $-0,76$ & $-0,54$ & 0,26 & $-0,35$ & $-0,05$ & $-1,1$ & 0,33 & 1,05 & 0,06 & 0,38 & 0,11 & $-0,32$ & 0,54 & 0,55 & $-0,09$ & $-0,22$ & 0,09 & 0,05 \\
\hline E C & 1,77 & 0,9 & $-0,20$ & 2,19 & 1,16 & $-1,1$ & $-3,15$ & 0,72 & $-1,18$ & $-0,27$ & $-0,27$ & $-0,53$ & 0,42 & $-0,38$ & 0,67 & $-0,06$ & 0,02 & $-0,73$ & $-0,76$ & $-0,7$ & $-0,49$ & $-0,53$ & $-0,1$ \\
\hline $\mathbf{M}$ a $\mathbf{M}$ & 2,19 & $-1,29$ & $-0,63$ & $-2,5$ & $-0,56$ & $-0,88$ & $-0,33$ & $-0,5$ & $-0,57$ & $-0,84$ & 1,74 & $-0,28$ & $-0,29$ & 0,17 & $-1,61$ & $-0,18$ & 0,96 & 1,26 & 0,63 & $-1,13$ & $-0,22$ & 0,3 & $-0,2$ \\
\hline $\mathbf{P} \quad \mathbf{M}$ & $-1,6$ & 1,45 & $-1,0$ & $-1,82$ & $-0,74$ & 0,001 & 0,96 & $-0,75$ & 0,07 & $-2,38$ & $-0,94$ & $-0,18$ & $-1,65$ & $-0,08$ & $-0,6$ & $-0,97$ & $-1,33$ & $-1,51$ & $-0,57$ & 1,39 & $-0,12$ & $-0,43$ & $-0,59$ \\
\hline$P C R$ & -3 & 0,46 & $-0,20$ & $-2,17$ & $-1,24$ & 1,98 & 3,52 & $-3,61$ & 0,63 & 0,31 & $-1,6$ & $-0,64$ & 0,26 & $-0,62$ & $-1,30$ & $-0,6$ & $-0,36$ & $-3,74$ & $-4,41$ & $-5,50$ & $-2,79$ & $-3,36$ & $-1,3$ \\
\hline D R X & $-3,2$ & $-2,54$ & 0,66 & 4,65 & $-0,10$ & $-1,54$ & $-0,8$ & 1,52 & $-0,27$ & 3,93 & 0,6 & 0,9 & 1,97 & 0,32 & $-1,72$ & 1,0 & 0,96 & 1,44 & 2,90 & 3,08 & 1,78 & 2,03 & 0,83 \\
\hline V C C & $-9,3$ & 0,91 & $-2,94$ & $-7,33$ & $-4,67$ & 2,84 & 4,64 & $-6,29$ & 0,4 & $-2,31$ & $-6,25$ & 0,46 & $-4,02$ & $-4,38$ & $-3,58$ & $-3,35$ & 0,19 & 0,57 & 0,92 & 0,07 & $-1,18$ & 0,11 & $-2,06$ \\
\hline Média & $-0,79$ & $-0,17$ & $-0,01$ & 0,05 & $-0,23$ & 0,25 & 0,29 & $-0,42$ & 0,04 & 0,37 & $-0,33$ & 0,10 & 0,02 & $-0,28$ & $-0,29$ & $-0,07$ & 0,24 & 0,07 & 0,05 & $-0,06$ & $-0,04$ & 0,05 & $-0,05$ \\
\hline Desvio & 3,41 & 1,37 & 1,24 & 3,2 & 1,65 & 1,39 & 2,15 & 2,56 & 0,92 & 1,88 & 2,16 & 0,61 & 1,57 & 1,38 & 1,55 & 1,24 & 0,88 & 1,54 & 1,68 & 2,21 & 1,16 & 1,32 & 0,93 \\
\hline
\end{tabular}


Tabela 4.10. Desempenho nos grupos do IPEN.

\begin{tabular}{|c|c|c|c|c|c|c|c|c|c|c|c|c|c|c|c|c|c|c|c|c|c|c|c|}
\hline Grupo & COA & COC & COD & $c 00$ & co & LII & LIA & LIC & LI & MOA & MOC & MOO & MOM & MORL & MORC & MO & TEM & TER & TECD & TEA & TECP & TE & DE \\
\hline Técnicos & 2,46 & $-0,07$ & 0,71 & 3,04 & 1,54 & 0,67 & $-0,83$ & 3,51 & 1,12 & 1,7 & 1,5 & 0,32 & 0,83 & 0,60 & $-0,09$ & 0,81 & 0,87 & 0,99 & 1,83 & 1,16 & 1,08 & 1,19 & 1,13 \\
\hline 2240 mêses & 1,84 & 0,27 & 0,50 & 0,90 & 0,88 & 0,60 & 0,67 & 0,72 & 0,67 & 0,78 & 0,47 & 0,35 & 0,59 & 0,13 & 0,79 & 0,52 & 0,27 & $\mid 0,76$ & 0,62 & 0,68 & 0,36 & 0,54 & 0,63 \\
\hline Mulheres & $-0,09$ & $-0,29$ & $-0,19$ & 0,29 & $-0,07$ & 0,01 & $-0,24$ & 1,47 & 0,42 & 0,09 & $-0,05$ & $-0,03$ & 0,47 & $-0,25$ & 0,28 & 0,09 & 0,16 & 0,14 & $-0,33 \mid$ & $-0,55$ & $-0,23 \mid$ & $-0,16$ & 0,04 \\
\hline Homens & 0,05 & 0,15 & 0,10 & $-0,15$ & 0,04 & $-0,006$ & 0,13 & $-0,78$ & $-0,22$ & $-0,05$ & 0,03 & 0,02 & $-0,25$ & 0,13 & $-0,15 \mid$ & $-0,05$ & $-0,08$ & $|-0,07|$ & 0,18 & 0,29 & 0,12 & 0,09 & $-0,02$ \\
\hline Físicos & $-0,05$ & 1,19 & $-0,05$ & $-0,40$ & 0,17 & 0,09 & $-0,37$ & $-0,86$ & $-0,38$ & $-1,21$ & 0,12 & 0,32 & $|-0,12|$ & $-0,25$ & 0,33 & $-0,13$ & $-0,23$ & $-0,31 \mid$ & $-0,91$ & $-0,41$ & $-0,78$ & $-0,53$ & $-0,22$ \\
\hline E $\mathbf{n g}$ & $-0,61$ & $-0,66$ & 0,02 & $\mid-0,67$ & $\mid-0,48$ & 0,11 & 0,8 & $-0,78$ & 0,04 & $-0,06$ & $-0,82$ & $-0,49$ & $|-0,22|$ & $-0,26$ & 0,39 & $-0,24$ & $-0,26$ & $-0,48 \mid$ & $-0,30 \mid$ & 0,49 & $-0,14$ & $-0,14$ & $-0,22$ \\
\hline$<240$ mêses & $5-2,32$ & $-0,34$ & $-0,63$ & $-1,14$ & $-1,11$ & $-0,76$ & $-0,84$ & $-0,91$ & $-0,84$ & $-0,98$ & $-0,60$ & $-0,44$ & $-0,74$ & $-0,16$ & $-1,0$ & $-0,65$ & $-0,34$ & $-0,96$ & $-0,78$ & $-0,86$ & $-0,46$ & $-0,68$ & $-0,79$ \\
\hline Média & 0,18 & 0,04 & 0,07 & 0,27 & 0,14 & 0,10 & $-0,10$ & 0,34 & 0,11 & 0,04 & 0,09 & 0,008 & 0,08 & $-0,007$ & 0,08 & 0,05 & 0,06 & 0,009 & 0,04 & 0,12 & $-0,005$ & 0,04 & 0,08 \\
\hline Desvio & 1,58 & 0,6 & 0,44 & 1,39 & 0,86 & 0,47 & 0,66 & 1,68 & 0,67 & 0,99 & 0,76 & 0,36 & 0,56 & 0,32 & 0,57 & 0,49 & 0,42 & $0,69 \mid$ & 0,95 & 0,74 & 0,61 & 0,64 & 0,63 \\
\hline
\end{tabular}


os lugares trocados, ou seja, o primeiro lugar do CTA é o segundo do IPEN e o primeiro lugar do IPEN é o segundo lugar do CTA. Assim, já não se pode concluir numa relação direta que maior comprometimento significaria maior desempenho, pode-se sim, concluir que com um maior comprometimento resulta numa maior tendência a obter um melhor desempenho, mais ainda lembrando da frágil amostra do IPEN pelos seus baixos números de observadores.

A Tabela 4.10 mostra o ranking dos grupos do IPEN sobre os 4 fatores do desempenho encontrando no primeiro lugar o grupo dos técnicos com 18 dos 22 valores máximos, ocupando a primazia em 14 domínios e nos 4 fatores de desempenho. O segundo lugar foi do grupo dos maiores ou iguais há 240 meses na organização com a primazia em 2 domínios. Olhando os valores mínimos destaca-se o grupo dos servidores com tempo de organização inferior a 240 meses obtendo a primazia negativa em 11 domínios e nos quatro fatores. No penúltimo lugar ficou o grupo dos engenheiros, com uma pequena diferença decimal sobre os físicos e com a primazia de valores mínimos em 4 domínios. Ao comparar esta última tabela com a sua semelhante sobre o ranking dos grupos no comprometimento (Tabela 4.6), encontra-se que os 2 primeiros grupos, ou seja, técnicos e maiores ou iguais há 240 meses, repetem sua colocação de forma idêntica na Tabela 4.6 sobre o comprometimento, o qual comprova novamente que maior comprometimento significa maior desempenho.

Olhando os dois últimos lugares nas Tabelas 4.6 e 4.10, detecta-se que os 2 últimos lugares para ambas as tabelas repetem-se na mesma posição, ou seja, no último lugar o grupo dos servidores de menos de 240 meses e no penúltimo lugar o grupo dos engenheiros, o qual indica neste caso que o maior não-comprometimento implicaria num menor desempenho. O anterior é uma conclusão atípica com o resto do estudo e não há interesse em discutí-la.

\subsection{Comparando o desempenho entre o CTA e o IPEN}

Os resultados atingidos nos Laboratórios do CTA com os fatores de desempenho (vide Tabela 4.7) são todos eles pouco maiores que no IPEN (vide Tabela 4.9). O valor do primeiro lugar na Tabela do CTA atingiu o valor de "1,53" versus os "1,27" do IPEN. A média geral foi de "0,131" para o CTA, versus os “-0,05" do IPEN. O valor do último lugar na Tabela do CTA foi de "-0,95" versus os “-2,06” do IPEN. 
Os resultados dos fatores de desempenho obtidos pelos grupos do IPEN (vide Tabela 4.10) foram maiores que dos grupos do CTA (vide Tabela 4.8). O valor da primeira posição nas tabelas foi de "1,13" do IPEN, versus os " 0,19 " do CTA. A média geral foi de "0,08" para o IPEN, versus os "-0,45" do CTA. O valor do último lugar na Tabela do IPEN foi de "-0,79“, versus os "-2,61" do CTA.

Assim, resume-se que os valores obtidos no desempenho dos institutos analisados foram superiores para o CTA nos seus Laboratórios, e para o IPEN quando pesquisados nos seus grupos estudados.

\subsection{Coeficiente alfa de Cronbach}

Usando o software SPSS rodou-se o programa com os 304 respondentes juntando as populações do IPEN e do CTA para o conjunto de variáveis que formaram cada um dos quatro constructos e os resultados foram os seguintes: o constructo ACEITA teve um alfa de "0,642"; o constructo REQUIP teve um alfa de "0,802", o constructo REORG teve um alfa de "0,799" e o constructo IDENT teve um alfa de "0,459. O constructo IDENT teve um alfa de Cronbach abaixo de 0,6 , entretanto mais adiante se verá que não foi o modelo escolhido.

\subsection{As variáveis mais importantes}

Para a elaboração do modelo estrutural e de mensuração, precisam-se conhecer da teoria, os constructos que definirão tal modelo. Assim, numa análise dos dados optou-se por conhecer primeiramente quais foram as variáveis mais importantes, ou seja, aquelas que ambos os públicos pesquisados as reconheceram como as mais importantes. Uma análise fatorial exploratória visando à redução de dados confirmou os fatores que continham as variáveis de maior carga fatorial.

O critério anterior é embasado pelas semelhanças que os dois institutos de pesquisa estudados apresentam:

- São dois centros de pesquisa de excelência na sua área, o primeiro na área aeroespacial e o segundo no campo nuclear, sendo que especificamente o CCTM onde se realizou a pesquisa do IPEN, destaca-se na área de materiais;

○ Ambos são enquadrados na área de Ciência e Tecnologia; 
- Dividem-se nas suas operações em três atividades: pesquisa, prestação de serviços e ligados a uma universidade de destaque, sendo o primeiro vinculado ao ITA e o segundo à USP.

Considerando-se assim, a semelhança de ambos locais, ao analisar ambas as populações imagina-se obter respostas semelhantes nesta pesquisa. Usando este critério de semelhança e procurando esta característica nas respostas da população do CTA e na do IPEN, utilizou-se a técnica de análise fatorial com rotação varimax e extração pelo método dos componentes principais com intuito de sumarizar um conjunto de variáveis em fatores.

Das tabelas obtidas atendendo à sugestão de Hair et al. (1998), que indicam carga fatorial superior a "0,75" para populações de 50 pessoas (no caso do IPEN) e superior a "0,35" para amostras de 250 pessoas (no caso do CTA), analisaram-se as matrizes rotacionadas de cada instituto comparando cada fator de ambas as tabelas. Assim, resultou que o fator 1 do IPEN é formado pelas variáveis COA4, COA1, COA2 e TER1 (a seqüência é dada de maior a menor carga fatorial), sendo que as mesmas 4 dentro de muitas se repetem no fator 1 do $\mathrm{IAE}$, obtendo desta forma as primeiras 4 variáveis mais importantes em ambas as instituições.

O fator 2 do IPEN é formado pelas variáveis COD2, MOA1, COO1 e COO2. Aqui também acontece que estas 4 variáveis repetem-se dentre de outras no fator 2 do CTA, obtendo desta forma mais 4 variáveis importantes.

O fator 3 do IPEN é formado pelas variáveis TEA2 e TEA3, as quais aparecem no fator 6 do CTA, entendendo tratar-se de uma questão de interpretação, o que é interpretado pela população do IPEN no fator 3 , a população do CTA entendeu como fator 6 .

Finalmente, o fator 6 do IPEN é formado pelas variáveis MOO1 e TEM1, as quais fazem parte do fator 3 do CTA, fato semelhante ao parágrafo anterior entendendo-se como uma questão de interpretação das populações. Salienta-se que o CTA apresentou doze novos fatores e o IPEN cinco (o fator 4 não foi considerado e sim o fator 6 ).

Como conclusão do raciocínio anterior, obteve-se 12 variáveis que por fazer parte justificadamente de ambas as populações são consideradas como as mais importantes e serão utilizadas mais tarde para realizar uma análise fatorial confirmatória. 
As 12 variáveis selecionadas foram:

V1 = COA1 = Há cooperação dentro da equipe de trabalho;

V2 = COA2 = Destaca-se o clima de alegria e bom humor na equipe de trabalho;

V3 = COA4 = As informações são precisas e confiáveis;

V4 = COD2 = A avaliação de desempenho individual é adequada;

$\mathrm{V} 5=\mathrm{COO} 1$ = Esta organização está realmente tentando fomentar um bom relacionamento com seus servidores;

V6 $=$ COO2 = Esta organização considera de fato que os servidores são seu maior patrimônio e comporta-se segundo esta crença;

V7 = MOA1 = O ambiente do serviço público num centro de pesquisas permite um ambiente de motivação;

V8 $=$ MOO1 = É importante para eu pertencer a uma organização que possua uma boa imagem na comunidade;

V9 $=$ TEM1 $=$ O trabalho em equipe é o fator mais importante no desempenho das pessoas;

V10 = TER1 = Os membros da equipe têm um relacionamento baseado na confiança mútua;

V11 = TEA2 = As pessoas não têm medo de sugerir novas e diferentes idéias, mesmo que estas sejam extremamente simples;

V12 = TEA3 = É normal que as discordâncias sejam expressas sem que as pessoas sejam malvistas.

\subsection{Elaboração dos modelos estrutural e de mensuração}

O leitor encontrará nas seções a seguir alguns assuntos sobre a metodologia e que seriam tema do capítulo 3, mas que foram propositalmente colocados junto aos resultados para facilitar sua compreensão e acompanhamento da leitura.

Cabe ao pesquisador, antes da construção dos modelos estrutural e de mensuração, desenvolver o modelo teórico que deverá ser comprovado empiricamente ao longo do estudo. Partindo da proposta de um modelo teórico e da definição de relações entre os constructos, constitui-se o diagrama de caminhos $^{(9)}$, que consiste na representação gráfica e esquemática das relações

\footnotetext{
${ }^{(9)}$ Livre tradução para path diagram.
} 
de causa e efeito entre os constructos. Nesse diagrama, o investigador pode apresentar não apenas as relações preditivas entre os constructos (relações entre variáveis dependentes e independentes), mas também as relações associativas (correlações) entre os constructos e os indicadores (Hair Jr. et al., 1998). Com este diagrama, é possível realizar a especificação do modelo com a definição das equações estruturais, suas ligações entre os constructos e o modelo de mensuração adotado para medir os constructos.

Com a utilização de softwares estatísticos com interface gráfica, os modelos (estrutural e de mensuração) podem ser representados simultaneamente em um modelo denominados de integrado, onde se encontram as representações gráficas das relações entre as variáveis latentes, bem como, quais são as variáveis observáveis que medem cada uma das variáveis latentes do modelo. Para Hoyle (1995b) quando o modelo estrutural e o modelo de mensuração são combinados, o resultado é um modelo estatístico abrangente que pode ser usado para avaliar as relações entre as variáveis que são livres de erros de mensuração.

Neste estudo a construção dos modelos de análise parte do estabelecimento inicial dos constructos que constituirão o modelo estrutural. Assim, o interesse então foi investigar como se associam os constructos e para tal utilizou-se a técnica de nomeação dos novos fatores após uma análise fatorial:

- Os fatores1 do IPEN e do CTA formados pelas variáveis (COA1-v1, COA2v2 e COA4-v3) foram nomeados como Relacionamento com a equipe e identificados com a sigla REQUIP;

- Os fatores 2 do IPEN e do CTA formados pelas variáveis (COD2-v4, COO1-v5, COO2-v6 e MOA1-v7) foram nomeados como Relacionamento com a organização e identificados com a sigla REORG;

- Os fatores 6 do IPEN e 3 do CTA formados pelas variáveis (MOO1-v8, com a sigla IDENT; e

- Os fatores 3 do IPEN e 6 do CTA formados pelas variáveis (TEA2-v11 e TEA3-v12) foram nomeados como Aceitação e participação e identificados com a sigla ACEITA.

O constructo REQUIP resultou ser formado por 3 variáveis originais do domínio ambiente do fator de desempenho clima organizacional. 
O constructo REORG resultou ser formado pela variável COD2 original do domínio desempenho do fator clima organizacional, mais duas variáveis originais do domínio organização (COO1 e COO2) do fator clima organizacional e mais a variável MOA1 originalmente do domínio ambiente do fator motivação.

O constructo IDENT resultou originalmente formado pela variável MOO1 proveniente do domínio organização do fator motivação e mais duas variáveis originais do fator trabalho em equipe, sendo elas, a variável TEM1 proveniente do domínio missão e a variável TER1 proveniente do domínio relacionamento, sendo que esta última foi eliminada mais tarde nas tentativas do LISREL ao procurar o melhor modelo de relacionamento causal.

O constructo ACEITA resultou ser formado por duas variáveis originais do domínio ambiente do fator trabalho em equipe. Chama-se a atenção ao leitor que os constructos REQUIP e ACEITA são formados por variáveis provenientes exclusivamente de domínios denominados de ambiente pertencente originalmente a dois fatores de desempenho: clima organizacional e trabalho em equipe. A observação anterior será retomada por ocasião da escolha do modelo final.

Desta formação dos 4 constructos explicada anteriormente e analisando a origem das 11 variáveis que fazem parte dos mesmos, observam-se que 6 delas são resultantes do fator clima organizacional, 3 do fator trabalho em equipe e 2 do fator motivação. Do total das 11 variáveis, 5 delas originalmente pertenciam a 2 domínios denominados de "ambiente" de dois fatores de desempenho, como foi citado no parágrafo anterior com os constructos REQUIP e ACEITA. Das variáveis originais pertencente ao fator de desempenho liderança nenhuma delas foi considerada como importante para fazer parte das 12 ou 11 escolhidas. A quantidade de variáveis resultantes como as mais importantes dos 4 fatores de desempenho são a confirmação da importância de cada um destes 4 fatores de desempenho após a análise fatorial exploratória.

A relação entre os 4 constructos (REQUIP, REORG, IDENT E ACEITA), da forma como concebida, poderá contribuir para o desenvolvimento de modelos desse grupo.

Assim, embasado pela recomendação de se contemplar "modelos rivais" nos estudos (MacCallum e Austin, 2000; Chin, 1998), selecionou-se para análise 4 diferentes composições estruturais, tomando-se como variação 
fundamental o fator antecedente (tratado também como variável independente ou exógena ${ }^{(10)}$ ) nas relações de causalidade.

Os sentidos de causalidade entre os constructos contemplaram, além da relação linear e aditiva entre os fatores, também a recursividade (fluxo causal em sentido único) e um número de trajetórias que evitassem a saturação do modelo, isto é, uma quantidade de caminhos ou parâmetros a serem estimados menor ou igual ao número de covariâncias entre as variáveis. Dessa forma, evita-se o problema de identificação do modelo.

Os modelos avaliados no presente estudo não apresentam essa inabilidade. São classificados como "sobre-identificados", e seguem estrutura similar à de exemplo apresentado por Pedhazur (1997).

Elegeu-se como "modelo nulo", pela convicção de ser o modelo que melhor representa o relacionamento entre os constructos, o denominado "modelo ACEITA - aceitação e participação", que se caracteriza por apresentar o fator aceitação e participação dos servidores como antecedente dos demais fatores. Pressupõe-se, nessa hipótese, que os elementos de aceitação, descontração, sugestão, liberdade de expressão, seriam exógenas, porque suas causas estão relacionadas às variáveis exógenas ou a outras variáveis externas do sistema, considerando estes como elementos iniciais para um melhor desempenho destes locais de pesquisas. O indivíduo, assim, seria levado a optar pela força que esses fatores aceitação e participação estariam exercendo sobre ele ao longo do seu trabalho profissional.

A representação gráfica e esquemática das relações causais entre os constructos, conhecida como "diagrama de caminhos" (path diagram), para essa hipótese, está indicado na Figura 4.6. Os constructos são representados pelas variáveis latentes - exógenas e endógenas (Bollen, 1989).

O "diagrama de caminhos" do "modelo ACEITA" - aceitação e participação está esquematizado na Figura 4.6 a seguir:

\footnotetext{
(10) As variáveis independentes são igualmente chamadas de exógenas porque suas causas são externas ao modelo sob análise, e as variáveis consideradas dependentes são denominadas endógenas, porque suas causas estão relacionadas às variáveis exógenas ou a outras variáveis internas do sistema (Byrne, 1998).
} 


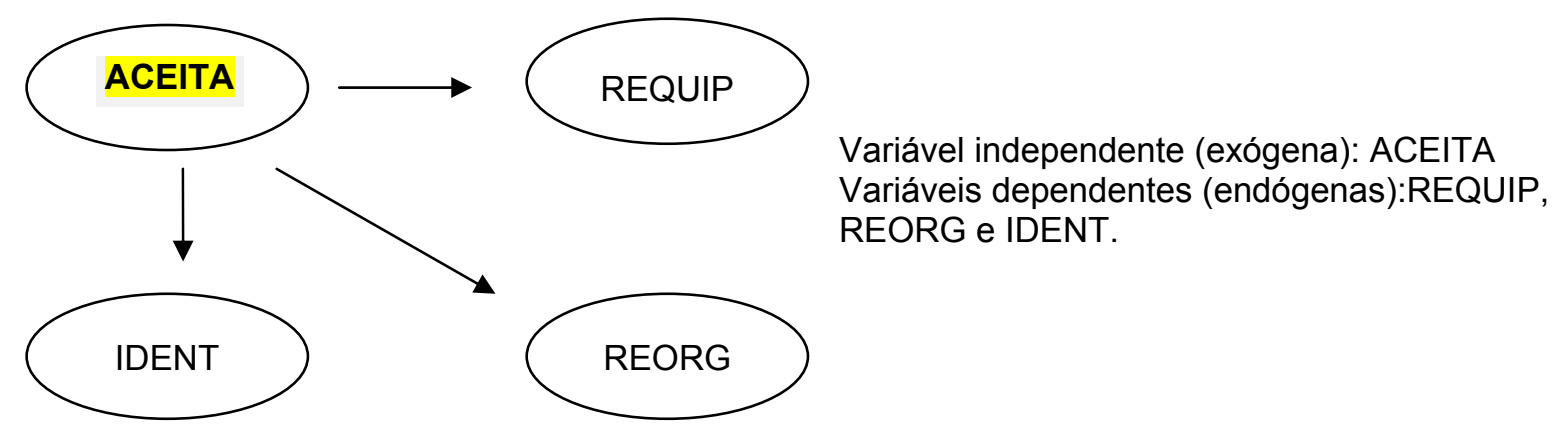

Figura 4.6 - Relação estrutural do "modelo ACEITA" - aceitação e participação. Adaptado de Bomtempo (2005)

No primeiro modelo alternativo, chamado de "modelo REQUIP" relacionamento com a equipe da Figura 4.7, estabeleceu-se que este fator estaria no centro do processo decisório. Seria o lado equipe preponderante sobre os demais. Complementando a relação entre os constructos, esse modelo prevê que o fator REQUIP também seria responsável pela geração de parte do fator ACEITA.

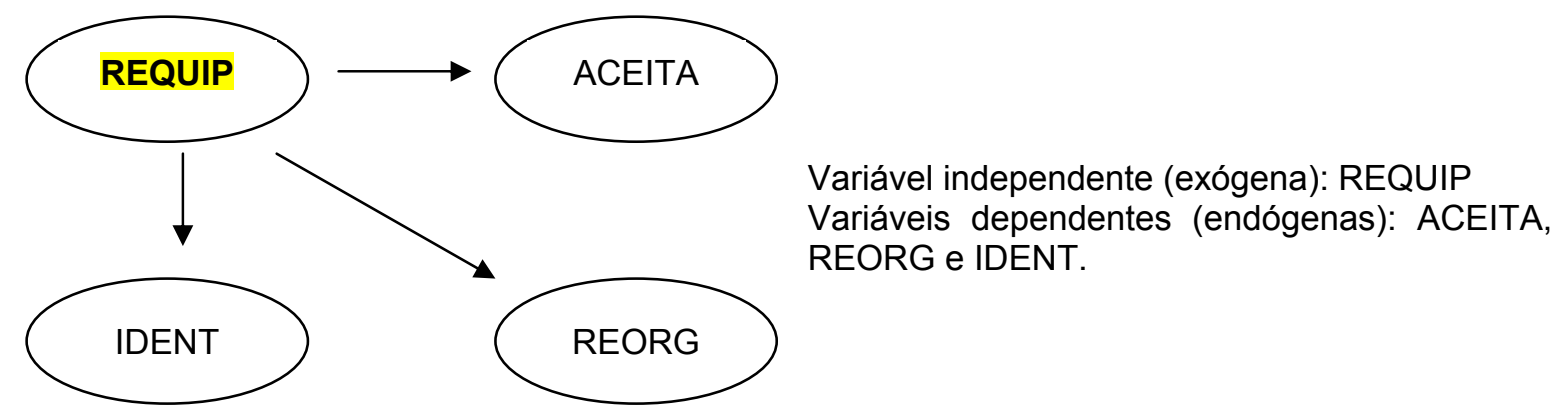

Figura 4.7 - Relação estrutural do "modelo REQUIP" - relacionamento com a equipe. Adaptado de Bomtempo (2005)

No segundo modelo alternativo, chamado de "modelo REORG" relacionamento com a organização da Figura 4.8, estabeleceu-se que este fator estaria no centro do processo decisório. Seria o lado organização preponderante sobre os demais. Complementando a relação entre os constructos, esse modelo prevê que o fator REORG também seria responsável pela geração de parte do fator ACEITA.

O terceiro modelo alternativo construído estabelece o fator Identidade como influenciador dos demais. O modelo considera também que o fator identidade seria causador de parte dos aspectos relacionamentos com o modelo ACEITA. A Figura 4.9 representa o "diagrama de caminhos" para essa hipótese. 


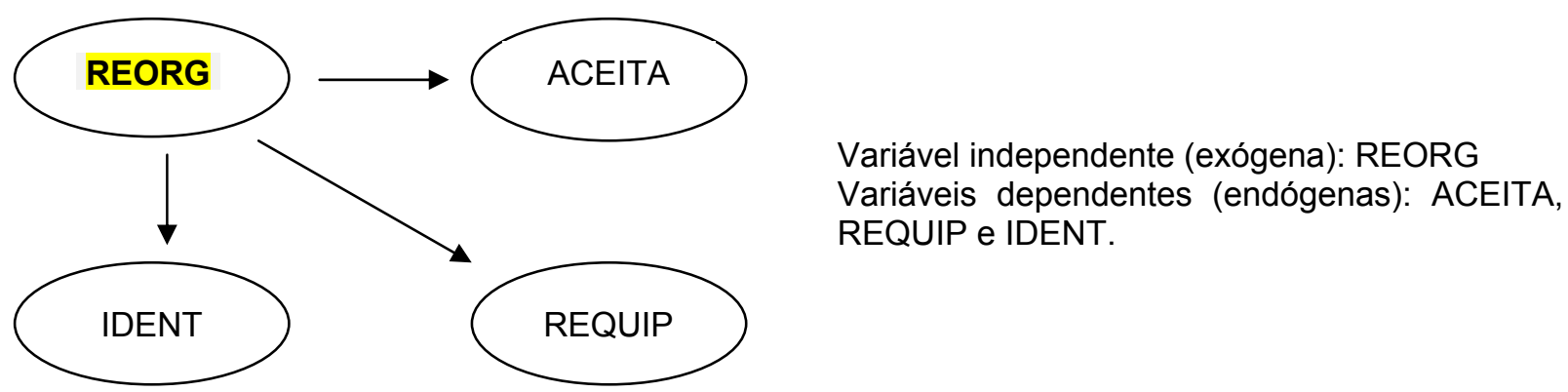

Figura 4.8 - Relação estrutural do "modelo REORG" - relacionamento organizacional. Adaptado de Bomtempo (2005)

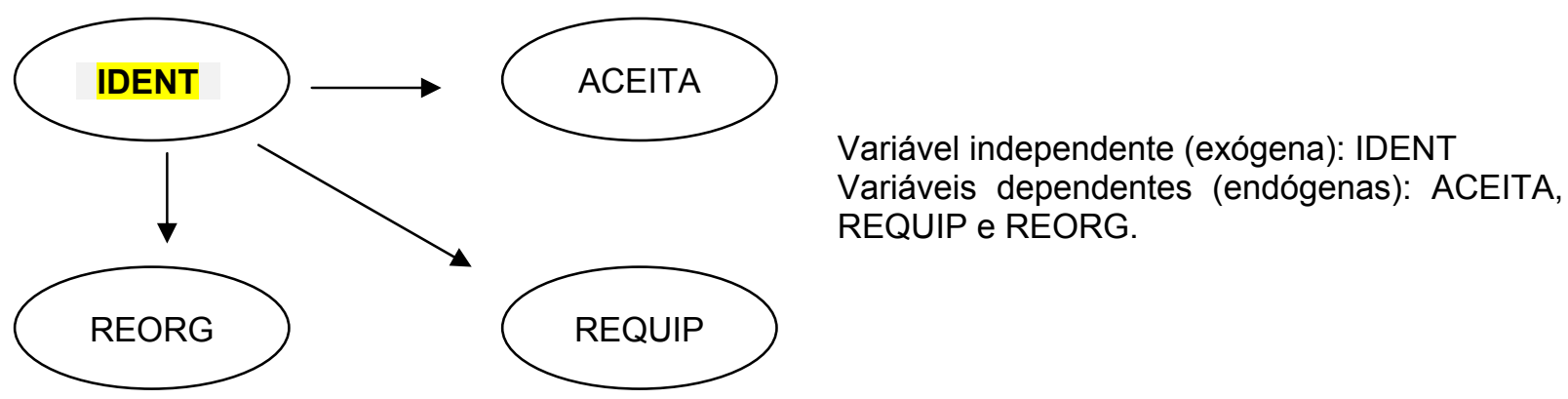

Figura 4.9 - Relação estrutural do "modelo IDENT" - identidade. Adaptado de Bomtempo (2005)

Conforme observam Hair et al. (1998), não sendo possível a mensuração direta, os constructos devem ser medidos através de indicadores também denominados variáveis manifestas ou valores observados. Assume-se que cada indicador possa ser mensurado pela expressão que as pessoas têm em relação ao seu desempenho. A determinação desses indicadores foi amparada pelos fatores de influência revisados na bibliografia.

\subsubsection{Modelo completo inicial (estrutural e de medidas)}

$\mathrm{Na}$ elaboração dos modelos de medidas e modelos estruturais, componentes básicos da SEM, foi possível formar os modelos completos para análise. Pedhazur (1997, p. 770) destaca que "embora não essencial para a análise numérica, é muito útil à representação gráfica das relações hipotéticas entre o conjunto de variáveis". Assim, foi desenhado graficamente o modelo nulo, conforme disposto no diagrama da Figura 4.10, seguindo o padrão utilizado na literatura: 


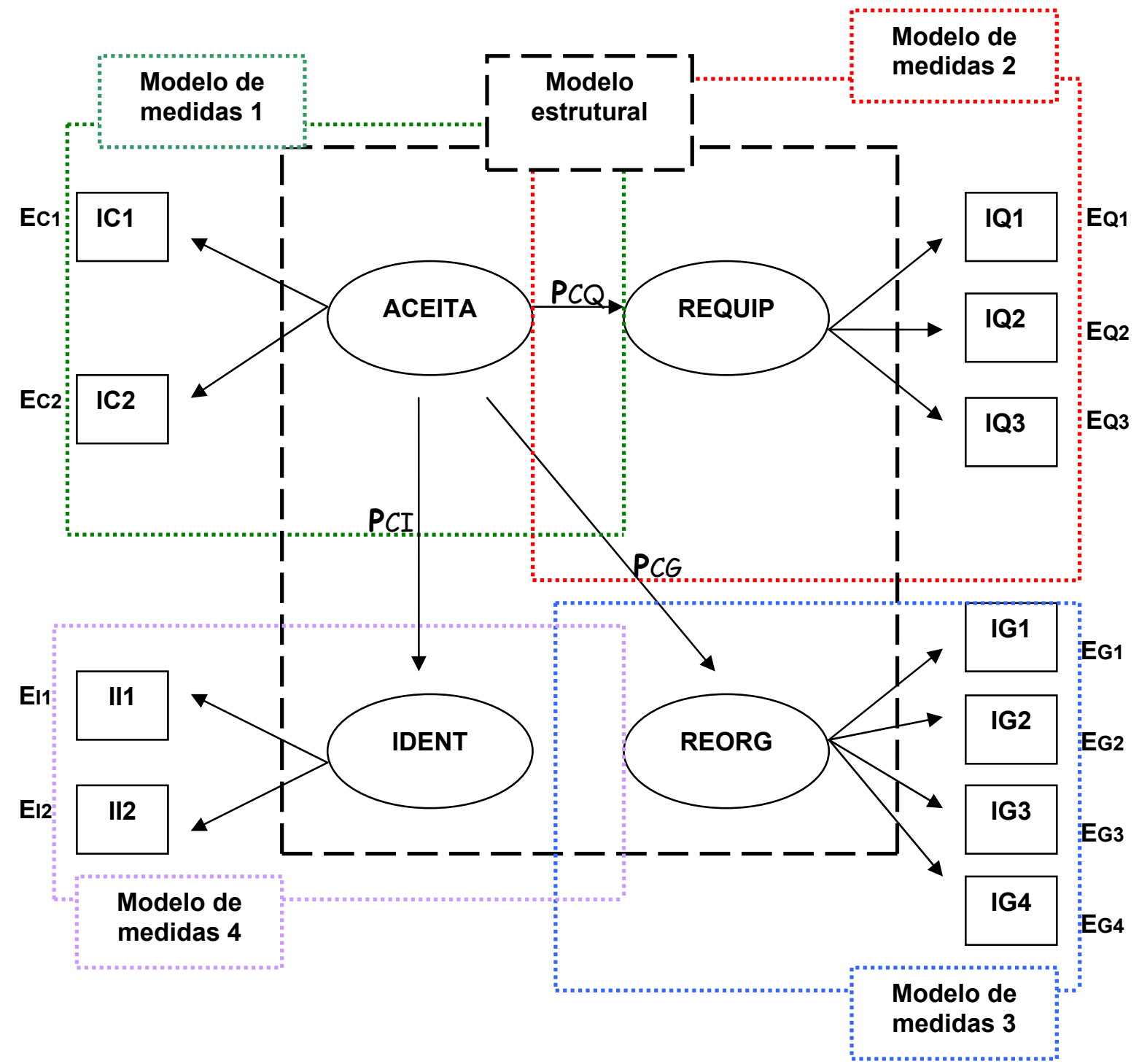

Figura 4.10 - Diagrama do modelo ACEITA (modelo nulo inicial). Adaptado de Bomtempo (2005, p. 75).

- as variáveis exógenas (independentes) e endógenas (dependentes) são os constructos ou variáveis latentes do estudo, e são representados por elipses;

- as variáveis manifestas ou indicadores são representadas por retângulos;

- $E_{i}$ são os erros de mensuração a que as variáveis manifestas estão sujeitas, uma vez que o respondente pode ficar na dúvida de como proceder, ou interpretar uma questão de forma diferente daquela que o pesquisador programou;

- as setas indicam relações de causalidade entre as variáveis latentes ou efeito das variáveis nos modelos de medidas; 
○ $\rho_{\mathrm{ij}}$ são os coeficientes de caminho, que indicam quanto variará o fator i para cada variação unitária do fator j na equação de regressão.

Observa-se que os indicadores de cada constructo da Figura 4.10 são teóricos, sendo que neste estudo correspondem a: IC1 = v11 ou TEA2, IC2 = v12 ou TEA3, IQ1 = v1 ou COA1, IQ2 = v2 ou COA2, IQ3 = v3 ou COA4, IG1 = v4 ou COD2, IG2 = v5 ou COO1, IG3 = v6 ou COO2, IG4 = v7 ou MOA1, II1 = v8 ou MOO1 e II2 = v9 ou TEM1.

O modelo prevê, ainda, a existência de resíduos para representar os efeitos de variáveis não incluídas na sua composição (Pedhazur, 1997). Os modelos alternativos (REQUIP, REORG e IDENT) têm representação gráfica similar, apenas com alteração do sentido dos caminhos (setas) entre os constructos no modelo estrutural.

As equações estruturais para os quatro modelos são:

\begin{tabular}{|c|c|c|c|c|}
\hline \multirow[t]{3}{*}{ "modelo ACEITA": } & REQUIP & $=$ & $\rho_{Q C}$ & ACEITA $+e_{Q}$ \\
\hline & REORG & $=$ & $\rho_{\mathrm{GC}}$ & ACEITA $+e_{G}$ \\
\hline & IDENT & $=$ & $\rho_{\mathrm{IC}}$ & ACEITA $+e_{I}$ \\
\hline \multirow[t]{3}{*}{ "modelo REQUIP": } & ACEITA & $=$ & $\mathrm{CQ}$ & $\mathrm{EQUIP}+\mathrm{e}_{\mathrm{C}}$ \\
\hline & REORG & $=$ & $\mathrm{GQ}$ & EQUIP $+e_{G}$ \\
\hline & IDENT & $=$ & $\mathrm{IQ}$ & EQUIP $+e_{1}$ \\
\hline \multirow[t]{3}{*}{ "modelo REORG": } & ACEITA & $=$ & $\rho_{C G}$ & REORG + \\
\hline & REQUIP & $=$ & $\rho_{Q G}$ & $\mathrm{REORG}+\mathrm{e}_{\mathrm{Q}}$ \\
\hline & IDENT & $=$ & $\rho_{\mathrm{IG}}$ & REORG + $e_{1}$ \\
\hline \multirow[t]{3}{*}{ "modelo IDENT": } & ACEITA & $=$ & $\rho_{\mathrm{Cl}}$ & IDENT $+e_{C}$ \\
\hline & REQUIP & $=$ & $\rho_{\mathrm{QI}}$ & IDENT $+e_{c}$ \\
\hline & REORG & $=$ & $\rho_{\mathrm{GI}}$ & IDENT $+e_{G}$ \\
\hline
\end{tabular}

\subsection{Procedimento de avaliação e escolha do modelo integrado}

A análise das relações estruturais hipotetizadas entre os constructos foi realizada para a avaliação do modelo integrado proposto. Tal procedimento leva 
em consideração os índices de ajuste do modelo e da significância e magnitude dos coeficientes de regressão (parâmetros) estimados para cada equação estrutural definida pela relação das variáveis latentes (Hoyle, 1995; Hair Jr. et al., 1998; Garver e Mentzer, 1999; Ullman, 2001).

$\mathrm{Na}$ identificação da significância dos coeficientes de regressão, foram analisados seus $t$-values, considerando significantes valores superiores a "1,96" (nível de significância de 0,05) (Dunn, Seaker e Waller, 1994). Partindo da presença de coeficientes de regressão significativos, conclui-se a existência de comprovação empírica da relação entre as variáveis latentes (Chou e Bentler, 1995; Hair Jr. et al., 1998). Com relação ao uso das medidas de ajuste para apreciação do modelo, Garver e Mentzer (1999) afirmam que, existindo uma avaliação satisfatória desses índices dentro das faixas de aceitação, conclui-se que o modelo possui validade preditiva.

Uma outra medida a ser considerada na verificação do modelo é o coeficiente de determinação $\left(R^{2}\right)$ dos ajustes das equações estruturais modeladas, pois segundo Hair Jr. et al. (1998), estes apontam a variância explicada da variável dependente associada a um conjunto de variáveis independentes da equação estrutural. A presença do coeficiente de determinação elevado indica um maior poder explicativo da equação de regressão, tendo assim, uma maior capacidade preditiva da variável dependente.

A conveniência de se promover alterações no modelo, buscando maior adequação dos constructos, é feita por meio de medidas de ajustamento que, de forma geral, quantificam as variações da matriz de entrada observada com aquela predita pelo modelo proposto (medidas de ajustes absolutas) ou comparam o modelo proposto com um modelo nulo (medidas de ajustes incrementais). Considerando os resultados obtidos no processo de avaliação do modelo, reespecificações do modelo podem ser requeridas. Tal processo acontece a partir da adição ou redução do número de parâmetros estimados no modelo original, desde que exista justificativa teórica para sua realização (Hair Jr. et al., 1998).

Assim, nesta fase foram avaliados todos os quatro modelos (REQUIP, REORG, ACEITA E IDENT), buscando-se a compreensão das relações estruturais hipotetizadas. 
Os ajustes dos modelos estruturais usaram a análise de regressão múltipla para apurar os efeitos causais entre as variáveis, calculando os "coeficientes de caminho" (path coefficients).

Os métodos alternativos escolhidos foram o dos mínimos quadrados generalizados (generalized least squares - GLS), o dos mínimos quadrados ponderados (weighted least squares - WLS) e o dos mínimos quadrados nãoponderados (unweighted least squares - ULS). Em cada um deles, sob a estrutura de antecedentes sociais, foram verificados não só os valores adotados no ajuste dos modelos de medidas, mas também os $t$-values dos coeficientes de regressão, calculados pelo quociente entre o valor estimado e seu erro padrão. 0 método que neste estudo obteve melhores índices foi de o dos mínimos quadrados não-ponderados - ULS destacando que este método não é permissivo com respeito à normalidade, pois não requer de uma normalidade forte, como é o caso do método MLE. A análise foi amparada complementarmente pelo gráfico QPlot fornecido pelo LISREL $^{\circledR}$ e que apresenta a distribuição dos resíduos padronizados relativamente a uma linha de $45^{\circ}$ do eixo. A proximidade dos pontos a essa linha indica distribuição normal dos resíduos (Hayduk, 1987).

Assim, foi rodado o software LISREL e procurando maximizar os resultados foi eliminada a variável v10 ("Os membros da equipe têm um relacionamento baseado na confiança mútua") por proporcionar menor carga fatorial e erros de mensuração, ficando no final formados os 4 constructos da seguinte forma:

- as variáveis COA1, COA2, COA4 formaram o constructo denominado de relacionamento com a equipe e identificado com a sigla REQUIP;

- as variáveis COD2, COO1, COO2 e MOA1 formaram o constructo relacionamento com a organização e identificado com a sigla REORG;

- as variáveis TEA2 e TEA3 formaram o constructo aceitação e participação e identificado com a sigla ACEITA; e finalmente

- as variáveis MOO1 e TEM1 formaram o constructo identidade e identificado com a sigla IDENT.

A partir da análise fatorial confirmatória, foi rodado o programa do LISREL que resultou em quatro modelos, sendo um para cada constructo: ACEITA, REQUIP, REORG e IDENT. Cada modelo tinha como elemento gerador o construto predominante (Figuras 4.6 a 4.9). Dos quatro modelos apenas os 
modelos REQUIP e ACEITA apresentaram o índice RMSEA dentro dos valores referenciais da Tabela 4.11. Os resultados representativos, dos quatro modelos do programa LISREL encontram-se nos Anexos VI (ACEITA), VII (REQUIP), VIII (REORG) e IX (IDENT) no final deste estudo. Destacam-se nestes Anexos entre outros os resíduos normalizados, as equações de medidas, as equações estruturais, o gráfico dos resíduos normalizados e a figura do modelo.

Tabela 4.11 - Medidas de ajustamento para os modelos REQUIP e ACEITA

\begin{tabular}{l|c|c|c}
\hline \multicolumn{1}{c|}{ Medidas } & $\begin{array}{c}\text { Valores } \\
\text { ajustados } \\
\text { REQUIP }\end{array}$ & $\begin{array}{c}\text { Valores } \\
\text { ajustados } \\
\text { ACEITA }\end{array}$ & $\begin{array}{c}\text { Valores } \\
\text { referenciais }\end{array}$ \\
\hline Qui-quadrado ponderado & $\mathbf{2 , 6 9}$ & $\mathbf{2 , 5 6}$ & Abaixo de 5,00 \\
\hline $\begin{array}{l}\text { RMSEA - root mean square } \\
\text { error of approximation }\end{array}$ & $\mathbf{0 , 0 7 5}$ & $\mathbf{0 , 0 7 2}$ & Entre 0,05 e 0,08 \\
\hline NFI - Normed fit index & $\mathbf{1 , 0 0}$ & $\mathbf{1 , 0 0}$ & Acima de 0,90 \\
\hline NNFI - Nonnormed fit index & $\mathbf{1 , 0 2}$ & $\mathbf{1 , 0 2}$ & Acima de 0,90 \\
\hline CFI - Comparative fit index & $\mathbf{1 , 0 0}$ & $\mathbf{1 , 0 0}$ & Acima de 0,90 \\
\hline GFI - Goodness-of-fit index & $\mathbf{0 , 9 9}$ & $\mathbf{0 , 9 9}$ & Acima de 0,90 \\
\hline AGFI - Adjusted goodness-of-fit & $\mathbf{0 , 9 8}$ & $\mathbf{0 , 9 8}$ & Acima de 0,90 \\
\hline
\end{tabular}

Fonte: Programa LISREL ${ }^{\circledR}$

Os modelos REORG e IDENT não atenderam aos valores referenciais do índice de ajuste RMSEA citado na Tabela 4.11, o qual deve variar entre "0,05" e "0,08", sendo que o modelo REORG obteve um índice RMSEA de "0,10" e o modelo IDENT um RMSEA de "0,094", ambos os valores acima do valor de corte de "0,08".

A Tabela 4.11 reúne os valores referenciais das medidas de ajuste escolhidas anteriormente e registra os resultados para os dois modelos sobrantes: REQUIP e ACEITA.

Analisando os modelos sobrantes REQUIP e ACEITA, nota-se na Tabela 4.11 que existem apenas pequenas diferenças nos índices obtidos por ambos modelos nos índices Qui-quadrado ponderado e RMSEA, já que os restantes índices apresentam exatamente os mesmos valores para ambos modelos.

Estudando a Tabela 4.11, encontram-se o índice "Qui-quadrado ponderado" com valor de "2,69" para o modelo REQUIP e o valor de "2,56" para o 
modelo ACEITA, e, o índice "RMSEA" com valor de "0,075" para o modelo REQUIP e de "0,072" para o constructo ACEITA, sendo que ambas diferenças são muito pequenas para tomar uma decisão na escolha de um dos 2 modelos. Assim, para optar por um dos dois modelos citados, decidiu-se então recorrer ao critério de escolha de aquele modelo que apresentasse os menores resíduos normalizados.

Comparando a Tabela 4.12 do modelo REQUIP e a Tabela 4.13 do modelo ACEITA, ambas para os resíduos normalizados, observam-se que na Tabela 4.12 os valores para o modelo REQUIP são o menor resíduo com valor "2,87" e o maior resíduo com valor de "3,3". A Tabela 4.13 indica o menor resíduo do modelo ACEITA com valor de "-2,03" e o maior resíduo com valor com "3,89".

Confrontando ambos os resíduos normalizados dos modelos sobrantes, temos que o modelo ACEITA obteve os menores valores. Por outro lado, comparando o índice de ajuste RMSEA de ambos os modelos, observam-se que o modelo ACEITA apresenta um índice de RMSEA mais distante do limite superior de "0,08", ou seja, finalmente concluí-se, que o modelo ACEITA possui um melhor índice de RMSEA e uma menor quantidade de resíduos normalizados, e assim, consequentemente, é o modelo escolhido deste estudo sendo apresentado na Figura 4.11 mais adiante.

\subsection{Resultados do modelo escolhido}

Olhando a seguir o modelo escolhido aceitação e participação - ACEITA da Figura 4.11, encontram-se suas duas variáveis independentes ou exógenas, v11 e v12, que formam o constructo ACEITA, das quais a variável v11 apresenta uma carga fatorial com valor de "0,67" e um erro com valor de "0,55", e, a variável v12 com carga fatorial de "0,59" e um erro de "0,65". Do lado direito do modelo ACEITA, encontram-se as variáveis dependentes ou endógenas v1 a v9 e os três constructos de cima para baixo: REQUIP, REORG e IDENT. No constructo REQUIP, a variável v1 apresenta uma carga fatorial de "0,87" e um erro com valor de "0,24". A variável v2 com uma carga fatorial de "0,88" e um erro com valor de "0,23". A variável v3 tem uma carga fatorial de "0,77" e um erro com valor de "0,41". No constructo REORG a variável v4 detêm uma carga fatorial de "0,74" e um erro com valor de "0,45". A variável v5 com uma carga fatorial de "0,86" e um erro com valor de "0,25". A variável v6 obteve uma carga fatorial de "0,85" e um 
erro com valor de "0,28". A variável v7 obteve uma carga fatorial de "0,64" e um erro com valor de "0,59".

Tabela 4.12 - Resíduos normalizados do modelo REQUIP

\begin{tabular}{|c|c|c|c|c|c|c|}
\hline & v4 & v5 & v6 & v7 & v8 & v9 \\
\hline v4 & - - & & & & & \\
\hline v5 & -1.29 & - & & & & \\
\hline v6 & -1.17 & -- & -- & & & \\
\hline v7 & 0.59 & - - & - - & - - & & \\
\hline v8 & -0.13 & 0.51 & -0.38 & 0.98 & - - & \\
\hline v9 & -0.30 & 0.90 & 0.05 & -0.13 & - - & -- \\
\hline v11 & 1.22 & 1.08 & 1.23 & 0.06 & -0.92 & -0.37 \\
\hline v12 & 0.19 & 1.48 & 2.55 & -0.16 & 0.99 & 1.49 \\
\hline v1 & 1.06 & -2.05 & -2.87 & -0.67 & 0.44 & 0.29 \\
\hline v2 & 0.11 & -1.23 & -1.10 & -1.24 & -0.31 & -1.05 \\
\hline v3 & 0.55 & 0.17 & 0.33 & 0.92 & -0.59 & -0.64 \\
\hline
\end{tabular}

Tabela 4.12 - Resíduos normalizados do modelo REQUIP (continuação)

$\begin{array}{lrrrrr} & \text { v11 } & \text { v12 } & \text { v1 } & \text { v2 } & \text { v3 } \\ \text { v11 } & -- & & & & \\ \text { v12 } & 0.00 & -- & & & \\ \text { v1 } & -0.77 & -0.54 & 0.00 & & \\ \text { v3 } & -0.58 & -1.04 & 3.31 & 0.00 & 0.00\end{array}$

Resumo estatístico dos resíduos normalizados do modelo REQUIP:

Menor resíduo normalizado $=-2.87$

Média dos resíduos normalizados $=0.00$

Maior resíduo normalizado $=3.31$ 
Tabela 4.13 - Resíduos normalizados do modelo ACEITA

\begin{tabular}{|c|c|c|c|c|c|c|}
\hline & v1 & v2 & v3 & v4 & v5 & v6 \\
\hline v1 & - - & & & & & \\
\hline v2 & 1.39 & -- & & & & \\
\hline v3 & -0.73 & - - & - - & & & \\
\hline v4 & 1.80 & 0.89 & 1.34 & -- & & \\
\hline v5 & -1.06 & -0.25 & 1.13 & -1.37 & -- & \\
\hline v6 & -1.95 & -0.22 & 1.26 & -1.33 & - - & - - \\
\hline v7 & 0.02 & -0.54 & 1.60 & 0.77 & - - & - - \\
\hline v8 & 0.98 & 0.24 & -0.05 & -0.36 & 0.22 & -0.67 \\
\hline v9 & 0.98 & -0.13 & 0.10 & -0.60 & 0.56 & -0.34 \\
\hline v11 & -0.41 & -0.24 & 0.02 & 0.01 & -0.62 & -0.41 \\
\hline v12 & -0.41 & -0.91 & -2.03 & -1.05 & -0.15 & 1.08 \\
\hline
\end{tabular}

Tabela 4.13 - Resíduos normalizados do modelo ACEITA (continuação)

$\begin{array}{lrrrrr} & v 7 & v 8 & v 9 & v 11 & \text { v12 } \\ \text { v7 } & -- & & & \\ \text { v8 } & 0.80 & -- & & \\ \text { v9 } & -0.38 & -- & -- & \\ \text { v11 } & -1.14 & -1.48 & -1.22 & 0.00 & \\ \text { v12 } & -1.31 & 0.46 & 0.90 & 3.89 & --\end{array}$

Resumo estatístico dos resíduos normalizados do modelo ACEITA:

Menor resíduo normalizado= -2.03

Média dos resíduos normalizados $=0.00$

Maior resíduo normalizado $=3.89$ 


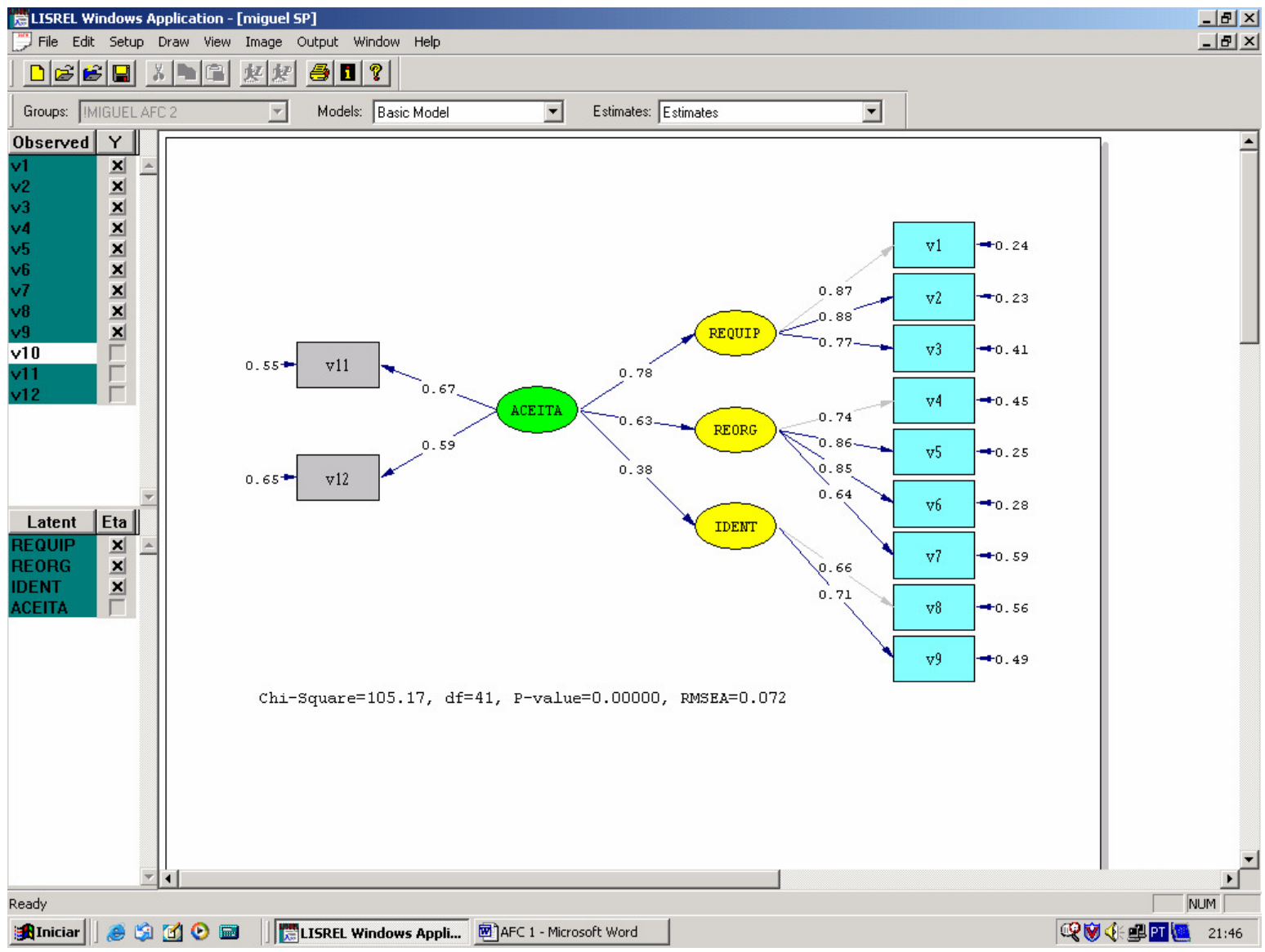

Figura 4.11 Modelo ACEITA. Fonte: LISREL.

No constructo identidade - IDENT a variável v8 apresenta uma carga fatorial de "0,66" e um erro com valor de "0,56". A variável v9 tem uma carga fatorial de "0,71" e um erro de "0,49".

O constructo aceitação e participação - ACEITA, apresenta o grau de aderência mais baixo dos três, "0,38", junto ao constructo Identidade - IDENT, ou seja, isto indicaria que ao existir uma maior aceitação e participação diminui a identidade dos funcionários, dito de outra forma, na medida em que aumenta a aceitação e participação os servidores estes esquecem seus anseios pessoais.

O constructo aceitação e participação - ACEITA, apresenta um grau de aderência intermediário, "0,63", quando relacionado ao constructo relacionamento com a organização - REORG, concluindo assim, que neste caso não existe uma relação causal acentuada entre ambos os constructos, nem favorável e nem desfavorável.

O constructo aceitação e participação - ACEITA, obteve o maior grau de aderência, com valor de "0,78" junto ao constructo relacionamento com a equipe - REQUIP, resultando ser este o maior relacionamento causal, indicando 
que, uma maior aceitação e participação dos servidores, indicaria num maior relacionamento com a equipe. Lembra-se ao leitor que anteriormente no item 4.11 observou-se que justamente estes dois constructos, ACEITA e REQUIP, são compostos exclusivamente por variáveis provenientes de domínios denominados de ambiente e agora resultou que ambos constructos apresentaram o maior grau de aderência entre os quatros, ou seja um maior relacionamento causal entre ambos. Analisando em detalhe a afirmação anterior e lembrando as variáveis que compõem o constructo aceitação e participação - ACEITA, logo a seguir, e posteriormente as do constructo relacionamento com a equipe - REQUIP:

○ $\mathrm{V} 11=\mathrm{TEA} 2$ = As pessoas não têm medo de sugerir novas e diferentes idéias, mesmo que estas sejam extremamente simples;

○ $\quad$ V12 $=$ TEA3 = É normal que as discordâncias sejam expressas sem que as pessoas sejam malvistas.

As variáveis que compõem o constructo relacionamento com a equipe REQUIP foram:

○ V1 = COA1 = Há cooperação dentro da equipe de trabalho;

○ $\quad$ 2 $=$ COA2 = Destaca-se o clima de alegria e bom humor na equipe de trabalho;

○ V3 = COA4 = As informações são precisas e confiáveis.

Comparando as variáveis componentes de ambos os constructos, ACEITA e REQUIP, pode-se concluir que: o constructo REQUIP, que apresenta o maior grau de aderência dos três ("0,78") e ao considerar-los junto às variáveis v1 e v2 que apresentam às maiores cargas fatoriais das nove variáveis dependentes, entende-se que o maior grau de aderência ao constructo aceitação e participação - ACEITA - dos servidores, tem como destaque principal as palavras cooperação, clima de alegria e bom humor. Seria um ambiente descontraído resultante das três idéias citadas, o qual facilita a espontaneidade do grupo para este gerar idéias eficientes, que podem ser até as mais simples, mas tudo refletido num ambiente que propicia sempre um maior desempenho.

Analisando as duas variáveis (v2 e v11) que se caracterizam por ter obtido as maiores cargas fatoriais na ligação dos 2 modelos com maior grau de aderência (ACEITA e REQUIP), observa-se que a variável v2 do modelo REQUIP é a variável que se destaca pelo clima de alegria e bom humor na equipe, existindo uma identificação maior com a variável v11 do modelo ACEITA onde as 
duas caracterizam-se pelo clima mais aberto, mais descontraído, o qual tem como resultado um ambiente mais propicio o que tem como resultado um melhor desempenho.

A relação causal do modelo escolhido do constructo ACEITA como elemento causador, ao ser confrontado conjuntamente com as variáveis v2 e v3, resulta numa maior carga fatorial da primeira porque o clima descontraído melhora o desempenho, mas a variável v3 sobre as informações, pode lembrar a formalização das mesmas que são os procedimentos do sistema da qualidade ou da organização e, isto naturalmente que representa para alguns não ser uma fonte de ambiente propicio ao desempenho.

No confronto do modelo escolhido frente às variáveis $v 7, v 4, v 6$ e v5, representadas nessa ordem de menor a maior carga fatorial obtida, nota-se numa escala de dificuldades para gerar um melhor desempenho. Nessa escala a maior das dificuldades seria a pouca motivação no serviço público, logo a insatisfação com o sistema de avaliação destas entidades, posteriormente a falta de reconhecimento da valorização dos servidores para estas entidades e finalmente menos grave resulta ser o relacionamento servidor - organização. Entenda-se o anterior como primeiras idéias que precisariam de novos estudos.

Ao confrontar o modelo escolhido conjuntamente com as variáveis de resultado inverso, v8 e v9, a carga fatorial maior da primeira variável pode ser fruto da preocupação do servidor com a imagem do centro de pesquisa na comunidade. O anterior é mais uma característica individualista do servidor e que é justamente o inverso de aquilo que representa a variável v9, que é o trabalho em equipe, de características muito diferentes na sua concepção e por isso resulta numa carga fatorial maior que da variável v8.

Aproveitando a citação bem conhecida do professor George H. Litwin, que clima organizacional é a qualidade do ambiente dentro da organização, e que é percebida pelos membros dessa organização como sendo boa ou não, e que influencia o seu comportamento; pode-se entender que, a influencia da qualidade do ambiente no comportamento dos servidores no cenário estudado, seria uma influência positiva e que favoreceria o maior desempenho.

Em função do anterior a mensagem que resulta é tentar trabalhar sempre o ambiente como qualidade do clima organizacional para melhoria do desempenho nos centros de pesquisa. 


\section{CAPÍTULO 5}

\section{CONCLUSÕES}

A grande vantagem da primeira pesquisa foi permitir a redução do elevado número de fatores de desempenho de uma forma gradual e condizente com a bibliografia encontrada, para que um número viável pudesse ser usado na pesquisa final e principalmente poder trabalhar com um número reduzido de fatores de desempenho.

Foi considerada a metodologia aplicável a institutos de pesquisa e mais especificamente aos seus laboratórios. É possível aplicar esta metodologia em institutos de pesquisa de diferentes áreas, como foi neste caso no campo nuclear e no campo aeroespacial, bem como, acredita-se que ela possa ser aplicada em outras áreas também.

O questionário da segunda fase apresentou dificuldades na sua aplicação devido ao elevado número de variáveis. Acredita-se que uma versão reduzida após uma análise fatorial exploratória e com um número menor de questões divididas em partes, sem dúvida, seria uma ferramenta de avaliação para organizações, inclusive de outros seguimentos e outros ambientes.

No caso do CTA o comprometimento dos servidores é principalmente com a ocupação, com a carreira e depois com a organização.

Ricco (1998) concluiu na época que mesmo em condições adversas os pesquisadores do CTA estavam comprometidos com a organização e o componente que se destacou dos três tipos foi o afetivo. Este estudo realizado após 8 anos do anterior confirma as conclusões de Ricco (1998) estendendo o comprometimento aos outros servidores do CTA e tendo o componente afetivo como destaque tanto no comprometimento organizacional como no ocupacional.

Ficou comprovado no estudo que os grupos (mais representativos) e locais (laboratórios no IPEN e divisões no CTA) que apresentaram um maior grau de comprometimento foram os que têm tendência a obter índices maiores de desempenho. O inverso da questão não foi comprovado, ou seja, menor comprometimento não significa necessariamente menor desempenho. 
Os valores de comprometimento e desempenho dos laboratórios são muito maiores que dos grupos formados, supondo que os primeiros são grupos com uma afinidade natural resultado do compartilhamento do dia-a-dia em cada laboratório e na procura de um objetivo comum, e os segundos são grupos reunidos por uma característica em comum, mas que não vivem o convívio direto dos primeiros.

O estudo obteve resultados diferentes de Mathieu e Zajac (1990) ao encontrar maiores níveis de comprometimento no IPEN, instituto que apresenta maiores índices de capacitação (ou titulação) que no CTA, provando-se que a capacitação tem correlação positiva com a o comprometimento. Observa-se nas Tabelas do IPEN (4.4 e 4.6) índices maiores que os obtidos no CTA (4.3 e 4.5) principalmente no tocante ao comprometimento instrumental citados pelos autores acima. Destaca-se que no estudo de Mathieu e Zajac a correlação apresentou pequenos valores negativos o qual não aconteceu no IPEN onde destaca-se que a maior titulação significa numa enorme motivação por ela representar uma gratificação de $52,5 \%$ sobre o salário-base para os mestres e de $105 \%$ para os doutores.

No CTA com um banco de dados mais robusto, os dois locais mais comprometidos foram os mesmos nos seus maiores índices nos seus fatores do desempenho.

O questionário desenvolvido tornou-se mais robusto e validado após a análise fatorial. A análise fatorial exploratória validou o questionário e o melhorou ao minimizar o número de variáveis, deixando este mais acessível na sua aplicação. Foram identificados após a análise fatorial exploratória os doze novos fatores que refletem o caso do CTA com sessenta variáveis e os cinco para o IPEN com onze variáveis.

Variáveis diferentes dos quatro fatores de desempenho que possuem um alto comprometimento e estando relacionadas com o ambiente são as variáveis que se destacam na percepção de um maior desempenho.

A análise fatorial exploratória para redução de dados procurando definir o modelo teórico para dar início na análise do LISREL, não relacionou nenhuma variável do fator de desempenho liderança, o qual indicaria a menor importância deste fator perante os outros três. Em ordem de grau de importância resultou primeiro o clima organizacional, logo o trabalho em equipe e finalmente a 
motivação. As duas variáveis, v11 e v2, que fizeram parte do caminho com o maior grau de aderência entre os constructos e da maior carga fatorial entre 0 constructo e os indicadores, pertencem aos fatores de desempenho trabalho em equipe e clima organizacional, que se destacaram como os mais importantes fatores de desempenho dos 4 estudados.

Utilizando a modelagem de equações estruturais foi selecionado o melhor modelo de quatro resultantes que explicam o relacionamento causal entre as variáveis principais de ambos os casos estudados. Destaca-se o forte relacionamento causal favorável entre os constructos ACEITA e REQUIP, sendo que ambos foram formados por variáveis oriundas de domínios de ambiente, concluindo ser esta característica o grande motivador do desempenho.

Talvez seja o anterior a indicação que o ambiente de trabalho seja no cenário estudado a futura preocupação dos dirigentes destas organizações para obter melhorias que propiciarão através do melhor desempenho de novos caminhos, de novas fontes de recursos, da melhoria da imagem frente à sociedade e maior motivação dos seus servidores.

Acredita-se que um passo importante foi dado no conhecimento do comprometimento e desempenho em centros de pesquisas, locais estes que sentem a falta de estudos e experiências anteriores na área de gestão para se estruturar e tornar-se mais competitivos. 


\section{CAPÍTULO 6}

\section{RECOMENDAÇÕES E TRABALHOS FUTUROS}

Neste estudo a técnica da SEM foi utilizada apenas junto às variáveis de desempenho, não sendo aproveitado o banco de dados com as variáveis de comprometimento, assim, podem-se estudar os diversos relacionamentos causais do comprometimento a seguir:

$\circ$... Estabelecer o relacionamento causal entre 0 comprometimento organizacional e cada um dos quatro fatores de desempenho;

$\circ$...Estabelecer o relacionamento causal entre o comprometimento ocupacional e cada um dos quatro fatores de desempenho.

O comprometimento pode ser confrontado a partir dos grupos ou associações entre eles dos três tipos de comprometimento definidos por Meyer et al. (1993): afetivo, instrumental e normativo. Incluindo os descomprometidos, os comprometidos nos três tipos e suas associações.

$\mathrm{Na}$ linha anterior pode-se estudar o relacionamento entre um determinado tipo de comprometimento para detalhá-lo junto a novos grupos de respondentes, como por exemplo, o comprometimento ocupacional afetivo junto aos casados, aproveitando para verificar a conclusão de Mathieu e Zajac (1990) que os casados têm maior níveis de comprometimento.

Este estudo foi realizado com uma coleta de dados de corte transversal, estudos semelhantes poderão ser realizados com corte longitudinal num levantamento e acompanhamento de dados num certo período de tempo.

Os estudos realizados e sugeridos poderão ser realizados em outros centros de pesquisa de outras áreas de destaque, ou até poderiam ser realizados também em centros de pesquisa da área privada. Replicar o estudo em centros de pesquisa de diversos tamanhos, em cenários distintos, de culturas semelhantes e distintas às dos casos estudados, procurando descobrir modelos explicativos do comprometimento e do desempenho parece um caminho para aumentar o conhecimento destes locais pesquisados. 


\section{REFERÊNCIAS BIBLIOGRÁFICAS}

AAKER, David A. Strategic Market Management. 5 ed. New York: John Wiley \& Sons, Inc. 1998.

ALLEN, Natalie J.; MEYER, John P. The measurement and antecedents of affective, continuance and normative commitment to the organization. Journal of Occupation Psychology, v. 63, part 1, p.1-18, march 1990.

ANDERSON, James C.; GERBING, David W. Structural equation modeling in practice: a review and recommended two-step approach. Psychological Bulletin, v. 103 , n. 3 , p. 411-23, 1988.

ARANYA, N.; POLLOCK, J.; ARMENIC, J. An examination of professional commitment in public accounting. Accounting, Organizations and Society, v. 6, p. 271-280, 1981.

ARBUCKLE, James L. Amos user's guide, version 3.6. Chicago, Ill.: Marketing Division, SPSS Inc.: SmallWaters Corporation, 1997.

ARCHER, Earnest R. Mito da motivação. In: BERGAMINI, Cecília W; CODA, Roberto. Psicodinâmica da vida organizacional: motivação e liderança. 2 ed. SP: Atlas, 1997.

ARYEE, Samuel; TAN, Kevin. Antecedents and outcomes of career commitment. Journal of Vocational Behavior. V. 40, n. 3, p. 288-305, june 1992.

BAGOZZI, Richard P.; BAUMGARTNER, Hans. The Evaluation of Structural Equation Models and Hypothesis Testing. In: BAGOZZI, Richard P. Principles of Marketing Research. Cambridge: Blackwell, p. 386-422, 1994.

BAGOZZI, Richard P.; YI, Youjae; PHILLIPS, Lynn W. Assessing Construct Validity in Organizational Research. Administrative Science Quarterly, v. 36, n. 3, p. 421-458, september, 1991.

BANDEIRA, M. L. Investigando o impacto das Políticas de Recursos Humanos no Comprometimento Organizacional em uma empresa de serviços do setor público. Dissertação de Mestrado - UFMG/CEPEAD, Universidade Federal de Minas Gerais, Belo Horizonte. 1999.

BARBOSA, Solange L.; FARIA, José H. Comprometimento: uma avaliação crítica sobre a práxis organizacional. Florianópolis: ENAMPAD, $\mathbf{2 4}^{\circ}$, Anais...2000.

BARROSO, Lúcia P.; ARTES, Rinaldo. Análise Multivariada. 48 $^{\mathrm{a}}$ reunião da RBRAS e $10^{\circ}$ SEAGRO. 07-11.07.03. Universidade Federal de Lavras. LavrasMG. 2003.

BASTOS, Antonio V. B. Comprometimento no Trabalho: o estado da arte e uma possível agenda de pesquisa. Cadernos de Psicologia, v. 1, n. 1, p. 44-63, 1996. 
BASTOS, A. V. B. Comprometimento no Trabalho: os caminhos da pesquisa e os seus desafios teórico-metodológicos. In TAMAYO, A. et al. Trabalho, Organização e Cultura. São Paulo: Cooperativa de Autores Associados, cap. 8, p. 105-127, 1997.

BASTOS, Antonio V. B. Medidas de comprometimento no contexto de trabalho: um estudo preliminar de validade discriminante. PSICO, v. 24, n. 2, p. 29-48, 1992.

BASTOS, Antonio V. B. O Conceito de Comprometimento: sua natureza e papel nas explicações do comportamento humano no trabalho. Enanpad, 18 ${ }^{\circ}$, Anais... Recursos Humanos, p. 287-304, 1994.

BASTOS, Antonio V. B. Padrões de comprometimento com a profissão e a organização: o impacto de fatores pessoais e da natureza do trabalho. Revista de Administração, São Paulo, v. 35, n. 4, p. 48-60, out./dez. 2000.

BECKER, H. S. Notes on the concept of commitment. The American Journal of Sociology. v. 66, p. 32-40, 1960.

BECKER, T. E. Foci and bases of commitment: are they distinctions worth making? Academy of Management Journal, v. 35, n. 1, p. 232-244, 1992.

BENTLER, P. M. Theory and implementation of EQS: a structural equation program. Los Angeles: BMDP Statistical Software, 1985.

BERGAMINI, Cecília W; CODA, Roberto. Apresentação da segunda edição. In: 1997. (Org.) Psicodinâmica da vida organizacional. São Paulo: Atlas, p. 7-19.

BERGAMINI, Cecília W. Motivação nas organizações. 4 ed. SP: Atlas, 1997.

BERGAMINI, Cecília W. Liderança: administração do sentido. SP: Atlas, 1994.

BERGAMINI, Cecília W. O desafio da liderança. In: BERGAMINI, Cecília W.; CODA, Roberto (Org.) Psicodinâmica da vida organizacional. São Paulo: Atlas, 2 ed. p. 319-342, 1997 a.

BISHOP, Ronald C.; SOLOMON, Esther. Sex differences in career development: locus of control and career commitment effects. Psychological Reports, v. 65, p. 107-114, 1989.

BLAU, Gary J. Testing the generalizability of a career commitment measure and its impact on employee turnover. Journal of Vocational Behavior, v. 35, p. 88103, 1989.

BLAU, Gary J.; PAUL, Allison; JOHN, Natalie St. On developing general index of work commitment. Journal of Vocational Behavior, v. 42, n. 3, p. 298-314, june 1993. 
BLAU, Gary J. The measurement and prediction of career commitment. Journal of Occupational Psychology, v. 58, n. 4, p. 277-288, 1985.

BLAU, Gary J. Further exploring the meaning and measurement of career commitment. Journal of Vocational Behavior, v. 32, p. 284-297, 1988.

BOLLEN, Kenneth A. Structural equations with latent variables. New York: John Wiley \& Sons, 1989.

BOMTEMPO, Maurício S. Análise dos fatores de influência na escolha pelo curso de graduação em administração: um estudo sobre as relações de causalidade através da modelagem de equações estruturais / Maurício Scagliante Bomtempo. - São Paulo: UNIFECAP. Dissertação de mestrado, 142f., 2005.

BORGES-ANDRADE, J. E. Comprometimento organizacional na Administração Pública e em seus segmentos meio e fim. XIX Reunião Anual de Psicologia, p. 50, 1989.

BOWDITCH, James L.; BUONO, Anthony F. Elementos de comportamento organizacional. São Paulo, Br; Austrália: Pioneira Thomson, 1992.

BRESCANCINI, Ana M. Insatisfeito, Satisfeito, Motivado. Revista Fundap n. 2. Disponível em: $<$ http://www.revista.fundap.sp.gov.br/revista2/paginas/ferramentas.htm>. Acesso em 10 maio 06.

BUCHANAN, Bruce. Building organizational commitment: the socialization of managers in work organizations. Administrative Science Quarterly, v. 18, p. 533546, 1974.

BYRNE, Barbara M. One Application of Structural Equation Modeling From Two Perspectives: Exploring the EQS and LISREL Strategies. In: HOYLE, Rick H (editor). Structural Equation Modeling: concepts, issues, and applications. London: SAGE, 1995.

BYRNE, Barbara M. Structural equation modeling with LISREL, PRELIS, and SIMPLIS: basic concepts, applications, and programming. Mahwah: Lawrence Erlbaum Associates, 1998.

CAMPBELL, J. P.; DUNNETTE, M. D.; LAWLER III, E.E.; WEICK JR, K. E. Managerial behavior, performance and effectiveness. New York: McGraw-Hill. 1970.

CARSON, Kerry D.; BEDEIAN, Arthur G. Career commitment: construction of a measure and examination of its psychometric properties. Journal of Vocational Behavior, v. 44, n. 3, p. 237-262, june 1994.

CASADO, T. O individuo e o grupo: a chave do desenvolvimento. In: FLEURY, M. T. L. (Org.). As pessoas na organização. São Paulo: Gente, p. 235-246, 2002. 
CASTRO, Claudio de M. Prática da pesquisa. São Paulo: McGraw-Hill, 1977.

CESAR, Ana M. R. V. C. Falar da dor, esvaziar o peito, ancorar o coração: uma metodologia para gestão de pessoas em situações de mudanças organizacionais / Ana Maria Roux Valentini Coelho César.- São Paulo: FEA/USP. Tese de doutorado, 244f., 2004.

CETIN, Munevver O. The Relationship Between Job Satisfaction, Occupational and Organizational Commitment. Journal of American Academy of Business, Cambridge; v. 8, n. 1, p. 78-88, mar. 2006.

CHANG JR., João. Gestão de Pessoas pelo desenvolvimento do Comprometimento Organizacional: uma abordagem holística e simultânea dos determinantes envolvidos no processo / João Chang Jr - São Paulo: FEA/USP. Tese (doutorado em administração), 192f., 2001.

CHAU, Patrick Y. K. On the use of construct reliability in MIS research: a metaanalysis. Information \& Management, v.35, n. 4, p. 217-227, april 1999.

CHIN, Wynne W. Issues and opinion on structural equation modeling. Management Information Systems Quarterly, Minneapolis, v. 22, n. 1, p. vii-xvi, mar. 1998.

CHOPRA, Deepak. A alma da liderança. HSM Management, p. 60-63, jul./ago. 2002.

CHOU, Chih-Ping; BENTLER, Peter M. Estimates and Tests in Structural Equation Modeling. In: HOYLE, Rick H (editor). Structural Equation Modeling: concepts, issues, and applications. London: SAGE, 1995.

CHURCHILL, Gilbert A. Marketing Research: methodological foundations. 7 ed. Orlando: The Dryden Press, 1999.

CODA, Roberto. Pesquisa de clima organizacional: uma contribuição metodológica. Tese de livre-docência. São Paulo: USP/FEA. 182f. 1992.

COOPER, Donald. R.; SCHINDLER, Pamela. S. Métodos de Pesquisa em Administração. 7 ed. Porto Alegre: Bookman, 2003.

CYMBAUM, John. Clima organizacional influencia no rendimento do trabalho. 29.11.2004. Disponível em: <http://www.calltocall.com.br/agenda.asp?|D=1982\&cat=Artigos >. Acesso em 07 fevereiro 2005.

DARDEN, William R.; HAMPTON, Ronald; HOWELL, Roy D. Career versus organizational commitment: antecedents and consequences of retail salespeoples' commitment. Journal of Retailing, v. 65, n. 1, p. 80-106, spring 1989.

DAVIS, Keith; NEWSTROM, John W. Comportamento humano no trabalho. São Paulo: Pioneira, 1992. 
DELUGA, Ronald J. The relationships of leader-member exchange with laissezfaire, transactional, and transformational leadership in naval environments. In: CLARK, Kenneth E.; CLARK, Miriam B.; CAMPBELL, David P. Impact of leadership, Greensboro: Center for Creative Leadership, 1992.

DILLON, William R.; GOLDSTEIN, Matthew. Multivariate analysis - methods and applications. New York: John Wiley \& Sons. 1984.

DILLON, William R.; MADDEN, Thomas J.; FIRTLE, Neil H. Marketing Research in a Marketing Environment. St Louis: Times Mirror, 1994.

DUNN, S. C.; SEAKER, R. F.; WALLER, M. A. Latent variables in business logistic research: scale development and validation. Journal of Business Logistics, $v$. 15, n. 2, p. 145-72, 1994.

ETZIONI, Amitai. Analise comparativa de organizações complexas: sobre o poder, o engajamento e seus correlatos. Rio de Janeiro: Zahar, 1974.

EVANS, Phil. Motivação. Rio de Janeiro: Zahar, 1976.

EVRARD, Yves; PRAS, Bernard; ROUX, Elyette. Market: études et recherches en marketing. 2 ed. Paris: Nathan, 1997.

FEHER, Ana C. M. Pesquisa de clima organizacional no IPEN. IPEN/Divisão de Desenvolvimento de Recursos Humanos. IPEN, 26 abril 2005. Entrevista concedida a Miguel Enrique Tejos-Saldivia.

FERREIRA, Ademir A.; REIS, Ana C. F.; PEREIRA, Maria I. Gestão empresarial: de Taylor aos nossos dias: evolução e tendências da moderna administração de empresas. São Paulo: Pioneira, 1997.

FERREIRA, Aurélio B. H. Novo Dicionário da Língua Portuguesa. - 2 ed. - Rio de Janeiro: Editora Nova Fronteira, 1986.

FIEDLER, Fred E. Liderança e administração eficaz. São Paulo: Pioneira, 1981.

FLEURY, Maria T. L.; FISCHER, Rosa M. Cultura e poder nas organizações. 2 ed. São Paulo: Atlas, 1996.

FONSECA, Carlos A. M.; BASTOS, Antonio V. B. Criatividade e comprometimento organizacional: suas relações com a percepção de desempenho no trabalho. EnANPAD, 26 ${ }^{\circ}$, Anais..GRT 588, Salvador, 2002.

FOREHAND, Garlie A.; GILMER, B. v. H. Environmental variation in studies of organizational behavior. Psychological Bulletin. v. 62, n. 6, p. 361-382, dec. 1964.

FORNELL, Claes; LARCKER, David F. Evaluating structural equation models with unobservable variables and measurement error. Journal of Marketing, v. 18, $n$. 1, p. 39-50, february, 1981. 
FRAME, J. Davidson. Managing projects in organizations: how to make the best use of time, techniques and people. San Francisco: Jossey-Bass, 1995.

GARDNER, John W. Liderança: sucesso e influência a caminho da modernidade. Rio de Janeiro: Record, 1990.

GARSON, G. David. PA765 - Statnotes: an online textbook. 2004. Disponível em: $<$ http://www2.chass.ncsu.edu/garson/pa765/structur.htm>. Acesso em: 07 fevereiro 2006.

GARVER, Michael S.; MENTZER, John T. Logistics research methods: employing structural equation modeling to test for constructs validity. Journal of Business Logistics, v. 20, n. 1, p. 33-57, 1999.

HACKMAN, J. Richard; OLDHAM, Greg R. Development of the job diagnostic survey. Journal of Applied Psychology, v. 60, n. 2, p. 159-170, 1975.

HAIR JR. Joseph F.; ANDERSON, Rolph E.; TATHAM, Ronald L.;BLACK, William C. Multivariate Data Analysis. 5 ed. New Jersey: Prentice Hall. 1998.

HALL JR., Calvin S.; LINDZEY, Gardner. Teorias da personalidade. 18 ed. São Paulo: Epu, v. 1. 1984.

HAMPTON, David R. Administração contemporânea. São Paulo: McGraw-Hill do Brasil, 1992.

HAYDUK, Leslie A. Structural equation modeling with LISREL: essentials and advances. Baltimore: The Johns Hopkins University Press, 1987.

HERSEY, Paul; BLANCHARD, Kenneth H. Psicologia para administradores: a teoria e as técnicas da liderança situacional. São Paulo: Epu, 1986.

HERZBERG, Frederick. One more time: how do you motivate employees? Harvard Business Review, v. 46, n. 1, p. 53-62, january-february, 1968.

HOYLE, Rick H (editor). Structural equation Modeling: concepts, issues, and applications. London: SAGE, 1995.

HOYLE, Rick $H$. The Structural equation Modeling: basic concepts and fundamental issues. In: HOYLE, Rick H (editor). Structural Equation Modeling: concepts, issues, and applications. London: SAGE, 1995b.

HOYLE, Rick H. \& PANTHER, Abigail T. Writing about Structural equation Models. In: HOYLE, Rick H (editor). Structural Equation Modeling: concepts, issues, and applications. London: SAGE, 1995.

HU, Li-tze; BENTLER, Peter M. Evaluating Model Fit. In: HOYLE, Rick H (editor). Structural Equation Modeling: concepts, issues, and applications. London: SAGE, 1995. 
HUNT, Shelby D.; CHONKO, Lawrence B.; WOOD, Van R. Organizational commitment and marketing. Journal of Marketing, v. 49, n. 1, p. 112-126, spring 1985.

JORESKOG, Karl G; SORBÖM, Dag. Lisrel 8 : user's reference guide. Lincolnwood, IL: Scientific Software International, 2001.

KANTER, R. M. Commitment and Social Organization: a study of commitment mechanism in Utopian Communities. American Sociological Review, v. 33, p. 499-517, 1968.

KATZENBACH, Jon R. Equipes campeãs: desenvolvendo o verdadeiro potencial de equipes e líderes. Rio de Janeiro: Campus, 2001.

KATZENBACH, Jon R.; SMITH, Douglas K. The wisdom of teams: creating the high-performance organization. Boston, Mass.: Harvard Business School Press, 1993.

KERLINGER, Fred N. Metodologia da pesquisa em ciências sociais: um tratamento conceitual. São Paulo: EPU, 1980.

KLEM, Laura. Path analysis. In: Grimm, Laurence G. and Yarnold, P. Reading and Understanding Multivariate Statistics, v. 1. Washington, DC: American Psychological Association. 1995.

KLINE, R. B. Principles and practice of structural equation modeling. New York: The Guilford Press, 1998.

KOSLOWSKY, Meni. Career commitment as a predictor of behavioral outcomes. The Journal of Social Psychology, v. 127, n. 5, p. 435-444, 1987.

KOTTER, John P. O fator liderança. São Paulo: Makron, McGraw-Hill, 1992.

KRUTMAN, Henriette M. Compartilhando Habilidades no INT: Um Projeto Organizacional Formativo. Nov. 1999. Disponível em: <http://www.bapera.com.br/REVISTA/Psicoterapia/compartilhando habilidades.ht

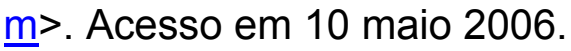

LAPLANCHE, Jean; PONTALIS, J. B. Vocabulário da psicanálise. 4 ed. São Paulo: Martins Fontes, 2001.

LAZAR, Bruce L. Occupational and organizational commitment and turnover intention of employees. Tese de doutorado. Universidade de Phoenix. $155 f$. 2006.

LAWLER III, Edward E. High-involvement management. San Francisco, Calif.: Jossey-Bass, 1991. 
LAWLER III, Edward E. Motivação nas organizações de trabalho. In: BERGAMINI, Cecília W.; CODA, Roberto. (Org.). Psicodinâmica da vida organizacional. São Paulo: Atlas, 1997.

LEITÃO, Jacqueline S. de S. Clima organizacional na transferência de treinamento. Revista de Administração, São Paulo, v. 31, n.3, p. 53-62, jul/set 1996.

LESSA, E. M. Equipes de alto desempenho: a tipologia de Jung nas organizações / Elvina Maciel Lessa. - 1 ed. São Paulo: Vetor, 2003.

LÈVY-LEBOYER, C. A crise das motivações. São Paulo: Atlas, 1994.

LIPP, Marilda N. Teoria do reforço de B. F. Skinner. In: DE LA PUENTE, Miguel. Tendências contemporâneas em psicologia da motivação. São Paulo: Autores Associados, 1982.

LITWIN, George H. Climate and motivation: an experimental study. In: KOL B. D. et al. (Eds) Organizational Psychology: a book of reading. Englewood Cliffs: Prentice-Hall, p. 109-123, 1971.

LITWIN, George H.; STRINGER JR, R. A. Motivation and Organizational Climate. Boston: Harvard University Press. 1968.

LITWIN, M.S. How to measure survey reliability and validity, Sage Publications, Inc, Survey Kit. 7. 1995.

LUTHANS, Fred; MARTINKO, Mark J. The practice of supervision and management. USA: McGraw-Hill, 1979.

LUZ, R. S. A qualidade do atendimento e o clima organizacional. RH em Síntese, $\mathrm{n}^{\circ} 10$, mai/jun - ano II, p. 47. Disponível em: $<$ http://www.gestaoerh.com.br/visitante/artigos/gead 011.php>. Acesso em 07 fevereiro 2004.

MACCALLUM, Robert C.; AUSTIN, James T. Applications of structural equation modeling in psychological research. Annual Review of Psychology, Palo Alto, n. 51, p. 201-226, 2000.

MACCALLUM, Robert C. Model Specification: Procedures, strategies, and Related Issues. In: HOYLE, Rick H (editor). Structural Equation Modeling: concepts, issues, and applications. London: SAGE, 1995.

MALHOTRA, Naresh K. Pesquisa de Marketing: uma orientação aplicada. 3 ed. Porto Alegre: Bookman, 2001.

MARUYAMA, Geoffrey M. Basics of structural equation modeling. Thousand Oaks: Sage Publications, 1998.

MASLOW, Abraham H. Motivación y personalidad. Barcelona: Sagitario, 1954. 
MATELL, Michael S.; JACOBY, Jacob. Is there, an optimal number of alternatives for likert-scale items? Journal of Applied Psychology,.v. 56, $n^{\circ} 6$, p. 506-509, 1972.

MATHIAS, Fábio M. Estilos de liderança de professores em ambiente de sala de aula: um estudo de caráter exploratório com alunos do curso de graduação de administração de empresas / Fábio Montenegro Mathias. São Paulo: Universidade São Marcos, 126f., 2001.

MATHIEU, John E.; ZAJAC, Dennis M. A review and meta-analysis of the antecedents, correlates and consequences of organizational commitment. Psychology Bulletin, v. 108, n. 2, p. 171-194, 1990.

MAXIMIANO, Antonio C. Amaru. Teoria Geral da Administração: da revolução urbana à revolução digital. 5 ed. São Paulo: Atlas. 2005.

MAXIMIANO, Antonio C. Amaru. Gerência de trabalho de equipe. 4 ed. São Paulo: Pioneira. 1993.

MAZZON, José A. Análise do Programa de Alimentação do Trabalhador Sob o Conceito de Marketing Social. 1981. Tese (Doutorado em Administração de Empresas). Programa de Pós-Graduação em Administração de Empresas. Universidade de São Paulo. SP. 1981.

McGREGOR, Douglas. O lado humano da empresa. São Paulo: Martins Fontes, 1980.

MEDEIROS, Carlos A. F. Comprometimento Organizacional, características pessoais e performance no trabalho: um estudo dos padrões de comprometimento organizacional. Dissertação de mestrado - Universidade Federal do RN, 1997.

MEDEIROS, Carlos A. F. Comprometimento Organizacional: um estudo da suas relações com características organizacionais e desempenho nas empresas hoteleiras. Tese de doutorado - Universidade de São Paulo: FEA, 181f., 2003.

MEDEIROS, Carlos A. F.; ENDERS, Wayne T. Validação do modelo de conceitualização de três componentes do comprometimento organizacional: um estudo dos padrões de comprometimento organizacional e suas relações com a performance no trabalho. Anais $21^{\circ}$ ENANPAD 1997, Rio de Janeiro. Recursos Humanos, CD-ROM. 1997.

MEYER, John P.; ALLEN, Natalie J.; GELLATLY, lan R. Affective and continuance commitment to the organization: evaluation of measures and analysis of concurrent and time-lagged relations. Journal of Applied Psychology, v. 75, n. 6, p. 710-720, dec. 1990.

MEYER, John P., ALLEN, Natalie J.; SMITH, Catherine A. Commitment to organizations and occupations: extension and test of a three-component conceptualization. Journal of Applied Psychology, v.78, n. 4, p.538-551, 1993. 
MITCHELL, T. R.; ALBRIGHT, D. W. Expectancy theory predictions of the satisfaction, effort, performance and retention of Naval Aviation officers. Organizational Behavior and Human Performance, v. 8, n. 1, p. 1-20, august 1972.

MOHRMAN, S. A; COHEN, S. G. - Designing Team-Based Organizations Jossey-Bass. 1995.

MORAES, L. F. R. e DIAS, J. M. G. Preditores de comprometimento organizacional na Emater-MG. XIX Reunião Anual de Psicologia, p. 52, 1989.

MORRIS, J. H.; STEERS, R. M. Structural influences on organizational commitment. Journal of Vocational Behavior, v. 17, p. 50-57, 1980.

MORROW, Paula C.; GOETZ JR., Joe F. Professionalism as a form of work commitment. Journal of Vocational Behavior, v. 32, p. 92-111, 1988.

MORROW, Paula C. Concept redundancy in organizational research: the case of work commitment. Academic Management Review, v. 8, n. 3, p. 486-500, july 1983.

MORROW, Paula C.; WIRTH, R. E. Work commitment among salaried professionals. Journal of Vocational Behavior, v. 34, n. 1, p. 40-56, feb. 1989.

MORROW Paula C. The theory and measurement of work commitment, Greenwich: JAI Press. 1993.

MOURA, Eurides. Abordagem estratégica aplicada a Unidades de Informação. Dissertação de mestrado. PUC. Campinas. 134f., 1997.

MOWDAY, Richard T.; STEERS, Richard M.; PORTER Lyman W. The measurement of organizational commitment. Journal of Vocational Behavior, $v$. 14, n. 2, p. 224-247, april 1979.

MOWDAY, Richard T.; PORTER Lyman W.; STEERS, Richard M. Employeeorganization linkages - a psychology of commitment, absenteism and turnover. New York: Academic Press, 1982

NUNNALLY, Jum C.; BERNSTEIN, Ira H. Psychometric theory. 3 ed. New York: McGraw-Hill, 1994.

OLIVEIRA, MARIA A. P. da S. Comprometimento organizacional e com a carreira: influência sobre a produção científica de pesquisadores brasileiros. Dissertação de mestrado. Brasília: Universidade de Brasília, $170 f, 1998$.

OLIVEIRA NETO, J. D.; RICCIO, E. L. Desenvolvimento de um Instrumento para Mensurar a Satisfação do Usuário de Sistemas de Informações através do Método Survey. In: 13th Asian-Pacific Conference on International Accounting Issues, 2001, Rio de Janeiro. Anais do 13th Asian-Pacific Conference on International Accounting Issues, 2001. 
OLIVEIRA, Nanete R. Clima organizacional da Embrapa. Dissertação de mestrado. São Paulo: USP/FEA. 1990.

O’REILLY III, Charles A.; PFEFFER, Jeffrey. Talentos ocultos: como as melhores empresas obtêm resultados extraordinários com pessoas comuns. Rio de Janeiro: Campus, 2001.

OSBALDESTON, M. D.; COX, J. S. G.; LOVEDAY, D. E. E. Creativity and organization in Pharmaceuticals R\&D. R\&D Management, v. 8, n. 3, p. 165-175, 1978.

PARKER, Glenn M. O poder das equipes: um guia pratico para implementar equipes interfuncionais de alto desempenho. Rio de Janeiro: Campus, 1994.

PASQUALI, Luiz. Psicometria: teoria dos testes na psicologia e na educação. Petrópolis: Vozes, 2003.

PAYNE, Roy L.; MANSFIELD, Roger. Relationships of perceptions of organizational climate to organizational structure context and hierarchical position.

Administrive Science Quarterly,.v. 18, n. 4, p. 515-526, dec. 1973.

PEDHAZUR, E. J. Multiple regression in behavioral research: explanation and prediction. Fort Worth: Harcourt Brace College Publishers, 1997.

PEREIRA, Júlio C. R. Análise de dados qualitativos: estratégias metodológicas para as ciências da saúde, humanas e sociais, 3 ed. São Paulo: EDUSP, 2001.

PERIN, Marcelo G. Relação entre orientação para mercado, aprendizagem organizacional e performance. Tese (Doutorado em Administração) - PPGA / Escola de Administração, UFRGS, Porto Alegre, 194f., 2001.

PORTER, L. W.; LAWLER, E. Managerial attitudes and performance. Homewood, III.: Irwin, 1968.

PORTER, L. W.; STEERS, R. M.; MOWDAY, R. T.; BOULIAN, P. V. Organizational commitment, job satisfaction, and turnover among psychiatric technicians. Journal of Applied Psychology, v. 59, p. 603-609, 1974.

PRITCHARD, Robert D.; KARASICK, Bernard W. The effects of organizational climate on managerial job performance and job satisfaction. Organizational Behavior and Human Performance, v. 9, n. 1, p. 126-146, feb. 1973.

REESE, Ellen P. Análise do comportamento humano. 3 ed., Rio de Janeiro: Jose Olimpio, 1976.

REISE, Steven P.; WIDAMAN, Keith P.; PUGH, Robin H. Confirmatory factor analysis and item response theory: two approaches for explorer measurement invariance. Psychological Bulletin, v. 114, 3, p. 552-66, november, 1993. 
RESZECKI, MARIA C. Implementação do trabalho em equipe em área comercial de uma instituição financeira - um estudo de caso / Maria Cristina Reszecki - Dissertação de mestrado. São Paulo: FEA/USP, 138F, 2002.

RICCO, Maria F. F. Comprometimento organizacional em condições adversas: o caso dos pesquisadores do Centro Técnico Aeroespacial. São Paulo: PPGA/FEA/USP. Dissertação de mestrado, 98f., 1998.

ROBBINS, Stephen P. Comportamento organizacional. São Paulo: Pearson Prentice Hall. 11 ed., 2005.

ROBBINS, Stephen P. Comportamento organizacional. Rio de Janeiro: Livros Técnicos e Científicos Editora, 1999.

SACHUK, Maria I. A motivação e o processo de indução dos indivíduos na organização. 1998. 233f. Tese de Doutorado - Escola de Administração de Empresas de São Paulo, Fundação Getúlio Vargas, 1998.

SALLES FILHO, Sérgio. L. M. et al. Ciência, tecnologia e Inovação: a reorganização da pesquisa pública no Brasil. Campinas: Komedi, 2000.

SAMPIERI, Roberto H.; COLLADO, Carlos F.; LUCIO, Pilar B. Metodología de la Investigación. Madrid: McGraw-Hill, 1991.

SANTOS, Fabio G. Trabalho em equipe: uma questão competitiva. 31 janeiro 2005. Disponível em: <http://www.rh.com.br/ler.php?cod=4008\&org=1>. Acesso em 10 maio 2006.

SCHEIN, Edgar H. Organizational culture and leadership. 2 ed. San Francisco: Jossey-Bass Publishers, 1992.

SCHNEIDER, Benjamin; SNYDER, Robert A. Some relationships between job satisfaction and organizational climate. Journal of Applied Psychology, v. 60, n. 3, p. 318-328. 1975

SCHULER, Maria. Análise multivariada de segunda geração: tudo o que eu queira saber sobre LISREL e os matemáticos foram herméticos demais para explicar. Enanpad, 19º $^{\circ}$ Anais.. p. 93-107, 1995.

SELLTIZ, Claire A.; WRIGHTSMAN; COOK, S. W. Métodos de pesquisa nas relações sociais. Volume 2: medidas na pesquisa social. 2 ed. brasileira. São Paulo: EPU. 1987.

SENGE, Peter M. A Quinta Disciplina. 2 ed. São Paulo: Best Seller, 1998.

SHERMAN, A; BOHLANDER, G; SNELL, S. Managing Human Resources. Cincinnati. South-western college publishing, 1998.

SHONK, James H. - Team-Based Organizations - Developing a Successful Team Environment - Hornewood, Illinois - Business One Irwin - 1997. 
SIQUEIRA, M. M. M. Compremetimento organizacional: os estudos realizados na Universidade Federal de Uberlândia. XIX Reunião Anual de Psicologia, p. 53, 1989.

STEENKAMP, Jan-Benedict E. M.; BAUMGARTNER, Hans. On the use of structural equation models for Marketing modeling. International Journal of Research in Marketing, v. 17, n. 2, p. 195-202, september, 2000.

STEERS, Richard M. Antecedents and outcomes of organizational commitment. Administrative Science Quarterly, v. 22, p. 46-56, 1977.

STEVENS, J. M.; BEYER, J. M.; TRICE, H. M. Assessing personal role, and organizational predictors of management commitment. Academy of Management Journal, v. 21, n. 3, p. 380-396, 1978.

SUTTON, Robert I.; STAW, Barry M. What theory is not. Administrative Science Quarterly, v. 30, n. 3, p. 371-384, september, 1995.

TAGIURI, R. The concept of organizational climate. In Organizational Climate: explorations of a Concept. Edyted by: Tagiuri, R; Litwin, G. H. Cambridge: Harvard University. 1968.

TERRIBILI FILHO, Armando. Avaliação dos aspectos motivadores e nãomotivadores na freqüência à escola dos alunos de um curso noturno de graduação em administração de empresas. Dissertação (Mestrado em Administração) - Fundação Escola de Comércio Álvares Penteado - FECAP, São Paulo, 2002.

TORRES JR, Alvair S. Retórica das ações: o outro lado da Torre de Babel: a comunicação organizacional como drama de ações com significado. Tese de doutorado. São Bernardo do Campo: Universidade Metodista, 375f., 2000.

UCLA Academic Tecnology Services. SPSS. FAQ. What does Cronbach's alpha mean? Los Angeles: Universidade de California. Disponível em:

<http://www.ats.ucla.edustatspssfaqalpha.html>. Acesso em 14 maio 2006.

ULLMAN, Jodie B. Structural Equation Modeling. In: TABACHNICK, Barbara G.; FIDELL, Linda S. Using Multivariate Statistics. Boston: Allyn \& Bacon, 4 ed., p. 653-771, 2001.

ULRICH, Dave. Recursos humanos estratégicos: novas perspectivas para os profissionais de RH. São Paulo: Futura, 2000.

VIANNA, Caio M. M. F. Comprometimento organizacional sob o enfoque da teoria motivacional das expectativas: um estudo de caso na empresa químico farmacêutica RMS. Dissertação de mestrado. São: USP/FEA. 142f. 2005.

VROOM, Victor H. Work and motivation. New York: Wiley, 1964. 
WAGNER III, John A.; HOLLENBECK, John R. Comportamento organizacional: criando vantagem competitiva. São Paulo: Saraiva, 1999.

WAHBA, Mahmoud A.; HOUSE, Robert J. Expectancy theory in work and motivation: some logical and methodological issues. Human Relations, v. 27, n. 2, p. 121-147, 1974

WATERS, L. K.; ROACH, Darrel; BATLIS, Nick. Organizational climate dimensions and job - related attitudes. Personnel Psychology. 27, p. 465-476, 1974.

WEINER, Bernard. Theories of motivation: from mechanism to cognition. Chicago: Rand McNally College, 1972.

WEST, Stephen G.; FINCH, John F.; CURRAN, Patrick J. Structural Equation Models With Nonnormal variables: problems and remedies. In: HOYLE, Rick H (editor). Structural Equation Modeling: concepts, issues, and applications. London: SAGE, 1995.

YU, C. H. Na introduction to computing and interpreting Cronbach Coeficient Alpha in SAS. Proceedings of 26 th SAS User Group International Conference. 22 a 25.04.2001. California: Long Beach. Disponível em: <http://www.asu.edu/sas/sugi26/stats/p246-26.pdf 


\begin{abstract}
ANEXOS
Anexo I - Laboratórios do IPEN que participaram da segunda fase 2

Anexo II - Laboratórios do CTA que participaram da segunda fase 3

Anexo III - Questionário da segunda fase 6

Anexo IV - Parte do questionário aplicado no CTA (pág. 1/1, 1/7 e 7/7) .... 14

Anexo V - Análise fatorial confirmatória (LISREL 8.71)

Anexo VI - Modelo ACEITA (LISREL 8.71) 28

Anexo VII - Modelo REQUIP (LISREL 8.71). 33

Anexo VIII - Modelo REORG (LISREL 8.71) 45

Anexo IX - Modelo IDENT (LISREL 8.71) 50
\end{abstract}


Anexo I - Laboratórios do IPEN que participaram da $2^{\mathrm{a}}$ Fase

Processamento Cerâmicos de Resíduos:

Quatro servidores

SOFC Insumos e Componentes:

Sete servidores

Eletro-cerâmicas:

Cinco servidores

Cerâmicas estruturais e biomateriais:

Sete servidores

Comportamento mecânico:

Quatro servidores

Processamento e materiais:

Dez servidores

Corrosão e tratamento de superfícies:

Oito servidores

Difração de raios $\mathrm{X}$ :

Dois servidores

Materiais magnéticos:

Sete servidores

Metalurgia do pó e intermetálicos:

Oito servidores

Microscopia e microanálise:

Sete servidores

Vidros e compósitos cerâmicos:

Dois servidores. 
Anexo II - Laboratórios do CTA que participaram da $2^{\mathrm{a}}$ Fase (96)

\begin{tabular}{|c|c|}
\hline \multirow{4}{*}{$\begin{array}{c}\text { AVE-Q } \\
\text { (4) }\end{array}$} & $\circ \quad$ Lab. de Controle Dimensional \\
\hline & - Lab. de Ensaios Não-Destrutivos \\
\hline & Lab. de Ensaios de Dureza \\
\hline & ○ Lab. de Calibração e Manutenção \\
\hline \multirow{12}{*}{$\operatorname{AEL}(12)$} & ○ Lab. de Desenvolvimento de Eletrônica \\
\hline & $\circ \quad$ Lab. de Alta Frequência \\
\hline & - Lab. de Montagem de Eletrônica (Sala Limpa) \\
\hline & $\circ \quad$ Lab. de Montagem de Eletrônica (Sala Higienizada) \\
\hline & $\circ$ Lab. de Ensaios de RF \\
\hline & ○ Campo de Antenas (parcialmente operacional) \\
\hline & ○ Lab. de Calibração Elétrica - LCE \\
\hline & $\circ$ Lab. de Ensaios Ambientais \\
\hline & - Lab. de Aquisição e Processamento de Dados de Telemetria - APD \\
\hline & ○ Lab. de Projetos de Sistemas de Telemetria \\
\hline & - Lab.. de Integração das Redes Elétricas \\
\hline & - Lab. de Integração de Sistemas de Apoio de Solo \\
\hline \multirow{16}{*}{$\begin{array}{l}\text { AIE } \\
(16)\end{array}$} & ○ Lab. de Instrumentação em Banco de Provas \\
\hline & $\circ \quad$ Lab. de Medidas e Instrumentação em Bancos \\
\hline & $\circ$ Lab de Ensaio de Vibrações \\
\hline & ○ Lab. de Calibração de Acelerômetros (em implantação) \\
\hline & - Lab. de Calibração Elétrica (AIE/MCA) (LCC) \\
\hline & ○ Lab. de Calibração de Pressão \\
\hline & ○ Lab. de Calibração de Força \\
\hline & ○ Lab. de Medições Acústicas (AlE/MAC) \\
\hline & - Lab. de Calibração de Microfones (em implantação) \\
\hline & $\circ$ Lab. Fotográfico (AIE-RAI) \\
\hline & ○ Lab. de Vídeo AIE-RAI) \\
\hline & $\circ$ Lab. de Alta Velocidade (AIE-RAI) \\
\hline & $\begin{array}{l}\text { ○ Lab. de Preparação, Integração de Veículos Espaciais e } \\
\text { Realização de Ensaios de Qualificação e Recebimentos de } \\
\text { Propulsores e Mísseis (AIE/OPE) "PIL" }\end{array}$ \\
\hline & - Lab. de Calibração de Torquímetros \\
\hline & $\circ \quad$ Lab. de Ensaios Hidropneumáticos (AIE/OEH) \\
\hline & - Lab. de Medidas de Propriedades de Massa - LMPM \\
\hline
\end{tabular}




\begin{tabular}{|c|c|c|}
\hline \multirow{2}{*}{$\begin{array}{l}\text { AME } \\
(02)\end{array}$} & ○ & Lab. de Soldagem \\
\hline & ○ & Lab. de Materiais Compósitos \\
\hline \multirow{12}{*}{$\begin{array}{l}\text { AQI } \\
(12)\end{array}$} & ○ & Lab. Instrumental Infravermelho (AQI/CIN) \\
\hline & ○ & Lab. Instrumental Análise Térmica (AQI/CIN) \\
\hline & ○ & Lab. Instrumental Análise Granulômetrica (AQI/CIN) \\
\hline & ○ & Lab. de Síntese (AQI/CLS) \\
\hline & ○ & Lab. de Análise Química (AQI/CAQ) \\
\hline & ○ & Lab. de Propelente \\
\hline & $\mathrm{O}$ & Lab. de Combustão - PCO \\
\hline & 0 & Lab. de Oxidantes \\
\hline & ○ & Lab. de Propriedades Mecânicas \\
\hline & ○ & Lab. de Adesão \\
\hline & ○ & Lab. de Borracha (AQI/EBO) \\
\hline & ○ & Lab. de Plásticos e Elastômeros \\
\hline \multirow{3}{*}{$\begin{array}{l}\text { ASE } \\
(03) \\
\end{array}$} & 인 & Lab. de Ensaios de Sensores Inerciais e Simulação \\
\hline & ○ & Banco de Provas de Propulsão Líquida \\
\hline & 0 & Lab. de Propulsão \\
\hline ACA (1) & 0 & Lab. de Meteorologia \\
\hline \multirow{4}{*}{$\begin{array}{l}\text { AEV } \\
(04)\end{array}$} & ○ & Lab. de Gravações Especiais \\
\hline & ○ & Lab. de Instrumentação \\
\hline & O & Lab. de Telemetria \\
\hline & ○ & Lab. de Calibração \\
\hline \multirow{9}{*}{ AMR } & $\mathrm{O}$ & Lab. de Metalografia - LEMET \\
\hline & 은 & Lab. Fotográfico \\
\hline & ○ & Lab. de Ensaios Mecânicos - LEM \\
\hline & ○ & Lab. de Ensaios de Fluência \\
\hline & ○ & Lab. de Análises Químicas - LAQ \\
\hline & ○ & Lab. de Processamento de Compósitos - LPC \\
\hline & ○ & Lab. de Caracteriza. Eletromagnética de Materiais Absorvedores \\
\hline & ○ & Lab. de Reparos de Compósitos - LR \\
\hline & 0 & Lab. de Formulação \\
\hline \multirow[t]{5}{*}{$(18)$} & & $\begin{array}{l}\text { Lab. de Produção de Sensores de Radiação Infravermeha } \\
\text { SINFRA }\end{array}$ \\
\hline & & Lab. de Processamento de Fibras de Carbono \\
\hline & & Lab. de Processamento de Materiais Carbonosos \\
\hline & & Lab. de Processamento de Materiais Cerâmicos \\
\hline & ○ & Lab. de Fusão e Refino \\
\hline
\end{tabular}




\begin{tabular}{|c|c|c|}
\hline \multirow{4}{*}{$\begin{array}{l}\text { AMR } \\
\text { (Cont.) }\end{array}$} & O & Lab. de Tratamento Térmico - LTT \\
\hline & 0 & Lab. de Análise de Falha \\
\hline & ○ & Lab. de Espectrometria de Raios X \\
\hline & $\circ$ & Lab. de Microscopia Eletrônica de Varredura - MEV \\
\hline \multirow{8}{*}{$\begin{array}{l}\text { ASD } \\
(08)\end{array}$} & $\mathrm{O}$ & Lab. Químico de Explosivos - XQI \\
\hline & $\mathrm{O}$ & Lab. de Pirotecnia \\
\hline & 0 & Lab. de Eletrônica \\
\hline & $\mathrm{O}$ & Lab. de Detônica \\
\hline & 0 & Lab. de Túnel Balístico \\
\hline & ○ & Lab. de Aceleração (Centrífuga) \\
\hline & ○ & Lab. de Fragmentação \\
\hline & $\mathrm{O}$ & Lab. de Ensaios Ambientais \\
\hline \multirow{16}{*}{$\begin{array}{l}\text { ASA } \\
(16)\end{array}$} & ○ & Lab. de Combustíveis e Lubrificantes \\
\hline & O & Lab. de Calibração de Temperatura (LCT) \\
\hline & ○ & Lab. de Calibração de Pressão (em implantação) \\
\hline & $\mathrm{O}$ & Lab. de Filtros do Ar (LFA) \\
\hline & 은 & Lab. de Filtros do Óleo (LFO) (em implantação) \\
\hline & ○ & Lab. de Motores Aeronáuticos (LMA) \\
\hline & 은 & Lab. de Ensaios de Motores a Pistão (Sala 12) \\
\hline & 0 & Lab. de Baixa Pressão (LBP) \\
\hline & ○ & Lab. de Baixa Força (LBF) \\
\hline & ○ & Lab. de Anemometria \\
\hline & 0 & Lab. de Ensaios Aerodinâmicos (TA-2) \\
\hline & ○ & Lab. do Túnel Transônico Piloto (TTP) (em reforma) \\
\hline & $\circ$ & Lab. de Ensaios Estruturais (LEE) \\
\hline & $\mathrm{O}$ & Lab. Central de Força (LCF) \\
\hline & & Lab. de Ensaios de Impacto (LEI) \\
\hline & 0 & Lab. de Ensaios de Trens de Pouso (LTP) \\
\hline
\end{tabular}




\section{Anexo III - Questionário da $2^{\mathrm{a}}$ Fase}

São Paulo, 04 de Fevereiro de 2005

Prezados Pesquisadores do IPEN

Tem este o objetivo de solicitar a sua valorosa contribuição em meu projeto de pesquisa: Relação entre fatores de desempenho e os comprometimentos organizacional e ocupacional nas atividades de serviços laboratoriais num centro de pesquisas.

Salienta-se, que a sua indicação como respondente deve-se à sua experiência tendo sido escolhido por meio de análise prévia a fim de corresponder aos anseios desta pesquisa.

Afirma-se que será preservado o anonimato dos respondentes, e os dados serão tratados e analisados coletivamente.

Antecipadamente grato pela atenção, aguardo sua resposta.

\section{Miguel Enrique Tejos-Saldivia}

Doutorando em Ciências na Área de Tecnologia Nuclear - Materiais com ênfase em Gestão Tecnológica

(12) $x x x x-x x x x$ ou (11) $x x x x-x x x x$

Dr. Jesualdo Luiz Rossi

Orientador / IPEN
Dr. Guilherme Ary Plonski

Co-orientador / USP-NPGT 


\section{QUESTIONÁRIO DA PESQUISA}

\section{Instruções para preenchimento}

O questionário consta de três partes: a primeira sobre o perfil do(a) entrevistado(a), a segunda sobre o comprometimento e a terceira sobre o desempenho.

No item desta página, "Outros comentários sobre seu perfil" pode ser registrado no caso da função atual que exerce um(a) servidor(a) ser diferente da sua formação. É o caso do(a) Técnico(a) que pode ter nível superior.

Entende-se pelo termo "laboratório" o local onde se realizam ensaios, experimentos, pesquisas ou calibrações, e pelo termo "chefe do laboratório", o(a) responsável de fato pelo mesmo local. As respostas deverão ser preenchidas assinalando a alternativa que mais condiz com a sua opinião, de acordo com a seguinte escala:

CT: Concordo Totalmente; C: Concordo; I: Indiferente; D: Discordo; e DT: Discordo Totalmente.

\section{Exemplo de preenchimento:}

No exemplo, observamos a afirmação: "O Chefe do laboratório sempre deve ser o mais experiente". Você não concorda com a assertiva.

Então você assinala a resposta que corresponde à sua opinião, ou seja, Indiferente I, Discordo D, ou Discordo Totalmente DT.

\section{Primeira parte}

1. Sexo:

$\mathbf{F}$

M

\begin{tabular}{|c|c|c|c|c|c|c|c|}
\hline \multicolumn{3}{|c|}{$\begin{array}{l}\text { 2. Faixa etária: até } 29 \text { anos } \\
\text { anos } \square\end{array}$} & & 30 a 39 anos $\square$ & \multicolumn{2}{|c|}{40 a 49 anos } & \multirow{2}{*}{$\begin{array}{c}\text { Acima de } 50 \\
\text { Eletrônico }\end{array}$} \\
\hline 3. & & Técnico & Mecânicc & Técnico & Químico $\square$ & & \\
\hline \multicolumn{4}{|c|}{ Outros $\square$} & \multicolumn{2}{|l|}{ Tecnólogo } & Físico $\square$ & Químico $\square$ \\
\hline & \multicolumn{3}{|c|}{ Eng $^{\circ}$ Mecânico $\square$} & \multicolumn{2}{|c|}{ Eng $^{\circ}$ Metalúrgico $\square$} & \multicolumn{2}{|c|}{$\mathrm{Eng}^{\circ}$ de Materiais $\square$} \\
\hline & \multirow{2}{*}{\multicolumn{3}{|c|}{$\begin{array}{l}\text { Eng }^{\circ} \quad \text { Químico } \square \\
\text { Outros }\end{array}$}} & $E^{\circ} g^{\circ}$ & Eletricista $\square$ & & Eletrônico $\square$ \\
\hline & & & & & & & \\
\hline
\end{tabular}

4. Maior escolaridade: Ensino Médio $\square$ Ensino Superior $\square \quad$ Especialização $\square$ Mestrado $\square$ Doutorado

5. Tempo de atuação no IPEN: anos e meses

6. Tempo de experiência na sua profissão: anos e meses

7. Tempo de experiência como chefe de laboratório: anos e meses

Outros comentários sobre seu perfil: 


\section{Segunda parte}

Questionário do comprometimento organizacional de Meyer, Allen e Smith (1993)

Comprometimento organizacional afetivo - CRA - (06):

\begin{tabular}{|l|l|l|l|l|l|}
\cline { 2 - 2 } & CT & C & I & D & DT \\
\hline CRA1 & $\begin{array}{l}\text { Eu ficaria muito feliz em dedicar o resto da minha carreira a } \\
\text { esta organização. }\end{array}$ & & & \\
\hline CRA2 & $\begin{array}{l}\text { Eu realmente sinto os problemas da organização como se } \\
\text { fossem meus. }\end{array}$ & & & & \\
\hline CRA3 & $\begin{array}{l}\text { Eu não sinto um forte senso de integração com minha } \\
\text { organização. }\end{array}$ & & & & \\
\hline CRA4 & $\begin{array}{l}\text { Eu não me sinto emocionalmente vinculado a esta } \\
\text { organização. }\end{array}$ & & & & \\
\hline CRA5 & $\begin{array}{l}\text { Eu não me sinto como uma pessoa de casa na minha } \\
\text { organização. }\end{array}$ & & & \\
\hline CRA6 & $\begin{array}{l}\text { Esta organização tem um imenso significado pessoal para } \\
\text { mim. }\end{array}$ & & & & \\
\hline
\end{tabular}

Comprometimento organizacional instrumental - CRI - (06):

\begin{tabular}{|l|l|l|l|l|l|}
\cline { 3 - 5 } & CT & C & I & D & DT \\
\hline CRI2 & $\begin{array}{l}\text { Na situação atual, permanecer na minha organização é na } \\
\text { realidade uma necessidade tanto quanto um desejo. }\end{array}$ & & & & \\
\hline Mesmo que eu quisesse, seria muito difícil para mim deixar & & & & \\
\hline CRI3 & $\begin{array}{l}\text { Se eu decidisse deixar minha organização agora, minha vida } \\
\text { ficaria bastante desestruturada. }\end{array}$ & & & & \\
\hline CRI4 & $\begin{array}{l}\text { Eu acho que teria poucas alternativas se deixasse esta } \\
\text { organização. }\end{array}$ & & & & \\
\hline CRI5 & $\begin{array}{l}\text { Se eu já não tivesse dado tanto de mim nesta organização, eu } \\
\text { poderia considerar trabalhar em outro lugar. }\end{array}$ & & & \\
\hline CRI6 & $\begin{array}{l}\text { Uma das poucas conseqüências negativas de deixar esta } \\
\text { organização seria a escassez de alternativas imediatas. }\end{array}$ & & & & \\
\hline
\end{tabular}

Comprometimento organizacional normativo - CRN - (06):

\begin{tabular}{|l|l|l|l|l|l|}
\cline { 2 - 4 } CRN1 & $\begin{array}{l}\text { Eu não sinto nenhuma obrigação em permanecer na minha } \\
\text { organização. }\end{array}$ & C & I & D & DT \\
\hline CRN2 & $\begin{array}{l}\text { Mesmo se fosse vantagem para mim, eu sinto que não seria } \\
\text { certo deixar minha organização agora. }\end{array}$ & & & & \\
\hline CRN33 & Eu me sentiria culpado se deixasse minha organização agora. & & & & \\
\hline CRN4 & Esta organização merece minha lealdade. & & & & \\
\hline CRN5 & $\begin{array}{l}\text { Eu não deixaria minha organização agora porque eu tenho } \\
\text { uma obrigação moral com as pessoas daqui. }\end{array}$ & & & & \\
\hline CRN6 & Eu devo muito à minha organização. & & & & \\
\hline
\end{tabular}

Comprometimento ocupacional afetivo - CCA - (06):

CCA1 A minha profissão é importante para minha auto-imagem.

CCA2 Eu tenho remorsos de ter ingressado na minha profissão.

CCA3 Eu sinto orgulho de ter ingressado na minha profissão.

\begin{tabular}{|l|l|l|l|l|}
\hline CT & C & I & D & DT \\
\hline
\end{tabular}




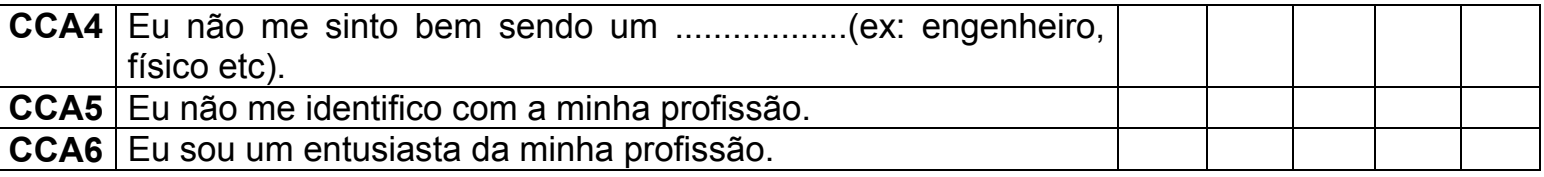

Comprometimento ocupacional instrumental $-\mathrm{CCl}-(06)$ :

\begin{tabular}{|c|c|c|c|c|c|c|}
\hline & & CT & C & I & D & DT \\
\hline $\mathrm{CCl1}$ & $\begin{array}{l}\text { Eu investi muito na minha profissão como para considerar uma } \\
\text { mudança agora. }\end{array}$ & & & & & \\
\hline $\mathrm{CCl} 2$ & Mudar de profissão agora seria difícil para mim. & & & & & \\
\hline $\mathrm{CCl3}$ & $\begin{array}{l}\text { Muito da minha vida seria interrompido se eu mudasse de } \\
\text { profissão. }\end{array}$ & & & & & \\
\hline $\mathrm{CCl} 4$ & Seria custoso para mim mudar minha profissão agora. & & & & & \\
\hline CCI5 & Não existem pressões para eu ficar mudando de profissão. & & & & & \\
\hline $\mathrm{CCl} 6$ & $\begin{array}{l}\text { Mudar a profissão agora seria um sacrifício pessoal } \\
\text { considerável. }\end{array}$ & & & & & \\
\hline
\end{tabular}

Comprometimento ocupacional normativo - CCN - (06):

\begin{tabular}{|c|c|c|c|c|c|c|}
\hline & & CT & C & I & D & DT \\
\hline CCN1 & $\begin{array}{l}\text { Eu acredito que as pessoas que foram treinadas numa } \\
\text { profissão têm a responsabilidade de permanecer naquela } \\
\text { profissão por um período razoável de tempo. }\end{array}$ & & & & & \\
\hline CCN2 & $\begin{array}{l}\text { Eu não sinto nenhuma obrigação em permanecer na minha } \\
\text { profissão. }\end{array}$ & & & & & \\
\hline CCN3 & Eu sinto a responsabilidade de continuar na minha profissão. & & & & & \\
\hline CCN4 & $\begin{array}{l}\text { Mesmo se fosse para eu levar vantagem, eu não acho que } \\
\text { seria certo deixar a minha profissão agora. }\end{array}$ & & & & & \\
\hline CCN5 & Eu me sentiria culpado se deixasse a minha profissão & & & & & \\
\hline CCN6 & $\begin{array}{l}\text { Eu sou (minha profissão) porque há um senso de lealdade com } \\
\text { isto. }\end{array}$ & & & & & \\
\hline
\end{tabular}

\section{Terceira parte}

\section{Clima organizacional - CO (21)}

\subsection{Ambiente - COA (08):}

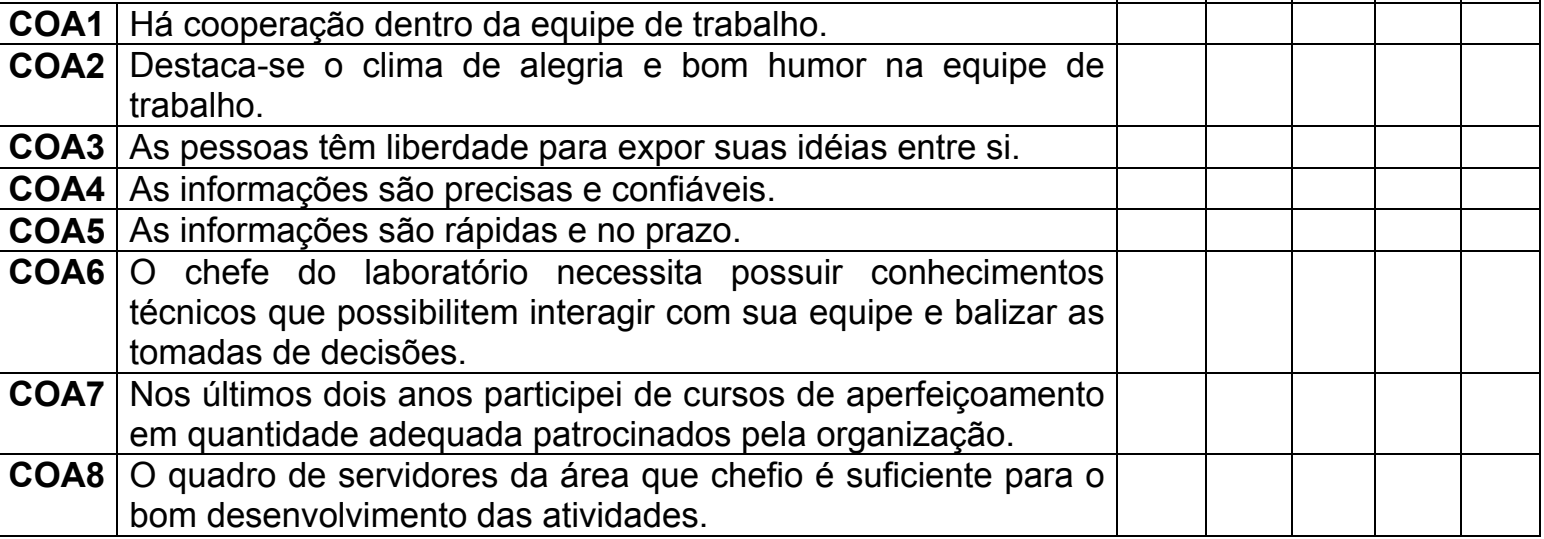


1.2 Criatividade - COC (05):

\begin{tabular}{|l|l|l|l|l|l|l|}
\cline { 3 - 4 } COC1 & $\begin{array}{l}\text { No meu setor existem normas, procedimentos e } \\
\text { especificações escritas que eu posso usar para facilitar e } \\
\text { orientar o meu trabalho. }\end{array}$ & & & & \\
\hline COC2 & $\begin{array}{l}\text { Os trabalhos devem ser sempre padronizados eliminando o } \\
\text { fator criatividade. }\end{array}$ & & & & \\
\hline COC3 & A organização precisa de pessoas mais criativas. & & & & \\
\hline COC4 & É possível trabalhar sem procedimentos formalizados. & & & & \\
\hline COC5 & $\begin{array}{l}\text { Conflitos e diferenças de opinião são aceitos como o preço da } \\
\text { criatividade. }\end{array}$ & & & & \\
\hline
\end{tabular}

\subsection{Desempenho - COD (02):}

COD1 Esta organização preocupa-se com a melhoria do desempenho individual.

COD2 A avaliação de desempenho individual é adequada.

\subsection{A organização - COO (06):}

\begin{tabular}{|c|c|c|c|c|c|c|}
\hline & & CT & C & I & D & DT \\
\hline COO1 & $\begin{array}{l}\text { Esta organização esta realmente tentando fomentar um bom } \\
\text { relacionamento com seus servidores. }\end{array}$ & & & & & \\
\hline $\mathrm{COO2}$ & $\begin{array}{l}\text { Esta organização considera de fato que os servidores são seu } \\
\text { maior patrimônio e comporta-se segundo esta crença. }\end{array}$ & & & & & \\
\hline $\mathrm{COO3}$ & $\begin{array}{l}\text { Cada laboratório conta com os recursos de apoio } \\
\text { administrativo e de infra-estrutura necessários à execução } \\
\text { eficaz dos trabalhos. }\end{array}$ & & & & & \\
\hline $\mathrm{COO4}$ & $\begin{array}{l}\text { Nesta organização há respeito e integração entre as diferentes } \\
\text { áreas funcionais. }\end{array}$ & & & & & \\
\hline COO5 & $\begin{array}{l}\text { Há uma clara definição de papéis e de quem responde a } \\
\text { quem. }\end{array}$ & & & & & \\
\hline C006 & $\begin{array}{l}\text { Nesta organização é mais importante a qualidade do que o } \\
\text { volume de produção. }\end{array}$ & & & & & \\
\hline
\end{tabular}

\section{Liderança - LI (15)}

\subsection{Importância - LII (03):}

\begin{tabular}{|l|l|l|l|l|l|}
\cline { 2 - 4 } LII1 & $\begin{array}{l}\text { O papel de liderança (conduzir as pessoas aos objetivos) é } \\
\text { fundamental aos chefes de laboratórios. }\end{array}$ & & & & \\
\hline LII2 & A liderança segue sempre a orientação pelo cliente. & & & & \\
\hline LII3 & $\begin{array}{l}\text { O chefe do laboratório deve proporcionar muita atenção } \\
\text { pessoal quando se inter-relaciona com os subordinados. }\end{array}$ & & & & \\
\hline
\end{tabular}

\subsection{Atitudes - LIA (04):}

\begin{tabular}{|l|l|l|l|l|l|l|}
\cline { 2 - 4 } LIA1 & $\begin{array}{l}\text { O chefe do laboratório tem que proporcionar suporte } \\
\text { pessoal/técnico/administrativo. }\end{array}$ & & & & \\
\hline LIA2 & $\begin{array}{l}\text { O chefe do laboratório deve encorajar novas maneiras de olhar } \\
\text { os habituais métodos utilizados na solução de problemas. }\end{array}$ & & & & \\
\hline LIA3 & $\begin{array}{l}\text { O chefe do laboratório tem que enfatizar o uso da criatividade e } \\
\text { de novos conceitos. }\end{array}$ & & & & \\
\hline LIA4 & $\begin{array}{l}\text { O chefe do laboratório deve procurar entender os sentimentos } \\
\text { dos subordinados. }\end{array}$ & & & & \\
\hline
\end{tabular}




\subsection{Características - LIC (08):}

\begin{tabular}{|l|l|l|l|l|l|}
\hline LIC1 & $\begin{array}{l}\text { O chefe do laboratório tem que ser admirado, respeitado e } \\
\text { inspirar confiança no subordinado. }\end{array}$ & C & I & D & DT \\
\hline LIC2 & $\begin{array}{l}\text { O chefe do laboratório somente intervém na rotina dos } \\
\text { subordinados quando erros são detectados. }\end{array}$ & & & & \\
\hline LIC3 & $\begin{array}{l}\text { A capacidade de persuasão é uma habilidade que deve } \\
\text { integrar o rol de qualidades do chefe do laboratório por não } \\
\text { agregar resultados. }\end{array}$ & & & & \\
\hline LIC4 & Meu chefe de divisão se expressa bem e de forma clara. & & & \\
\hline LIC5 & $\begin{array}{l}\text { Meu chefe de divisão demonstra confiança no que faz e age } \\
\text { com convicção. }\end{array}$ & & & \\
\hline LIC6 & $\begin{array}{l}\text { As posições de liderança na organização são ocupadas por } \\
\text { pessoas com habilidade gerencial e capacidade profissional. }\end{array}$ & & & \\
\hline LIC7 & $\begin{array}{l}\text { A autoridade dos nossos chefes de laboratórios está } \\
\text { perfeitamente definida e divulgada no âmbito da organização. }\end{array}$ & & & & \\
\hline LIC8 & $\begin{array}{l}\text { Os conhecimentos mais ricos estão na cabeça das pessoas, } \\
\text { portanto, o chefe do laboratório deve estar preparado para } \\
\text { captar, codificar e disseminar estas informações. }\end{array}$ & & & & \\
\hline
\end{tabular}

3 Motivação - MO (21)

\subsection{Ambiente - MOA (05):}

\begin{tabular}{|l|l|l|l|l|l|}
\cline { 2 - 2 } \multicolumn{2}{|l|}{ CT } & C & I & D & DT \\
\hline MOA2 & $\begin{array}{l}\text { O ambiente do serviço público num centro de pesquisas } \\
\text { permite um ambiente de motivação. }\end{array}$ & & & \\
\hline Ma minha área, os problemas são debatidos entre todos os & & & & \\
envolvidos, buscando uma rápida solução. & $\begin{array}{l}\text { As pessoas têm tranqüilidade para executar suas tarefas } \\
\text { dentro de um ritmo normal de trabalho, com orientação e } \\
\text { distribuição eqüitativa da carga de trabalho entre os colegas. } \\
\text { Oambiente de trabalho não é tenso. }\end{array}$ & & & & \\
\hline MOA4 & $\begin{array}{l}\text { Sempre que necessito é muito fácil buscar informações nas } \\
\text { outras áreas. }\end{array}$ & & & & \\
\hline MOA5 & $\begin{array}{l}\text { A Motivação é uma necessidade e minimiza erros nas nas } \\
\text { atividades. }\end{array}$ & & & & \\
\hline
\end{tabular}

\subsection{Chefia - MOC (05):}

\begin{tabular}{|c|c|c|c|c|c|c|}
\hline & & CT & C & I & D & DT \\
\hline MOC1 & $\begin{array}{l}\text { O Chefe do Laboratório deve fornecer aos seus subordinados } \\
\text { apenas a motivação estritamente necessária. }\end{array}$ & & & & & \\
\hline MOC2 & $\begin{array}{l}\text { Mesmo os ocupantes recentes de cargos de Chefia encontram } \\
\text { facilidade em obter apoio de outras áreas funcionais quando } \\
\text { necessário. }\end{array}$ & & & & & \\
\hline MOC3 & $\begin{array}{l}\text { Meu(Minha) superior imediato(a) encoraja meu crescimento } \\
\text { profissional. }\end{array}$ & & & & & \\
\hline MOC4 & $\begin{array}{lccc}\text { Meu(Minha) } & \text { superior imediato(a) } & \text { reconhece } & \text { quando } \\
\text { demonstro um desempenho acima do esperado. } & \end{array}$ & & & & & \\
\hline MOC5 & $\begin{array}{l}\text { Meu(Minha) superior imediato(a) se preocupa em manter seus } \\
\text { subordinados informados sobre as coisas que possam afetar o } \\
\text { trabalho em nossa área. }\end{array}$ & & & & & \\
\hline
\end{tabular}




\subsection{A organização - MOO (02):}

\begin{tabular}{|c|c|c|c|c|c|c|}
\hline & CT & C & I & D & DT \\
\hline MOO1 & $\begin{array}{l}\text { É importante para mim pertencer a uma organização que } \\
\text { possua uma boa imagem na comunidade. }\end{array}$ & & & & & \\
\hline MOO2 & $\begin{array}{l}\text { As pessoas que são envolvidas num trabalho interdivisional } \\
\text { trabalham de forma coesa, como se não pertencessem a } \\
\text { setores diferentes. }\end{array}$ & & & & & \\
\hline
\end{tabular}

\subsection{Motivação própria - MOM (03):}

\begin{tabular}{|l|l|l|l|l|l|l|}
\cline { 2 - 2 } MOM1 & $\begin{array}{l}\text { Cu aconselharia meu(minha) melhor amigo(a) a trabalhar } \\
\text { nesta organização. }\end{array}$ & & & & C & DT \\
\hline MOM2 & $\begin{array}{l}\text { A equipe que lidero é motivada e buscam os mesmos } \\
\text { objetivos. }\end{array}$ & & & & \\
\hline MOM3 & Eu considero meu trabalho útil e importante. & & & & & \\
\hline
\end{tabular}

\subsection{Relacionamento - MORL (02):}

\begin{tabular}{|l|l|l|l|l|l|}
\hline MORL1 & $\begin{array}{l}\text { No meu local de trabalho existe um bom relacionamento } \\
\text { interpessoal. }\end{array}$ & & C & D & DT \\
\hline MORL2 & $\begin{array}{l}\text { O grupo de pessoas com as quais eu trabalho relacionam-se } \\
\text { dentro e fora do ambiente de trabalho. }\end{array}$ & & & \\
\hline
\end{tabular}

\subsection{Reconhecimento - MORC (04):}

\begin{tabular}{|l|l|l|l|l|l|}
\cline { 2 - 2 } \multicolumn{1}{|l|}{ MORC1 } & $\begin{array}{l}\text { As pessoas têm a oportunidade de expressar o que sentem e } \\
\text { pensam, de propor idéias e oferecer sugestões nas decisões } \\
\text { da organização, sobre aspectos relacionados a sua área de } \\
\text { atuação. }\end{array}$ & I & D & DT \\
\hline MORC2 & $\begin{array}{l}\text { Meu salário é uma resposta adequada para o meu trabalho, } \\
\text { representando o retorno equivalente a meu rendimento } \\
\text { dentro desta organização. }\end{array}$ & & & \\
\hline MORC3 & $\begin{array}{l}\text { O trabalho que realizo é devidamente reconhecido pela } \\
\text { organização. }\end{array}$ & & & \\
\hline MORC4 & $\begin{array}{l}\text { Sinto que quanto mais resultados eu apresento, mais apoio } \\
\text { da Direção recebo para as decisões que tomo em meu } \\
\text { cargo. }\end{array}$ & & & \\
\hline
\end{tabular}

4 Trabalho em equipe - TE (14)

\subsection{Missão - TEM (02):}

TEM1 O Trabalho em Equipe é o fator mais importante no desempenho das pessoas.

TEM2 As tarefas são claras e bem definidas

\subsection{Relacionamento - TER (03):}

\begin{tabular}{|l|l|l|l|l|l|}
\cline { 2 - 5 } \multicolumn{2}{|l|}{ CT } & C & I & D & DT \\
\hline TER2 & $\begin{array}{l}\text { Os membros da equipe têm um relacionamento baseado na } \\
\text { confiança mútua. }\end{array}$ & & & & $\begin{array}{l}\text { Predominam as idéias compartilhadas dentro da equipe de } \\
\text { trabalho. }\end{array}$ \\
\hline TER3 & $\begin{array}{l}\text { Os membros da equipe são obrigados a participar, a sugerir } \\
\text { novas maneiras de trabalho e de resolução de problemas, e as } \\
\text { discussões são em torno da tarefa. }\end{array}$ & & & & \\
\hline
\end{tabular}


4.3 Conduta - TECD (03):

\begin{tabular}{|l|l|l|l|l|l|l|}
\cline { 2 - 4 } \multicolumn{2}{l|}{ TECD1 } & $\begin{array}{l}\text { As pessoas mostram respeito entre si, escutando o que os } \\
\text { outros têm a dizer e dando a cada idéia a devida atenção. }\end{array}$ & & & & \\
\hline TECD2 & $\begin{array}{l}\text { As decisões são atingidas por consenso, ficando claro para } \\
\text { todos que foi tomada com a concordância de todos e que } \\
\text { todos vão fazer o máximo para agir e fazer acontecer } \\
\text { conforme foi decidido. }\end{array}$ & & & & \\
\hline TECD3 & $\begin{array}{l}\text { Existe união da equipe de trabalho em situações de } \\
\text { mudança. }\end{array}$ & & & & \\
\hline
\end{tabular}

4.4 Ambiente - TEA (04):

TEA1 Os membros sentem-se livres para expressar suas idéias e sentimentos, mesmo quando isso acontece em relação a problemas operacionais da mesma equipe.

TEA2 As pessoas não têm medo de sugerir novas e diferentes idéias, mesmo que extremamente singelas.

TEA3 É normal que as discordâncias sejam expressas sem que as pessoas sejam malvistas ou que a discordância seja abafada.

TEA4 Diferenças são cuidadosamente examinadas na medida em que a equipe procura compreender todos os pontos de vista.

\subsection{Comprometimento - TECP (02):}

TECP1 Cada indivíduo se compromete com as tarefas da equipe.

\begin{tabular}{l|l}
\hline TECP2 & Nota-se uma identificação com a empresa (vestir a camisa).
\end{tabular}

\begin{tabular}{|l|l|l|l|l|}
\hline CT & C & I & D & DT \\
\hline & & & & \\
\hline & & & & \\
\hline & & & & \\
\hline & & & & \\
\hline
\end{tabular}

Data de preenchimento: 
Anexo IV - Parte do questionário aplicado no CTA (pág. 1/1, 1/7 e 7/7)

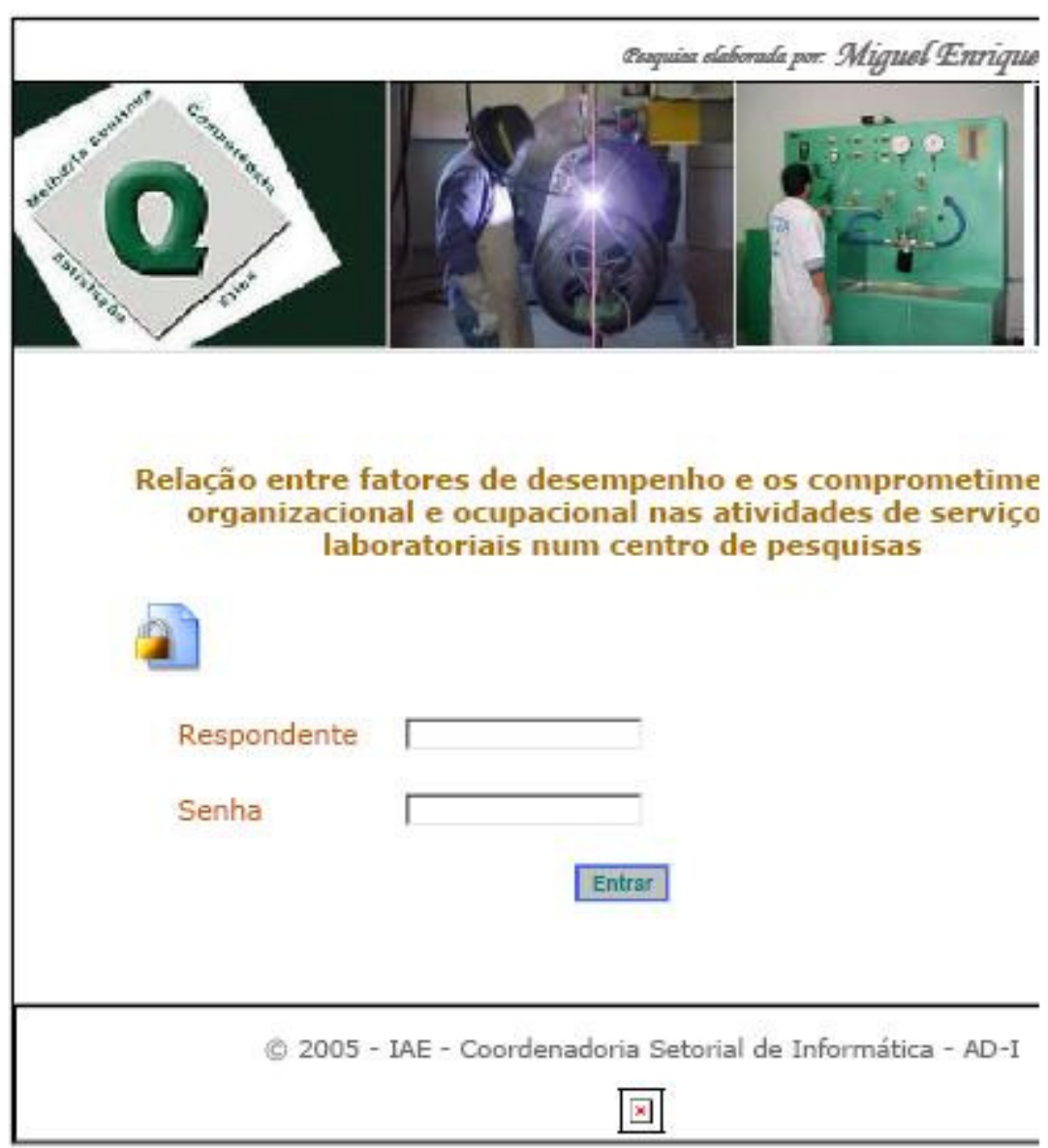




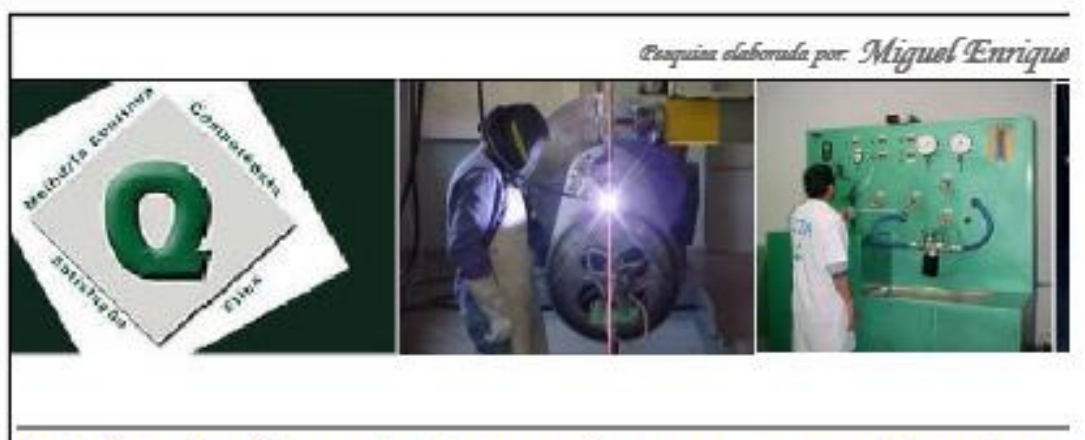

Relação entre fatores de desempenho e os comprometimentos or e ocupacional nas atividades de serviços laboratoriais num centrı pesquisas

Sua indicaça o para responder este questionário deve-se à sua experiência com ensais pesquisas ou calibraçōes, tendo sido escolhido por meio de análise prévia a fim de cc anseios desta pesquisa

PERFIL

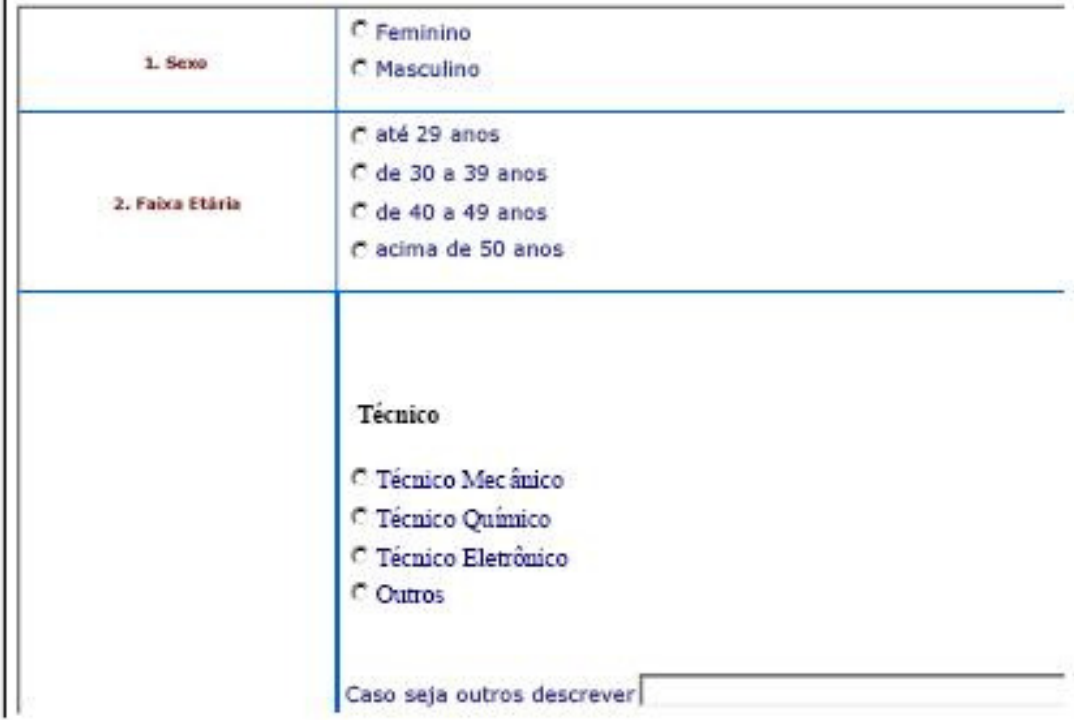


62. Os membros da equipe săo obrigados a participar," a sugerir novas maneiras de trabalho e de resoluçăo de problemas," é as discussóes sta C CT C C C I CD C L em torno da tarefa.

63. As pessoas mostram respeito entre si," escutando o que os outros bền a dizer e dando a cada idéía a devidá atençóo.

64. As decisões săo atingidas por consenso," ficando claro para todos que foi tomada com a concordåncia de todos e que todos vảo fazer o máximo para agir e fazer acontecer conforme foi decidido.

65. Existe uniăo da equipe de trabalho em situaçó de mudança.

66. Os servidores sentem-se livres para expressar suas idélas e sentimentos, mesmo quando isso acontece em rela ça a problemas operacionais da mesma equipe.

67. As pessoas nåo têm medo de sugerir novas e diferentes idélas, mesmo que estas sejam extremamente simples.

68. É normal que as discordancias sejam expressas sem que as pessoas sejam malvistas ou que a discordåncia seja abafada.

69. Diferencas stio cuidadosamente examinadas na medida em que a equipe procura compreender todos os pontos de vista.

70. Cada individuo se compromete com as tarefas da equipe.

CCTCCICDCL

C CTCCICDCL

$\mathrm{CCTCCICDCC}$

$C \mathrm{CTCCICDCD}$

CCTCCICDCL

CCT CCOICDCL

71. Nota-se uma identificaça com a empresa (vestir a camisa). 


\section{Anexo V - Análise Fatorial Confirmatória}

\section{ULS - $\quad$ RMSEA $=\mathbf{0 . 0 6 8}$}

DATE: $1 / 13 / 2006$

TIME : $21: 30$

L I S R E L 8.71 BY

Karl G. Jöreskog and Dag Sörbom

This program is published exclusively by

Scientific Software International, Inc.

7383 N. Lincoln Avenue, Suite 100

Lincolnwood, IL 60712, U.S.A.

Phone: (800)247-6113, (847)675-0720, Fax: (847)675-2140

Copyright by Scientific Software International, Inc., 1981-2004

Use of this program is subject to the terms specified in the

Universal Copyright Convention.

Website: Www.ssicentral.com

The following lines were read from file

C: \Documents and Settings\dirceuds.GLOBAL \Desktop \OPERAÇÃO \miguel \miguel SP.spj :

Observed Variables:

v1 v2 v3 v4 v5 v6 v7 v8 v9 v10 v11 v12

Correlation Matrix from file Mmi

Sample Size: $\mathbf{3 0 4}$

Latent Variables: REQUIP REORG ACEITA IDENT

Relationships:

v1 v2 v3=REQUIP

v4 v5 v6 v7=REORG

v11 v12=ACEITA

v8 $v 9=$ IDENT

Options: $\mathrm{ND}=2$ RS ME=UL $\mathrm{ADD}=\mathrm{OFF}$ IT=100 MI

path diagram

END OF PROBLEM 
6.6 in. 02 in

Sample Size $=304$

\section{$\underline{! M I G U E L A F C 2}$}

Correlation Matrix

v1
v2
v3
v4
v5
v6
v7
v8
v9
v11
v12

$\mathbf{v 1}$
1.00
0.82
0.64
0.42
0.33
0.28
0.28
0.22
0.22
0.44
0.38

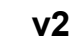

v3

v4

v5

v6

Correlation Matrix (continued)

$\begin{array}{lrr} & \mathbf{v 7} & \text { v8 } \\ \text { v7 } & 1.00 & \\ \text { v8 } & 0.15 & 1.00 \\ \text { v9 } & 0.09 & 0.47 \\ \text { v11 } & 0.22 & 0.09 \\ \text { v12 } & 0.17 & 0.17\end{array}$

$$
\begin{aligned}
& 1.00 \\
& 0.35 \\
& 0.38 \\
& 0.38 \\
& 0.32 \\
& 0.15 \\
& 0.17 \\
& 0.40 \\
& 0.26
\end{aligned}
$$

$\begin{array}{ll}1.00 & \\ 0.79 & 1.00 \\ 0.55 & 0.55 \\ 0.15 & 0.10 \\ 0.17 & 0.13 \\ 0.34 & 0.34 \\ 0.32 & 0.37\end{array}$

\section{$\underline{! M I G U E L A F C 2}$}

Number of Iterations $=4$

LISREL Estimates (Unweighted Least Squares)

Measurement Equations 


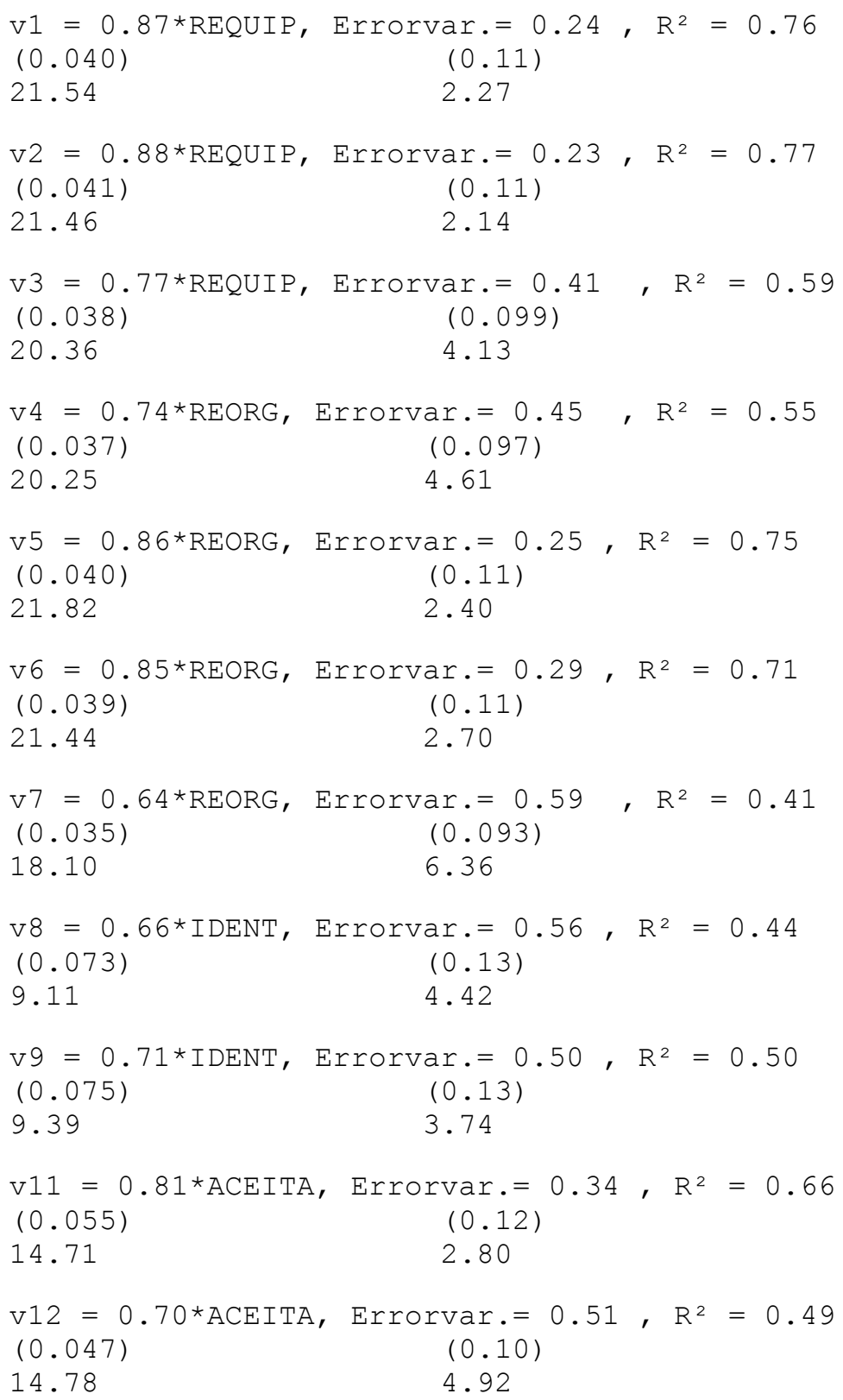

Correlation Matrix of Independent Variables

$\begin{array}{lrrrr} & \text { REQUIP } & \text { REORG } & \text { ACEITA } & \text { IDENT } \\ \text { REQUIP } & 1.00 & & & \\ \text { REORG } & 0.52 & 1.00 & & \\ & (0.03) & & & \\ \text { ACEITA } & 17.16 & & & \\ & 0.61 & 0.50 & & \\ \text { IDENT } & (0.05) & (0.04) & & \\ & 12.13 & 11.33 & & \\ & 0.33 & 0.23 & 0.28 & \\ & (0.05) & (0.04) & (0.06) & \\ & 7.11 & 5.63 & 4.68 & \end{array}$

\section{Goodness of Fit Statistics}

W_A_R_N_I_N_G: Chi-square, standard errors, t-values and standardized residuals are calculated under the assumption of multi-variate normality. 
Degrees of Freedom $=38$

Normal Theory Weighted Least Squares Chi-Square $=91.54(\mathrm{P}=0.00)$

Estimated Non-centrality Parameter $(\mathrm{NCP})=53.54$

90 Percent Confidence Interval for $\mathrm{NCP}=(29.29 ; 85.49)$

Minimum Fit Function Value $=0.087$

Population Discrepancy Function Value $(\mathrm{FO})=0.18$

90 Percent Confidence Interval for $\mathrm{FO}=(0.097 ; 0.28)$

Root Mean Square Error of Approximation (RMSEA) $=0.068$

90 Percent Confidence Interval for RMSEA $=(0.050 ; 0.086)$

$\mathrm{P}-\mathrm{Value}$ for Test of Close Fit (RMSEA $<0.05)=0.046$

Expected Cross-Validation Index (ECVI) $=0.49$

90 Percent Confidence Interval for ECVI $=(0.41 ; 0.59)$

ECVI for Saturated Model $=0.44$

ECVI for Independence Model $=7.71$

Chi-Square for Independence Model with 55 Degrees of Freedom $=2315.51$

Independence $\mathrm{AIC}=2337.51$

Model $\mathrm{AIC}=147.54$

Saturated $\mathrm{AIC}=132.00$

Independence CAIC $=2389.40$

Model CAIC $=279.61$

saturated CAIC $=443.32$

Normed Fit Index (NFI) $=1.00$

Non-Normed Fit Index $($ NNFI) $=1.02$

Parsimony Normed Fit Index $(\mathrm{PNFI})=0.69$

Comparative Fit Index (CFI) $=1.00$

Incremental Fit Index (IFI) $=1.02$

Relative Fit Index (RFI) $=1.00$

Root Mean Square Residual (RMR) $=0.036$ Standardized $\mathrm{RMR}=0.036$

Goodness of Fit Index (GFI) $=0.99$

Adjusted Goodness of Fit Index (AGFI) $=0.99$

Parsimony Goodness of Fit Index (PGFI) $=0.57$

\section{$\underline{\text { !MIGUEL AFC } 2}$}




\section{Fitted Covariance Matrix}

$\begin{array}{lrr} & \mathbf{v 1} & \text { v2 } \\ \text { v1 } & 1.00 & \\ \text { v2 } & 0.76 & 1.00 \\ \text { v3 } & 0.67 & 0.67 \\ \text { v4 } & 0.33 & 0.34 \\ \text { v5 } & 0.39 & 0.39 \\ \text { v6 } & 0.38 & 0.38 \\ \text { v7 } & 0.29 & 0.29 \\ \text { v8 } & 0.19 & 0.19 \\ \text { v9 } & 0.20 & 0.20 \\ \text { v11 } & 0.43 & 0.43 \\ \text { v12 } & 0.37 & 0.37\end{array}$

Fitted Covariance Matrix (continued)

$\begin{array}{lrr} & \mathbf{v 7} & \text { v8 } \\ \text { v7 } & 1.00 & \\ \text { v8 } & 0.10 & 1.00 \\ \text { v9 } & 0.10 & 0.47 \\ \text { v11 } & 0.26 & 0.15 \\ \text { v12 } & 0.22 & 0.13\end{array}$

1.00
0.30

0.30

0.34
0.34

0.34
0.25

0.17

0.18

0.38

$\begin{array}{ll}0.37 & 0.33\end{array}$

1.00

$0.64 \quad 1.00$

0.63

0.47

0.11

0.12

0.30

0.26

0.73

0.55

1.00

0.13

0.14

0.30

0.34

0.29

v9

v11

v12

\section{Fitted Residuals}

$\begin{array}{lrr} & \text { v1 } & \text { v2 } \\ \text { v1 } & 0.00 & \\ \text { v2 } & 0.06 & 0.00 \\ \text { v3 } & -0.03 & -0.03 \\ \text { v4 } & \mathbf{0 . 0 8} & 0.03 \\ \text { v5 } & -0.06 & -0.03 \\ \text { v6 } & -0.10 & -0.02 \\ \text { v7 } & -0.01 & -0.04 \\ \text { v8 } & 0.04 & 0.00 \\ \text { v9 } & 0.02 & -0.02 \\ \text { v11 } & 0.01 & 0.02 \\ \text { v12 } & 0.01 & -0.01\end{array}$

v3

1.00

1.00
0.16

0.14

0.57

1.00

$\begin{array}{lll}.15 & 0.16 & 1.00 \\ 13 & 0.14 & 0.57\end{array}$

v2 v3

v4

v5

v6

Fitted Residuals (continued) 


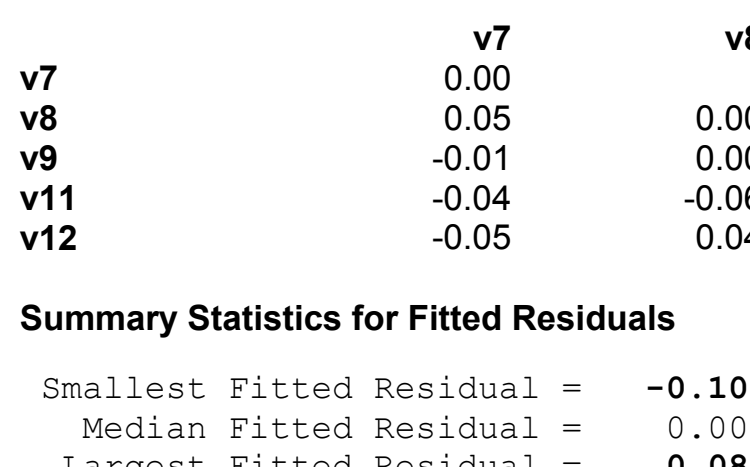

\section{Stemleaf Plot}

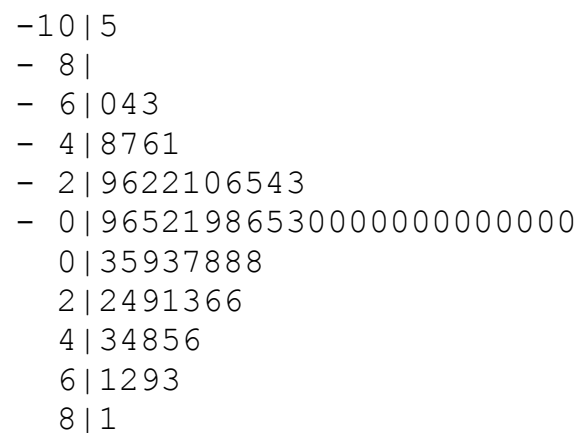

\section{Standardized Residuals}

\begin{tabular}{|c|c|c|c|c|c|c|}
\hline & v1 & v2 & v3 & v4 & v5 & v6 \\
\hline v1 & 0.00 & & & & & \\
\hline v2 & 1.65 & 0.00 & & & & \\
\hline v3 & -0.81 & -0.81 & - & & & \\
\hline v4 & 1.60 & 0.61 & 1.08 & - - & & \\
\hline v5 & -1.28 & -0.53 & 0.71 & -1.13 & 0.00 & \\
\hline v6 & -2.09 & -0.49 & 0.84 & -1.11 & 1.65 & - - \\
\hline v7 & -0.21 & -0.74 & 1.29 & 0.63 & -0.07 & 0.11 \\
\hline v8 & 0.73 & -0.10 & -0.38 & -0.30 & 0.35 & -0.61 \\
\hline v9 & 0.45 & -0.49 & -0.24 & -0.47 & 0.64 & -0.18 \\
\hline
\end{tabular}


v11

Standardized Residuals (continued)

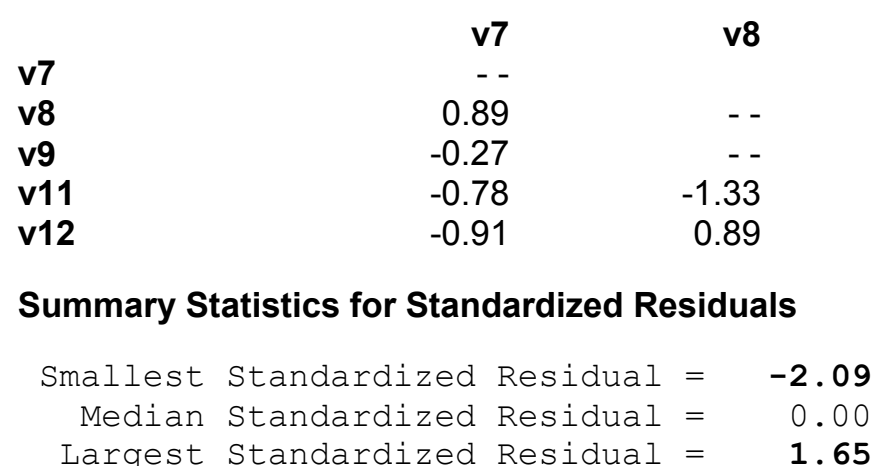

Stemleaf Plot

$-2 \mid 1$

$-11$

- 1143311

- 01988877765555

- $0 \mid 43322221110000000000000$

$0 \mid 11233344$

$0 \mid 5566677899$

$1 \mid 133$

$1 \mid 5666$

\section{$\underline{! M I G U E L A F C 2}$}

Qplot of Standardized Residuals

v9

v11

v12

$-0 . \overline{65}$

1.28

0.00

0.00 


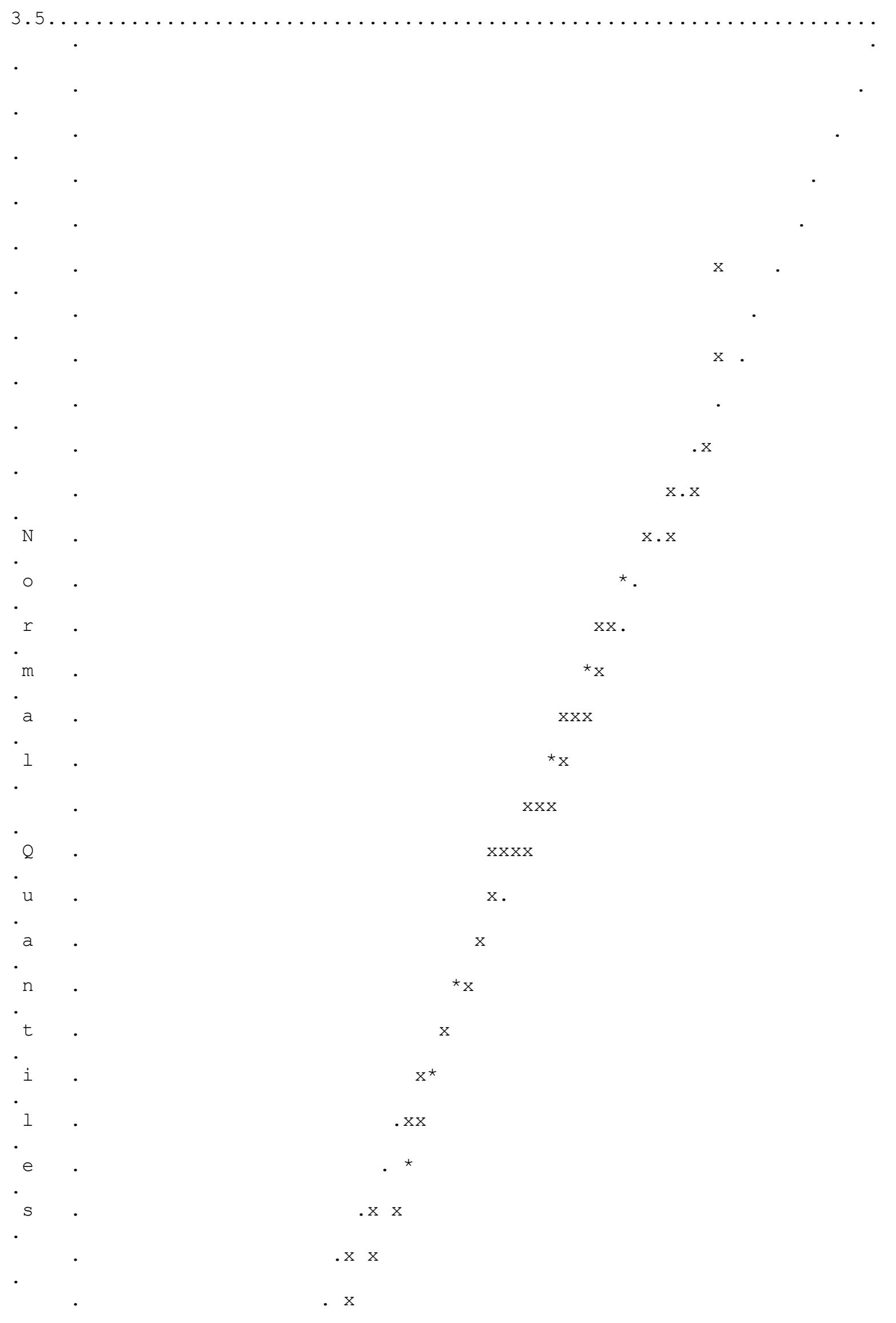


$-3.5$

3.5

\section{$\stackrel{\text { MIGUEL AFC } 2}{ }$}

Modification Indices and Expected Change

Modification Indices for LAMBDA-X

$\begin{array}{lrrrr} & \text { REQUIP } & \text { REORG } & \text { ACEITA } & \text { IDENT } \\ \text { v1 } & -- & 2.27 & 0.02 & 0.66 \\ \text { v2 } & -- & 0.64 & 0.02 & 0.27 \\ \text { v3 } & -- & 7.47 & 0.12 & 0.09 \\ \text { v4 } & 5.16 & -- & 0.98 & 0.00 \\ \text { v5 } & 0.44 & -- & 0.03 & 0.30 \\ \text { v6 } & 1.08 & -- & 0.04 & 0.59 \\ \text { v7 } & 0.06 & -- & 1.08 & 0.06 \\ \text { v8 } & 0.04 & 0.01 & 0.16 & -- \\ \text { v9 } & -- & 0.01 & 1.22 & -- \\ \text { v11 } & 0.92 & 0.11 & -- & 2.66 \\ \text { v12 } & 1.12 & 0.14 & -- & 3.40\end{array}$

Expected Change for LAMBDA-X

$\begin{array}{lrrrr} & \text { REQUIP } & \text { REORG } & \text { ACEITA } & \text { IDENT } \\ \text { v1 } & -- & -0.12 & -0.02 & 0.07 \\ \text { v2 } & -- & -0.07 & -0.02 & -0.04 \\ \text { v3 } & -- & 0.23 & 0.05 & -0.03 \\ \text { v4 } & 0.18 & -- & 0.09 & 0.00 \\ \text { v5 } & -0.05 & -- & -0.02 & 0.04 \\ \text { v6 } & -0.08 & -- & 0.02 & -0.06 \\ \text { v7 } & -0.02 & -- & -0.08 & 0.02 \\ \text { v8 } & 0.04 & 0.01 & -0.06 & -- \\ \text { v9 } & -- & -0.01 & 0.47 & - \\ \text { v11 } & 0.23 & -0.04 & -- & -0.17 \\ \text { v12 } & -0.24 & 0.04 & -- & 0.18\end{array}$




\section{Modification Indices for THETA-DELTA}

$\begin{array}{lrrr}\text { v1 } & \text { v1 } & \text { v2 } & \text { v3 } \\ \text { v2 } & -- & & \\ \text { v3 } & 2.71 & -- & - \\ \text { v4 } & 0.66 & 0.65 & 1.17 \\ \text { v5 } & 2.56 & 0.38 & 0.51 \\ \text { v6 } & 1.64 & 0.28 & 0.70 \\ \text { v7 } & 4.36 & 0.24 & 1.68 \\ \text { v8 } & 0.04 & 0.54 & 0.15 \\ \text { v9 } & 0.53 & 0.01 & 0.06 \\ \text { v11 } & 0.21 & 0.24 & 0.27 \\ \text { v12 } & 0.04 & 0.16 & 1.98\end{array}$

v4

Modification Indices for THETA-DELTA (continued)

$\begin{array}{lrrr} & \text { v7 } & \text { v8 } & \text { v9 } \\ \text { v7 } & -- & & \\ \text { v8 } & 0.80 & -- & -- \\ \text { v9 } & 0.07 & -- & 0.43 \\ \text { v11 } & 0.61 & 1.77 & 1.64 \\ \text { v12 } & 0.82 & 0.79 & \end{array}$

\section{Expected Change for THETA-DELTA}

$\begin{array}{lr}\text { v1 } & \text { v1 } \\ \text { v2 } & -- \\ \text { v3 } & 0.16 \\ \text { v4 } & -0.07 \\ \text { v5 } & 0.10 \\ \text { v6 } & -0.08 \\ \text { v7 } & -0.14 \\ \text { v8 } & -0.01 \\ \text { v9 } & 0.05 \\ \text { v11 } & 0.03 \\ \text { v12 } & 0.01 \\ \end{array}$

$\begin{array}{rr}\mathbf{v 1} & \mathbf{v 2} \\ -- & \\ 0.16 & -- \\ -0.07 & -0.07 \\ 0.10 & 0.04 \\ -0.08 & -0.04 \\ -0.14 & -0.03 \\ -0.01 & -0.05 \\ 0.05 & -0.01 \\ 0.03 & -0.03 \\ 0.01 & 0.03 \\ 0.02 & -0.01\end{array}$

$-0.05$

$-0.01$

0.03
-0.01

0.07
0.05
0.05
0.08
-0.02
-0.02
0.04
-0.09

--
-0.09
-0.09
0.05
-0.02
-0.03
0.02
-0.04

$\begin{array}{lll}0.02 & 0.02 & -0.04\end{array}$

$\begin{array}{lll}-0.03 & 0.04 & -0.01\end{array}$

Expected Change for THETA-DELTA (continued) 
v7

v8

v9

v11

v12 v7

0.05

$-0.02$

$-0.05$

$-0.06$ v8

$-0.09$

0.06 v9

v11

v12

Maximum Modification Index is 7.47 for Element ( 3, 2) of LAMBDA-X Time used:

0.094 Seconds

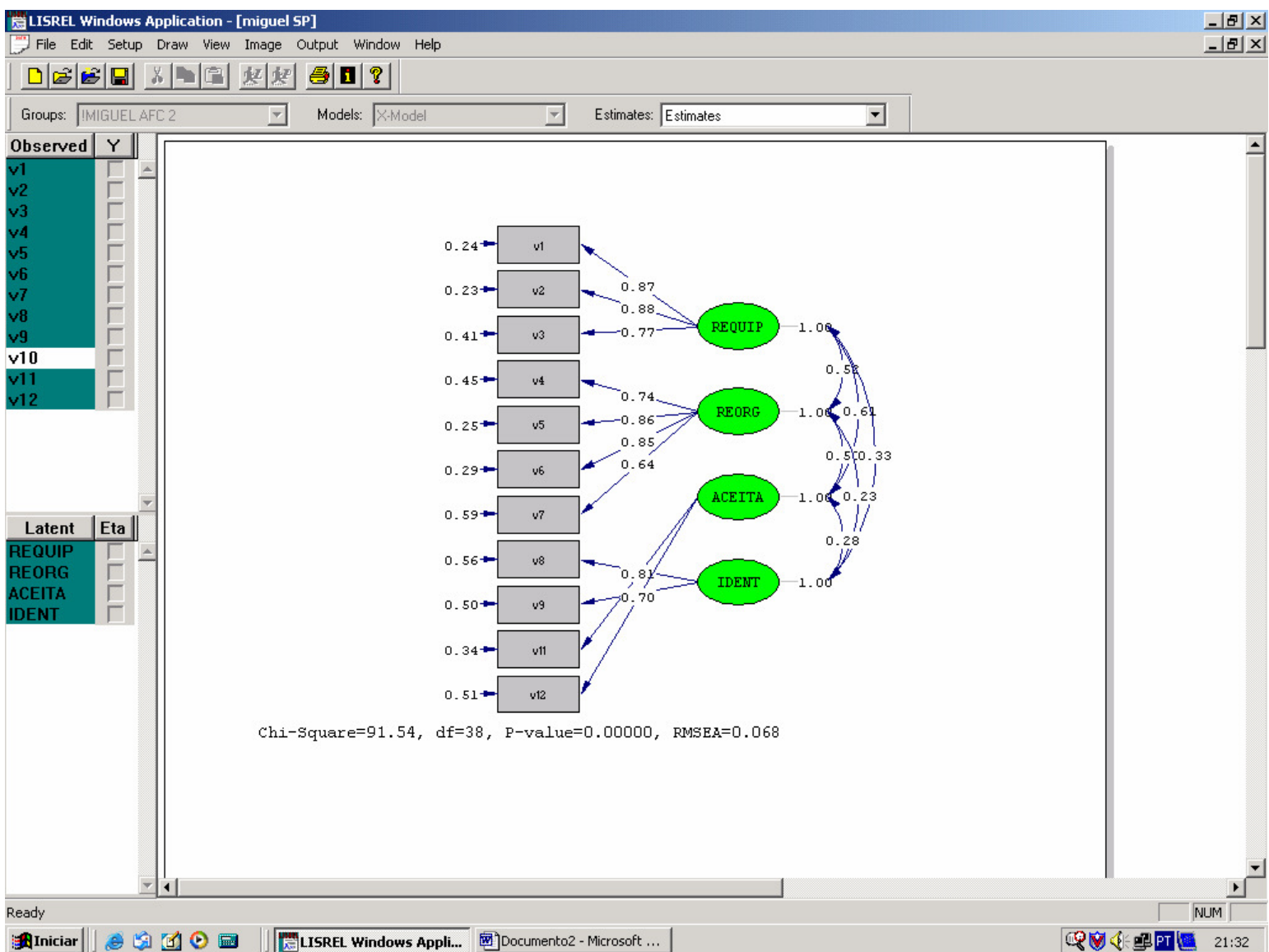




\section{Anexo VI - Modelo ACEITA}

\section{ULS \\ DATE: $1 / 13 / 2006$}

TIME: $21: 50$

L I S R E L 8.71 BY

Karl G. Jöreskog and Dag Sörbom

This program is published exclusively by

Scientific Software International, Inc.

7383 N. Lincoln Avenue, Suite 100

Lincolnwood, IL 60712, U.S.A.

Phone: (800)247-6113, (847)675-0720, Fax: (847)675-2140

Copyright by Scientific Software International, Inc., 1981-2004

Use of this program is subject to the terms specified in the

Universal Copyright Convention.

Website: www.ssicentral.com

The following lines were read from file C:\Documents and

Settings\dirceuds. GLOBAL \Desktop \OPERAÇÃO\miguel\miguel SP.spj:

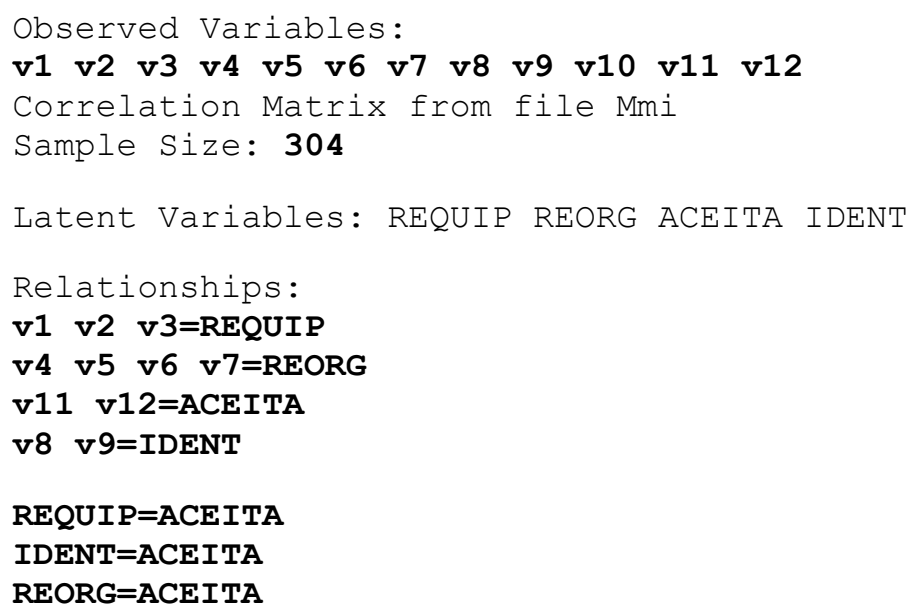

\section{LISREL Estimates (Unweighted Least Squares)}

\section{Measurement Equations}

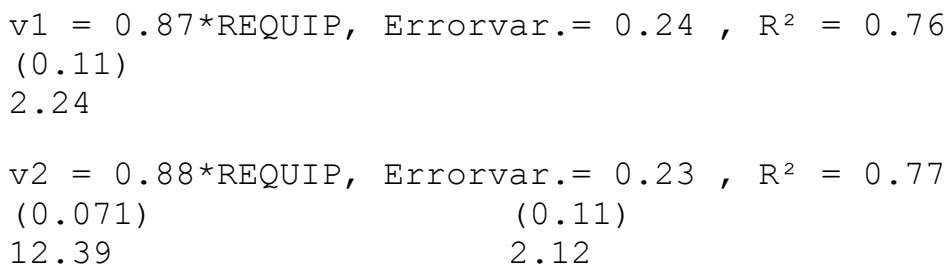




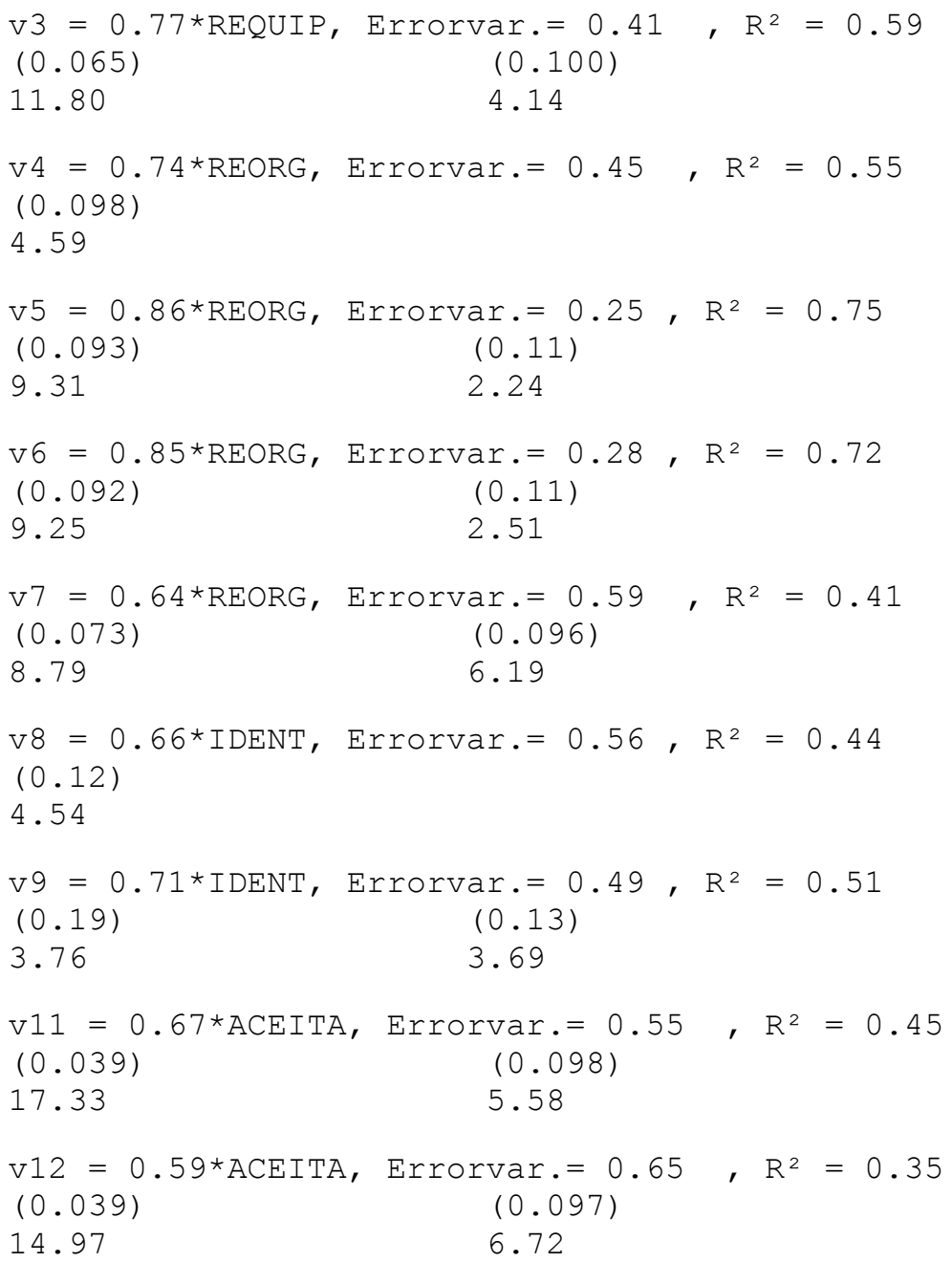

\section{Structural Equations}

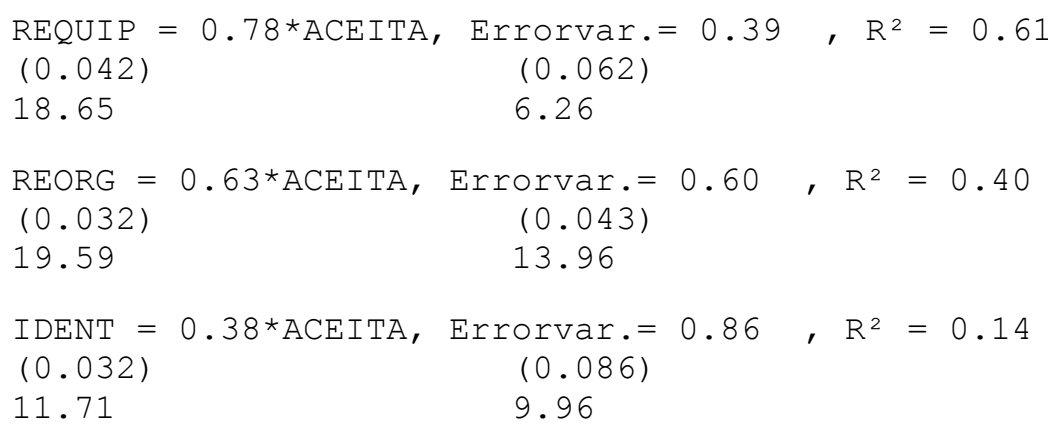

\section{Goodness of Fit Statistics}

W_A_R_N_I_N_G: Chi-square, standard errors, t-values and standardized ressiduals are calculated under the assumption of multi-variate normality.

Degrees of Freedom $=41$

Normal Theory Weighted Least Squares Chi-Square $=105.17(\mathrm{P}=0.00)$

Estimated Non-centrality Parameter $(\mathrm{NCP})=64.17$

90 Percent Confidence Interval for $\mathrm{NCP}=(37.66 ; 98.35)$

Minimum Fit Function Value $=0.13$

Population Discrepancy Function Value $(\mathrm{F} 0)=0.21$

90 Percent Confidence Interval for $\mathrm{FO}=(0.12 ; 0.32)$

Root Mean Square Error of Approximation (RMSEA) $=0.072$ 
90 Percent Confidence Interval for RMSEA $=(0.055 ; 0.089)$

P-Value for Test of Close Fit (RMSEA $<0.05)=0.018$

Expected Cross-Validation Index (ECVI) $=0.51$

90 Percent Confidence Interval for ECVI $=(0.42 ; 0.62)$

ECVI for Saturated Model $=0.44$

ECVI for Independence Model $=7.71$

Chi-Square for Independence Model with 55 Degrees of Freedom $=2315.51$

Independence $\mathrm{AIC}=2337.51$

Model $\mathrm{AIC}=155.17$

Saturated $\mathrm{AIC}=132.00$

Independence $\mathrm{CAIC}=2389.40$

Model $\mathrm{CAIC}=273.09$

Saturated $\mathrm{CAIC}=443.32$

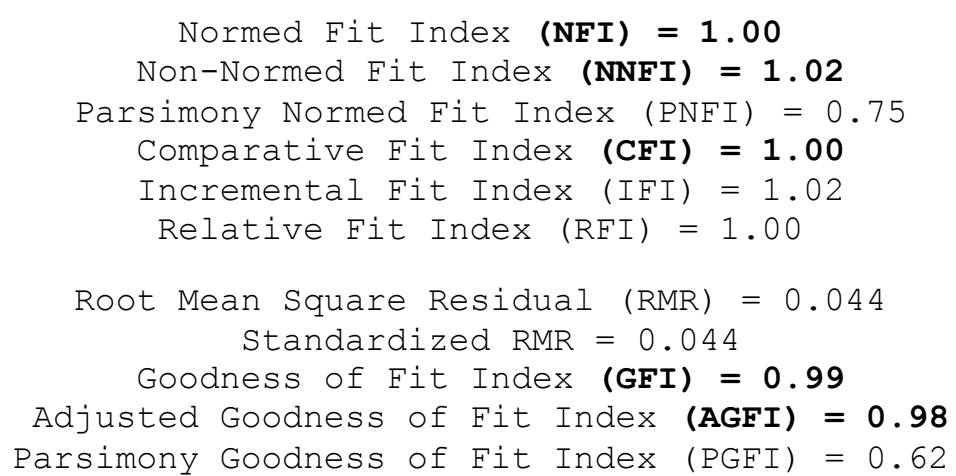

\section{Summary Statistics for Standardized Residuals}

$\begin{array}{rr}\text { Smallest Standardized Residual }= & -\mathbf{2 . 0 3} \\ \text { Median Standardized Residual }= & 0.00 \\ \text { Largest Standardized Residual }= & \mathbf{3 . 8 9}\end{array}$

\section{Stemleaf Plot}

$-210$

- $1 \mid 954332111$

- $0 \mid 9776654444433221110000000000000000000$

$0 \mid 122568899$

$1 \mid 001133468$

21

319

\section{Largest Positive Standardized Residuals}

$\begin{array}{lllll}\text { Residual for } & \text { v12 } & \text { and } & \text { v11 }\end{array}$

\section{!MIGUEL AFC 2}

\section{Qplot of Standardized Residuals}

3.5 
x .

u

a

$\mathbf{x}$

$\mathbf{x}$.

$\mathbf{x}$

$t$

i

1

e

n

t

1

$\mathbf{x x}$

$\mathbf{x}$.

$\mathbf{x x}$

$\mathbf{x}$

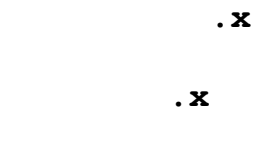

$\mathbf{x x}$

. $\mathrm{x}$

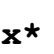

. $x x$

$\mathbf{x x} \times$
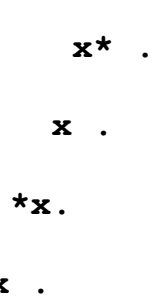

* $\mathbf{x}$

Xx

.

x . 


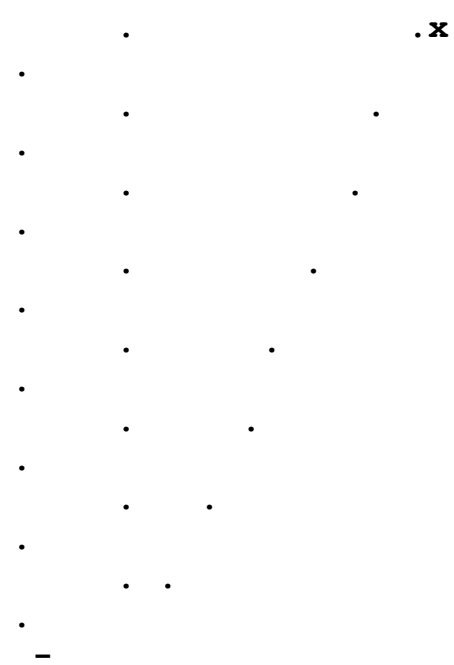

3.5 .

$-3.5$

3.5

Time used: $\quad 0.078$ Seconds

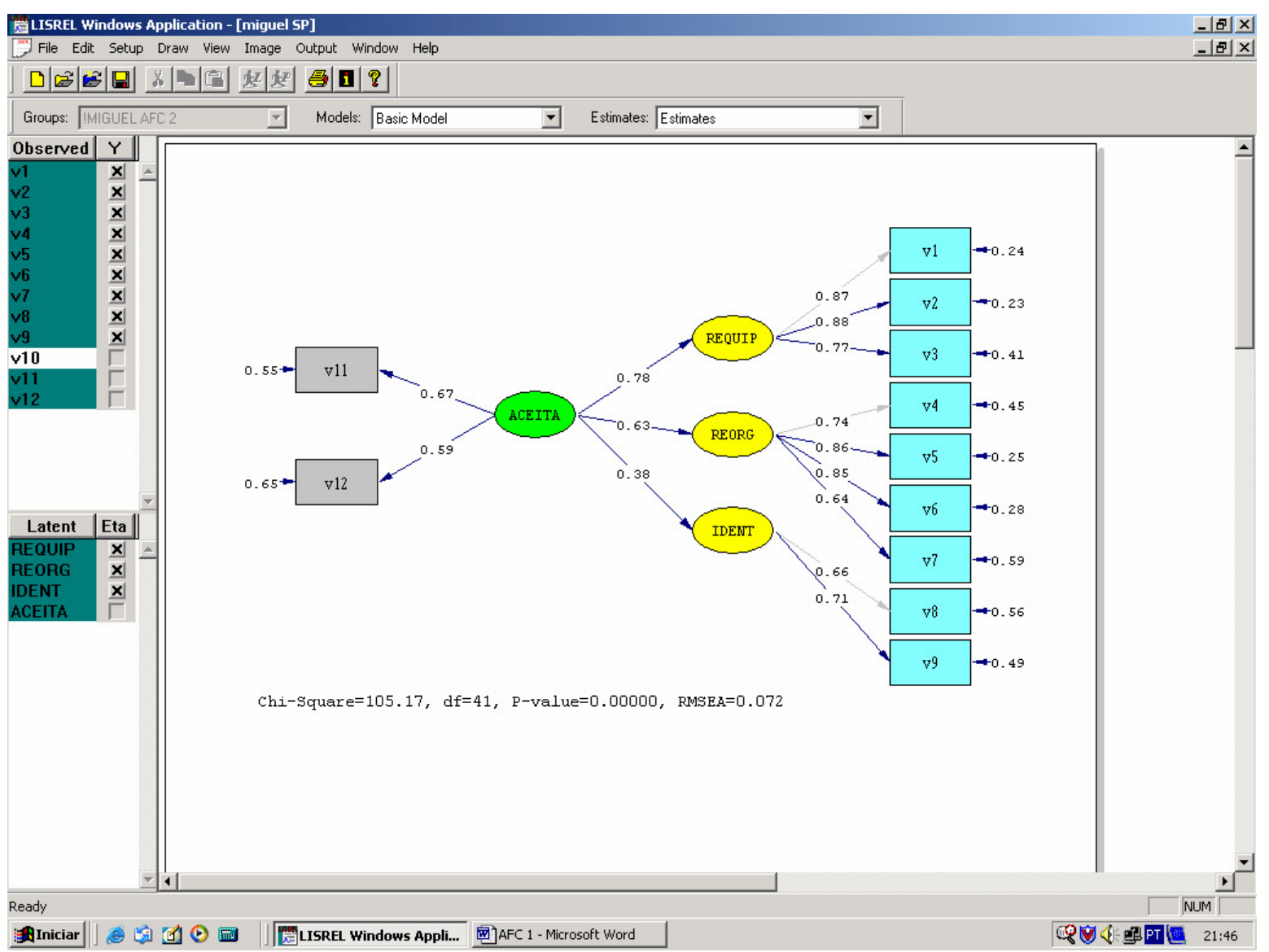




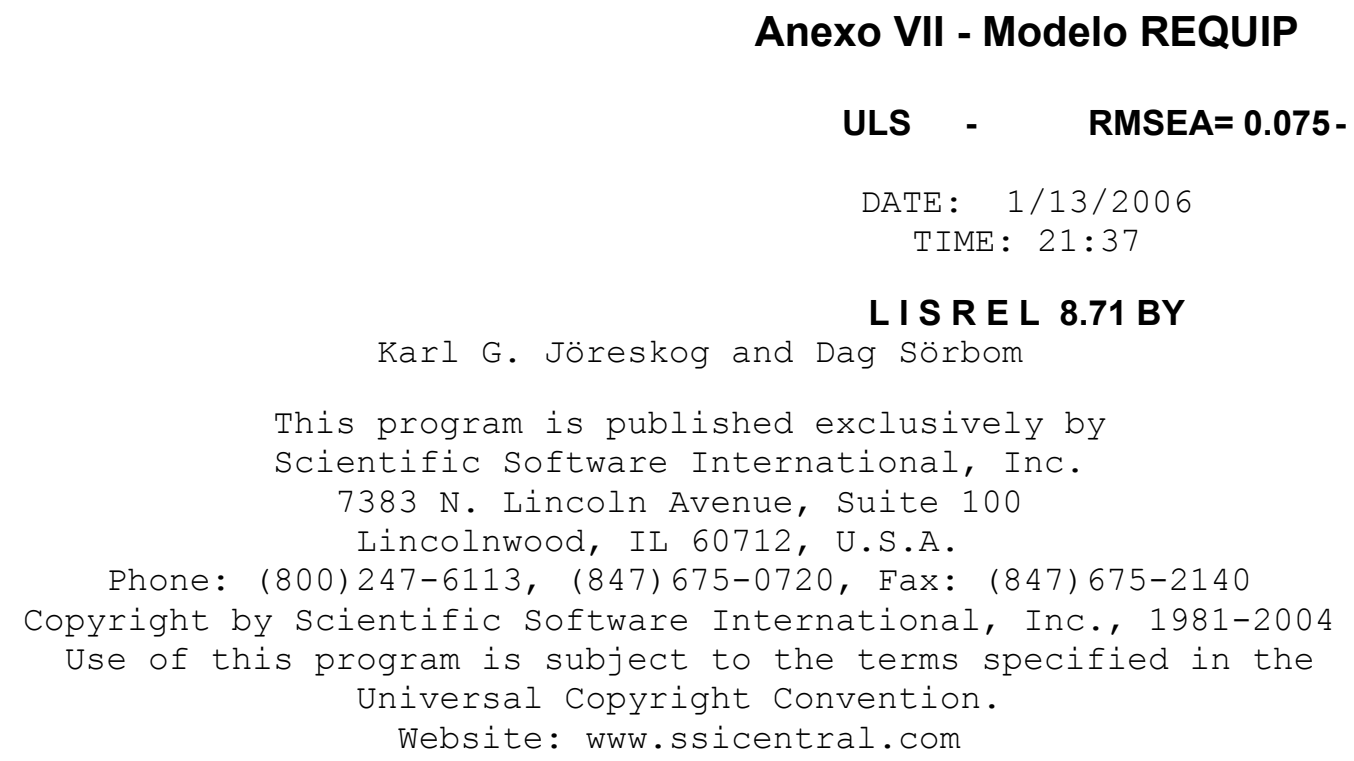

The following lines were read from file

C: \Documents

and Settings\dirceuds. GLOBAL \Desktop \OPERAÇÃO\miguel \miguel SP.spj :

Observed Variables:

v1 v2 v3 v4 v5 v6 v7 v8 v9 v10 v11 v12

Correlation Matrix from file Mmi

Sample Size: 304

Latent Variables: REOUIP REORG ACEITA IDENT

Relationships:

v1 v2 v3=REQUIP

v4 v5 v6 7 $7=$ REORG

$\mathrm{v} 11 \mathrm{v} 12=\mathrm{ACE} I T A$

v8 $v 9=$ IDENT

REORG $=$ REOUIP

ACEITA $=$ REQUI

IDENT $=$ REOUIP 
Options: $\mathrm{ND}=2 \mathrm{RS} \mathrm{ME}=\mathrm{UL} \mathrm{ADD}=\mathrm{OFF} \quad \mathrm{TT}=100 \mathrm{MI}$ path diagram

END OF PROBLEM

6.6 in. 02 in

Sample Size $=\mathbf{3 0 4}$

\section{$\underline{\text { !MIGUEL AFC } 2}$}

\section{Correlation Matrix}

$\begin{array}{ll}\text { v4 } & \\ \text { v5 } & 1.00 \\ \text { v6 } & 0.59 \\ \text { v7 } & 0.58 \\ \text { v8 } & 0.50 \\ \text { v9 } & 0.10 \\ \text { v11 } & 0 . \\ \text { v12 } & 0.32 \\ \text { v1 } & 0.22 \\ \text { v2 } & 0.4 \\ \text { v3 } & 0.37\end{array}$

$\mathbf{v 4}$
1.00
0.59
0.58
0.50
0.10
0.10
0.32
0.22
0.42
0.37
0.35

Correlation Matrix (continued)

$\begin{array}{lll} & \mathbf{v 1 1} & \mathbf{v 1 2} \\ \text { v11 } & 1.00 & \\ \text { v12 } & 0.57 & 1.00 \\ \text { v1 } & 0.44 & 0.38 \\ \text { v2 } & 0.45 & 0.36 \\ \text { v3 } & 0.40 & 0.26\end{array}$

1.00

0.79

1.00

0.55

$\begin{array}{ll}0.55 & 0.15 \\ 0.15 & 0.10\end{array}$

$0.17 \quad 0.13$

$0.34-0.34$

$0.32 \quad 0.37$

$\begin{array}{ll}0.33 & 0.28\end{array}$

$0.37-0.36$

$0.38 \quad 0.38$

1.00

$0.15 \quad 1.00$

$0.09 \quad 0.47$

$0.22 \quad 0.09$

$0.17 \quad 0.17$

$0.28 \quad 0.22$

$0.25 \quad 0.18$

$0.32 \quad 0.15$

0.18

\section{$\underline{! M I G U E L A F C 2}$}

Number of Iterations $=10$

\section{LISREL Estimates (Unweighted Least Squares)}




\section{Measurement Equations}

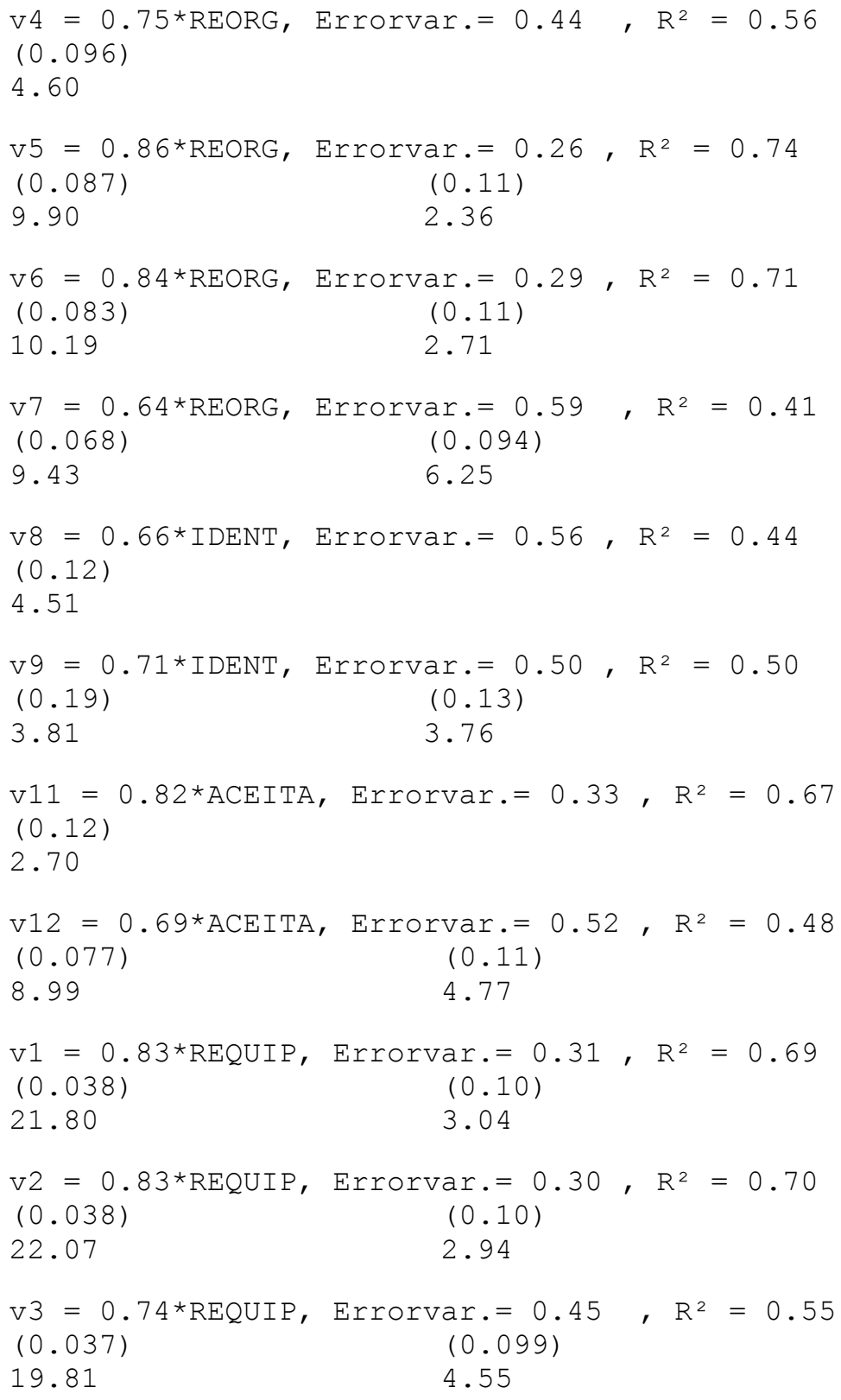

Structural Equations

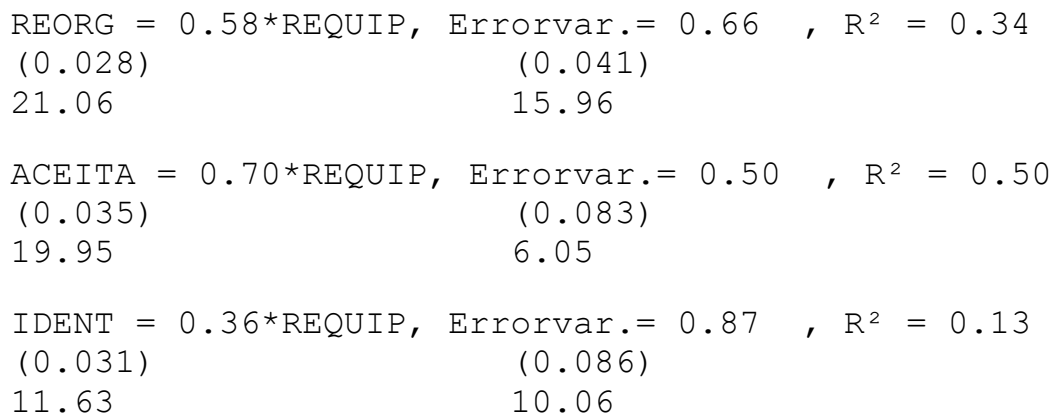

\section{Correlation Matrix of Independent Variables}




\section{Covariance Matrix of Latent Variables}

$\begin{array}{lrrrr} & \text { REORG } & \text { ACEITA } & \text { IDENT } & \text { REQUIP } \\ \text { REORG } & 1.00 & & & \\ \text { ACEITA } & 0.41 & 1.00 & & \\ \text { IDENT } & 0.21 & 0.26 & 1.00 & \\ \text { REQUIP } & 0.58 & 0.70 & 0.36 & 1.00\end{array}$

\section{Goodness of Fit Statistics}

W_A_R_N_I N G: Chi-square, standard errors, t-values and standardized residuals are calculated under the assumption of multi-variate normality.

\section{Degrees of Freedom $=41$}

Normal Theory Weighted Least Squares Chi-Square $=110.38(\mathrm{P}=0.00)$ Estimated Non-centrality Parameter $(\mathrm{NCP})=69.38$

90 Percent Confidence Interval for $\mathrm{NCP}=(41.95 ; 104.48)$

Minimum Fit Function Value $=0.14$

Population Discrepancy Function Value (FO) $=0.23$

90 Percent Confidence Interval for $\mathrm{FO}=(0.14 ; 0.34)$

Root Mean Square Error of Approximation (RMSEA) $=0.075$

90 Percent Confidence Interval for RMSEA $=(0.058 ; 0.092)$

P-Value for Test of Close Fit (RMSEA $<0.05)=0.0084$

Expected Cross-Validation Index (ECVI) $=0.53$

90 Percent Confidence Interval for ECVI $=(0.44 ; 0.65)$

ECVI for Saturated Model $=0.44$

ECVI for Independence Model $=7.71$

Chi-Square for Independence Model with 55 Degrees of Freedom $=2315.51$

Independence $\mathrm{AIC}=2337.51$

Model $\mathrm{AIC}=160.38$

Saturated AIC $=132.00$

Independence $\mathrm{CAIC}=2389.40$

Model $\mathrm{CAIC}=278.31$

Saturated $\mathrm{CAIC}=443.32$

Normed Fit Index (NFI) $=1.00$

Non-Normed Fit Index (NNFI) $=1.02$ 


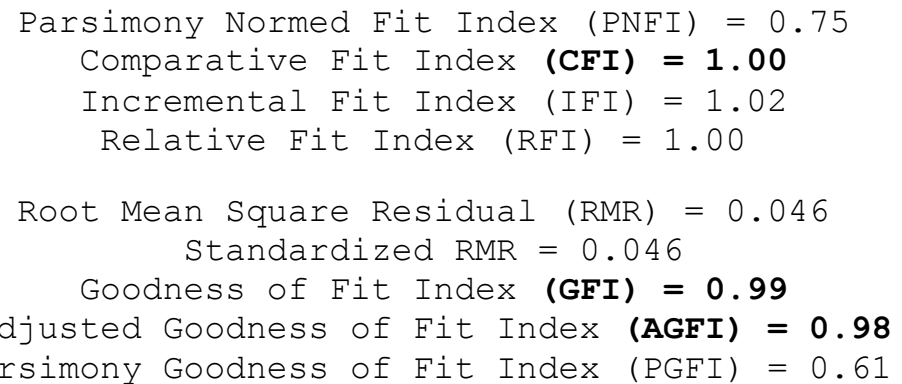

\section{!MIGUEL AFC 2}

Fitted Covariance Matrix

$\begin{array}{lr} & \text { v4 } \\ \text { v4 } & 1.00 \\ \text { v5 } & 0.64 \\ \text { v6 } & 0.63 \\ \text { v7 } & 0.48 \\ \text { v8 } & 0.10 \\ \text { v9 } & 0.11 \\ \text { v11 } & 0.25 \\ \text { v12 } & 0.21 \\ \text { v1 } & 0.36 \\ \text { v2 } & 0.36 \\ \text { v3 } & 0.32\end{array}$

Fitted Covariance Matrix (continued)

$\begin{array}{lll} & \mathbf{v 1 1} & \mathbf{v 1 2} \\ \text { v11 } & 1.00 & \\ \text { v12 } & 0.57 & 1.00 \\ \text { v1 } & 0.48 & 0.40 \\ \text { v2 } & 0.48 & 0.41 \\ \text { v3 } & 0.43 & 0.36\end{array}$

Fitted Residuals

$\begin{array}{lr}\text { v4 } & 0.00 \\ \text { v5 } & -0.05 \\ \text { v6 } & -0.05\end{array}$

v5

1.00

0.72

0.55

0.12

0.13

0.29

0.24

0.42

0.37

v6

1.00

0.54

0.12

0.13

0.28

0.24

0.41

0.41

0.36

v1

1.00

0.69

0.61

v6

0.00

0.07

0.00 v7

1.00

0.09

0.10

0.21

0.18

0.31

0.31

0.28

v2

1.00

0.62

v7

v8

v9 v9

0.15
0.13

0.21

0.22

0.19 


\begin{tabular}{|c|c|c|c|c|c|c|}
\hline v7 & 0.03 & 0.00 & 0.01 & 0.00 & & \\
\hline v8 & -0.01 & 0.03 & -0.02 & 0.06 & 0.00 & \\
\hline v9 & -0.02 & 0.04 & 0.00 & -0.01 & 0.00 & 0.00 \\
\hline v11 & 0.07 & 0.05 & 0.06 & 0.00 & -0.05 & -0.02 \\
\hline v12 & 0.01 & 0.07 & 0.13 & -0.01 & 0.06 & 0.07 \\
\hline v1 & 0.06 & -0.09 & -0.13 & -0.03 & 0.02 & 0.01 \\
\hline v2 & 0.01 & -0.05 & -0.05 & -0.06 & -0.02 & -0.04 \\
\hline v3 & 0.03 & 0.01 & 0.02 & 0.05 & -0.03 & -0.03 \\
\hline
\end{tabular}

Fitted Residuals (continued)

$\begin{array}{lrrr} & \mathbf{v 1 1} & \mathbf{v 1 2} & \mathbf{v} \\ \mathbf{v 1 1} & 0.00 & & \\ \mathbf{v 1 2} & 0.00 & 0.00 & \\ \text { v1 } & -0.04 & -0.02 & 0.00 \\ \text { v2 } & -0.03 & -0.04 & \mathbf{0 . 1 3} \\ \text { v3 } & -0.02 & -0.11 & 0.02\end{array}$

\section{Summary Statistics for Fitted Residuals}

Smallest Fitted Residual $=-0.13$

Median Fitted Residual $=0.00$

Largest Fitted Residual $=0.13$

\section{Stemleaf Plot}

- 1 131

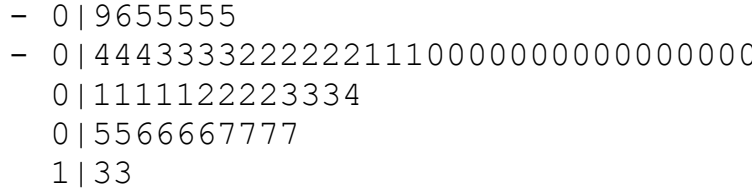

- 019655555

- $0 \mid 44433332222221110000000000000000$

$0 \mid 1111122223334$

$0 \mid 5566667777$

$1 \mid 33$

Standardized Residuals

\begin{tabular}{|c|c|c|c|c|c|c|}
\hline & v4 & v5 & v6 & v7 & v8 & v9 \\
\hline v4 & - - & & & & & \\
\hline v5 & -1.29 & - - & & & & \\
\hline v6 & -1.17 & - & - - & & & \\
\hline v7 & 0.59 & - - & - & - & & \\
\hline v8 & -0.13 & 0.51 & -0.38 & 0.98 & - & \\
\hline v9 & -0.30 & 0.90 & 0.05 & -0.13 & _. & \\
\hline
\end{tabular}




\begin{tabular}{|c|c|c|c|c|c|c|}
\hline v11 & 1.22 & 1.08 & 1.23 & 0.06 & -0.92 & -0.37 \\
\hline v12 & 0.19 & 1.48 & 2.55 & -0.16 & 0.99 & 1.49 \\
\hline v1 & 1.06 & -2.05 & -2.87 & -0.67 & 0.44 & 0.29 \\
\hline v2 & 0.11 & -1.23 & -1.10 & -1.24 & -0.31 & -1.05 \\
\hline v3 & 0.55 & 0.17 & 0.33 & 0.92 & -0.59 & -0.64 \\
\hline
\end{tabular}

Standardized Residuals (continued)

\begin{tabular}{|c|c|c|c|c|c|}
\hline & v11 & v12 & v1 & v2 & v3 \\
\hline v11 & - & & & & \\
\hline v12 & 0.00 & - - & & & \\
\hline v1 & -0.77 & -0.54 & 0.00 & & \\
\hline v2 & -0.58 & -1.04 & 3.31 & 0.00 & \\
\hline v3 & -0.45 & -2.34 & 0.51 & 0.55 & 0.00 \\
\hline
\end{tabular}

Summary statistics for standardized Residuals

Smallest Standardized Residual = $\mathbf{- 2 . 8 7}$

Median Standardized Residual $=0.00$

Largest Standardized Residual = $\mathbf{3 . 3 1}$

\section{Stemleaf Plot}

- 21931

- 113222100

- 019876665444332110000000000000000

$0 \mid 111223345555699$

$1 \mid 00112255$

216

313

Largest Negative Standardized Residuals

Residual for

v1 and

V6

$-2.87$

Largest Positive Standardized Residuals

Residual for

v2 and

V1

3.31

!MIGUEL AFC 2 
Qplot of Standardized Residuals

$3.5 \ldots$

$\mathbf{x}$

$\mathbf{x}$

○

$r$

m

a

1

Q

$\mathrm{u}$

a

n

t

i

1

s

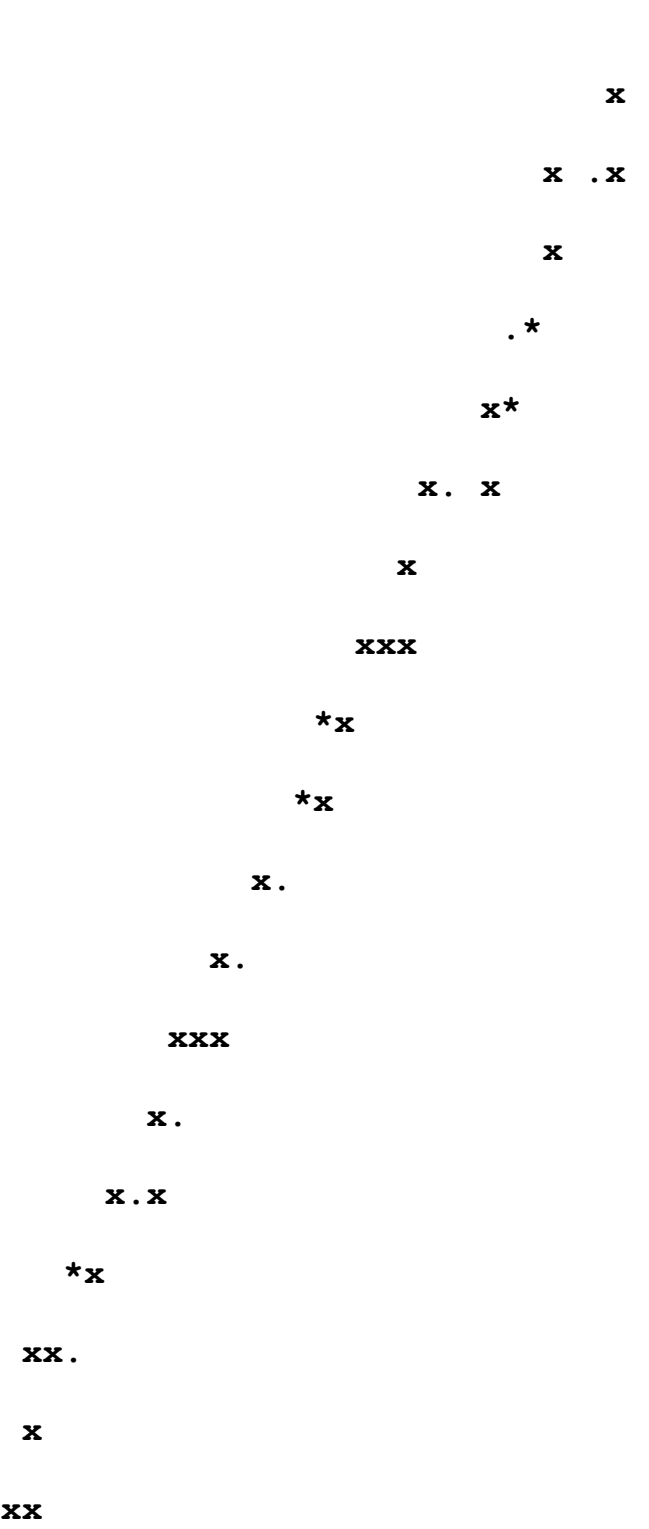




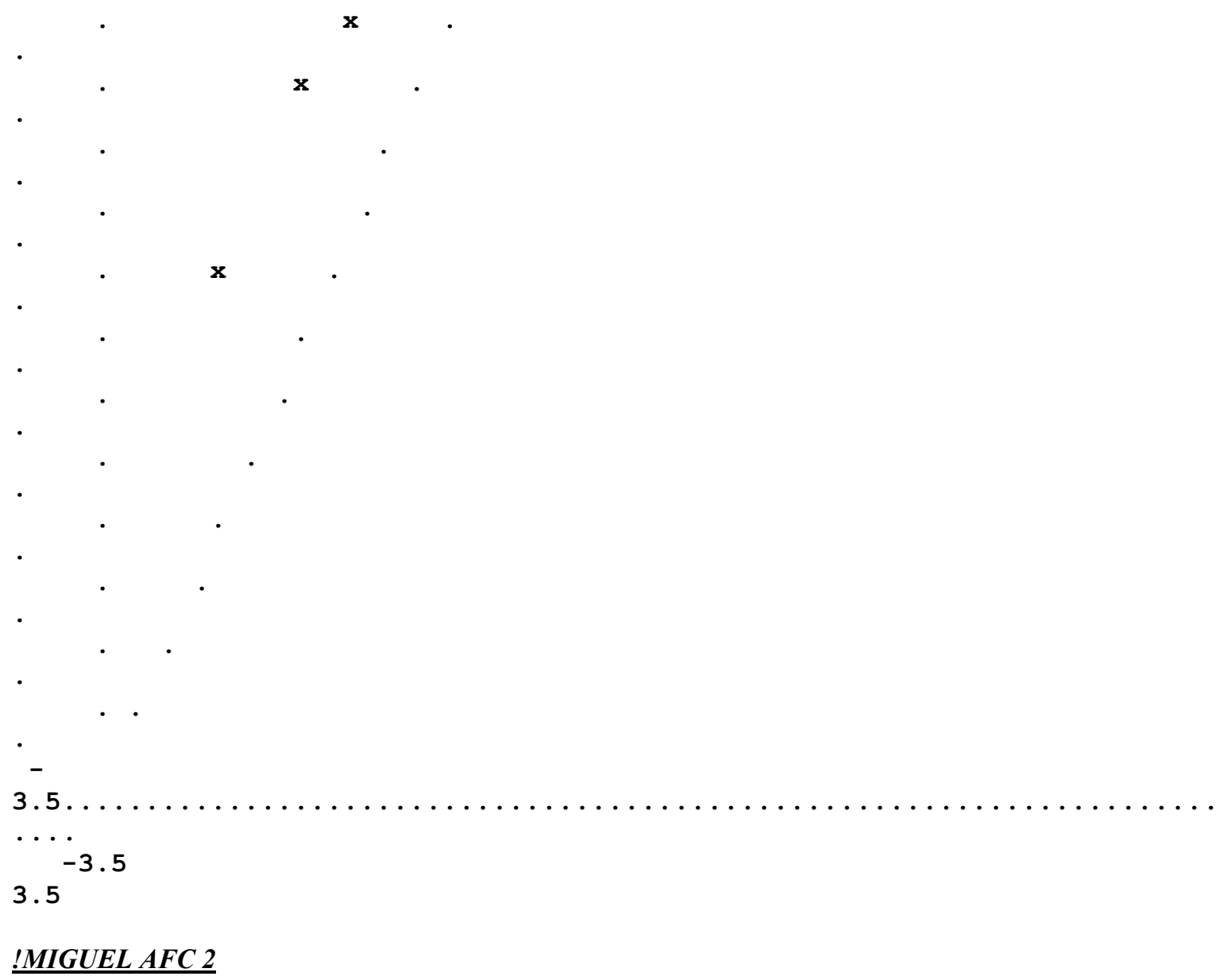

Modification Indices and Expected Change

Modification Indices for LAMBDA-Y

$\begin{array}{lrrr} & \text { REORG } & \text { ACEITA } & \text { IDENT } \\ \text { v4 } & -- & 1.02 & 0.04 \\ \text { v5 } & -- & -- & -- \\ \text { v6 } & -- & -- & -- \\ \text { v7 } & -- & -- & -- \\ \text { v8 } & 0.07 & 0.00 & -- \\ \text { v9 } & -- & -- & -- \\ \text { v11 } & 1.99 & -- & 0.58 \\ \text { v12 } & -- & -- & --\end{array}$

Expected Change for LAMBDA-Y

\begin{tabular}{lrrr} 
v4 & REORG & ACEITA & IDENT \\
v5 & -- & 0.04 & 0.01 \\
v6 & -- & -- & -- \\
v7 & -- & -- & -- \\
v8 & -- & -- & -- \\
v9 & 0.01 & 0.00 & -- \\
v11 & -- & -- & -- \\
v12 & 0.07 & -- & -0.05 \\
\multicolumn{2}{l}{ No Non-Zero Modification } & -- \\
\end{tabular}

The Modification Indices Suggest to Add the

Path to from Decrease in Chi-Square

ACEITA REORG 
Modification Indices for BETA

$\begin{array}{lrrr} & \text { REORG } & \text { ACEITA } & \text { IDENT } \\ \text { REORG } & ---1 & -- & -- \\ \text { ACEITA } & 31.73 & -- & 0.27 \\ \text { IDENT } & -- & -- & -- \\ \text { Expected Change for BETA } \\ \text { REORG } & \text { ACEITA } & \text { IDENT } \\ \text { REORG } & -- & -- & -- \\ \text { ACEITA } & 0.65 & -- & 0.04 \\ \text { IDENT } & -- & -- & -- \\ \text { No Non-Zero Modification Indices for GAMMA } \\ \text { No Non-Zero Modification Indices for PHI }\end{array}$

The Modification Indices Suggest to Add an Error Covariance
Between and
Decrease in Chi-Square

ACEITA REORG

\section{Modification Indices for PSI}

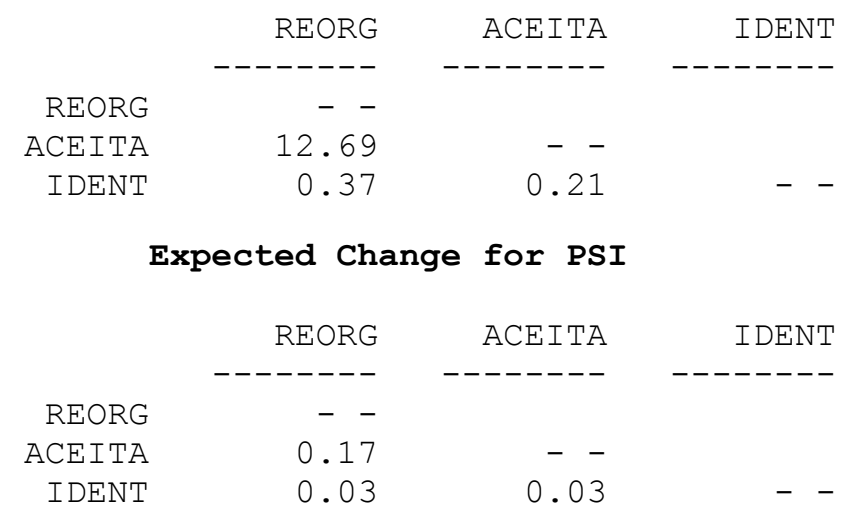

The Modification Indices Suggest to Add an Error Covariance

Between and Decrease in Chi-Square

$$
\begin{array}{ll}
\text { v1 } & \text { v6 } \\
\text { v2 } & \text { v1 }
\end{array}
$$

\begin{tabular}{|c|c|c|c|c|c|}
\hline v4 & v5 & v6 & v7 & v8 & v9 \\
\hline $\begin{array}{c}------- \\
-\quad-\end{array}$ & --------- & -------- & -------- & -------- & ----- \\
\hline 1.67 & $-\quad-$ & & & & \\
\hline 1.36 & $-\quad-$ & $-\quad-$ & & & \\
\hline 0.34 & $-\quad-$ & $-\quad-$ & $-\quad-$ & & \\
\hline 0.02 & 0.26 & 0.14 & 0.97 & $-\quad-$ & \\
\hline 0.09 & 0.80 & 0.00 & 0.02 & - & $-\quad-$ \\
\hline 1.50 & 1.18 & 1.50 & 0.00 & 0.85 & 0.13 \\
\hline 0.03 & 2.19 & 6.52 & 0.02 & 0.98 & 2.22 \\
\hline
\end{tabular}

Modification Indices for THETA-EPS
New Estimate

$12.7 \quad 0.17$
$8.2-0.21$

$\begin{array}{ll}11.0 & 0.29\end{array}$

Modification Indices for THETA-EPS

$\begin{array}{ccc} & \text { V11 } & \text { V12 } \\ \text { v11 } & ------- & ------- \\ \text { V12 } & - & -\end{array}$


Expected Change for THETA-EPS

\begin{tabular}{|c|c|c|c|c|c|}
\hline v4 & v5 & v6 & v7 & v8 & v9 \\
\hline $\begin{array}{c}-------- \\
-\quad-\end{array}$ & -------- & -------- & -------- & -------- & ------ \\
\hline-0.11 & $-\quad-$ & & & & \\
\hline-0.10 & - & $-\quad-$ & & & \\
\hline 0.04 & $-\quad-$ & $-\quad-$ & $-\quad-$ & & \\
\hline-0.01 & 0.03 & -0.02 & 0.06 & $-\quad-$ & \\
\hline-0.02 & 0.06 & 0.00 & -0.01 & $-\quad-$ & $-\quad-$ \\
\hline 0.07 & 0.07 & 0.08 & 0.00 & -0.05 & -0.03 \\
\hline 0.01 & 0.10 & 0.17 & -0.01 & 0.06 & 0.10 \\
\hline
\end{tabular}

Expected Change for THETA-EPS

Modification Indices for THETA-DELTA-EPS

$\begin{array}{ccccccc} & \text { V4 } & \text { V5 } & \text { V6 } & \text { V7 } & \text { V8 } & \text { V9 } \\ \text { V1 } & 1.12 & 4.22 & 8.23 & 0.45 & 0.19 & 0.08 \\ \text { V2 } & 0.01 & 1.51 & 1.20 & 1.53 & 0.10 & 1.10 \\ \text { V3 } & 0.30 & 0.03 & 0.11 & 0.85 & 0.35 & 0.42\end{array}$

Modification Indices for THETA-DELTA-EPS

$\begin{array}{ccc} & \mathrm{v} 11 & \mathrm{~V} 12 \\ \mathrm{~V} 1 & 0.60 & 0.29 \\ \text { V2 } & 0.34 & 1.08 \\ \text { V3 } & 0.20 & 5.48\end{array}$

Expected Change for THETA-DELTA-EPS

$\begin{array}{ccccccc} & \text { V4 } & \text { V5 } & \text { V6 } & \text { V7 } & \text { V8 } & \text { V9 } \\ \text { V1 } & ------- & ------- & ------- & ------- & ------- & ------ \\ \text { V2 } & 0.07 & -0.15 & -0.21 & -0.05 & 0.03 & 0.03 \\ \text { V3 } & 0.01 & -0.09 & -0.08 & -0.08 & -0.02 & -0.10 \\ & 0.03 & 0.01 & 0.02 & 0.06 & -0.04 & -0.05\end{array}$

\section{Expected Change for THETA-DELTA-EPS}

$\begin{array}{lll} & \text { V11 } & \text { V12 } \\ \text { v1 } & ------- & ------- \\ \text { v2 } & -0.05 & -0.04 \\ \text { v3 } & -0.04 & -0.08 \\ & -0.03 & -0.17\end{array}$




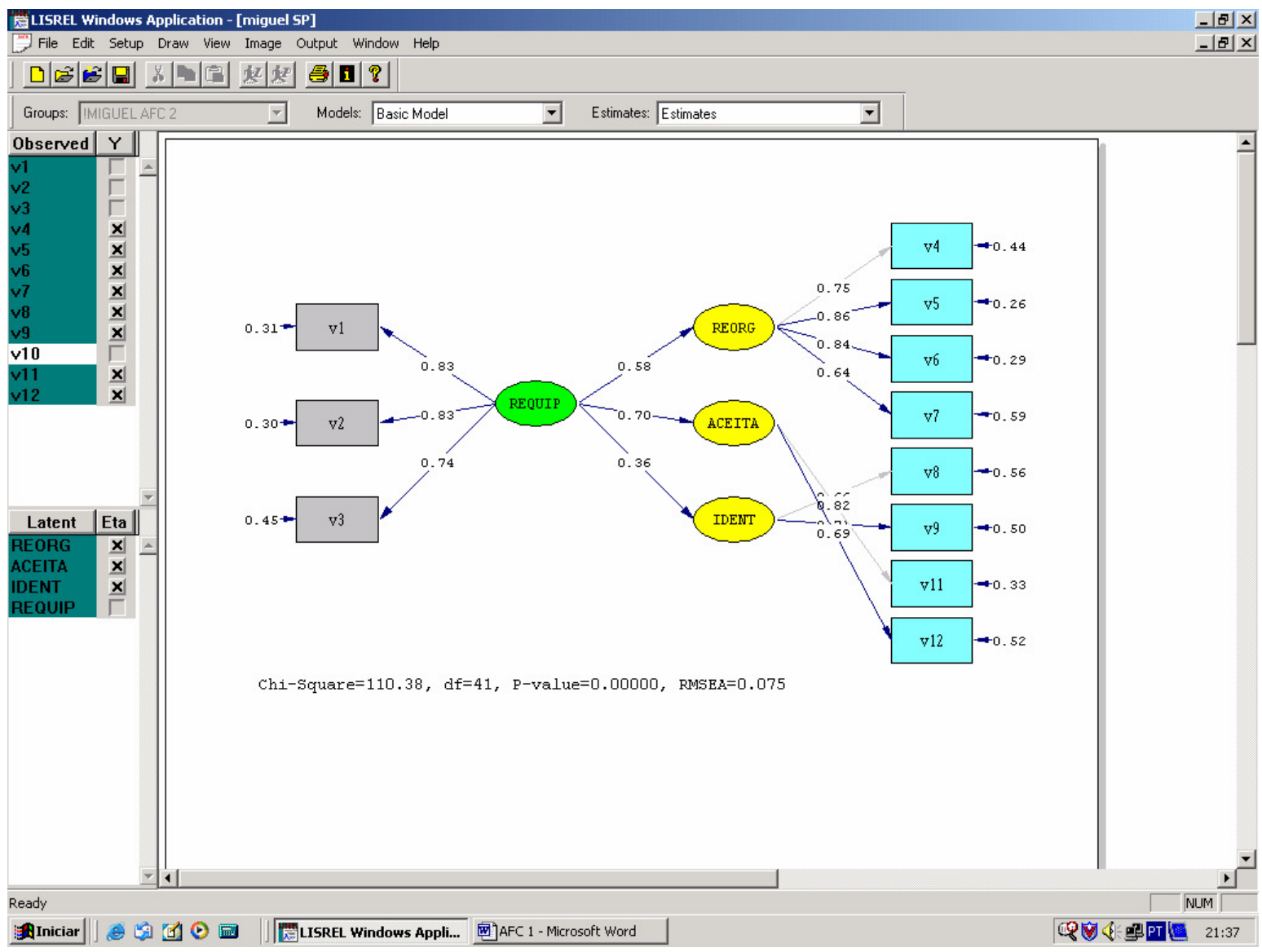

Modification Indices for THETA-DELTA

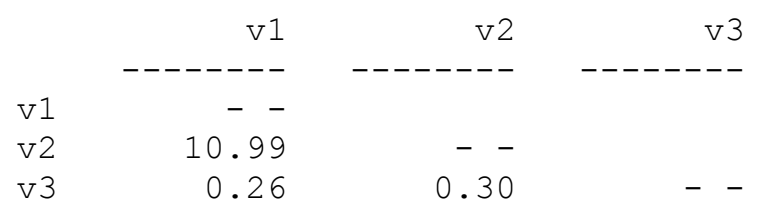

Expected Change for THETA-DELTA

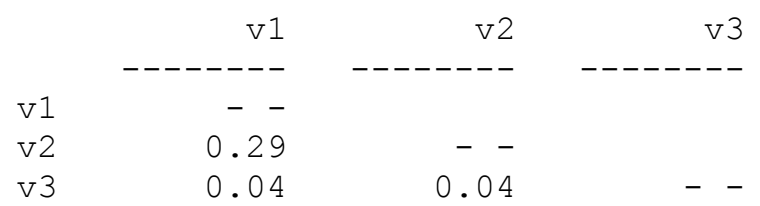

Maximum Modification Index is 31.73 for Element ( 2, 1) of BETA Time used: 0.094 Seconds 


\title{
Anexo VIII - Modelo REORG
}

\author{
ULS - RMSEA $=0.10$ \\ DATE: $\quad 1 / 13 / 2006$ \\ TIME : $21: 40$ \\ L I S R E I 8.71 BY
}

Karl G. Jöreskog and Dag Sörbom

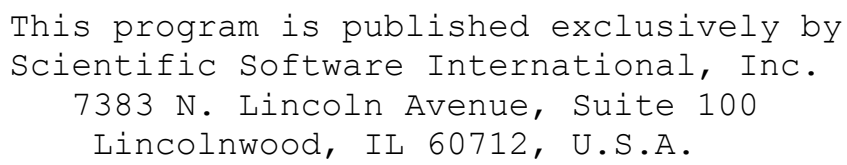

The following lines were read from file c:lDocuments and

Settings\dirceuds.GLOBAL \Desktop\OPERAÇÃO\miguel \miguel SP . spj :

Observed Variables:

v1 v2 v3 v4 v5 v6 v7 v8 v9 v10 v11 v12

Correlation Matrix from file Mmi

Sample Size: 304

Latent Variables: REQUIP REORG ACEITA IDENT

\section{Relationships: \\ v1 v2 $v 3=$ REQUIP \\ v11 v12=ACEITA \\ v8 $v 9=$ IDENT \\ REQUIP=REORG \\ ACEITA $=$ REORG \\ IDENT $=$ REORG}

v4 v5 v6 v7=REORG

Options: $\mathrm{ND}=2$ RS ME=UL $\mathrm{ADD}=\mathrm{OFF} \quad \mathrm{IT}=100 \mathrm{MI}$

path diagram

END OF PROBLEM

6.6 in. 02 in

Sample Size =

304

\section{$\stackrel{\text { MIGUEL AFC } 2}{ }$}

Number of Iterations $=12$

\section{LISREL Estimates (Unweighted Least Squares)}

Measurement Equations

$\mathrm{V} 1=0.86 * \mathrm{REQUIP}$, Errorvar. $=0.26, \mathrm{R}^{2}=0.74$

$(0.11)$

2.40

$\mathrm{V} 2=0.87 * \mathrm{REQUIP}$, Errorvar. $=0.24, \mathrm{R}^{2}=0.76$

$(0.072)$

$(0.11)$

12.21

2.13

$\mathrm{v} 3=0.78 * \mathrm{REQUIP}$, Errorvar. $=0.40, \mathrm{R}^{2}=0.60$ 


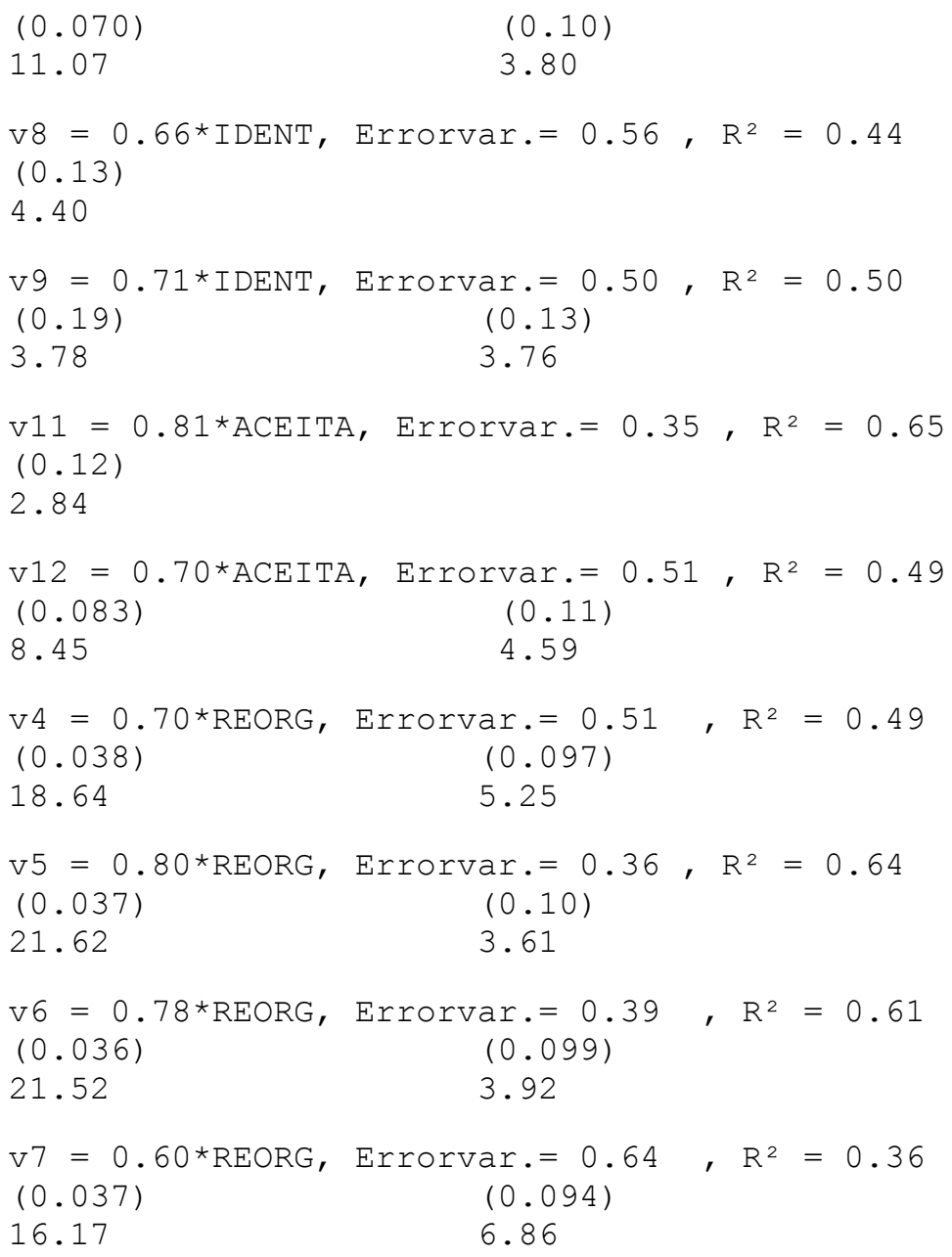

\section{Structural Equations}

REQUIP $=0.64 *$ REORG, Errorvar. $=0.59, \mathrm{R}^{2}=0.41$
(0.032)
20.09
$(0.057)$
10.28

$\mathrm{ACEITA}=0.66 * \mathrm{REORG}$, Errorvar. $=0.56, \mathrm{R}^{2}=0.44$
$(0.034)$
19.44
$(0.082)$
6.83

IDENT $=0.34 *$ REORG, Errorvar. $=0.89, \mathrm{R}^{2}=0.11$
(0.029)
$(0.093)$
11.52
9.56

\section{Goodness of Fit Statistics}

W_A_R_N_I_N_G: Chi-square, standard errors, t-values and standardized ressiduals are calculated under the assumption of multi-variate normality.

\section{Degrees of Freedom $=41$}

Normal Theory Weighted Least Squares Chi-Square $=165.65(P=0.00)$

Estimated Non-centrality Parameter $(\mathrm{NCP})=124.65$

90 Percent Confidence Interval for $\mathrm{NCP}=(88.74 ; 168.13)$

Minimum Fit Function Value $=0.32$

Population Discrepancy Function Value $(F 0)=0.41$

90 Percent Confidence Interval for $\mathrm{FO}=(0.29 ; 0.55)$

Root Mean Square Error of Approximation (RMSEA) $=0.10$

90 Percent Confidence Interval for RMSEA $=(0.085 ; 0.12)$ 


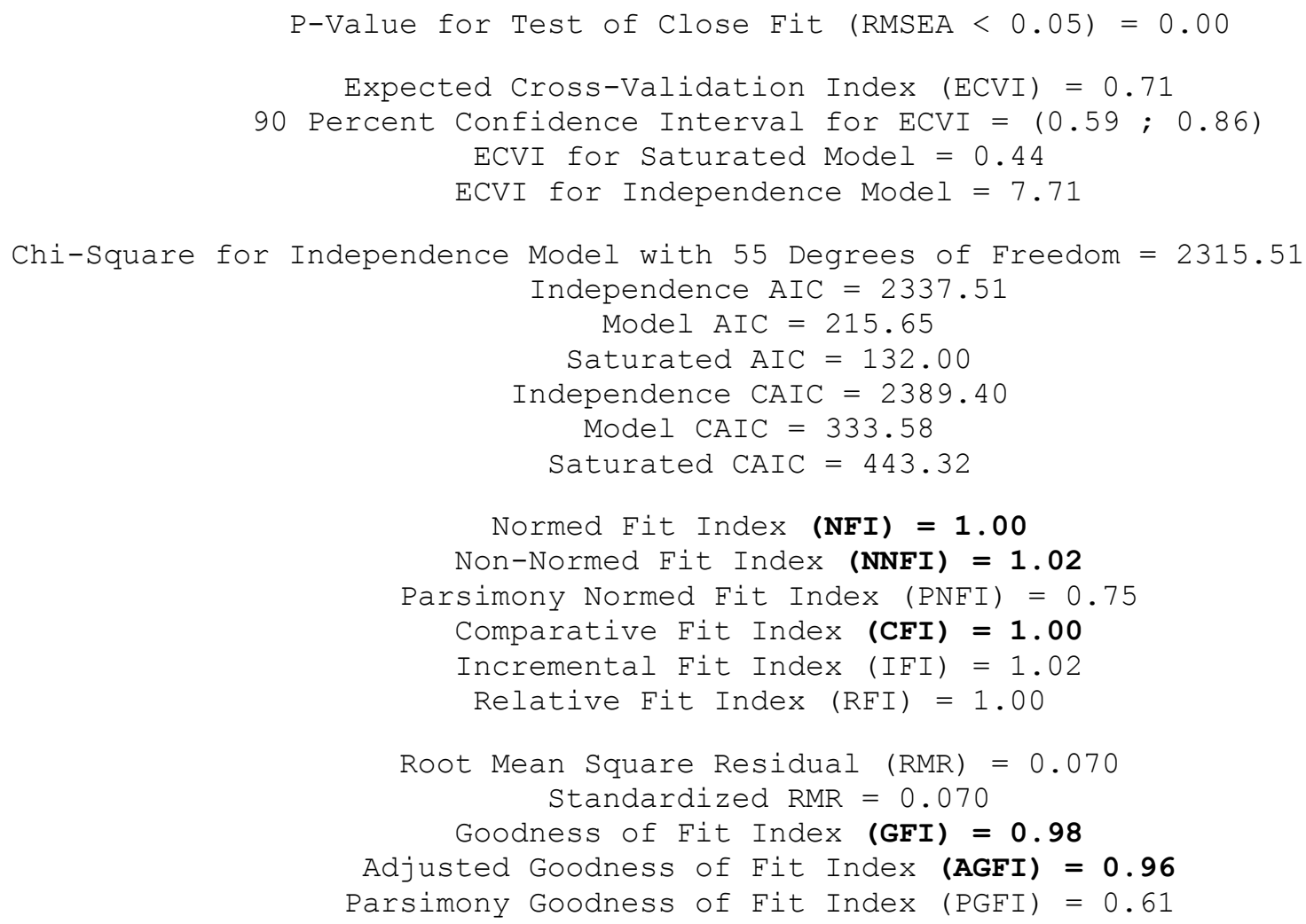

\section{Summary Statistics for Standardized Residuals}

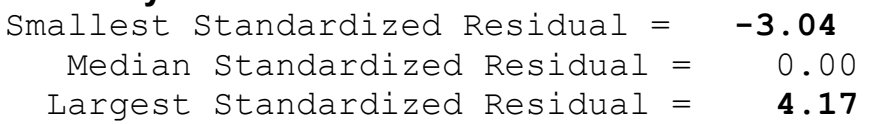

\section{Stemleaf Plot}

$-310$

$-213320$

- 117777655431110

- 019655442000000000000000

$0 \mid 11255668899$

$1 \mid 126777888$

$2 \mid 15779$

31

$4 \mid 2$

\section{Largest Negative Standardized Residuals}

Residual for

Residual for

Residual for

Residual for

Residual for

$\begin{aligned} \mathrm{v} 6 & \text { and } \\ \mathrm{v} 11 & \text { and } \\ \mathrm{v} 11 & \text { and } \\ \mathrm{v} 11 & \text { and } \\ \mathrm{v} 6 & \text { and }\end{aligned}$

v1

v1

v2

v3

v5
4.17

!MIGUEL AFC 2

\section{Qplot of Standardized Residuals}

$3.5 \ldots$ 
$\mathbf{x}$

$\mathbf{N}$

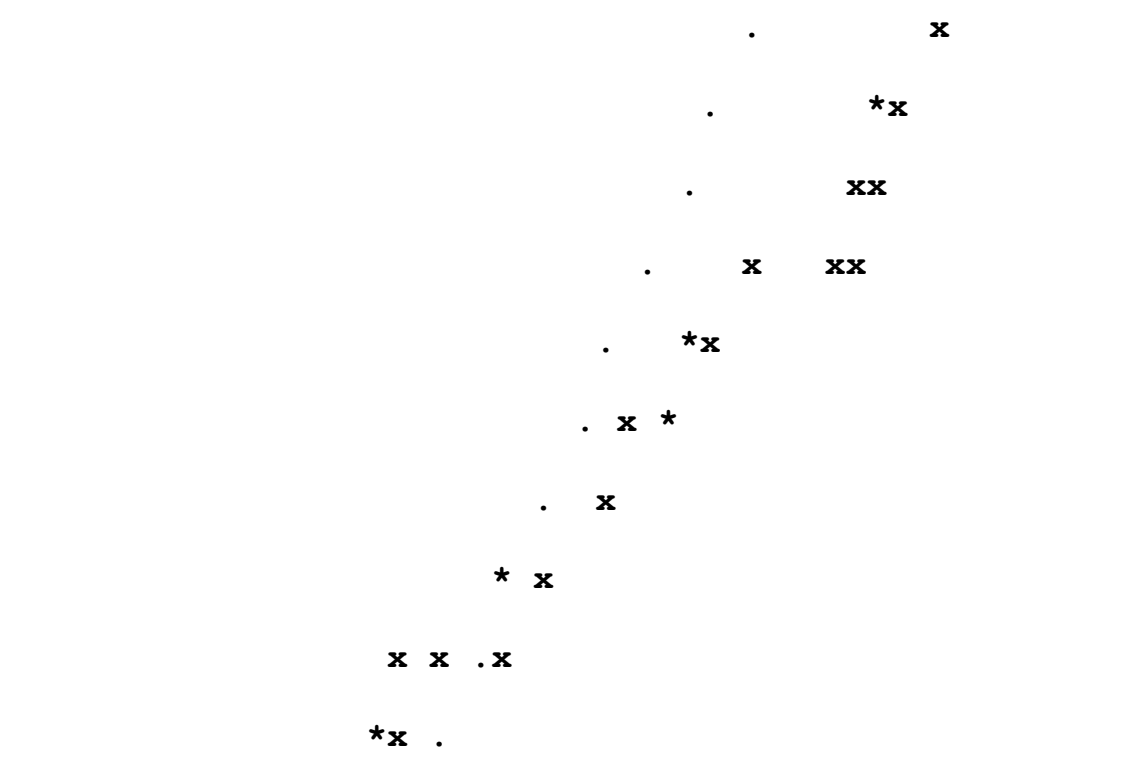

n

$\mathbf{x} \mathbf{x}$.
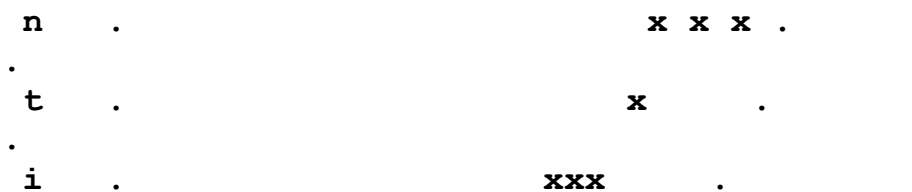

i

1

$\mathbf{x x}$

e

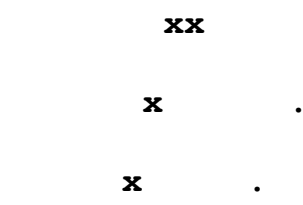

$\mathbf{x} \mathbf{x}$

$\mathbf{x}$

$\mathbf{x}$

$\mathbf{x}$ 
3.5

$-3.5$

3.5

Time used: $\quad 0.094$ Seconds

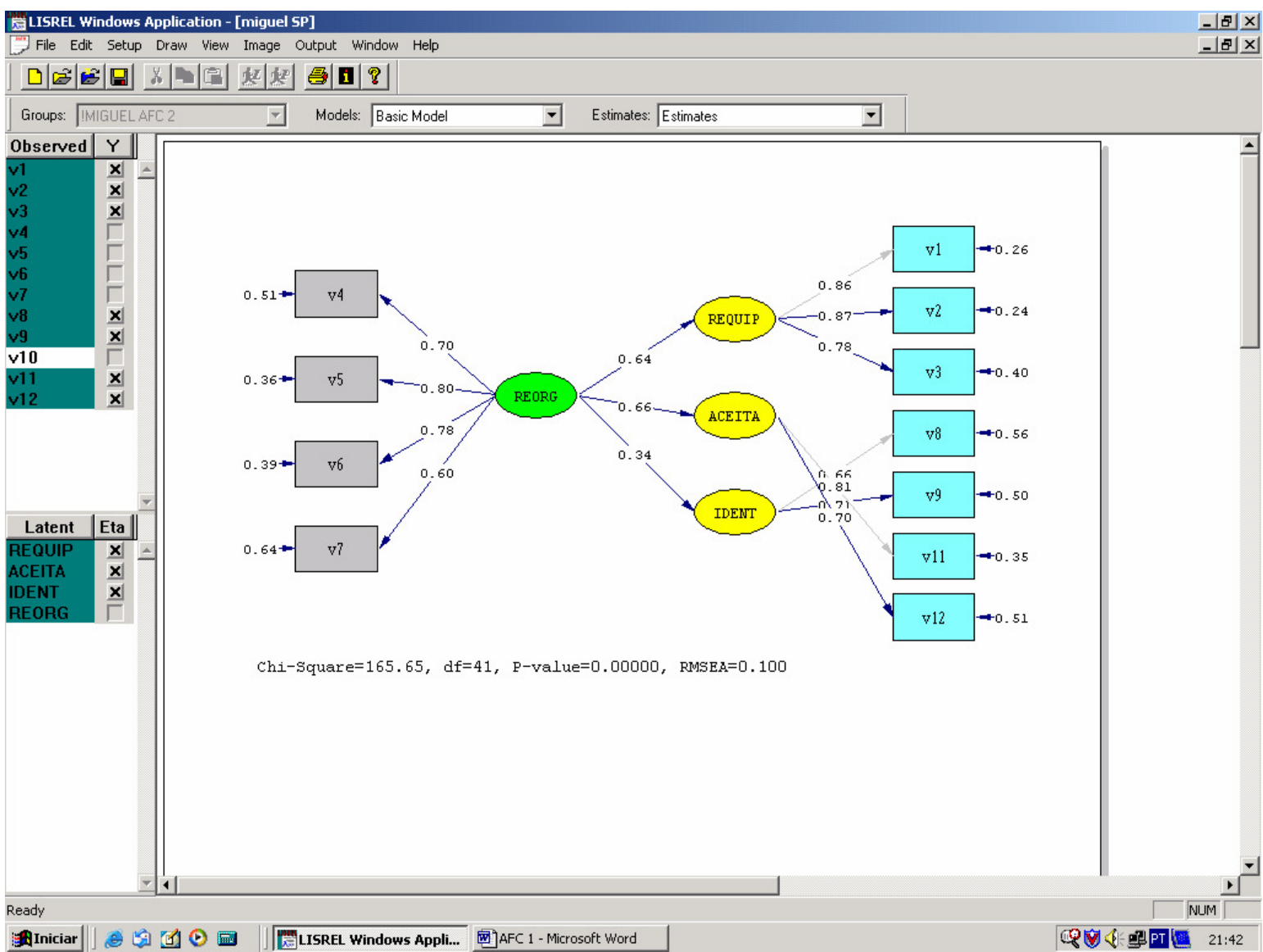




\title{
Anexo IX - Modelo IDENT
}

\author{
ULS - RMSEA $=0.094$ \\ DATE: $1 / 13 / 2006$
}

TIME : $21: 44$

L I S R E L 8.71 BY

Karl G. Jöreskog and Dag Sörbom

This program is published exclusively by

Scientific Software International, Inc.

7383 N. Lincoln Avenue, Suite 100

Lincolnwood, IL 60712, U.S.A.

Phone: (800)247-6113, (847)675-0720, Fax: (847)675-2140

Copyright by Scientific Software International, Inc., 1981-2004

Use of this program is subject to the terms specified in the

Universal Copyright Convention.

Website: www.ssicentral.com

The following lines were read from file C:\Documents and

Settings\dirceuds. GLOBAL \Desktop \OPERAÇÃO\miguel\miguel SP.spj:

\section{Observed Variables:}

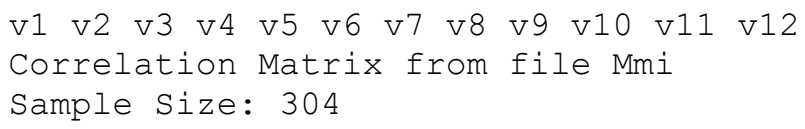

Latent Variables: REQUIP REORG ACEITA IDENT

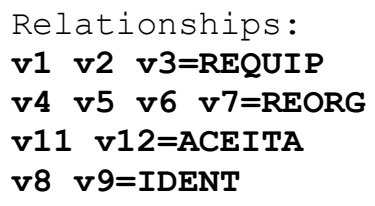

Options: $\mathrm{ND}=2 \mathrm{RS}$ ME=UL $\mathrm{ADD}=\mathrm{OFF}$ IT=100 MI

path diagram

END OF PROBLEM

6.6 in. 02 in

Sample Size $=$

304

\section{$\stackrel{\text { MIGUEL AFC } 2}{2}$}

Number of Iterations $=22$

\section{LISREL Estimates (Unweighted Least Squares)}

\section{Measurement Equations}

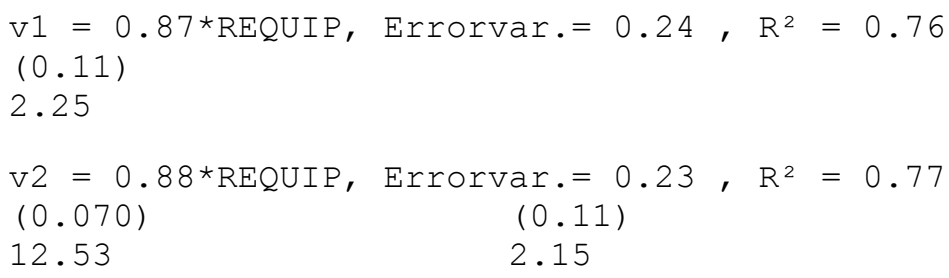




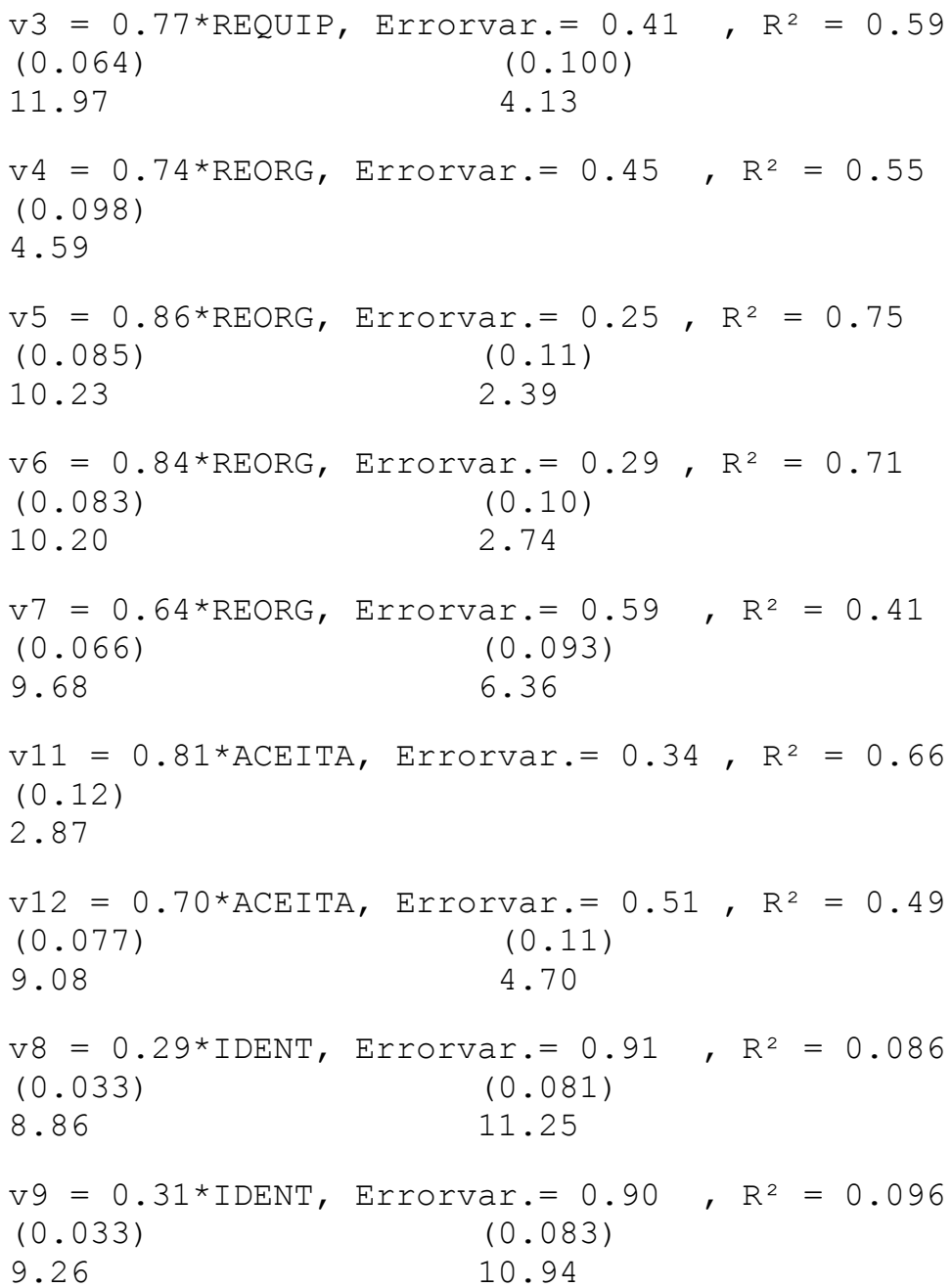

\section{Structural Equations}

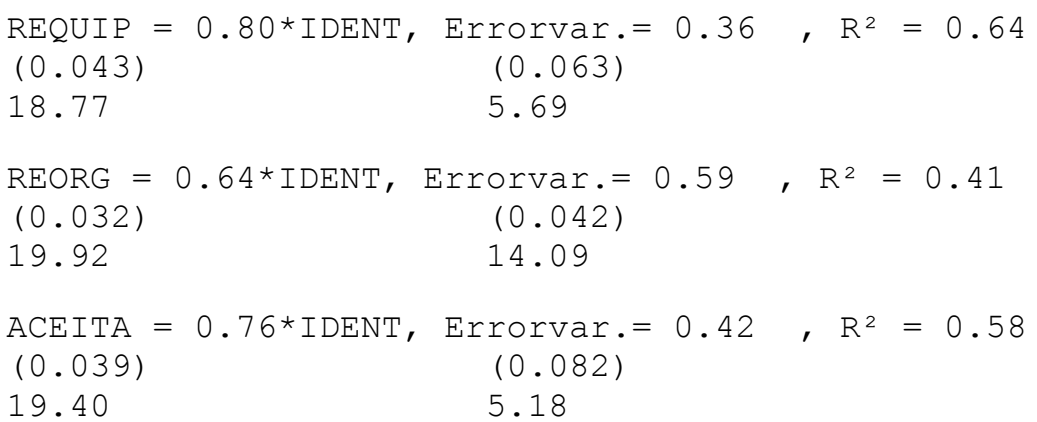

\section{Goodness of Fit Statistics}

W_A_R_N_I_N_G: Chi-square, standard errors, t-values and standardized ressidua $\bar{l}$ s are calculated under the assumption of multi-variate normality.

\section{Degrees of Freedom $=41$}

Normal Theory Weighted Least Squares Chi-Square $=149.81(\mathrm{P}=0.00)$ Estimated Non-centrality Parameter $(\mathrm{NCP})=108.81$ 90 Percent Confidence Interval for $\mathrm{NCP}=(75.13 ; 150.08)$

Minimum Fit Function Value $=0.24$ Population Discrepancy Function Value $(\mathrm{F} 0)=0.36$ 90 Percent Confidence Interval for $\mathrm{FO}=(0.25 ; 0.50)$ Root Mean Square Error of Approximation (RMSEA) $=0.094$ 
90 Percent Confidence Interval for RMSEA $=(0.078 ; 0.11)$

P-Value for Test of Close Fit (RMSEA $<0.05)=0.00$

Expected Cross-Validation Index (ECVI) $=0.66$

90 Percent Confidence Interval for ECVI $=(0.55 ; 0.80)$

ECVI for Saturated Model $=0.44$

ECVI for Independence Model $=7.71$

Chi-Square for Independence Model with 55 Degrees of Freedom $=2315.51$

Independence $\mathrm{AIC}=2337.51$

Model $\mathrm{AIC}=199.81$

Saturated $\mathrm{AIC}=132.00$

Independence $\mathrm{CAIC}=2389.40$

Model CAIC $=317.74$

Saturated $\mathrm{CAIC}=443.32$

\author{
Normed Fit Index (NFI) $=1.00$ \\ Non-Normed Fit Index (NNFI) $=1.02$ \\ Parsimony Normed Fit Index (PNFI) $=0.75$ \\ Comparative Fit Index (CFI) $=1.00$ \\ Incremental Fit Index (IFI) $=1.02$ \\ Relative Fit Index (RFI) $=1.00$ \\ Root Mean Square Residual (RMR) $=0.060$ \\ Standardized RMR $=0.060$ \\ Goodness of Fit Index (GFI) $=0.98$ \\ Adjusted Goodness of Fit Index (AGFI) $=0.97$ \\ Parsimony Goodness of Fit Index (PGFI) $=0.61$
}

\title{
!MIGUEL AFC 2
}

\section{Summary Statistics for Standardized Residuals}

$\begin{array}{rr}\text { Smallest Standardized Residual }= & -\mathbf{2 . 1 1} \\ \text { Median Standardized Residual }= & 0.00 \\ \text { Largest Standardized Residual }= & \mathbf{6 . 8 2}\end{array}$

\section{Stemleaf Plot}

$-2110$

- $1 \mid 7531111$

- 01998777776665544222000000000000000

$0 \mid 11223334455566779$

$1 \mid 014467$

$2 \mid$

31

$4 \mid$

51

$6 \mid 8$

Largest Positive Standardized Residuals

Residual for

v9 and

v8

6.82

!MIGUEL AFC 2

\section{Qplot of Standardized Residuals}

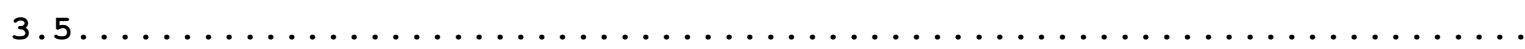


x

$\mathbf{N}$

o

$\mathbf{x} \times$

$r$

m

a

1

Q

$\mathbf{x x}$ *

$\mathrm{u}$

* $\mathbf{x}$.

a

$\mathbf{x x x}$

n

$t$

i

1

e

s
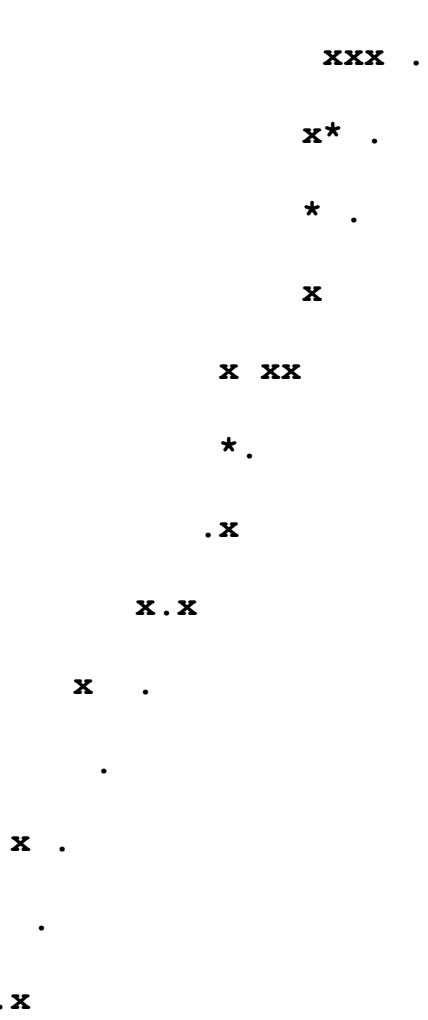

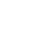

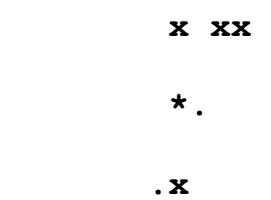


3.5

$-3.5$

3.5

Time used: $\quad 0.094$ Seconds

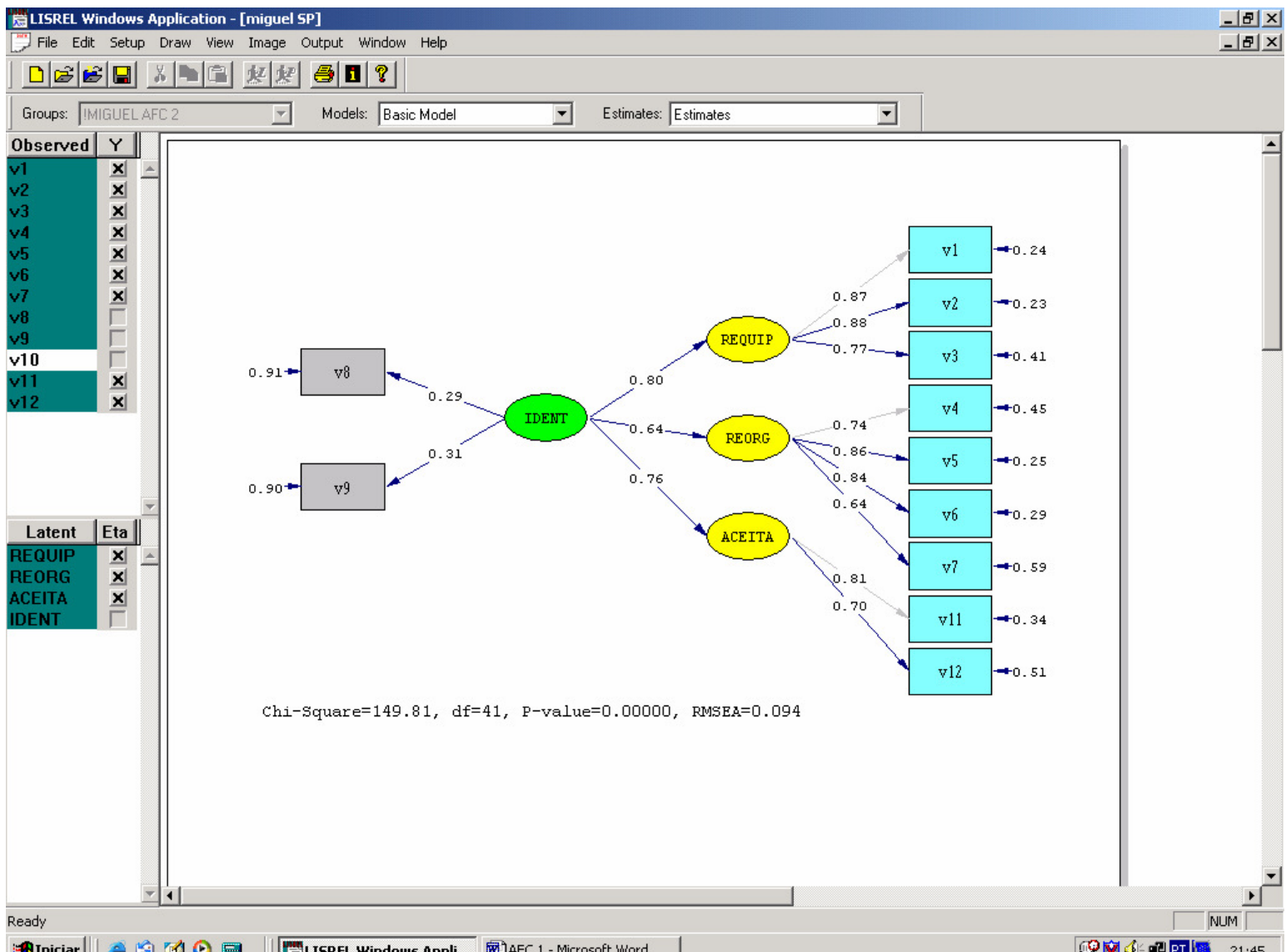

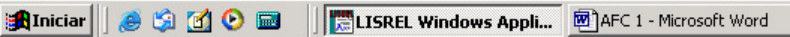

